\title{
Development and Demonstration of a Modeling Framework for Assessing the Efficacy of Using Mine Water for Thermoelectric Power Generation
}

\author{
DE-FC26-06NT42723 \\ Final Report Submitted to: U.S. Department of Energy \\ National Energy Technology Laboratory \\ June 1, 2010 \\ National Mine Land Reclamation Center \\ West Virginia University \\ PO Box 6064 \\ 150 Evansdale Drive \\ Morgantown, West Virginia 26506
}




\section{Disclaimer}

This report was prepared as an account of work sponsored by an agency of the United States Government. Neither the United States Government nor any agency thereof, nor any of their employees, make any warranty, express or implied, or assumes any legal liability or responsibility for the accuracy, completeness, or usefulness of any information, apparatus, product, or process disclosed, or represents that its use would not infringe privately owned rights. Reference herein to any specific commercial product, process, or service by trade name, trademark, manufacturer, or otherwise does not necessarily constitute or imply its endorsement, recommendation, or favoring by the United States Government or any agency thereof. The views and opinions of authors expressed herein do not necessarily state or reflect those of the United States Government or any agency thereof. 


\begin{abstract}
Thermoelectric power plants use large volumes of water for condenser cooling and other plant operations. Traditionally, this water has been withdrawn from the cleanest water available in streams and rivers. However, as demand for electrical power increases it places increasing demands on freshwater resources resulting in conflicts with other off stream water users. In July 2002, NETL and the Governor of Pennsylvania called for the use of water from abandoned mines to replace our reliance on the diminishing and sometimes over allocated surface water resource.
\end{abstract}

In previous studies the National Mine Land Reclamation Center (NMLRC) at West Virginia University has demonstrated that mine water has the potential to reduce the capital cost of acquiring cooling water while at the same time improving the efficiency of the cooling process due to the constant water temperatures associated with deep mine discharges. The objectives of this project were to develop and demonstrate a userfriendly computer based design aid for assessing the costs, technical and regulatory aspects and potential environmental benefits for using mine water for thermoelectric generation. The framework provides a systematic process for evaluating the hydrologic, chemical, engineering and environmental factors to be considered in using mine water as an alternative to traditional freshwater supply.

A field investigation and case study was conducted for the proposed $300 \mathrm{MW}$ Beech Hollow Power Plant located in Champion, Pennsylvania. The field study based on previous research conducted by NMLRC identified mine water sources sufficient to reliably supply the 2-3,000gpm water supply requirement of Beech Hollow. A water collection, transportation and treatment system was designed around this facility. Using this case study a computer based design aid applicable to large industrial water users was developed utilizing water collection and handling principals derived in the field investigation and during previous studies of mine water and power plant cooling.

Visual basic software was used to create general information/evaluation modules for a range of power plant water needs that were tested/verified against the Beech Hollow project. The program allows for consideration of blending mine water as needed as well as considering potential thermal and environmental benefits that can be derived from using constant temperature mine water. Users input mine water flow, quality, distance to source, elevations to determine collection, transport and treatment system design criteria. The program also evaluates low flow volumes and sustainable yields for various sources. All modules have been integrated into a seamless user friendly computer 
design aid and user's manual for evaluating the capital and operating costs of mine water use.

The framework will facilitate the use of mine water for thermoelectric generation, reduce demand on freshwater resources and result in environmental benefits from reduced emissions and abated mine discharges. 


\section{Table of Contents}

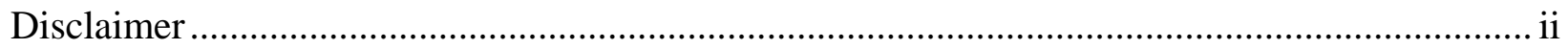

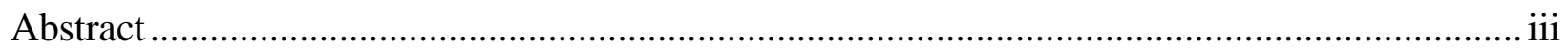

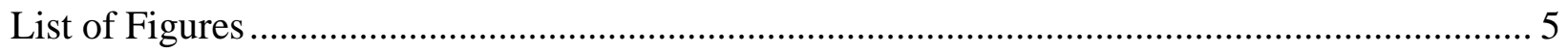

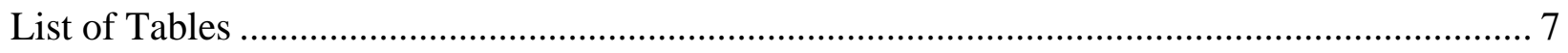

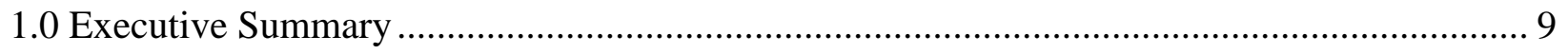

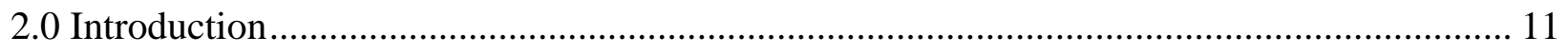

2.1. Need for alternate cooling water from mine sources .......................................................... 11

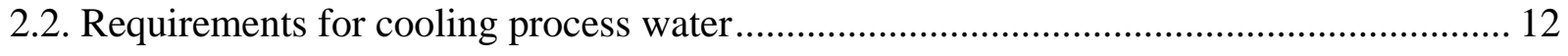

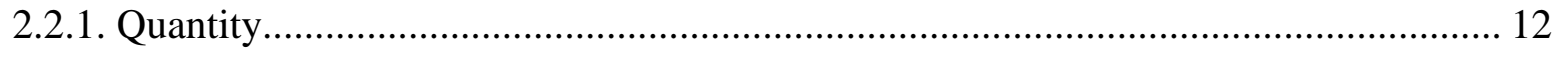

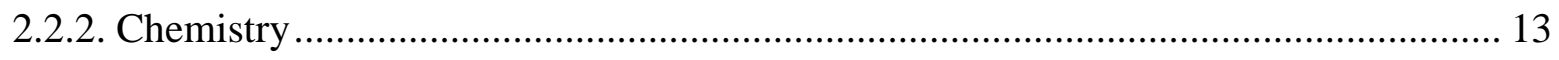

2.3. Characteristics of water from underground coal mines .................................................... 14

2.3.1. Water Quantity ......................................................................................................... 14

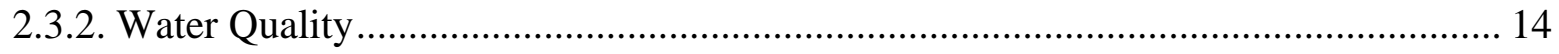

2.4. Application of mine-water based cooling concepts ............................................................. 14

3.0. BEECH HOLLOW POWER PROJECT - ROBINSON POWER COMPANY ..................... 16

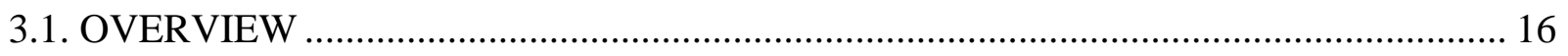

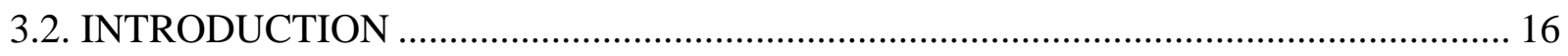

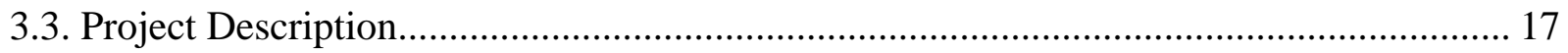

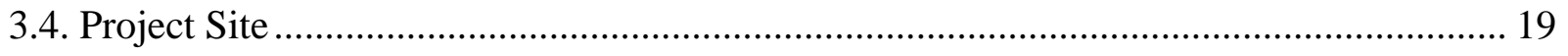

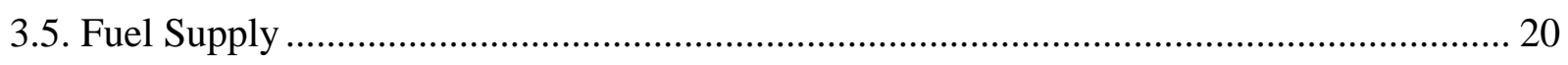


3.6. Power Generation Facility ………………………........................................................ 21

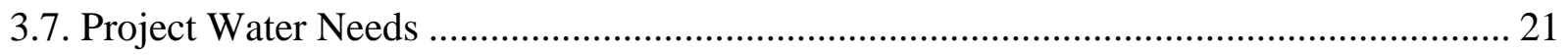

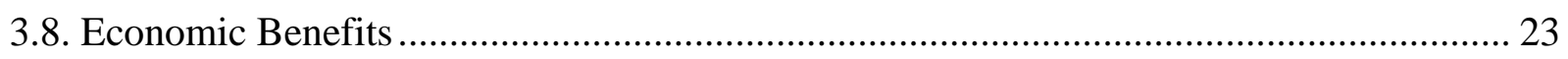

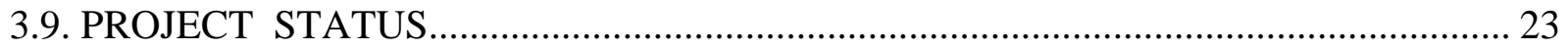

4.0. Power Plants utilizing mine water directly or indirectly ........................................................... 24

4.1. Power Plants Directly Utilizing Mine Pool Water........................................................... 24

4.2. Power Plants Indirectly Utilizing Mine Pool Water ....................................................... 27

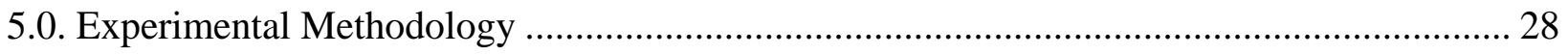

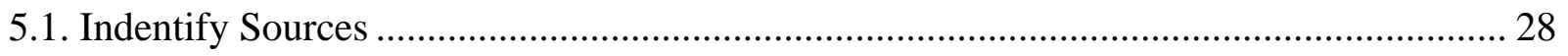

5.2. Quantify Volume and Quality of Mine Water ................................................................. 33

5.2.1. JB-1 (average 941 gpm) ...................................................................................... 33

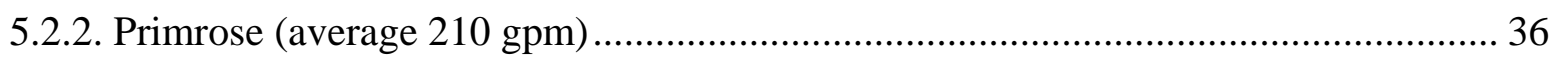

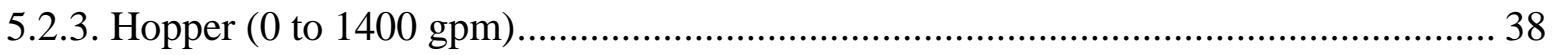

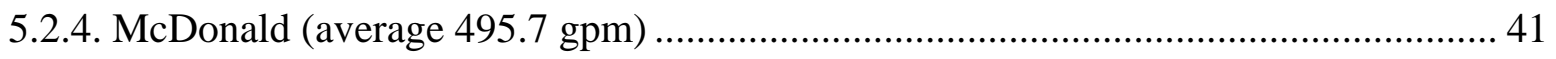

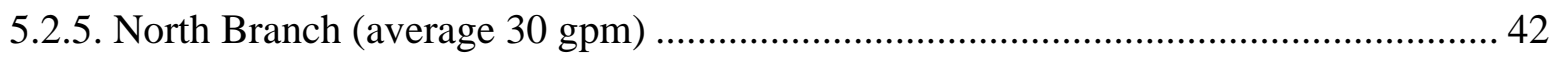

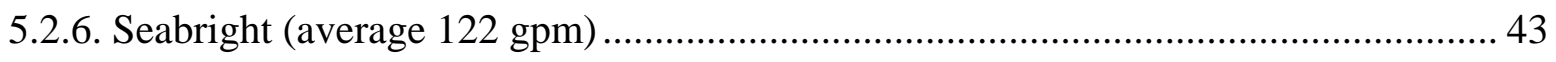

5.3. Monitoring Wells ......................................................................................................... 44

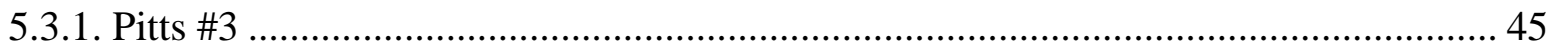

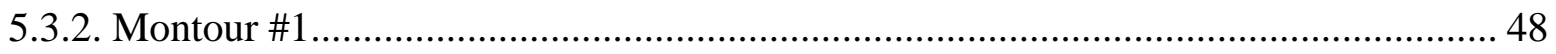

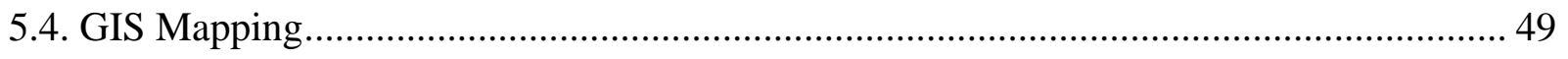

5.5. Select Mine Water Source ………………………….................................................. 51 
5.6. Design Collection, Piping, and Treatment ......................................................................... 52

5.7. Projecting Mine Water Availability from Underground Mines.......................................... 57

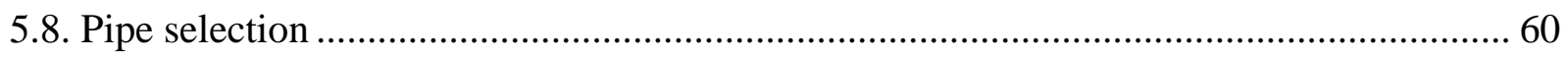

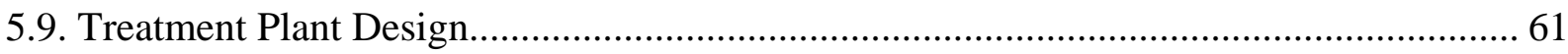

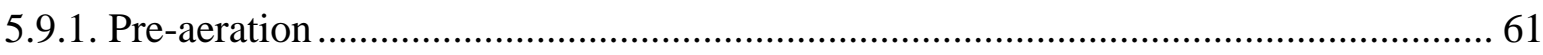

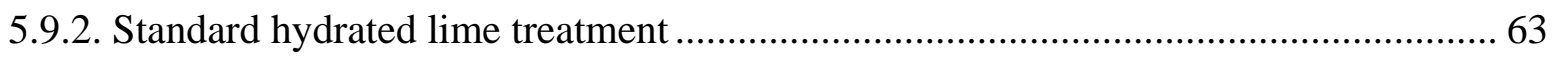

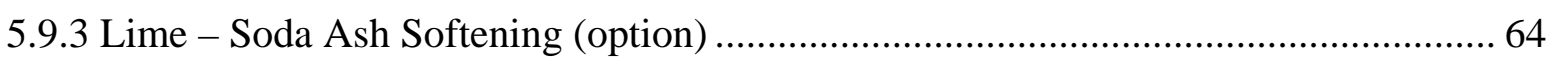

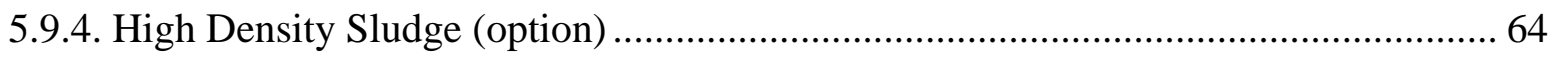

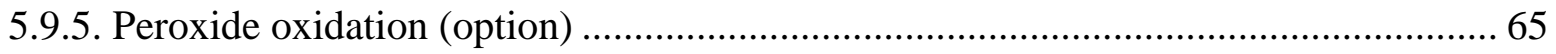

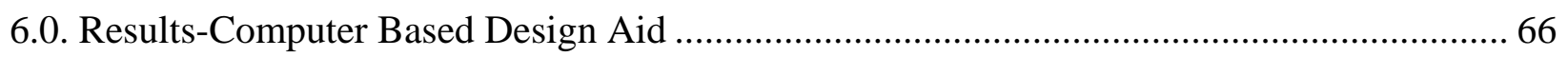

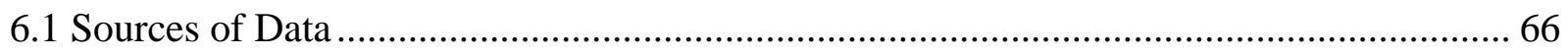

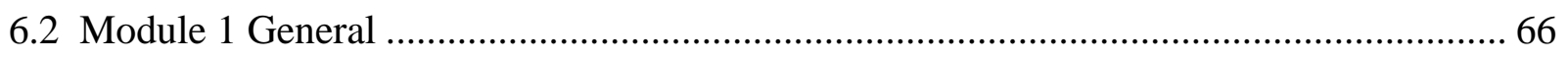

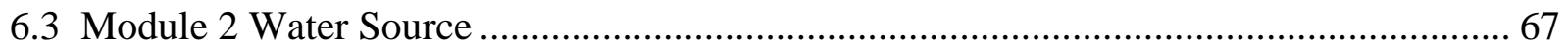

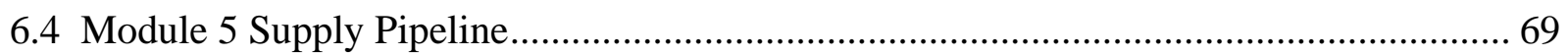

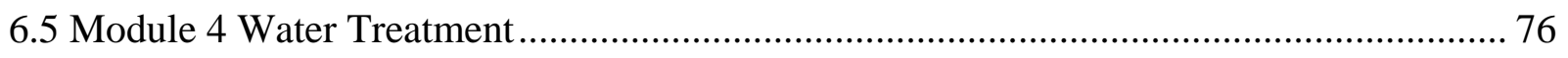

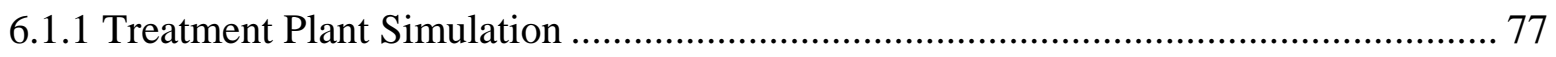

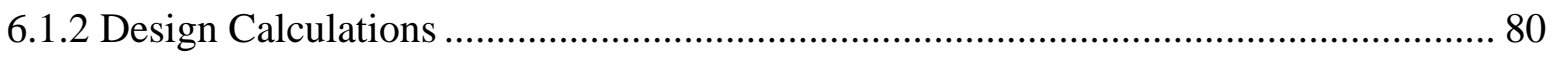

6.1.3 Summary Output Worksheet................................................................................... 97

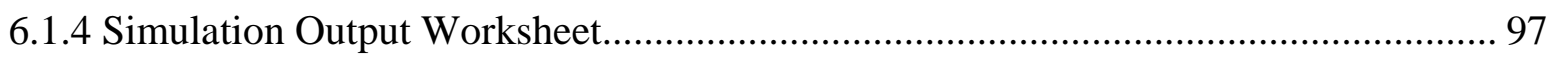

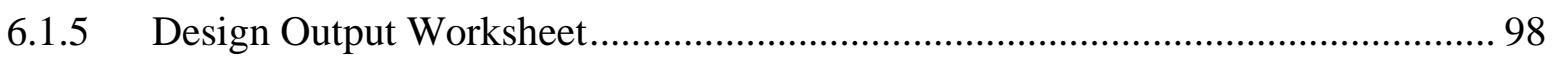

6.2 Module 5 Thermal Efficiency .................................................................................... 102 
6.2.1 Design Module Input Data............................................................................................ 102

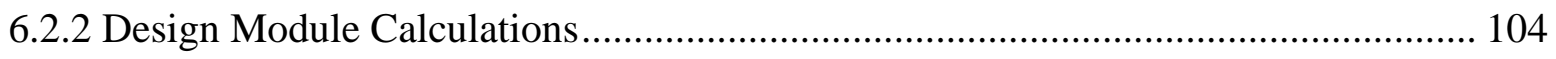

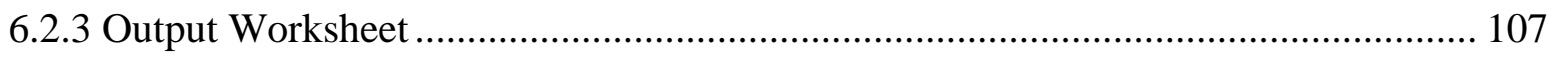

6.3 Module 6 Report Generator .......................................................................................... 107

7.0. Benefits of Using Mine Water for Beech Hollow .......................................................... 108

7.1. Cost of Using Mine Water for Beech Hollow ……........................................................... 108

7.2. Emission Benefits of Using Mine Water ................................................................... 115

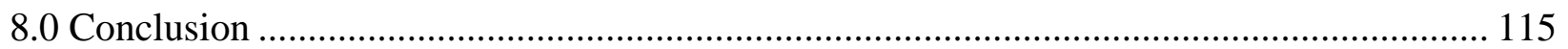

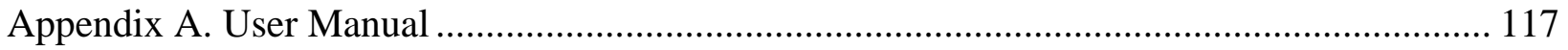

Using Microsoft Excel Spreadsheets with Macros ……............................................................ 117

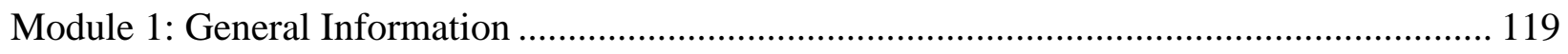

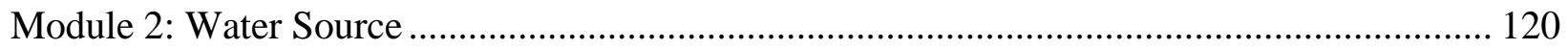

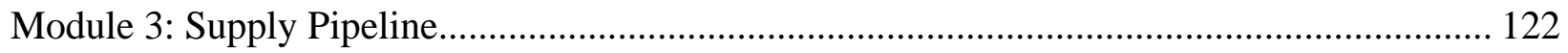

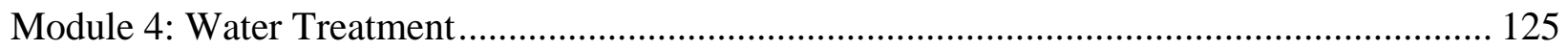

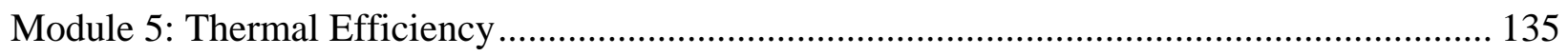

Module 6: Integration ..................................................................................................... 139

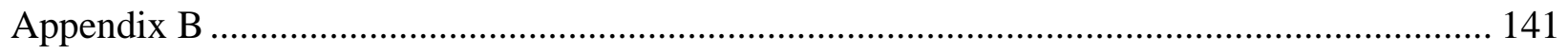

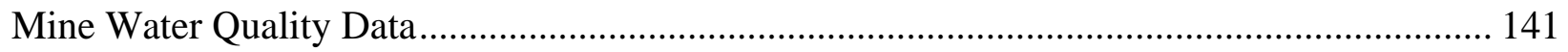

Appendix C. Benefits of Using Constant Temperature Mine Water .............................................. 144 


\section{List of Figures}

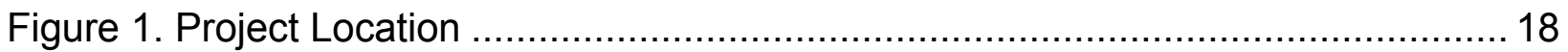

Figure 2. Aerial View of the Location of Beech Hollow Power Plant Site and Coal Refuse

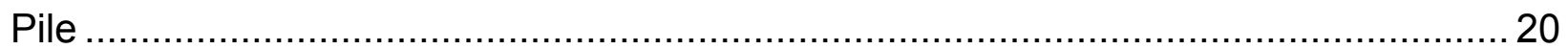

Figure 3. Mining and mine discharges in the vicinity of Beech Hollow. ....................... 32

Figure 4. JB-1 Discharge after the construction of the passive treatment system.........34

Figure 5. Head discharge relationship for the JB-1 (Pitts\#3 mine) .............................. 35

Figure 6. Mine discharge rate and temperature from JB-1 …................................... 35

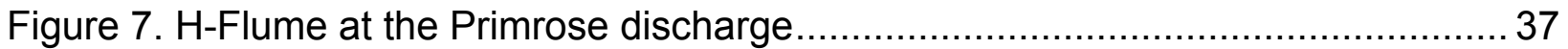

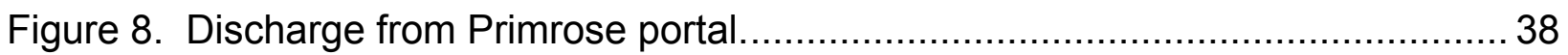

Figure 9. Hydrograph of the Hopper Discharge ..................................................... 40

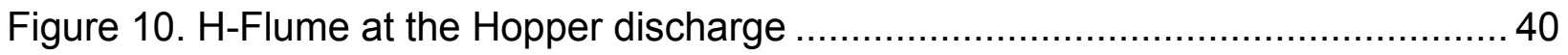

Figure 11. McDonald discharge hydrograph ...................................................... 41

Figure 12. Mine discharge on the North Branch of Robinson Run. Note: the high flow measurements between Feb 1, 2007 and Feb 5, 2007 were the result of ice in the stilling well. The rapid drop in flow during the month of May was the result of clearing

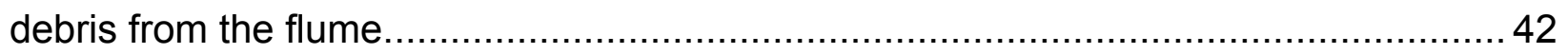

Figure 13. Mine discharge on Seabright Road .................................................... 43

Figure 14. Hydrograph of the Pitts \#3 monitoring well............................................. 45

Figure 15. Comparison of water level response at JB-1 and Pitts \#3. Note: the JB-1 data are inverted so that they don't plot on top of one another. .................................46

Figure 16. Calculation of transmissivity using the distance drawdown method. ............47

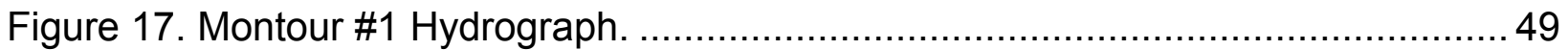


Figure 18. Conceptual water handling system for the Beech Hollow Facility.

Figure 19. Two year hydrograph of the JB-1 discharge ........................................... 57

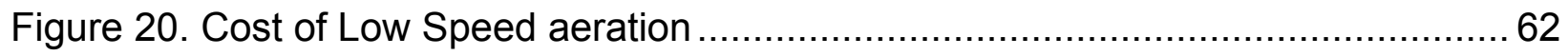

Figure 21. LSI of example treated mine water without softening ............................ 111

Figure 22. GSI of example treated mine water without softening ............................ 112

Figure 23. LSI of example treated mine water with softening ................................ 113

Figure 24. GSI of example treated mine water with softening .................................114 


\section{List of Tables}

Table 1. Anthradte Waste Coal Plants Using Coal Mine Pool Water ........................... 26

Table 2. Power Plants Indirectly Utilizing Coal Mine Pool Water................................28

Table 3. Approximate area of flooding of mines in vicinity of Beech Hollow..................50

Table 4. Available mine water in vicinity of Beech Hollow ........................................51

Table 5. Recommended pump capacity and pipeline length ...................................54

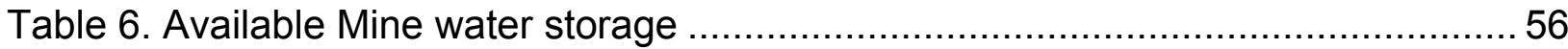

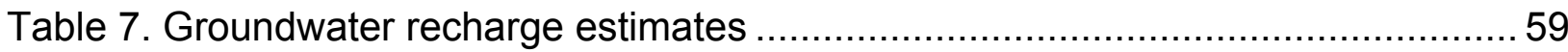

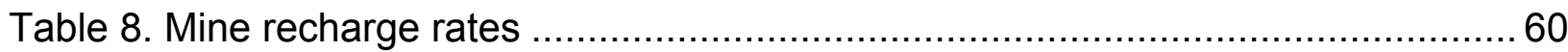

Table 9. Supply pipeline design parameters with default values. ............................. 71

Table 10. Pipeline diameters employed by the Supply Pipeline Design Module ..........72

Table 11. Design Parameters for the Water Treatment Module on the Control

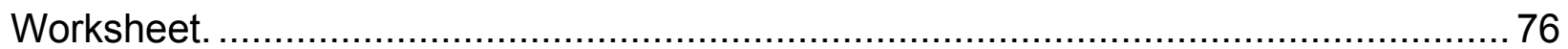

Table 12. Water Treatment Module Pre-Aeration Design Parameters ........................ 80

Table 13. Water Treatment Module Mech-Aeration Design Parameters...................... 82

Table 14. Water Treatment Module Lime-Plant Design Parameters. .......................... 85

Table 15. Water Treatment Module Soda-Ash Design Parameters. ........................... 88

Table 16. Water Treatment Module High-Density-Sludge Design Parameters. ............ 89

Table 17. Water Treatment Module Peroxide Design Parameters............................. 91

Table 18. Water Treatment Module Annual-Cost Design Parameters.......................... 95

Table 19. Computer design aid example inputs ................................................... 109 
Table 20. Example Results

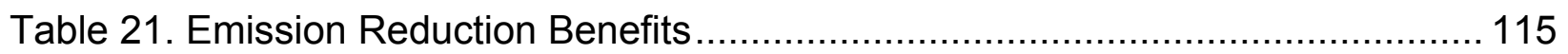




\subsection{Executive Summary}

Water discharging from mines represents a large untapped resource for power plant cooling. Large thermoelectric power plants need to evaporate thousands of gallons per minute to maintain their operations. This consumptive use often competes with other water uses such as navigation, drinking water and other industrial uses. Increased environmental concerns related to power plant water use are driving the consideration of alternate sources of water besides streams and rivers. Suitable alternate water sources must be capable of providing large dependable quantities of flow; be thermally stable on a seasonal basis; and not cause different, but equally serious, environmental concerns compared to river water. Finally, any alternative water source must be legally developable and be economic.

The utilization of mine water for cooling has advantages and disadvantages over a conventional surface water source. The quantity of water available from mines is less seasonal than a surface water source. The mine void itself can be used as reservoir of water that can be drawn down during dry weather conditions. The ambient water temperature is less variable than surface water hence over designing for summer weather conditions is reduced. A negative aspect of mine water utilization is the need for water treatment, but this is also an environmental advantage when legacy mine waters that are polluting streams are used for cooling water purposes.

This study evaluates the potential economic and environmental benefits of using mine water at the proposed Beech Hollow Power Project. As originally proposed this study was intended to be developed and integrated into the engineering and construction of the power plant. However, due to the recession and resulting difficulty with financing development of the Beech Hollow project has been delayed. As proposed, Beech Hollow consists of the design, construction, and operation of an approximately $320 \mathrm{MW}$ coal waste-fired power generation facility to be located in Robinson Township, Washington County, Pennsylvania. The project will generate approximately $288 \mathrm{MW}$ of electrical energy for sale into the grid. Project fuel will consist of approximately 37.5 million tons of bituminous waste coal material ("gob") in place on 600 acres adjacent to the project site. The bituminous coal waste material represents the waste product from coal cleaning and processing operations conducted at the site for a period of in excess of 50 years. Coal Combustion Byproducts (CCB) generated from the combustion of the waste coal will be beneficially used in the reclamation of the permitted area adjacent to the project site and other unreclaimed mine lands in the area.

Numerous mine water sources exist within, or just outside of a five mine radius of the proposed Beech Hollow Power Plant. The locations of these discharges were identified using published reports on mine discharges in the area, combined with field 
reconnaissance. Of the 49 discharges identified in the study, six were selected for in depth study. Four of these discharges, JB-1, Primrose, McDonald, and Hopper are classified as high volume discharges. Two discharges were monitored that are low volume sources. These discharges are North Branch and Seabright. Because power plants require large volumes of cooling water, the focus of this investigation is on the larger discharges.

Two monitoring wells were drilled into flooded mine pools. One of these pools, Pitts \#3 is connected to the JB-1 discharge. The second pool is in the Montour \#1 mine. These mine pools not only provide additional water for cooling but they can also provide water from storage which can be drawn down during summer low flow conditions and recharged during the winter and spring. Another potential benefit from flooded underground mine pools is that they can serve as conduits for water transfer underground without the need for building a pipeline.

A conceptual water transfer system was designed to move the water from five mines to a water treatment plant and the treated water was then pumped to the power plant. Water treatment is based on hydrated lime followed by aeration and precipitation. Water pumping, transmission and treatment were based on mining industry standards utilizing vertical turbine pumps, HDPE piping, and standard hydrated lime treatment. A clarifier is used to minimize temperature rise in the treatment process and to facilitate sludge disposal. Additional options in the computer based design aid include high density sludge, hydrogen peroxide oxidation, lime soda ash softening, and thermal insulation on the buried pipeline.

Cost data from equipment suppliers were used in conjunction with cost data from a recently built hydrated lime water treatment plant to create estimation equations for the various components of a mine water collection and treatment system. These equations were built into a computer based design aid that will allow an engineer, who may be unfamiliar with mine drainage pumping transmission and treatment, to estimate the cost and benefit of using mine water for makeup water in a coal fired power plant. In addition, the computer based design aid calculates the thermal benefit of cool makeup water in the power plant operation. This benefit is expressed in the value of electric power that can be generated without increasing the heat rate and the emissions that are avoided by not increasing the heat rate.

Using mine water from the five mines in the example problem the amount of additional electricity generated is calculated to be $10,003,508.48 \mathrm{Kwh} / \mathrm{yr}$ which is equal to $\$ 630,221.03$ based on an electricity rate of $\$ 0.063 / \mathrm{kwh}$. The avoided emissions from 
this site are $10,210 \mathrm{t} / \mathrm{yr}$ of carbon dioxide, $357 \mathrm{t} / \mathrm{yr}$ of sulfur dioxide, $143 \mathrm{t} / \mathrm{yr}$ of NOx and $3.48 \mathrm{lb} / \mathrm{yr}$ of mercury. The cost of building the water collection and treatment system is $\$ 11,110,189.51$ with an estimate cost of operation of $\$ 618,829.32$. This translates into a water acquisition cost of $\$ 518.93 /$ million gallons compared to a cost of $\$ 3,000.00$ per million gallons from the municipal water supply.

\subsection{Introduction}

\subsection{Need for alternate cooling water from mine sources}

Water discharging from mines represents a large untapped resource for power plant cooling. Large power plants use thousands of gallons of water per minute for evaporative cooling to maintain their operations. This consumptive use often competes with other water uses such as navigation, drinking water and other industrial uses. In addition, sections 316(a) and 316(b) of the Clean Water Act, recently updated in 2002, apply more stringent environmental controls than had been employed in the past to minimize effects on surface-water ecosystems caused by (a) thermal discharge of cooling water, and (b) power plant water intakes. Increased fresh water resource demand and environmental concerns related to power plant water use are driving the consideration of using alternate sources of water for thermoelectric generation. Suitable alternate water sources must be capable of providing large dependable quantities of flow; be thermally stable on a seasonal basis; and not cause different, but equally serious, environmental concerns compared to river water. Finally, any alternative water source must be legally developable and be economically competitive with traditional water sources.

Water in above and below drainage underground mines is such a potential water source. The highest concentration of flooded mines in the nation lies within coal deposits of the Appalachian region (Final Phase III Report, USDOE/NETL Contract \# DE-AM26-99FT40463). Here in one coal basin alone near Pittsburgh, at least 10,800 hectares of flooded mines exist, and this number is thought to have the potential to increase substantially as mine flooding continues. In addition, this flooded mine area does not include the area of unflooded above drainage mines. These mine-water "reservoirs" could serve as either a buffer for water storage and transport, or as a source of water to replace surface water sources. The potential for such use and the techniques/technologies/costs it would require have been studied under DOE/ NETL contract DE-PS26-03NT41719-0.

The utilization of mine water for cooling has advantages and disadvantages over a conventional surface water source. The quantity of water available from mines is less 
variable in quantity and temperature than a surface water source. The mine void itself can be used as reservoir of water that can be drawn down during dry weather conditions. The ambient water temperature is less variable than surface water hence the cost of over designing cooling systems for summer weather conditions is reduced. A negative aspect of mine water utilization is the need for water treatment. Except for newly flooded mines and up dip mines, mine water is frequently alkaline with low iron concentrations. Under these conditions the removal of metals is a straight forward procedure. However, up dip mines, which are also considered in this report, generally have low $\mathrm{pH}$ values and low metal concentrations that are dominated by aluminum.

Mines seldom generate sufficient water individually to sustain a consumptive use as large as a power plant. In order to obtain the needed quantity of water, a number of mines must be linked hydraulically, either by direct connection or through the use of mine to mine transfer pumps. Water, in sufficient quantity can then be withdrawn, treated, and supplied to the plant.

Most coal-fired power plants pump significant amounts of water across the condensers. The amount of water needed to maintain the condensers at a constant temperature is controlled by the effectiveness of the cooling towers and the temperature of the makeup water. The use of mine water to replace river water during extreme summer temperatures has been shown to reduce the pumping requirement by 6.4 percent. The water emanating from underground mines is typically $16^{\circ} \mathrm{C}$. This cool water can be utilized to dissipate some of the cooling load. For example, raising the temperature of mine water from $16^{\circ}$ to $21^{\circ} \mathrm{C}$ will account for over $5,000,000$ BTUs per hour for a flow of 1000 gallons per minute.

\subsection{Requirements for cooling process water}

\subsubsection{Quantity}

The quantity of water consumed by a power generation facility is dependent upon a number of factors, most prominently the megawatts (MW) of the facility. This generating capacity dictates the design of the entire facility and water capacity requirements for cooling water and process water systems. The major consumption of water in the facility is the condensate cooling water system. The steam must be cooled to achieve a vacuum within the condenser. The resulting condensate is pumped back to the boiler for reuse. The other major consumption of water is for makeup to the boiler and auxiliary cooling systems. Coal-fired power generating facilities also use water in the flue gas scrubber, ash conditioning and other systems. The proposed Beech Hollow power plant is expected to use between 3 and 4 thousand gallons per minute. The 
variation in the water requirement is a function of the source water quality, water treatment requirements, and ash conditioning requirements.

\subsubsection{Chemistry}

The quality of the water used in the power generation facility is a key factor in plant design. Condensate cooling water circulates between the plant and cooling tower in a closed loop, which receives makeup water to maintain a specific volume. The cooling water makeup water rate is determined by evaporative and other losses. Cooling water quality must be maintained within specific limits by chemical treatment to control deposition, corrosion, and biological growth. Inability to control negative waterchemistry factors could result in reduced performance or inoperability. Total dissolved solids (TDS) are monitored during operations to estimate makeup-water demand and the potential for corrosion or the formation of scale. Water is periodically "blowndown" (removed from the tower and discharged) to maintain a specific cycle of concentration. The more dilute the initial makeup water quality is to the cooling tower, the more cycles of concentration can be achieved. There is an economic trade-off relating to the cost to treat or purify cooling tower makeup water. Acceptable cooling tower makeup water quality will be dependent upon $\mathrm{pH}$, TDS, total suspended solids, iron, silica, and other physical/chemical parameters.

The quality of other water consuming systems, within the power facility, must also be considered. The boiler makeup water system must purify the water to minimize deposition and fouling within the boiler, steam, and turbine system. The quality of water to the makeup system will dictate the configuration of components necessary to produce pure water. Incoming water quality will translate to capital and operating costs for this system. These systems typically produce water quality with specific conductivity of $<2 \mathrm{mhos} / \mathrm{cm}$, iron concentrations $<5 \mathrm{ppb}$, and silica concentrations $<20 \mathrm{ppb}$.

The other process systems within the power facility will have varying degrees of water quality requirements. Critical pumps and bearing system may require pure water from the boiler water makeup to avert corrosion and deposition. Other systems such as ash handling and FGD will require lesser quality water, which could be reclaimed wastewater from within the facility. 


\subsection{Characteristics of water from underground coal mines}

\subsubsection{Water Quantity}

Based on results from the Final Phase III Report, USDOE/NETL Contract \# DE-AM2699FT40463, it is estimated that over $6.4 \times 10^{6} \mathrm{~m}^{3}$ of mine water discharges annually from the Pittsburgh coal basin, $50 \%$ of which is not currently treated. Specifically, in the area of the proposed Beech Hollow power plant, the Cherry Valley mine complex is known to be discharging about 1,200 gallons per minute. This discharge is the most significant source of contamination to the Raccoon Creek Watershed. Other discharges in the area were not quantified in the USDOE/NETL report because they originate in above drainage underground mines. These mines discharge to Robinson Run and the North Branch of Robinson Run. Both of these streams are severely impacted by these acid mine drainage discharges. One discharge of significance in this area is from the Nickel Plate Mine. This mine caused a mine blowout in the town of McDonald, Pennsylvania, and is currently flowing at about 1,300 gpm. Other large discharges are known to exist in the area but have not been documented. None of these discharges are currently treated.

\subsubsection{Water Quality}

Water quality from the Cherry Valley Mine Complex was measured under DOE/NETL Contract \# DE-AM26-99FT40463. This water had a pH of 5.36, an alkalinity of $5 \mathrm{mg} / \mathrm{l}$, an iron of $57.8 \mathrm{mg} / \mathrm{l}$, manganese was $1.7 \mathrm{mg} / \mathrm{l}$, aluminum $2.9 \mathrm{mg} / \mathrm{l}$, and sulfate $694 \mathrm{mg} / \mathrm{l}$.

Water quality from the Nickel Plate mine is of lower quality than the Cherry Valley Mine. The $\mathrm{pH}$ is in the $4-5$ range, iron is over $100 \mathrm{mg} / \mathrm{l}$, but both aluminum and manganese are low. This lower quality is to be expected from above drainage underground mine in the Pittsburgh coal seam.

\subsection{Application of mine-water based cooling concepts}

In this project, we are concerned with demonstrating the feasibility of mine water utilization at an actual power plant as opposed to a hypothetical power plant, and, from the knowledge gained, develop a computer based evaluation tool for the use of mine water at other power plants or industrial sites.

The power plant cooling study sponsored by DOE/ NETL contract DE-PS2603NT41719-0 found that the use of mine water for power plant cooling was comparable in cost to the use of a traditional river water source. This was particularly true for mine 
waters that did not require a large amount of treatment prior to use in the power plant. The water quality thus far identified in the area of the Beech Hollow plant is of somewhat poorer quality that the water quality in the DOE/NETL study and as a result will require more treatment. On the other hand, in the DOE/NETL study available river water was adjacent to the power plant and little water pumping was required. In the case of Beech Hollow, the nearest river is some 15 miles away. This is expected to affect the mine water utilization economics favorably.

The proposed use of public water for power plant cooling purposes was not anticipated in the prior study. It is likely that the use of public water at the Beech Hollow facility will prove more expensive than the river water source contemplated in the study thus favoring the use of mine water at this facility.

The mines that were selected for power plant use in the prior study all had large discharges, and the plant was located close to these discharges to minimize piping and pumping requirements. This same condition does not exist at the Beech Hollow site. Mine water will have to be pumped some distance from at least two different directions to achieve the required volume. This additional piping and pumping is expected to add cost to the use of mine water at this facility.

The Beech Hollow power plant represents a significantly different set of circumstances as compared to the DOE/NETL study of power plant cooling. These different circumstances allow for an expanded engineering cost analysis which will provide broader applicability of the cost assessment framework to other potential mine water applications.

The use of mine water by power plants, particularly where that use is integrated directly into the power plant cooling design, is a new and unfamiliar concept to power plant designers and investors. The creation of a computer based design aid will increase the confidence of both designers and investors that mine water use is a viable alternative to river water cooling. 


\subsection{BEECH HOLLOW POWER PROJECT - ROBINSON POWER COMPANY}

\subsection{OVERVIEW}

The Beech Hollow Power Project was used as the base-case for developing and demonstrating the efficacy of this modeling framework for evaluating the use of mine water for thermoelectric power generation. The $320 \mathrm{MW}$ waste coal electric generation project is currently under development in Robinson Township, Washington County. The estimated capital cost of this Project is $\$ 738,000,000$. The Project will consume approximately 2 million tons of waste coal per year. The fuel will come from the Champion Refuse Pile located on 600 acres of land adjacent to the Plant Site and contains in excess of 37.5 million tons of fuel. Environmentally, the Power Project will reclaim and recycle the discarded energy in the refuse pile, neutralize the waste coal, reconfigure and reclaim the Champion Refuse Site and ultimately reclaim other mine sites in the area. The neutralization of the waste coal and reclamation of the site will eliminate (1) the need for long-term treatment (presently treating acid water and runoff from the site); and (2) the potential for the waste coal site to catch on fire producing uncontrolled emissions. The facility will produce low cost power to compete in today's electric power market. The economic decline in the capital markets has resulted in the Project being unable to meet the time constrains established in its Air Quality Plan Approval and the Department's decision not to extend the time frames in the permit. The Project is currently updating and will be reapplying for a new Air Quality Permit

\subsection{INTRODUCTION}

Robinson Power Company is developing a 320 Megawatt ("MW") waste coal electric generating facility in Robinson Township, Washington County, known as the Beech Hollow Power Project.

The Project will employ circulating fluidized bed technology utilizing bituminous coal waste material located adjacent to the project site as its primary feedstock as well as other waste coal in the immediate area to create a TIER II - Alternative energy Credit under Pennsylvania's Alternative Energy Program. Champion Processing Inc. ("CPI") has permitted the coal refuse disposal site as a waste coal remining operation. CPI is presently treating water, maintaining erosion and sedimentation control facilities, 
insuring mine fires do not develop, and addressing other environmental related issues as they arise. The 37.5 million tons of coal refuse at the site represents an unused source of energy. The project would utilize the coal refuse as fuel reclaiming/recycling the energy stored in the pile. This will result in the waste coal being neutralized. The neutralized/alkaline waste coal combustion byproducts will be utilized to reconfigure and contour the existing refuse site creating a developable property in the future and to reclaim other unreclaimed mine lands in the area, a beneficial use of coal combustion byproducts under Pennsylvania law and regulation.

By burning and neutralizing the waste coal and reclaiming the site, the Project will eliminate the need for a long-term mine drainage treatment and the potential for the refuse pile to combust. Thus, insuring the long-term water quality of Little Raccoon Creek and improving the portion of Raccoon State Park drained by Raccoon Creek. Presently, CPI is treating the acid mine drainage from the refuse disposal site.

The Project will serve as the cornerstone in an economic development effort in this part of Washington County in a Keystone Opportunity Zone ("KOZ") known as the Route 980/AR22-Environmental Redemption Site. Washington County has determined that the site needs environmental restoration. The Project Site is within the KOZ and the 600 acres waste coal fuel site is located immediate adjacent to the KOZ.

\subsection{Project Description}

The Beech Hollow Power Project consists of the design, construction, ownership, and operation of an approximately $320 \mathrm{MW}$ coal waste-fired power generation facility to be located in Robinson Township, Washington County, Pennsylvania (Figure 1). The project will generate approximately $288 \mathrm{MW}$ of electrical energy for sale into the grid.

Project fuel will consist of approximately 37.5 million tons of bituminous waste coal material ("gob") in place on 600 acres adjacent to the project site. The bituminous coal waste material represents the waste 
Figure 1. Project Location

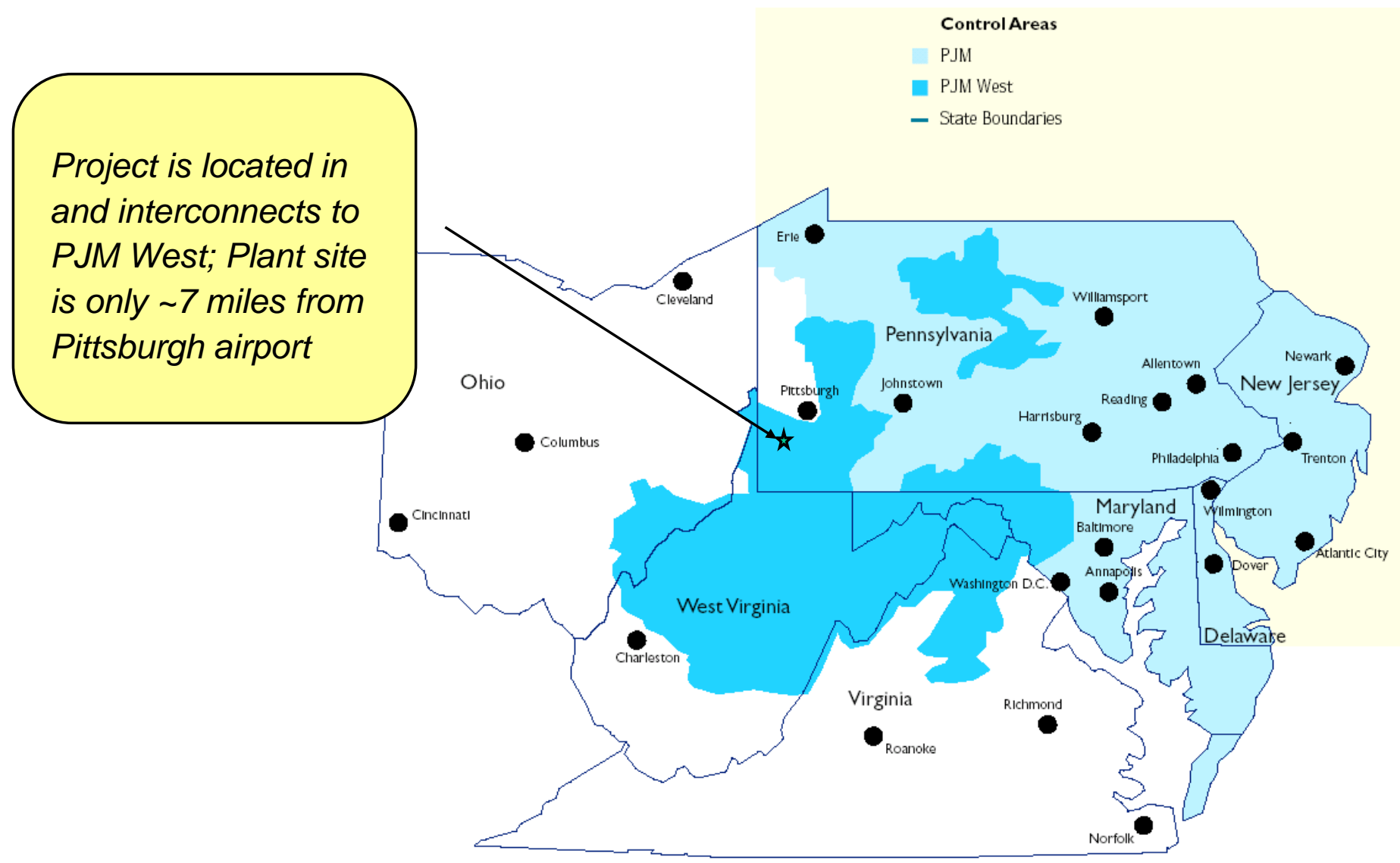

product from coal cleaning and processing operations conducted at the site for a period of in excess of 50 years.

Coal Combustion Byproducts (CCB) generated from the combustion of the waste coal will be beneficially used in the reclamation of the permitted area adjacent to the project site and other unreclaimed mine lands in the area. A PA DEP (formerly DER) Coal Refuse Permit/Waste Coal Handling/ Ash Management/NPDES permit was issued authorizing the removal of coal waste for use as fuel for the Project and the beneficial use of CCB to reclaim the site and other unreclaimed mine lands in the area. (The renewal permit application has been submitted to DEP.) 
One or more local municipal water companies could provide the project water requirements. Pennsylvania American Water Company, the closest utility to the Plant site, had proposed to install sufficient transmission and storage facilities to serve the project and upgrade and extend their existing water distribution system for the area. The Water Supply Agreements with $3^{\text {rd }}$ Parties to provide water will need to be finalized after the revised design prepared by the Architectural and Engineering Firm are complete. Further, the water supply agreements will insure adequate water will be available within the $\mathrm{KOZ}$ for other commercial and industrial facilities and provide services to residential areas near the site.

RPC will examine the use of treated water from abandoned deep mines in the area as potential sources of water to meet the needs of the project or to be blended with water from a contract supplier. Presently, two large mine complexes has been identified for further review as potential water supply sources (Cherry Valley Mine and the Partridge Mine). The water would be used to supplement or replace water from Pennsylvania American Water in the future.

Based on RPC's preliminary analysis, the proposed equipment configuration will consist of a single 2,000,000-lb/hr circulating fluidized bed (CFB) boiler with reheat and a single steam turbine generator and related facilities with a gross design capacity of approximately $320 \mathrm{MW}$. The A\&E Firm will finalize the recommendations on plant configuration after discussion with PADEP on air and water related issues.

\subsection{Project Site}

The power generation facility will be constructed on an approximately 40 -acre site. The site is located approximately 12 miles west of Pittsburgh at the intersection of US route 22 and PA Route 980 (Figure 2). 


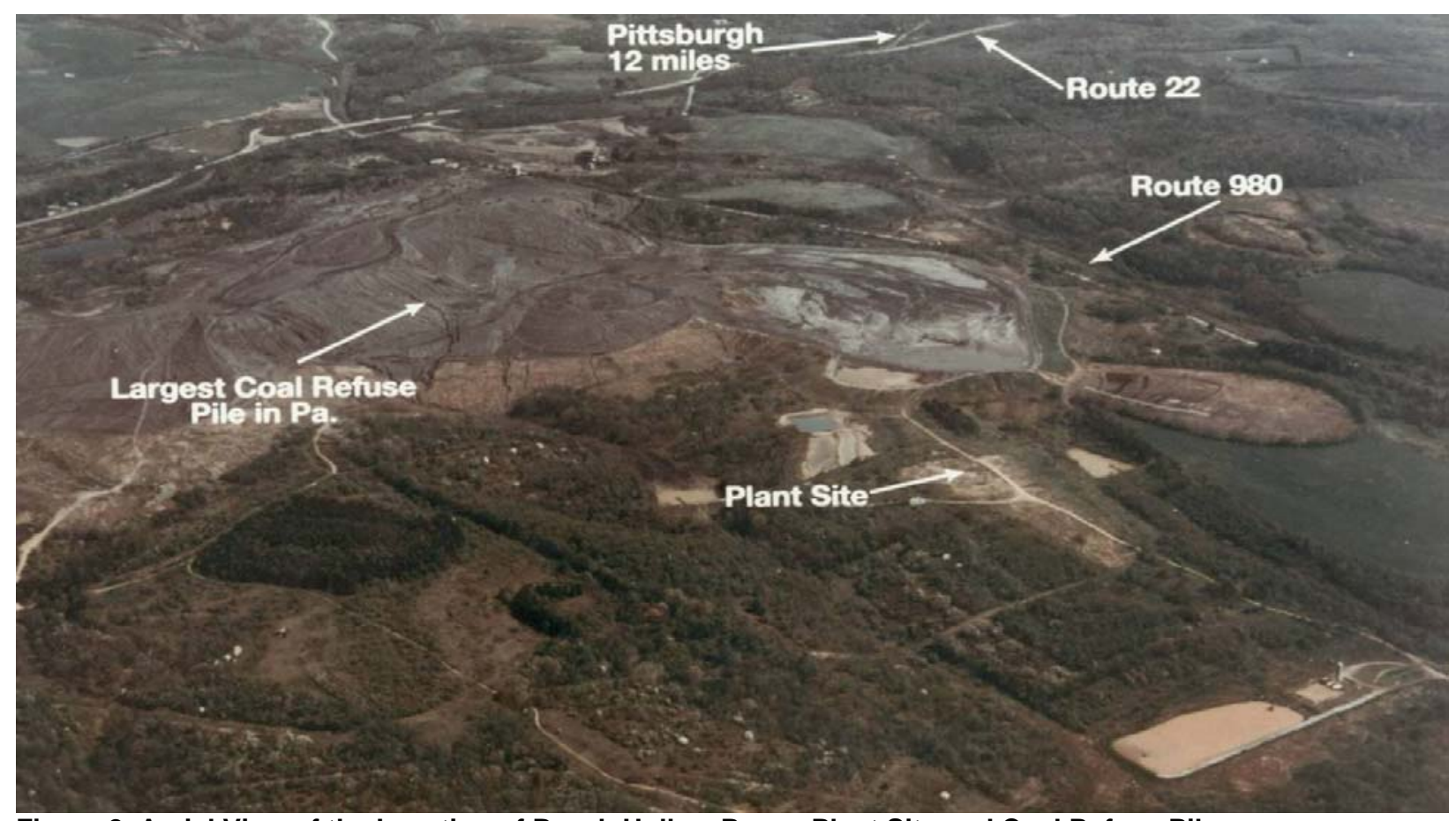

Figure 2. Aerial View of the Location of Beech Hollow Power Plant Site and Coal Refuse Pile

The Plant Site is part of an industrial zoned surface tract of land and part of the Washington County Keystone Opportunity Zone (known as the Route 980/SR 22 Environmental Redemption Site). The feedstock fuel and ash disposal area are located adjacent to the Plant Site on approximately 600 acres of permitted land. The power generation facility is located about 3300 feet from the designated interconnection with the West Penn Power transmission system. However, an alternative interconnect site located 7 miles from the Plant Site is being examined. This interconnect site is in the Duquesne Light Transmission System. If this is the better interconnection site, Beech Hollow will need to acquire right-of-ways and complete environmental assessments of the right-of-way.

The Plant Site is covered with approximately one foot of topsoil. The sedimentation traps and retention pond have been constructed. Bedrock is shallow (less than 10 feet in depth) and overlain by residual soils, which can support footings and mat foundations. ${ }^{1}$

\subsection{Fuel Supply}

The gob pile encompasses approximately 600 acres, and was created and previously owned by Consolidation Coal Company. The pile mainly consists of "coarse" gob, deposited in aboveground piles, and "fine" gob (or silt) deposited as slurry in impoundments. The coarse material has an in-place heating value of $3500 \mathrm{Btu} / \mathrm{lb}$ (dry) and the fines have an in-place heating value of 9087 Btu/lb (dry basis). Blending the 
two sources in an $70 / 30$ blend (70\% coarse by weight and $30 \%$ fines by weight), yields a blended heating value of $5,000 \mathrm{Btu} / \mathrm{lb}$ (dry basis). In addition to the waste coal, the plant will employ 200,000 tons per year of woody biomass as a fuel source.

The site is presently permitted and water is being managed through the use erosion and sediment controls and mine drainage treatment facilities in order to protect Little Raccoon Creek. (This creek drains to Raccoon Creek, which flows through a portion of Raccoon Creek State Park.)

\subsection{Power Generation Facility}

As currently configured, the power generation facility will consist of a single 2,000,000 pound per hour circulating fluidized bed boiler, a single steam turbine generator, fuel and ash handling equipment, and all ancillary facilities including a baghouse, de-NOx controls (SCNR), a dry scrubber, cooling tower and transformer/switch gear equipment.

The primary steam generator will be a single circulating fluidized bed boiler with a combined heat input capacity of approximately $2,730 \mathrm{MMBtu} / \mathrm{hr}$. The boiler will be fired during operation with the bituminous waste coal located on site. Based on the blended heating value of approximately $5,100 \mathrm{Btu} / \mathrm{lb}$, fuel consumption at full output is expected to average approximately $622,000 \mathrm{lbs} / \mathrm{hr}$. The CFB boiler will be capable of producing approximately $2,000,000$ pounds of steam at 2,450 psig and $1050^{\circ} \mathrm{F}$. High-pressure steam will be directed to the steam turbine to generate electricity. The boiler house will be totally enclosed and heated and ventilated appropriately. Limestone will be injected with the fuel to control Sulfur Dioxide emissions and a de-NOx/SCNR system will be used to control NOx-emissions. A fabric filter will be used to control emissions of fly ash and reactive and un-reactive limestone.

The final configuration will be made by the EPC Contractor (Engineering Procurement and Construction) based on the permits and performance requirements of the plant.

\subsection{Project Water Needs}

Water for process and cooling is a critical commodity for the plant.

The proposed power plant has a high-water demand requiring an estimated $2835 \mathrm{gpm}$ for the cooling tower. In addition, there is need for another $130 \mathrm{gpm}(+/-)$ for demineralization makeup, washdowns, and potable water. The maximum summer case requires a makeup flowrate of $3394 \mathrm{gpm}$.

There are multiple options relating to the source of water for the plant. The project continues to evaluate different scenarios/options for meeting the water demands of the project. 
There are several approaches (separately or jointly) that can be utilized to provide the necessary water for cooling and process water for the plant. The sources are:

o Existing Municipal Water Authorities and one privately owned company in the surrounding area

o Other sources:

- Privately owned lakes

- Acid Mine Drainage Plant Effluent

- Water from abandoned underground coal mines

- Wastewater from industrial waste discharges

- Install a water line to pump water from the Ohio River to the Plant

To varying degrees, the public water suppliers (whoever selected and contracted with) would need to extend their transmission systems to service the facility. In general, these conventional sources would be thought as reliable and would provide high quality water to the plant. (As such, these sources would be looked upon favorably from an investment perspective as having less risk.) The four primary public water supply sources evaluated are: Allegheny County Municipal Authority; Findlay Township Water Authority; Pennsylvania American Water; and Aliquippa Water Authority. There had been concern over whether or not any or all of these can supply the needs of the plant. However, Pennsylvania American Water and Aliquippa Water Authority have the potential to supply the plant and Pennsylvania American Water is prepared to enter into a contract to supply the water for the plant.

Unconventional sources include privately owned lakes, the AMD plant effluent from Champion Processing, several deep mine complexes; and industrial waste water sources. It was determined that individually these sources could not reliably supply the power plant's full water requirement. However, a combination of sources would be able to meet the demand during dry periods of reduced flow. A scenario utilizing the multiple sources of the AMD plant, St. Patrick's Reservoir and the Clark Mine Pool.

Another potential source is the construction of a new water transmission from the Plant Site to the Ohio River utilizing the Montour Railroad right-of-way and obtaining the water from the Ohio River. (A municipal water authority could be created as a vehicle to accomplish this. Further, the authority could be the provider of water to additional industrial development of the Champion Property.)

A study prepared by BioMost Inc., for the Washington County Conservation District in June of 2006 entitled "Raccoon Creek Restoration Project" provides insights on ways to concentrate discharges from several mines for passive treatment and potential use of 
the water from the passive treatment system as a water supply for the Beech Hollow Power Project.

\subsection{Economic Benefits}

The Beech Hollow Power Project will carry many economic benefits for the Commonwealth of Pennsylvania and more specifically, Washington County. They include, but are not limited to: ${ }^{2}$

o Reclamation of scarred land eventually used for economic development along the Findlay Connector and US Route 22/Airport corridor

o Employment of 700 skilled workers during construction

o Employment of 90 - Full Time Jobs with an annual payroll of $\$ 6$ million

o Infusion of an additional $\$ 61$ million into the local economy each year for 30-years

\subsection{PROJECT STATUS}

The recent economic crisis has impacted the project slowing down project financing and construction. As a result, the Pennsylvania Department of Environmental Protection (PADEP) made a determination that the air quality plan approval that allowed Robinson Power Co. to build the Beech Hollow Power Plant in Washington County is no longer valid after the company allowed construction to lapse for more than 18 months. ${ }^{3}$

At this time, RPC will be resubmitting an application for an air quality plan approval mid2010

1. Almes \& Associates, Report prepared for Washington Power Project, Robinson Twp., Washington County, PA, entitled "Report: Subsurface Exploration and Foundation Recommendations", August, 1994.

2. Robinson Power Company, Handout entitled Beech Hollow Power Project"

3. Pennsylvania Department of Environmental Protection, News Release, Helen Humphreys, entitled "Delay in Construction Leads DEP to Invalidate Beech Hollow Air Quality Plan's Approval" on Jan. 20, 2010

4. BioMost, Inc., Report entitled "Raccoon Creek Restoration Project", prepared for the Washington County Conservation District, June, 2006, 


\subsection{Power Plants utilizing mine water directly or indirectly}

The majority of the United State's electricity is generated at power plants that use steam-based systems, whether the plant is utilizing coal, natural gas, or nuclear energy. In order to condense steam to use in electricity generation, power plants must employ a cooling system. Most of the country's electric power plants use water in this cooling process, except for a few plants utilizing air-cooling systems. Traditionally, power plants have withdrawn freshwater from surface waters, or even withdrawn water from saline water sources, to facilitate the cooling process. With many water supplies throughout the country reaching capacity limits or facing freshwater shortages, the electric power industry has had to turn to alternative sources of water for cooling. One such alternative source is mine pool water, or the groundwater collected in underground pools associated with coal mines.

Anthracite coal has been mined from the coal fields in northeastern Pennsylvania for many years, extracted from both underground and, after World War II, surface mines. As the underground mining operations ceased, and the maintenance and pumping of these mines eventually stopped, the unchecked mines collected pools of groundwater and stormwater. These large pools of water accumulated in old underground mines have great potential for utilization by the steam-based electric power plants. (Veil et al, 2003)

However, the use of water from coal mine pools has been limited, and the only such examples occur in Pennsylvania. The use of mine pools has been limited for a variety of reasons. The two most critical elements have been the availability of water from surface sources and the costs of treating mine water to meet the water quality specifications needed for cooling water.

\subsection{Power Plants Directly Utilizing Mine Pool Water}

There are seven power plants located within the Anthracite of Northeastern Pennsylvania where the power plants developed as small power production facilities or cogeneration units, which used anthracite culm (a waste fuel) as their fuel. Six of these plants were located in areas that needed to be developed utilizing mine water directly from abandoned deep mine pool complexes in the region. Table 1 lists these six power plants, as well as their electricity generating capacity, cooling water withdrawal rate, and treatment process used, among other information. 
The Anthracite Mine Pools being utilized as water supplies for the power plants generally have typical quality as follows:

$\begin{array}{ll}\mathrm{pH} & 5.5-\text { to }-6.8 \mathrm{~s} . \mathrm{u} . \\ \text { Alkalinity } & 2-\text { to }-77 \mathrm{mg} / \mathrm{l} \\ \text { Acidity } & 14-\text { to }-600 \mathrm{mg} / \mathrm{l} \\ \text { Iron } & 30-\text { to }-60 \mathrm{mg} / \mathrm{l} \\ \text { Manganese } & 8-\text { to }-12 \mathrm{mg} / \mathrm{l} \\ \text { Zinc } & 0.19-\text { to }-0.33 \mathrm{mg} / \mathrm{l} \\ \text { Copper } & 0.01-\text { to }-0.04 \mathrm{mg} / \mathrm{l} \\ \text { TDS } & 950-\text { to }-1350 \mathrm{mg} / \mathrm{l} \\ \text { Sulfates } & 600-\text { to }-750 \mathrm{mg} / \mathrm{l}\end{array}$

All six of the power plants need to treat the mine pool water before using it. Typically, the cooling water must have a pH level between 7.0 to 9.0 standard $\mathrm{pH}$ units. The mine pool water contains the metals listed above, and an effect of raising the $\mathrm{pH}$ of the water is the formation of metal hydroxides, which can be clarified or filtered by the plant's treatment processes.

The projects were developed utilizing mine water for cooling. Five of the plants, with the exception of the Northeastern Power Company, use the mine pool water as makeup water in a closed-cycle cooling system. A closed-cycle system uses the water to cool the condenser, but instead of directly discharging the heated water back to the surface waters as in a once-through cooling process, it re-circulates the water to a separate structure before being returned to the condenser for additional use. This cooling method is more efficient since it requires far less volume of makeup water, and reduces the adverse effects on the surface waters.

Two projects (Panther Creek and Schuylkill Energy Resources) were able to utilize reservoirs as their primary source of water but need mine water to supplement their primary sources; especially during low flow conditions. A third plant (Northeast Power Company) utilizes air-cooled condensers but maintains a small auxiliary wet cooling 
tower. The six plants listed have rated capacities ranging from $31 \mathrm{MW}$ to $100 \mathrm{MW}$. The volume of mine pool water used for the cooling systems range from 100 to $1,100 \mathrm{gpm}$.

Table 1. Anthradte Waste Coal Plants Using Coal Mine Pool Water

Table 1 - Anthradite Waste Coal Plants Using Caal Mine Pod Water

\begin{tabular}{|c|c|c|c|c|c|c|}
\hline $\begin{array}{l}\text { Company } \\
\text { Name }\end{array}$ & Plant Lecativa & $\begin{array}{l}\text { Generating } \\
\text { Capacity }\end{array}$ & $\begin{array}{l}\text { Seurcer of } \\
\text { Cealing } \\
\text { Water }\end{array}$ & $\begin{array}{l}\text { Widhingraval } \\
\text { Rate }\end{array}$ & Cumnents & Trealment Prucreses Used \\
\hline $\begin{array}{l}\text { Fillertun } \\
\text { Pewrer } \\
\text { Cempany }\end{array}$ & Frediwling FA & BAMW & $\begin{array}{l}\text { Uninerined } \\
\text { mins poul }\end{array}$ & 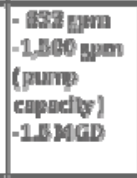 & 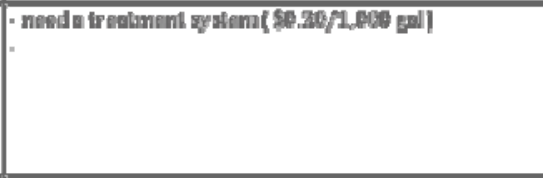 & 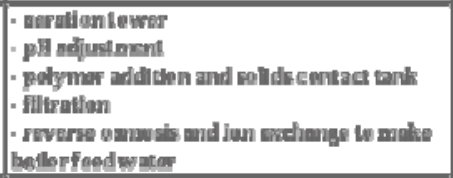 \\
\hline 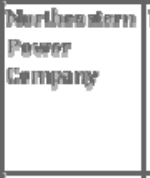 & Medeluw, PA & SOMW & $\begin{array}{l}\text { Flywitrouk } \\
\text { mhas bash }\end{array}$ & 190 grm & 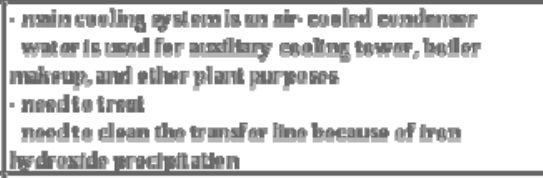 & 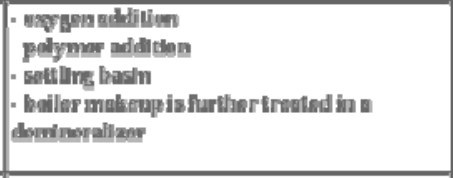 \\
\hline $\begin{array}{l}\text { Pendlier } \\
\text { Greok } \\
\text { Genernting } \\
\text { Antion }\end{array}$ & Mrequehening & GSMW & 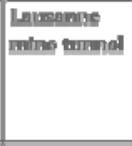 & $\begin{array}{l}\text { 7eAgam } \\
\text { LI Mars }\end{array}$ & 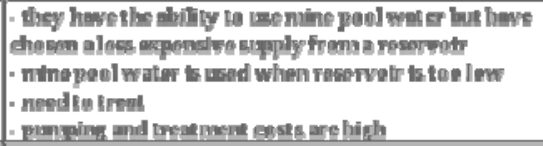 & 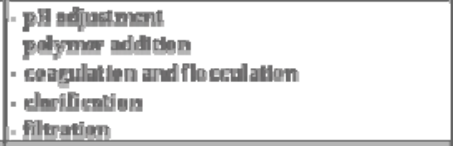 \\
\hline $\begin{array}{l}\text { Echuylkill } \\
\text { Encris } \\
\text { Raseureas, } \\
\text { Ine }\end{array}$ & Shemandealh FA & 1PONW & $\begin{array}{l}\text { Aaple Hill } \\
\text { mine }\end{array}$ & 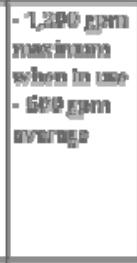 & 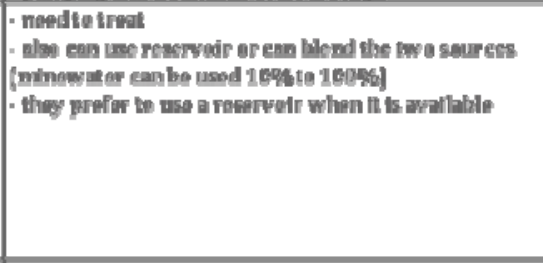 & 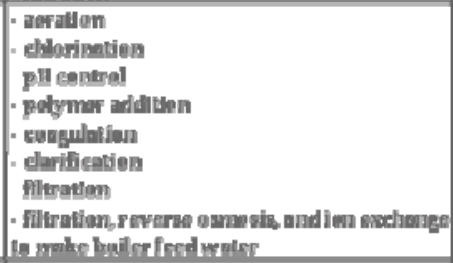 \\
\hline $\begin{array}{l}\text { Wra - } \\
\text { Weahweud } \\
\text { Fenerentian } \\
\text { Pfant }\end{array}$ & Tremont, PA & 71 BWW & 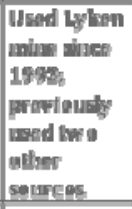 & ERes & 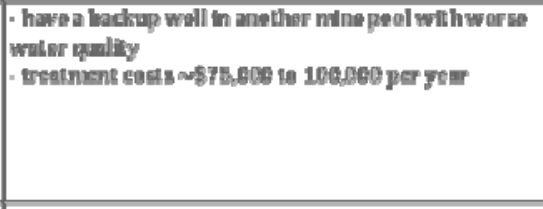 & $\begin{array}{l}\text { - ceagulation } \\
\text { - hulge setilers } \\
\text { - Filtratien }\end{array}$ \\
\hline 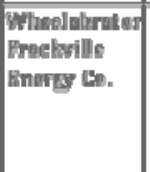 & Frndtwilln, FA & $4 \mathrm{AZW}$ & Mareaming & $\begin{array}{l}490-700 \\
\text { EPm }\end{array}$ & - needie ineal & 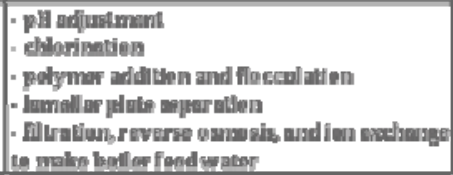 \\
\hline
\end{tabular}

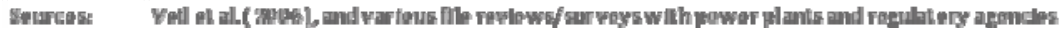




\subsection{Power Plants Indirectly Utilizing Mine Pool Water}

Two projects either currently utilize mine pool water indirectly or plan to in the future, the Exelon Corporation Limerick Generating Station and the proposed GenPower, LLC Longview Power Plant. Table 2 shows the generating capacities and withdrawal rates of the plants.

The Limerick nuclear power plant traditionally withdrew its water to be used in its cooling process from the Schuylkill River and its tributary, the Perkiomen Creek. During periods of low flow, the plant supplemented the natural flows with diverted waters from the Delaware River. This process was found to be costly, and therefore, the plant identified alternative sources of cooling water. Exelon sought and received approval from the Delaware River Basin Commission (DRBC) for a demonstration project to utilize up to $10,000 \mathrm{gpm}$ of mine pool water from the Wadesville Mine Pool. Located approximately 70 miles upstream along the Schuylkill River, the Wadesville mine property is pumped by its owner, the Reading Anthracite Company, to allow recovery of coal that would otherwise be flooded.

The Wadesville mine pool water has water quality that is high enough that it can be discharged without treatment. Therefore, the mine water can be discharged directly into the headwaters of the Schuylkill River, and flow downstream, where it can be withdrawn for use at the Limerick plant. The study so far has successfully reduced the diversion flow from the Delaware River without showing any significant adverse effects to the waters receiving mine pool water.

The 695-MW coal-fired electric station, the Longview Power Plant, located in Fort Martin, WV near the Pennsylvania border, also will utilize mine pool water indirectly (Veil et al, 2006). The plant started construction in 2007 and plans to be online in 2010. Originally, the plant expected to use treated acid mine water from the abandoned Shannopin mine in southwestern PA, but the mine water proved to have less than desirable quality. The mine water, high in iron and $\mathrm{pH}$, would overflow naturally into the Dunkard River, causing environmental harm to the basin watershed. Treatment would have been expensive, and a high volume of reject water would have been produced.

Instead, AMD Reclamation Inc., a non-profit organization formed by GenPower, will pump from the mine pool (currently 7,000 gpm), treat the water, and discharge it to the Monongahela River and its tributary, the Dunkard River. The clarifier to treat the water has paid for in part by PA Department of Environmental Protection grants. The Longview plant then will draw from the Monongahela River, at a point six miles downstream in Greene County, PA, and use the treated water in its plant's cooling process. The power plant anticipates needing 5,000 to $6,000 \mathrm{gpm}$ for cooling. 


\begin{tabular}{|c|c|c|c|c|c|c|}
\hline & & & \multicolumn{3}{|c|}{ Table 2 - Power Plants Indirectly Utilizing Coal Mine Pool Water } & \\
\hline $\begin{array}{l}\text { Company } \\
\text { Name }\end{array}$ & Plant Location & $\begin{array}{l}\text { Generating } \\
\text { Capacity }\end{array}$ & \begin{tabular}{|l} 
Indirect \\
Source of \\
Cooling \\
Water
\end{tabular} & $\begin{array}{l}\text { Withdrawal } \\
\text { Rate of Mine } \\
\text { Pool Water }\end{array}$ & Comments & Treatment Processes Used \\
\hline $\begin{array}{l}\text { Exelon } \\
\text { Generation } \\
\text { Company }\end{array}$ & Limerick, PA & $\begin{array}{l}1,138 \mathrm{MW} \\
\text { each for } 2 \\
\text { units }\end{array}$ & $\begin{array}{l}\text { Wadesville } \\
\text { Mine Pool }\end{array}$ & \begin{tabular}{|l} 
- up to \\
$10,000 \mathrm{gpm}$
\end{tabular} & $\begin{array}{l}\text { - nuclear power plant } \\
\text { - units cooled by closed-cycle natural-draft cooling } \\
\text { towers } \\
\text { - cooling water needed } 24,300 \text { gpm total }(29,200 \mathrm{gpm} \\
\text { max }\end{array}$ & $\begin{array}{l}\text { - mine pool water has good quality, no } \\
\text { treatment needed before discharge to surface } \\
\text { waters }\end{array}$ \\
\hline $\begin{array}{l}\text { Longview } \\
\text { Power Plant }\end{array}$ & Fort Martin, WV & $695 \mathrm{MW}$ & $\begin{array}{l}\text { Shannopin } \\
\text { deep mine }\end{array}$ & $\begin{array}{l}-5,000 \text { to } \\
6,000 \mathrm{gpm}\end{array}$ & $\begin{array}{l}\text { - water is used for a pulverized coal boiler with a } \\
\text { supercritical steam cycle } \\
\text { - need to treat }\end{array}$ & $\begin{array}{l}\text { - duel clarifier } \\
\text { - reverse osmosis }\end{array}$ \\
\hline Sources: & Veil et al. (2006), & asey (2008) & & & & \\
\hline
\end{tabular}

Table 2. Power Plants Indirectly Utilizing Coal Mine Pool Water

\subsection{Experimental Methodology}

\subsection{Indentify Sources}

The initial task in this study was to identify mine water sources within a five mile radius of the Beech Hollow Plant site. Numerous mine water sources exist within, or just outside of a five mile radius of the proposed Beech Hollow Power Plant. The location of these discharges were identified using published reports on mine discharges in the area, combined with field reconnaissance by project personnel. In addition, people knowledgeable about mine discharges in the area were contacted for additional information about discharge locations. These people include Pennsylvania DEP inspectors, active or retired, and watershed organizations. A hand held GPS receiver was used to locate many of the mine discharges found in the field. If the site was not accessible, discharges found in published reports were plotted based on the reported location.

Figure 3 shows the location of the proposed Beech Hollow facility, a circle of five mine radius from the facility and the locations of the mine discharges that were indentified. In addition, Figure 3 also shows the outlines of the underground mines in the area. Where the mines are known to be flooded the flooded area is shown in blue, all other mine area are shown in gray. The table below contains the name and location of the discharge. If the discharge was identified on an Operation Scarlift report the id and flow data from the report are included in the table. 


\begin{tabular}{|c|c|c|c|c|c|c|c|}
\hline \multirow{3}{*}{ No. } & \multirow{3}{*}{$\begin{array}{c}\text { Discharge } \\
\text { Name }\end{array}$} & \multirow{3}{*}{ Latitude } & \multirow{3}{*}{ Longitude } & \multicolumn{4}{|c|}{ Operation Scarlift Data } \\
\hline & & & & \multirow{2}{*}{ ID } & \multicolumn{3}{|c|}{ Flow } \\
\hline & & & & & Min & Max & Average \\
\hline 1 & Bertha & $\begin{array}{l}546,642.5 \\
5\end{array}$ & $\begin{array}{l}4,467,823.0 \\
1\end{array}$ & & & & \\
\hline 2 & Erie & $\begin{array}{l}551,671.1 \\
5\end{array}$ & $\begin{array}{l}4,468,925.3 \\
5\end{array}$ & & & & \\
\hline 3 & Francis & $\begin{array}{l}551,048.7 \\
6\end{array}$ & $\begin{array}{l}4,469,481.3 \\
9\end{array}$ & & & & \\
\hline 4 & Hopper & $\begin{array}{l}557,978.0 \\
8\end{array}$ & $\begin{array}{l}4.467,962.4 \\
3\end{array}$ & & & & \\
\hline 5 & JB-1 & $\begin{array}{l}554,398.2 \\
9\end{array}$ & $\begin{array}{l}4,467,779.6 \\
3\end{array}$ & & & & \\
\hline 6 & JB-2 & $\begin{array}{l}554,053.0 \\
5\end{array}$ & $\begin{array}{l}4,468,670.7 \\
5\end{array}$ & & & & \\
\hline 7 & Langloth & $\begin{array}{l}551,417.0 \\
9\end{array}$ & $\begin{array}{l}4,467,202.2 \\
8\end{array}$ & & & & \\
\hline 8 & McDonald & $\begin{array}{l}565,379.3 \\
9\end{array}$ & $\begin{array}{l}4,469,828.5 \\
9\end{array}$ & & & & \\
\hline 9 & $\begin{array}{l}\text { North } \\
\text { Branch }\end{array}$ & $\begin{array}{l}562,909.4 \\
7\end{array}$ & $\begin{array}{l}4,471,844.3 \\
3\end{array}$ & $\begin{array}{c}404 \\
1\end{array}$ & 120 & 360 & 248 \\
\hline 10 & Primrose & $\begin{array}{l}562,046.1 \\
6\end{array}$ & $\begin{array}{l}4,467,359.9 \\
2\end{array}$ & $\begin{array}{c}401 \\
9\end{array}$ & 0 & 310 & 81 \\
\hline 11 & $\begin{array}{l}\text { Seabright } \\
\text { Rd }\end{array}$ & $\begin{array}{l}563,660.2 \\
1\end{array}$ & $\begin{array}{l}4,472,717.2 \\
1\end{array}$ & $\begin{array}{c}482 \\
9 \\
\end{array}$ & 2 & 300 & 31 \\
\hline 12 & & $\begin{array}{l}563,445.7 \\
1\end{array}$ & $\begin{array}{l}4,473,021.0 \\
8\end{array}$ & $\begin{array}{c}483 \\
4\end{array}$ & 60 & 240 & 120 \\
\hline 13 & & $\begin{array}{l}561,201.6 \\
9\end{array}$ & $\begin{array}{l}4,479,576.1 \\
9\end{array}$ & & & & \\
\hline 14 & & $\begin{array}{l}561,374.0 \\
0\end{array}$ & $\begin{array}{l}4,479,706.1 \\
7\end{array}$ & & & & \\
\hline 15 & & $\begin{array}{l}560,157.8 \\
3\end{array}$ & $\begin{array}{l}4,471,048.9 \\
8\end{array}$ & $\begin{array}{c}400 \\
6\end{array}$ & 15 & 90 & 48 \\
\hline 16 & & $\begin{array}{l}562,307.8 \\
7 \\
\end{array}$ & $\begin{array}{l}4,467,767.1 \\
0 \\
\end{array}$ & $\begin{array}{c}403 \\
1 \\
\end{array}$ & 5 & 60 & 21 \\
\hline 17 & & $563,060.4$ & $4,468,010.4$ & 403 & 10 & 130 & 56 \\
\hline
\end{tabular}




\begin{tabular}{|c|c|c|c|c|c|c|}
\hline & 2 & 7 & 4 & & & \\
\hline 18 & $\begin{array}{l}562,068.1 \\
2\end{array}$ & $\begin{array}{l}4,470,696.9 \\
4\end{array}$ & $\begin{array}{c}404 \\
5\end{array}$ & 13 & 60 & 30 \\
\hline 19 & $\begin{array}{l}564,466.1 \\
6\end{array}$ & $\begin{array}{l}4,468,406.8 \\
3\end{array}$ & $\begin{array}{c}415 \\
3\end{array}$ & 60 & 120 & 76 \\
\hline 20 & $\begin{array}{l}563,930.3 \\
2\end{array}$ & $\begin{array}{l}4,470,092.5 \\
8\end{array}$ & $\begin{array}{c}405 \\
5\end{array}$ & 45 & 300 & 111 \\
\hline 21 & $\begin{array}{l}565,861.6 \\
0\end{array}$ & $\begin{array}{l}4,471,222.6 \\
8\end{array}$ & $\begin{array}{c}495 \\
7\end{array}$ & 2 & 160 & 65 \\
\hline 22 & $\begin{array}{l}566,033.2 \\
0\end{array}$ & $\begin{array}{l}4,471,306.9 \\
8\end{array}$ & $\begin{array}{c}495 \\
6\end{array}$ & 15 & 360 & 83 \\
\hline 23 & $\begin{array}{l}561,927.4 \\
2\end{array}$ & $\begin{array}{l}4,475,752.5 \\
5\end{array}$ & & & & \\
\hline 24 & $\begin{array}{l}561,781.1 \\
9\end{array}$ & $\begin{array}{l}4,475,963.7 \\
7\end{array}$ & & & & \\
\hline 25 & $\begin{array}{l}561,033.7 \\
9\end{array}$ & $\begin{array}{l}4,479,922.8 \\
1\end{array}$ & & & & \\
\hline 26 & $\begin{array}{l}560,947.1 \\
4\end{array}$ & $\begin{array}{l}4,479,457.0 \\
4\end{array}$ & & & & \\
\hline 27 & $\begin{array}{l}560,990.4 \\
7\end{array}$ & $\begin{array}{l}4,480,123.2 \\
0\end{array}$ & & & & \\
\hline 28 & $\begin{array}{l}561,201.6 \\
9\end{array}$ & $\begin{array}{l}4,479,576.1 \\
9\end{array}$ & & & & \\
\hline 29 & $\begin{array}{l}564,443.7 \\
2\end{array}$ & $\begin{array}{l}4,472,803.6 \\
1\end{array}$ & $\begin{array}{c}480 \\
5 \\
\end{array}$ & 60 & 340 & 123 \\
\hline 30 & $\begin{array}{l}564,318.6 \\
0\end{array}$ & $\begin{array}{l}4,472,675.5 \\
1\end{array}$ & $\begin{array}{c}482 \\
4 \\
\end{array}$ & 3 & 200 & 25 \\
\hline 31 & $\begin{array}{l}564,622.4 \\
6\end{array}$ & $\begin{array}{l}4,473,140.2 \\
5\end{array}$ & $\begin{array}{c}480 \\
4 \\
\end{array}$ & 0 & 240 & 27 \\
\hline 32 & $\begin{array}{l}561,842.9 \\
4\end{array}$ & $\begin{array}{l}4,475,189.8 \\
9\end{array}$ & $\begin{array}{c}481 \\
0 \\
\end{array}$ & 45 & 800 & 145 \\
\hline 33 & $\begin{array}{l}563,585.7 \\
3\end{array}$ & $\begin{array}{l}4,473,983.3 \\
4\end{array}$ & $\begin{array}{c}480 \\
8\end{array}$ & 10 & 175 & 28 \\
\hline 34 & $\begin{array}{l}564,175.6 \\
0\end{array}$ & $\begin{array}{l}4,473,896.9 \\
5\end{array}$ & $\begin{array}{c}604 \\
8\end{array}$ & 120 & 480 & 234 \\
\hline 35 & $\begin{array}{l}565,081.2 \\
5\end{array}$ & $\begin{array}{l}4,474,802.6 \\
0\end{array}$ & $\begin{array}{c}480 \\
2\end{array}$ & 1 & 600 & 70 \\
\hline 36 & $565,024.6$ & $4,474,778.7$ & 480 & 15 & 200 & 59 \\
\hline
\end{tabular}




\begin{tabular}{|l|l|l|l|c|c|c|c|}
\hline & 5 & 6 & 1 & & & \\
\hline 37 & & $564,306.7$ & $4,476,205.7$ & 482 & 10 & 150 & 32 \\
& 0 & 7 & 0 & & & \\
\hline 38 & $565,161.6$ & $4,476,000.2$ & 481 & 4 & 120 & 18 \\
& 9 & 1 & 5 & & & \\
\hline 39 & $565,119.9$ & $4,476,015.1$ & 481 & 15 & 250 & 52 \\
& 8 & 0 & 6 & & & \\
\hline 40 & $568,936.9$ & $4,475,440.8$ & 468 & 30 & 270 & 85 \\
& 8 & 8 & 8 & & & \\
\hline 41 & $561,884.0$ & $4,476,781.5$ & & & & \\
& 9 & 8 & & & & \\
\hline
\end{tabular}

\begin{tabular}{|l|l|l|l|l|l|l|l|}
\hline \multirow{2}{*}{ No. } & \multirow{2}{*}{ Discharge } & \multirow{2}{*}{ Name } & Latitude & \multirow{2}{*}{ Longitude } & \multicolumn{4}{|c|}{ Operation Scarlift } \\
\cline { 6 - 8 } & & & \multirow{2}{*}{ ID } & \multicolumn{3}{|c|}{ Flow } \\
\cline { 6 - 8 } & & & & Min & Max & Average \\
\hline 42 & & $561,521.23$ & $4,477,209.43$ & & & & \\
\hline 43 & & $560,524.69$ & $4,476,716.58$ & & & & \\
\hline 44 & & $560,703.42$ & $4,476,619.10$ & & & & \\
\hline 45 & & $566,487.79$ & $4,472,529.49$ & 4952 & 60 & 180 & 115 \\
\hline 46 & & $567,129.05$ & $4,472,526.26$ & 4951 & 45 & 240 & 103 \\
\hline 47 & & $563,262.76$ & $4,472,929.08$ & & & & \\
\hline 48 & & $566,834.25$ & $4,476,624.51$ & & & & \\
\hline 49 & & $561,947.21$ & $4,472,398.45$ & 4039 & 10 & 90 & 31 \\
\hline
\end{tabular}




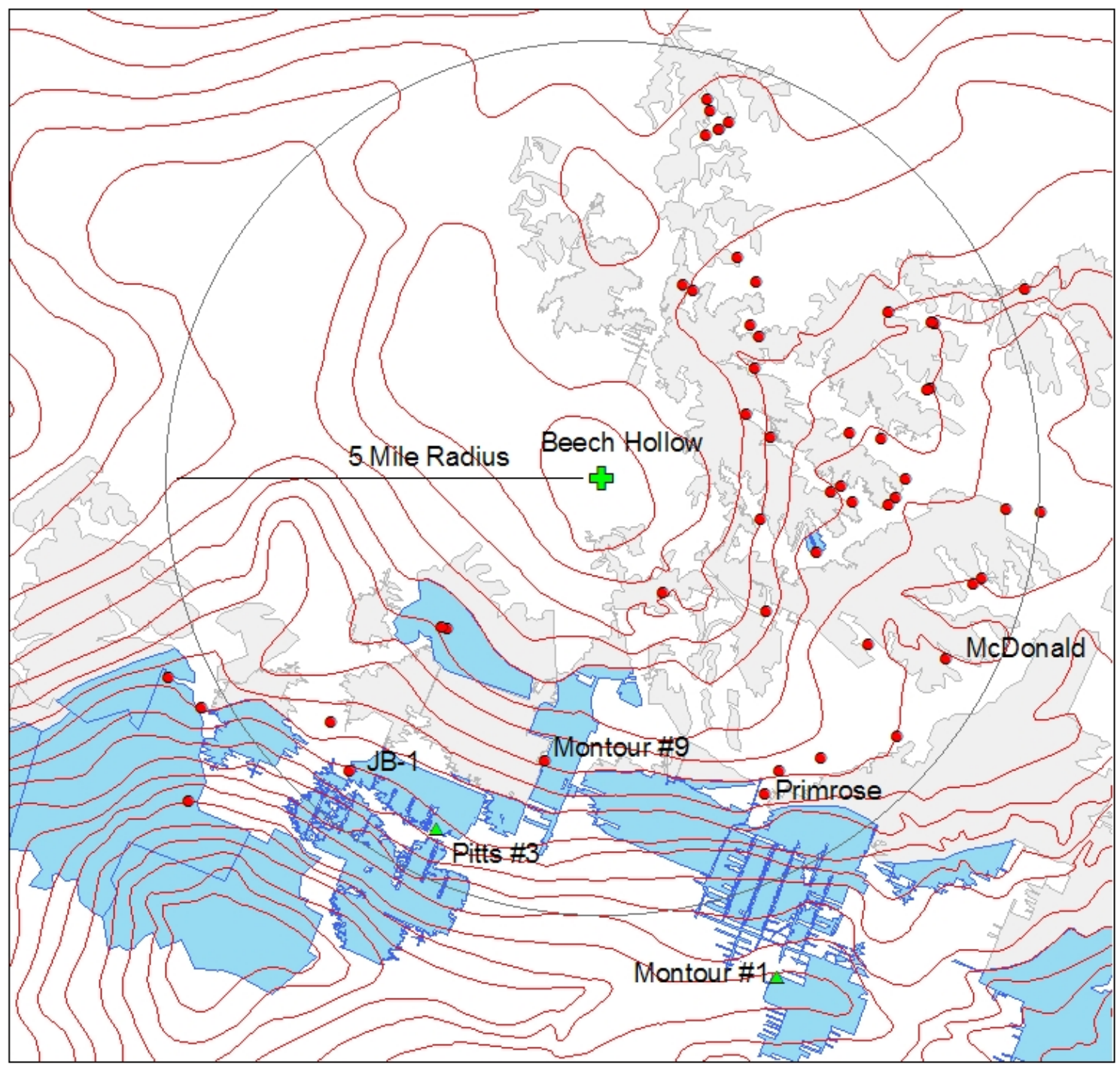

Figure 3. Mining and mine discharges in the vicinity of Beech Hollow. 


\subsection{Quantify Volume and Quality of Mine Water}

Of the 49 discharges identified in the study, six were selected for in depth study. Four of these discharges, JB-1, Primrose, McDonald, and Hopper are classified as high volume discharges. Two discharges were monitored that are low volume sources. These discharges are North Branch and Seabright. Because power plants require large volumes of cooling water, the focus of this investigation is on the larger discharges. They represent the most cost effective way of gathering water where the total volume of water required cannot be obtained from a single source. Two smaller discharges were included so that the cost of including this size discharge could be considered in the computer model development.

Four of the discharges; JB-1, Primrose, Hopper and North Branch were fitted with $\mathrm{H}$ Flumes. These flumes ranged in size from 1 foot (Primrose and North Branch), 1.5 foot Hopper, and 2 foot JB-1. Preexisting weirs were used at Seabright and McDonald. The Seabright weir is a $90^{\circ} \mathrm{V}$-notch and the McDonald weir is a rectangular weir with a width of 36 inches. All of the weirs and flumes with the exception of Seabright were fitted with recording pressure transducers.

\subsubsection{JB-1 (average $941 \mathrm{gpm})$}

The JB-1 discharge is from a partially flooded mine complex that includes Pitts \#2, Pitts \#3, Varner, part of Armide, and barrier leakage from Montour \#9.

The JB-1 discharge emanates from the Pitts \#3 mine in Raccoon Creek. It is the largest discharge in the study, and hence the primary target as a mine water source. The discharge is from a mine portal that had a concrete head wall. This head wall was used to attach a two foot H-Flume. A Hobo pressure transducer from Onset Computer was installed in the stilling well of the H-Flume. A second transducer was suspended in the stilling well to record the barometric pressure. Data from the barometric transducer is used to correct the data recorded by the submerged transducer to obtain the pressure of the water over the transducer. This pressure is then converted to depth of water over the transducer.

The flume and transducers were installed on June 10, 2006 and recorded data at 30 minute intervals until February 1, 2007. At this time the flume was removed as part of a passive treatment system that was being installed to treat the mine water. The design of the passive system buried the mine portal and caused the mine discharge to flow in two pipes that were inserted into the mine portal. These pipes conveyed the mine water to 21 separate discharge locations around the periphery of a treatment wetland (Figure 
3). On March 21, 2007 the transducers were reinstalled in the mine upstream of the piped discharge system. Without a primary measuring device a rating curve for the discharge system had to be established. Several attempts were made to measure the flow of water in the main pipes using a water velocity meter. These measurements did not yield repeatable results hence this method was abandoned. A second method for establishing the discharge / head relationship for this discharge was employed using the bucket and stopwatch technique. The discharge from each of the individual discharge pipes was measured using a calibrated five gallon bucket. The time required to fill the bucket was measured three times and the average value was used to calculate the flow rate from that pipe. This test was repeated at each of the 21 pipes and the sum of the flows was correlated with the water level in the mine at that point in time. This test was repeated eleven times at different head levels and the data are presented in Figure 5. A polynomial regression analysis yielded an equation with an $R^{2}$ value of 0.997 . The equation for this site is:

$\mathrm{GPM}=-382.3(X)^{2}+2154(X)-455.4$

This equation was applied to all of the data recorded after March 21, 2007.

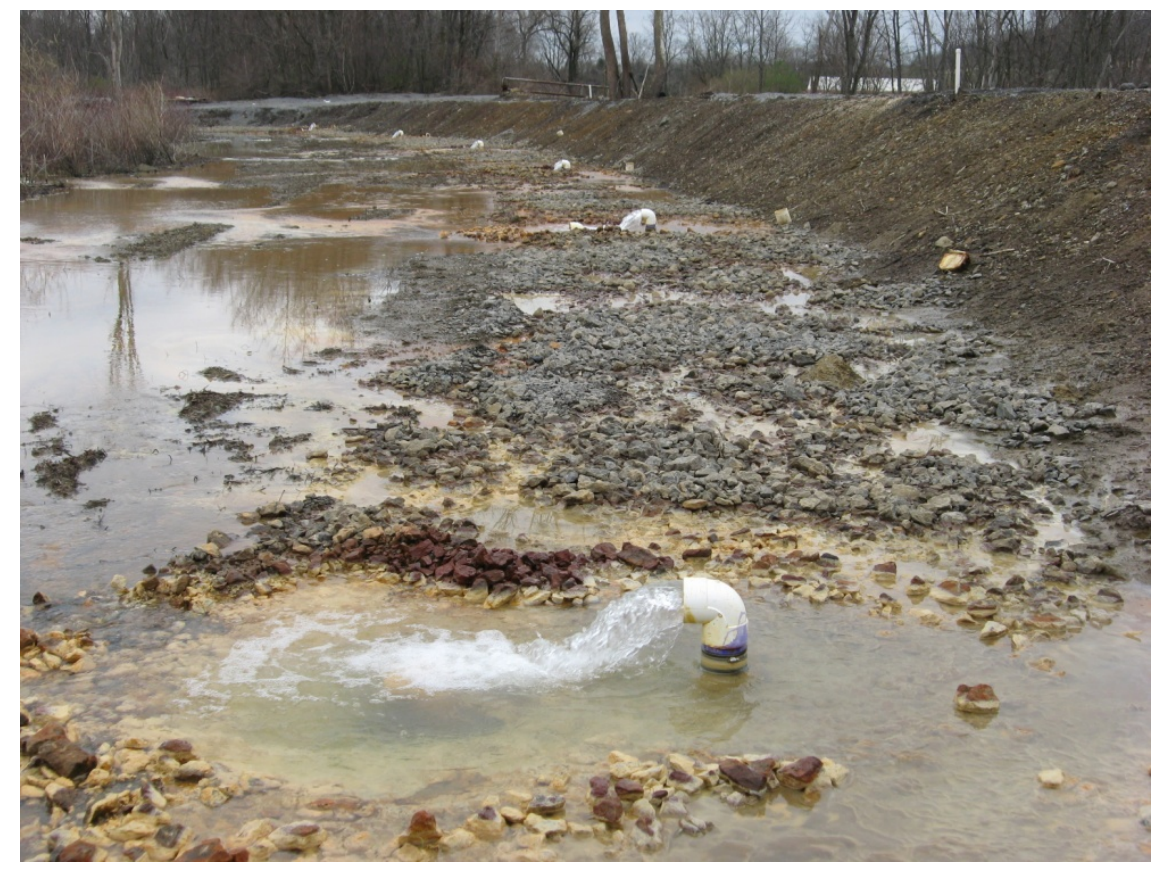

Figure 4. JB-1 Discharge after the construction of the passive treatment system. 


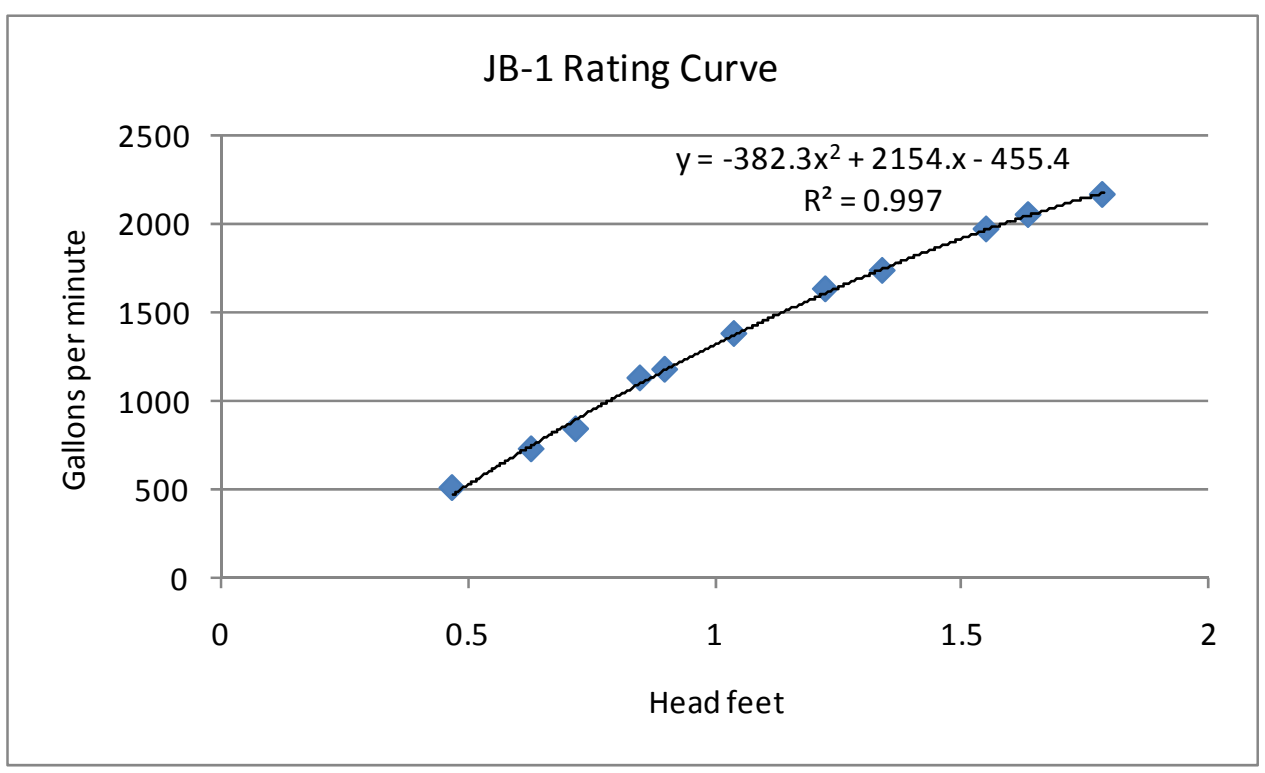

Figure 5. Head discharge relationship for the JB-1 (Pitts\#3 mine)

Utilizing the data from the $\mathrm{H}$-Flume and from the rating curve Figure 6 was created showing the mine discharge flow from JB-1. Note that the temperature showed considerable fluctuation while the H-Flume was installed and that this temperature stabilized once the probe was place inside the mine. This temperature fluctuation was due to the minimal flow in the stilling well which allows the mine water time to adjust to ambient temperature conditions.

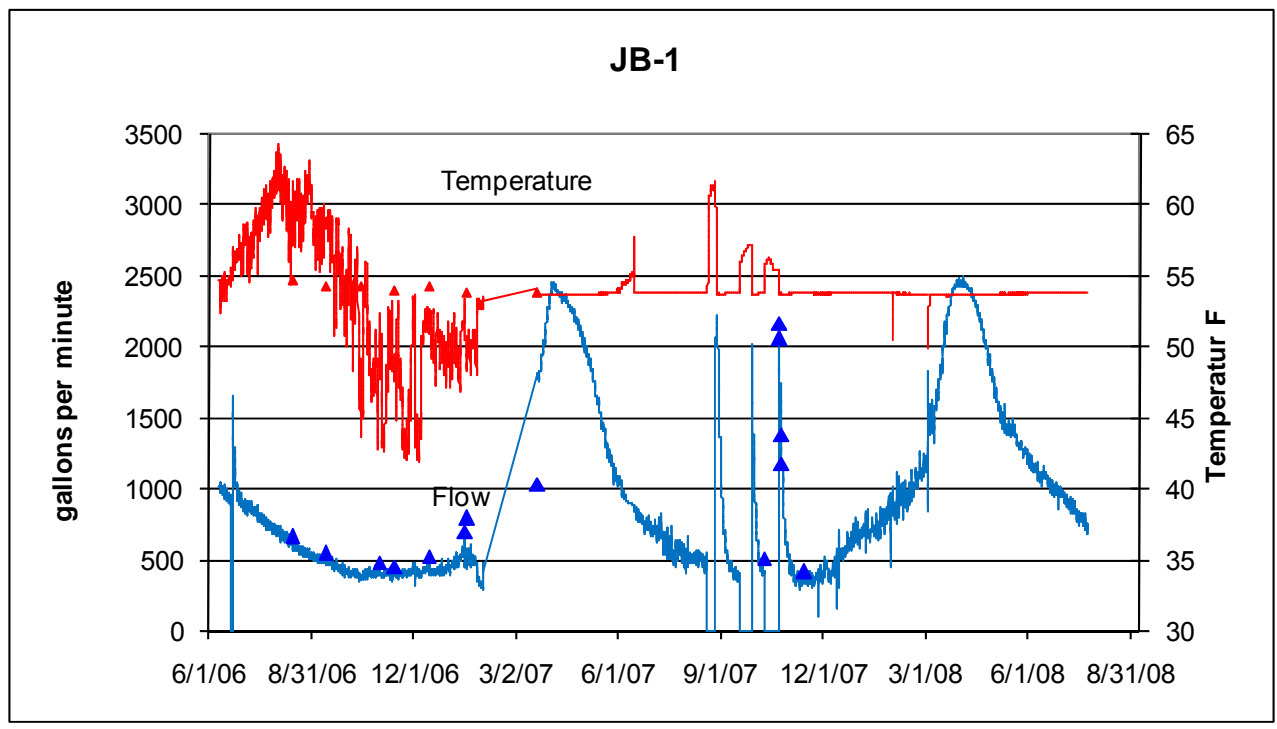

Figure 6. Mine discharge rate and temperature from JB-1 
Several manual measurements were made of the water temperature and the water level in the mine or stilling well. These data are shown in Figure 7 as blue or red triangles corresponding to flow or temperature. The manual temperature data were measured in the mine discharge itself and are not influenced by the stilling well. These manual measurements are consistent with the temperature data collected by the transducer in the mine itself. These data indicate a near constant temperature of $54 \mathrm{~F}^{\circ}$.

In August to October 2007 tests were conducted to estimate the amount of storage available in the mine. The discharge valves on the two discharge pipes were closed causing water to build up in the mine. The three water level traces that have the appearance of a storm response are the result of this testing and do not reflect a precipitation response (Figure 7). These tests were very helpful in developing the rating curve for this discharge as they provided both high and low flow in a short span of time.

The average water chemistry data from 14 samples at this site are:

\begin{tabular}{|c|c|c|c|c|c|c|c|c|c|c|}
\hline T C $^{\circ}$ & DO & SC & $\begin{array}{c}\text { Alk. } \\
\text { field }\end{array}$ & Acidity & SO4 & TDS & $\begin{array}{c}\text { Total } \\
\mathrm{Mg}\end{array}$ & $\begin{array}{c}\text { Total } \\
\mathrm{Ca}\end{array}$ & $\begin{array}{c}\text { Total } \\
\mathrm{Fe}\end{array}$ & $\begin{array}{c}\text { Total } \\
\mathrm{Al}\end{array}$ \\
\hline 12.4 & 0.6 & 1548 & 9.2 & 304.8 & 794.4 & 1178.1 & 48.0 & 141.4 & 74.9 & 10.0 \\
\hline
\end{tabular}

The field $\mathrm{pH}$ ranges from 4.03 to 5.53 standard units. Detailed water chemistry data are shown in Appendix B.

\subsubsection{Primrose (average $210 \mathrm{gpm}$ )}

The Primrose mine discharges into Robinson Run, a tributary of Chartiers Creek, through interconnected entries of an abandoned "country mine" (a small mining operation near the coal outcrop). The mine is almost entirely full of water with the discharge near the up dip end of the mine.

A one foot $\mathrm{H}$-Flume was installed at the Primrose discharge on July 14, 2006. The flume was located in an open channel downstream of a small pool. This installation utilized a stilling well which is subject to variations in ambient temperature. To minimize this effect and to reduce the potential for freezing in the stilling well a small diameter hole was placed in the stilling well to allow water to flow into and out of the well without having a significant effect on the recorded water level. Due to the potential of this water to precipitate iron and aluminum this weep hole frequently plugged between site visits. 
Figure 8 is a photo of the Primrose installation. The stilling well is located on the right side of the flume, and the weep hole is located at the top of the vertical iron stain on the front of the stilling well.

As with JB-1 a hobo pressure transducer was located in the stilling well. Barometric correction is provided by data from the recoding barometer at the JB-1 site.

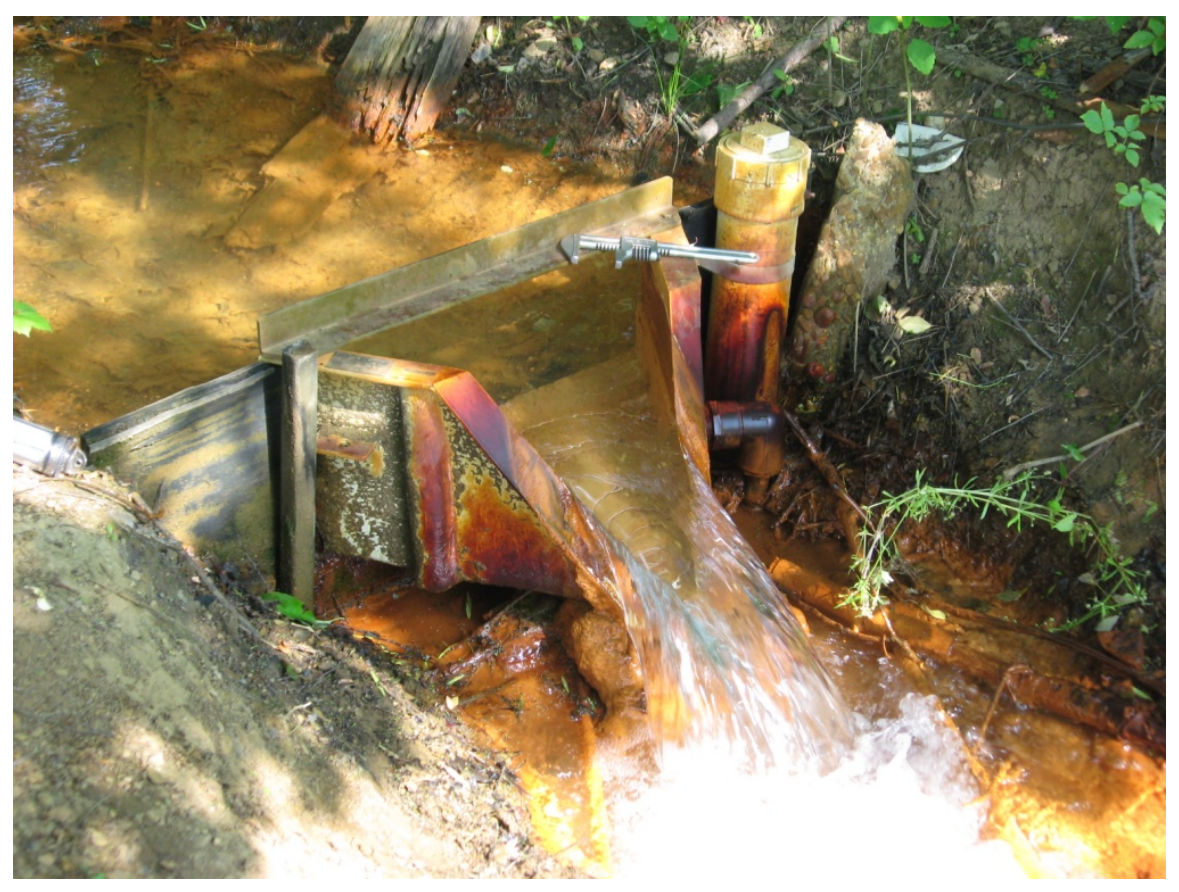

Figure 7. H-Flume at the Primrose discharge 


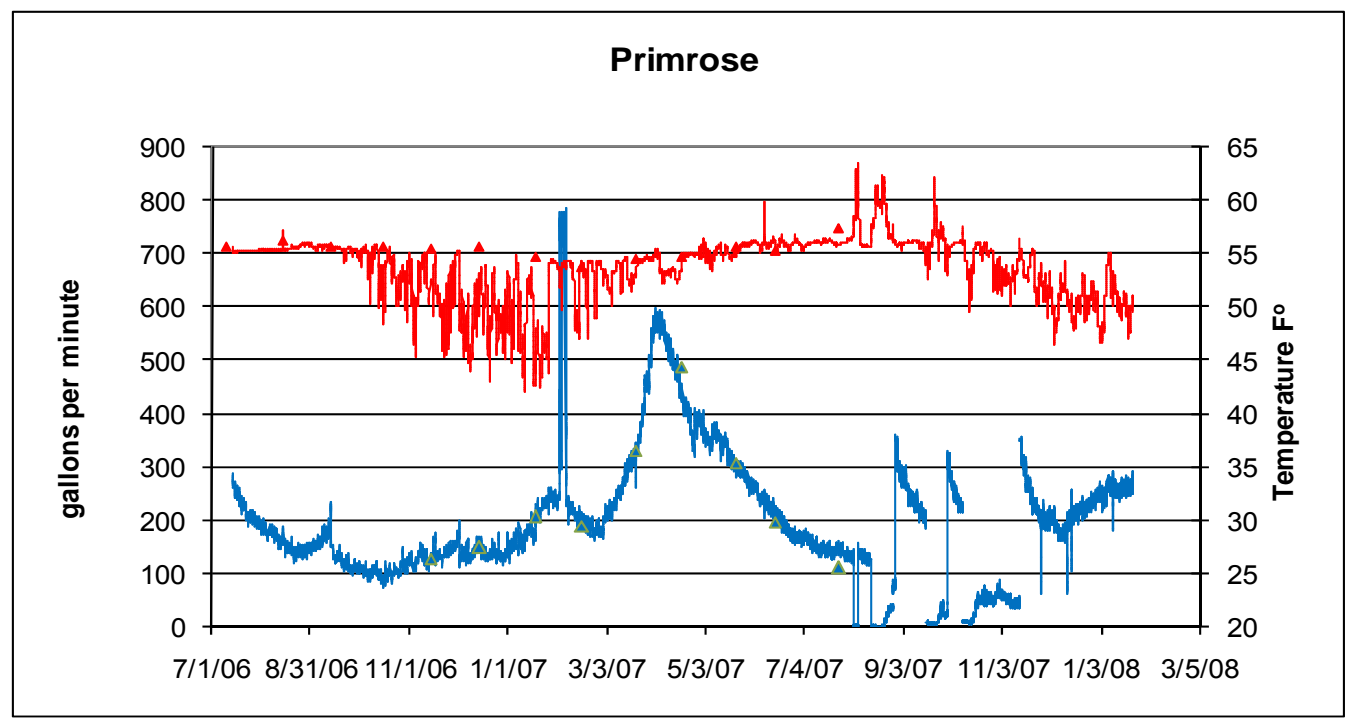

Figure 8. Discharge from Primrose portal.

Note: the high flow measurements between Aug 23, 2006 and Sep 13, 2006 was abnormal due to debris in flume, and the high flow measurements between Feb 1, 2007 and Feb 5, 2007 were the result of ice in the stilling well. Zero flows in August are the result of mine storage tests.

Utilizing the data from the H-Flume and stilling well Figure 8 was created showing the mine discharge flow and temperature from Primrose.

Detailed water chemistry of the Primrose Discharge is contained in Appendix B. The average data from 14 samples at this site are:

\begin{tabular}{|c|c|c|c|c|c|c|c|c|c|c|}
\hline $\mathrm{TC}^{\circ}$ & DO & SC & $\begin{array}{c}\text { Alk. } \\
\text { field }\end{array}$ & Acidity & SO4 & TDS & $\begin{array}{c}\text { Total } \\
\text { Mg }\end{array}$ & $\begin{array}{c}\text { Total } \\
\text { Ca }\end{array}$ & $\begin{array}{c}\text { Total } \\
\text { Fe }\end{array}$ & $\begin{array}{c}\text { Total } \\
\text { Al }\end{array}$ \\
\hline 13.0 & 0.9 & 1901 & 149.8 & 130 & 788.4 & 1392.3 & 34.7 & 113.7 & 91.1 & 1.1 \\
\hline
\end{tabular}

The field $\mathrm{pH}$ ranges from 5.32 to 6.38 standard units.

\subsubsection{Hopper ( 0 to $1400 \mathrm{gpm})$}

This discharge was not identified in the initial search for mine discharges primarily because of the low iron content of the water and it is not near the coal outcrop. Iron staining downstream of the site is minimal at the first road crossing, but it was later 
identified by the field investigator while he was looking for a potential monitoring well site in the area.

The Hopper discharge is from a vertical shaft into the Montour \#9 mine. The shaft is located in a down dip portion of the mine, but because of the overburden thickness at this location the mine is mostly flooded. The discharge is also located in the channel of a first order stream. Consequently, during precipitation events water can either run into the mine or increase the size of the discharge depending on the antecedent head level in the mine. Because Montour \#9 is flooded and the adjacent Verner mine is not, leakage through the barrier pillar can occur from the Montour \#9 mine and into the Verner mine. Ultimately the Verner mine is connected to the JB-1 Discharge consequently any leakage is part of the JB-1 Discharge. During the dry months the water level in the shaft is below the overflow level and there is no discharge from the site. During wet conditions the shaft overflows. This is evident in the site hydrograph Figure 10. Short duration high flows are indicative of precipitation induced runoff. Sustained flows are indicative of ground water recharge to the mine. When these two aspects of the discharge are separated the maximum ground water contribution is about 600 gallons per minute plus the amount of barrier pillar leakage.

A 1.5 foot H-Flume with an integral stilling well was installed downstream of the shaft Figure 11. This flume was also fitted with a recording pressure transducer. Because of the nature of this discharge the temperature data are erratic. During no flow conditions the temperature in the stilling well fluctuates with the ambient air temperature, but once flow from the mine begins, the temperature data are more representative of mine water. The impact of runoff from the first order stream can be seen both in the flow data and in the temperature data.

Detailed water chemistry of the Hopper Discharge is contained in Appendix B. Because this site was identified late in the study and did not flow on several site visits only 2 data points are available to average. Due to the placement of the sampling point downstream of the shaft, and the exposed surface area of the shaft the data for temperature and $\mathrm{DO}$ are believed to be suspect. The field $\mathrm{pH}$ ranged from 6.00 to 6.59 standard units. The averages are:

\begin{tabular}{|c|c|c|c|c|c|c|c|c|c|c|}
\hline $\mathrm{TC}^{\circ}$ & $\mathrm{DO}$ & $\mathrm{SC}$ & $\begin{array}{c}\text { Alk. } \\
\text { field }\end{array}$ & Acidity & SO4 & TDS & $\begin{array}{c}\text { Total } \\
\mathrm{Mg}\end{array}$ & $\begin{array}{c}\text { Total } \\
\mathrm{Ca}\end{array}$ & $\begin{array}{c}\text { Total } \\
\mathrm{Fe}\end{array}$ & $\begin{array}{c}\text { Total } \\
\mathrm{Al}\end{array}$ \\
\hline 13.0 & 0.9 & 1901 & 149.8 & 130 & 788.4 & 1392.3 & 34.7 & 113.7 & 91.1 & 1.1 \\
\hline
\end{tabular}




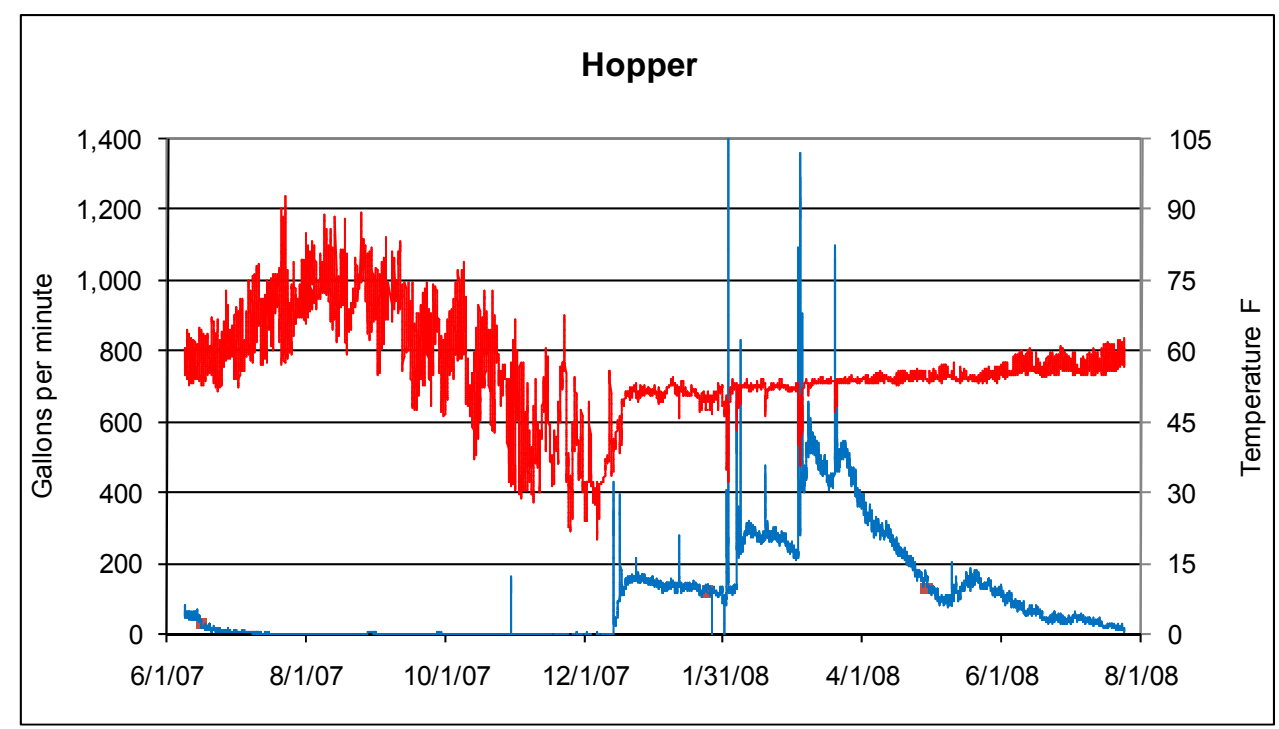

Figure 9. Hydrograph of the Hopper Discharge

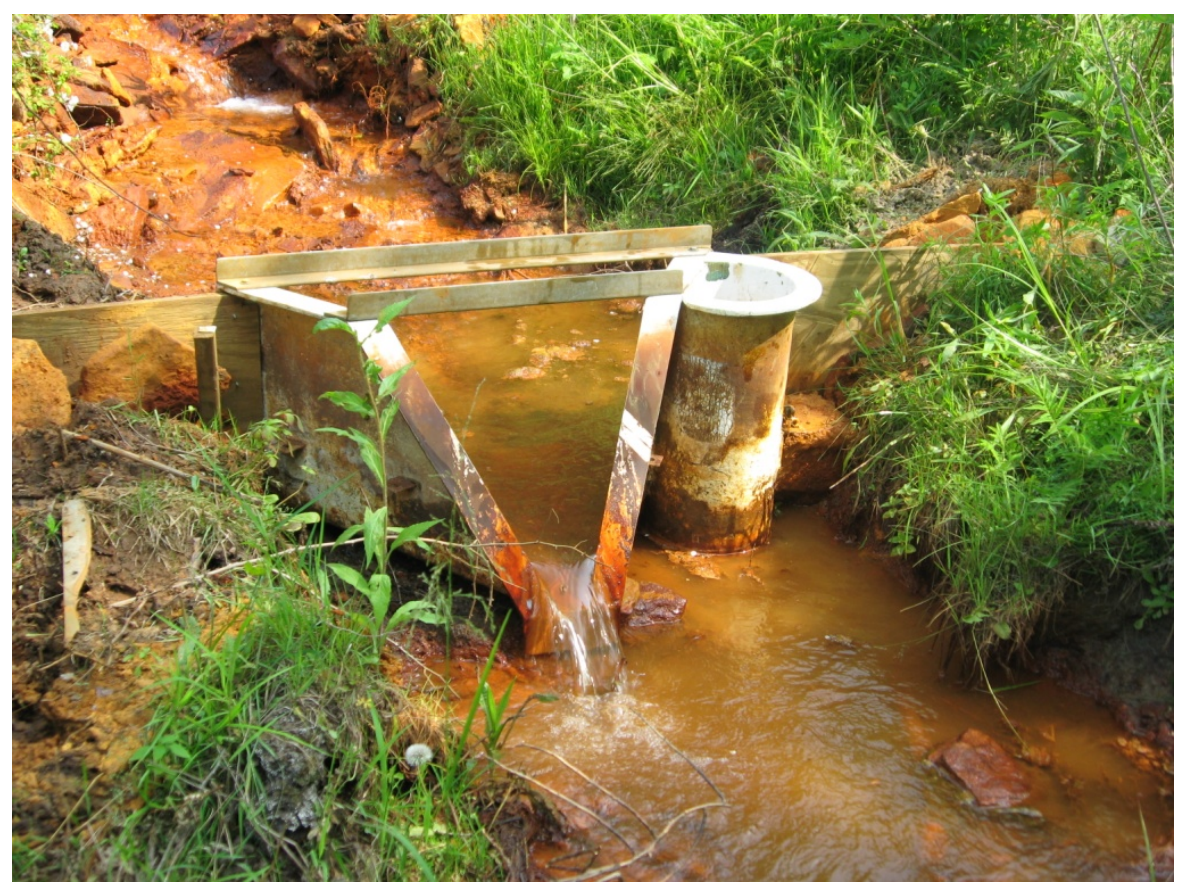

Figure 10. H-Flume at the Hopper discharge 


\subsubsection{McDonald (average $495.7 \mathrm{gpm}$ )}

The McDonald discharge was created as a solution to a mine breakout from the Nickleplate mine in 2005. Due to high water levels in the mine the Nickleplate mine began discharging within the city of McDonald. A new discharge point was created that is lower than the discharge in McDonald consequently the new location controls the water level in the mine.

A concrete rectangular weir was established at the new discharge as part of the emergency response and the Pennsylvania DEP equipped this discharge with a recording pressure transducer. Data from this transducer have been graciously provided by the Bureau of Abandoned Mine lands. A hydrograph of the McDonald discharge is shown in Figure 11.

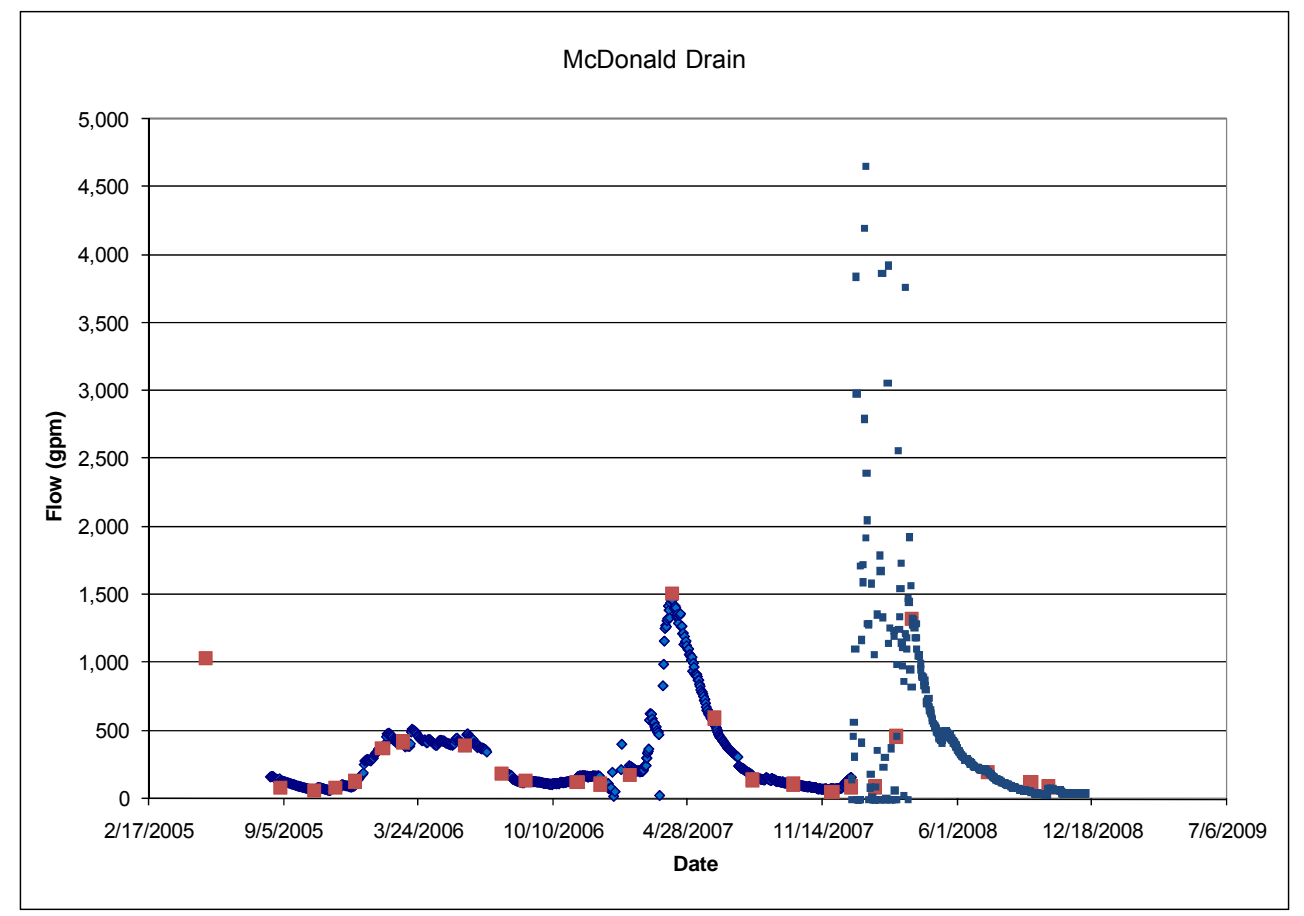

Figure 11. McDonald discharge hydrograph

Erratic data in the first few months of 2008 are due to a transducer malfunction. Manual readings in this time period conform to the expected seasonal rise in flow.

Detailed water chemistry of the McDonald Discharge is contained in Appendix B. The average data from 12 samples at this site are: 


\begin{tabular}{|c|c|c|c|c|c|c|c|c|c|c|}
\hline $\mathrm{TC}^{\circ}$ & DO & SC & $\begin{array}{c}\text { Alk. } \\
\text { field }\end{array}$ & Acidity & SO4 & TDS & $\begin{array}{c}\text { Total } \\
\mathrm{Mg}\end{array}$ & $\begin{array}{c}\text { Total } \\
\mathrm{Ca}\end{array}$ & $\begin{array}{c}\text { Total } \\
\mathrm{Fe}\end{array}$ & $\begin{array}{c}\text { Total } \\
\mathrm{Al}\end{array}$ \\
\hline 12.3 & 1.0 & 1214 & 11 & 188 & 602 & 1181 & 54.5 & 109.0 & 27.8 & 3.9 \\
\hline
\end{tabular}

The field $\mathrm{pH}$ ranges from 4.03 to 5.53 standard unit.

\subsubsection{North Branch (average $30 \mathrm{gpm}$ )}

North Branch Discharge is a small discharge from an up-dip underground mine. A 1 foot $\mathrm{H}$-Flume was installed in the discharge channel immediately downstream of the outfall. Consequently there was very little temperature change. This discharge was reported to be much larger when it was measured during Operation Scarlift. At that time the discharge was reported to have a minimum flow of $120 \mathrm{gpm}$, a maximum flow of 360 $\mathrm{gpm}$ and an average flow of $248 \mathrm{gpm}$. From the data presented in Figure 12 this flow has fallen to 20 to 50 gallons per minute.

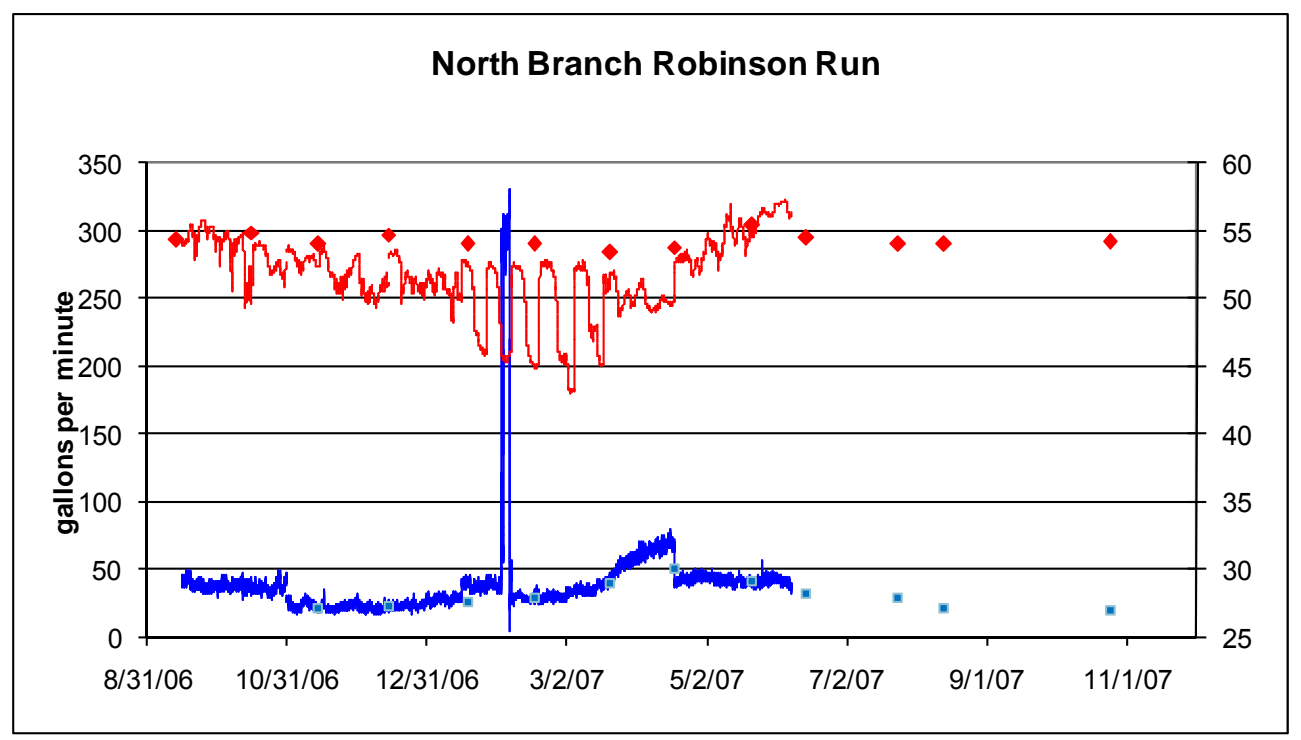

Figure 12. Mine discharge on the North Branch of Robinson Run. Note: the high flow measurements between Feb 1, 2007 and Feb 5, 2007 were the result of ice in the stilling well. The rapid drop in flow during the month of May was the result of clearing debris from the flume

Manual temperature measurements taken in the flow provide more accurate data than the temperature measurements taken in the stilling well. The average temperature of 13 readings was $54.2 \mathrm{~F}^{\circ}$. 
Detailed water chemistry of the North Branch Discharge is contained in Appendix B. The $\mathrm{pH}$ ranged from 5.24 to 6.05 . The average data from 13 samples at this site are:

\begin{tabular}{|c|c|c|c|c|c|c|c|c|c|c|}
\hline T C $^{\circ}$ & DO & SC & $\begin{array}{c}\text { Alk. } \\
\text { field }\end{array}$ & Acidity & SO4 & TDS & $\begin{array}{c}\text { Total } \\
\mathrm{Mg}\end{array}$ & $\begin{array}{c}\text { Total } \\
\mathrm{Ca}\end{array}$ & $\begin{array}{c}\text { Total } \\
\mathrm{Fe}\end{array}$ & $\begin{array}{c}\text { Total } \\
\mathrm{Al}\end{array}$ \\
\hline 12.3 & 1.7 & 2356 & 183.4 & 122 & 1518.8 & 2466.9 & 146.9 & 401.0 & 45.6 & 0.1 \\
\hline
\end{tabular}

\subsubsection{Seabright (average $122 \mathrm{gpm}$ )}

The Seabright discharge originates from an above drainage underground mine 40 to 50 feet above creek level. The water flows down hill several hundred feet before it passes through a preexisting $90^{\circ} \mathrm{V}$-notch weir. It was not possible to obtain land owner permission to install a flume at the point of discharge so the water was sampled at the preexisting weir in road right-of-way. Only manual measurements were taken at this site. Figure 13 is a hydrograph of these data.

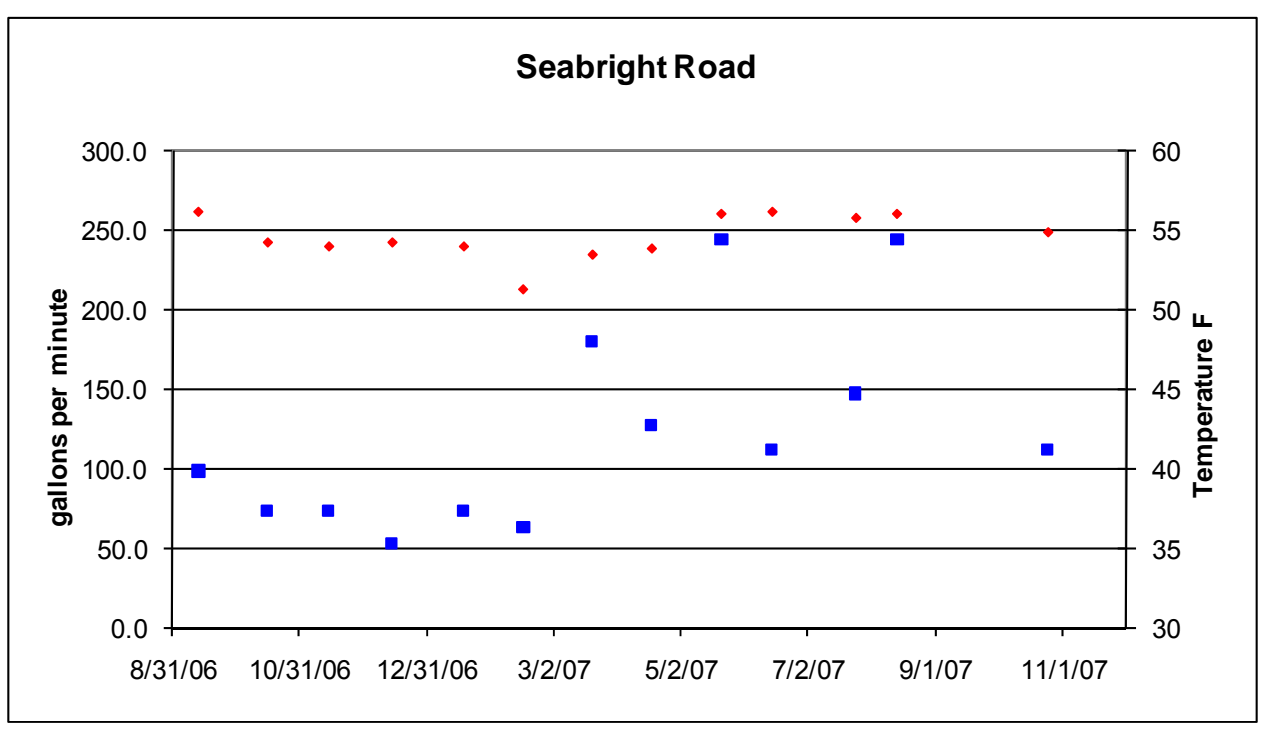

Figure 13. Mine discharge on Seabright Road 
High flow measurements On May 22 and August 14 do not correspond with high water temperatures. This leads to the conclusion that these flow are from the mine and not form rainfall runoff. Rainfall runoff would more closely represent seasonal temperatures on those dates. High mine discharge in the summer suggests that this mine is influenced by rapid recharge in response to precipitation.

The average temperature at this site was $54.6 \mathrm{~F}^{\circ}$ which is in line with other mine water temperature readings however, this is only by chance. The long overland flow of this discharge, before the sampling point, allows the temperature to fall below normal mine water temperature in the winter and rise above normal in the summer.

Detailed chemistry of the Seabright Road Discharge is contained in Appendix B. The $\mathrm{pH}$ ranged from 3.07 to 4.07 . The average data from 13 samples at this site are:

\begin{tabular}{|c|c|c|c|c|c|c|c|c|c|c|}
\hline T C $^{\circ}$ & DO & SC & $\begin{array}{c}\text { Alk. } \\
\text { field }\end{array}$ & Acidity & SO4 & TDS & $\begin{array}{c}\text { Total } \\
\mathrm{Mg}\end{array}$ & $\begin{array}{c}\text { Total } \\
\mathrm{Ca}\end{array}$ & $\begin{array}{c}\text { Total } \\
\mathrm{Fe}\end{array}$ & $\begin{array}{c}\text { Total } \\
\mathrm{Al}\end{array}$ \\
\hline 12.3 & 1.7 & 2356 & 183.4 & 122 & 1518.8 & 2466.9 & 146.9 & 401.0 & 45.6 & 0.1 \\
\hline
\end{tabular}

Note that the average DO from the Seabright site is near saturation. This is consistent with the aeration of the discharge as it flows downhill from the source to the $V$-notch weir.

\subsection{Monitoring Wells}

Two monitoring wells were drilled into flooded mine pools. One of these pools, Pitts \#3 is connected to the JB-1 discharge. The second pool is in the Montour \#1 mine. This mine does not discharge within the five mile radius of the power plant, but the mine pool is within the radius and could be pumped to supply cooling water.

These mine pools not only provide additional water for cooling but they can also provide water from storage which can be drawn down during summer low flow conditions and recharged during the winter and spring. Another potential benefit from flooded underground mine pools is that they can serve as conduits for water transfer underground without the need for building a pipeline, provided that the mine entries remain open. 


\subsubsection{Pitts \#3}

A two inch monitoring well was completed into Pitts \#3 mine. This well is located about 1.2 miles (1925 meters) from the JB-1 discharge. The purpose of this well was to test the degree of interconnection between this well and the mine discharge point. If the mine is highly connected then it is possible to use the mine as a conduit. A pressure transducer was installed in this well and the data collected are presented in Figure 14.

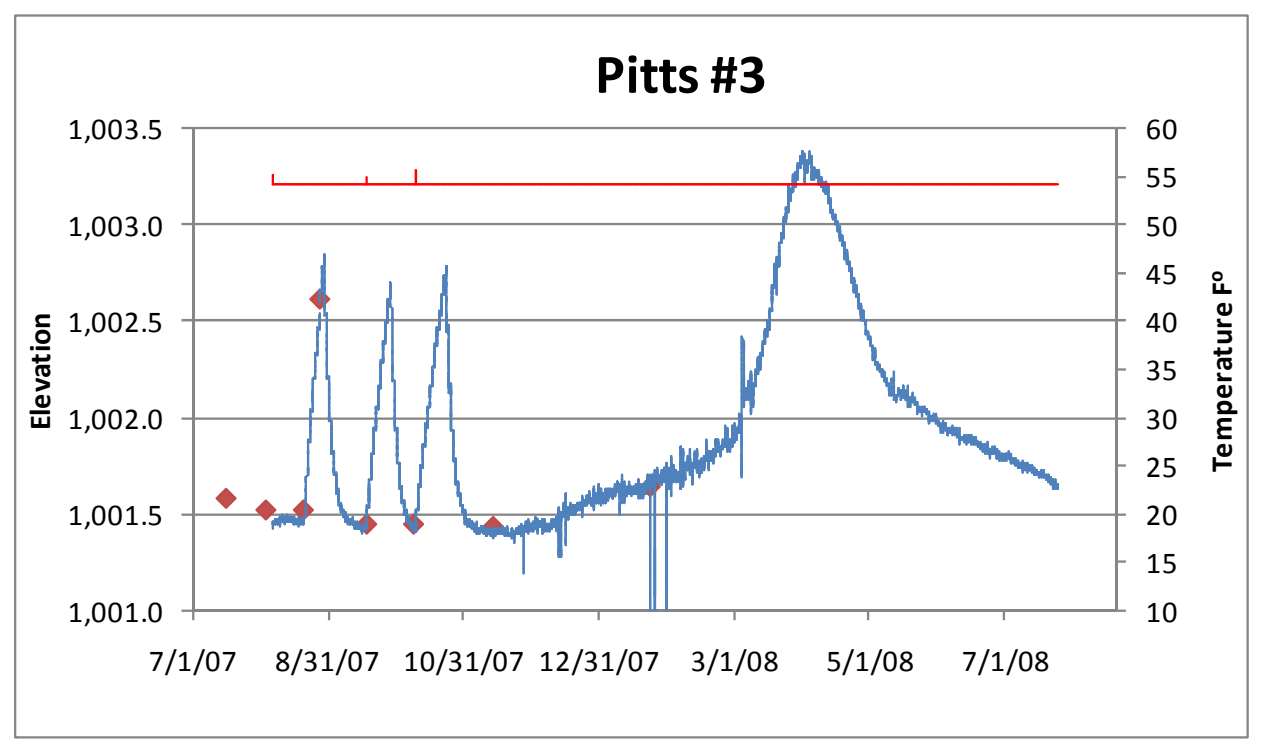

Figure 14. Hydrograph of the Pitts \#3 monitoring well.

The water temperature recorded in this well is a constant $54.3 \mathrm{~F}^{\circ}$. The three water level rises and declines in August through October 2007 are the result of shutting off the discharge at JB-1 and then opening a few days later. This same water level response can be seen in the JB-1 hydrograph Figure 14. Both the Pitts \#3 and JB-1 transducers were initialized from the same time base. This allows for comparison of the reaction time at the well compared to the stimulus time at the mine discharge. Figure 15 is a plot of both of these water level data. The JB-1 data are inverted for presentation purposes. 


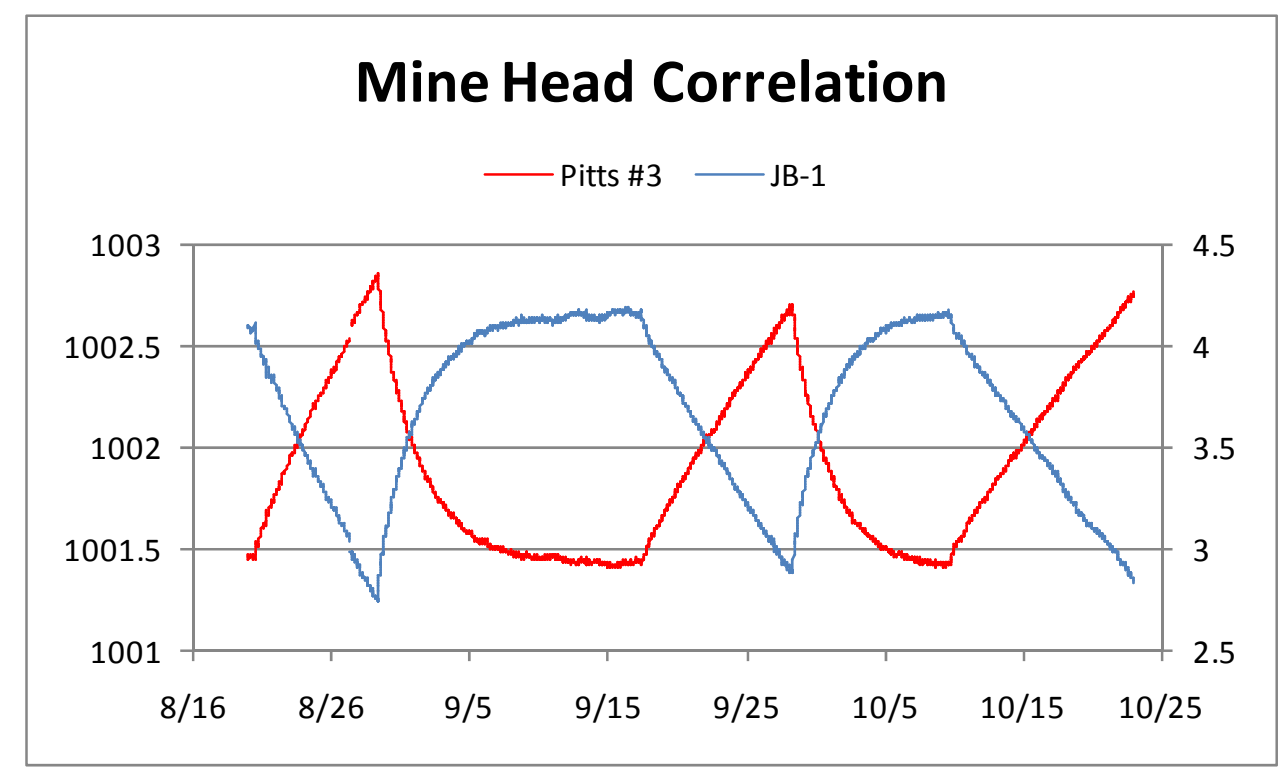

Figure 15. Comparison of water level response at JB-1 and Pitts \#3. Note: the JB-1 data are inverted so that they don't plot on top of one another.

Even though these monitoring points are 1.2 miles apart their response to the stimulus is almost identical. The discharge at JB-1 was shut off on 8-20-2007 10:00 AM and turned back on 8-27-2007 10:00 AM. The second test ran from 9-17-2007 10:00 AM to 9-28-2007 10:00 AM. The third test ran from 10-9-2007 4:00 PM to 10-23 2007 8:00 AM.

It is possible to estimate the transmissivity of the mine voids using the Jacobs approximation sometimes referred to as the distance drawdown method. This method requires the use of three monitoring wells at different distances from the production well. In addition, a constant pumping rate is required. At the Pitts \#3 mine only two wells were monitored and the pumping rate (mine discharge) was declining through time. Based on the preliminary data, the transmissivity is expected to be very high. This allows the rapid transfer of head changes throughout the mine thus minimizing the effect of a variable (pumping) rate. The third well is used to confirm that the assumptions, upon which the Jacob method is based, are not violated. Without a third well, the validity of the underlying assumption cannot be verified. Drawdown data are plotted on a semi-log graph with drawdown on the linear axis and distance on the log axis. The drawdown over one log cycle $\Delta s$ is determined from the plot. This value is used in the formula $T=528 \mathrm{Q} / \Delta \mathrm{s}$ where $\mathrm{Q}$ is the pumping (discharge) rate (Sterrett, RJ 2007). This formula is in English unit only. For the purpose of this evaluation data at 24 hours after discharge initiation were used. At this point in time the mine discharge was $1,575 \mathrm{gpm}$, the drawdown at the discharge (JB-1) was 0.482 feet and the drawdown at 
the Pitts \#3 monitoring well was 0.456 feet. The plot of these data is shown in Figure 16.

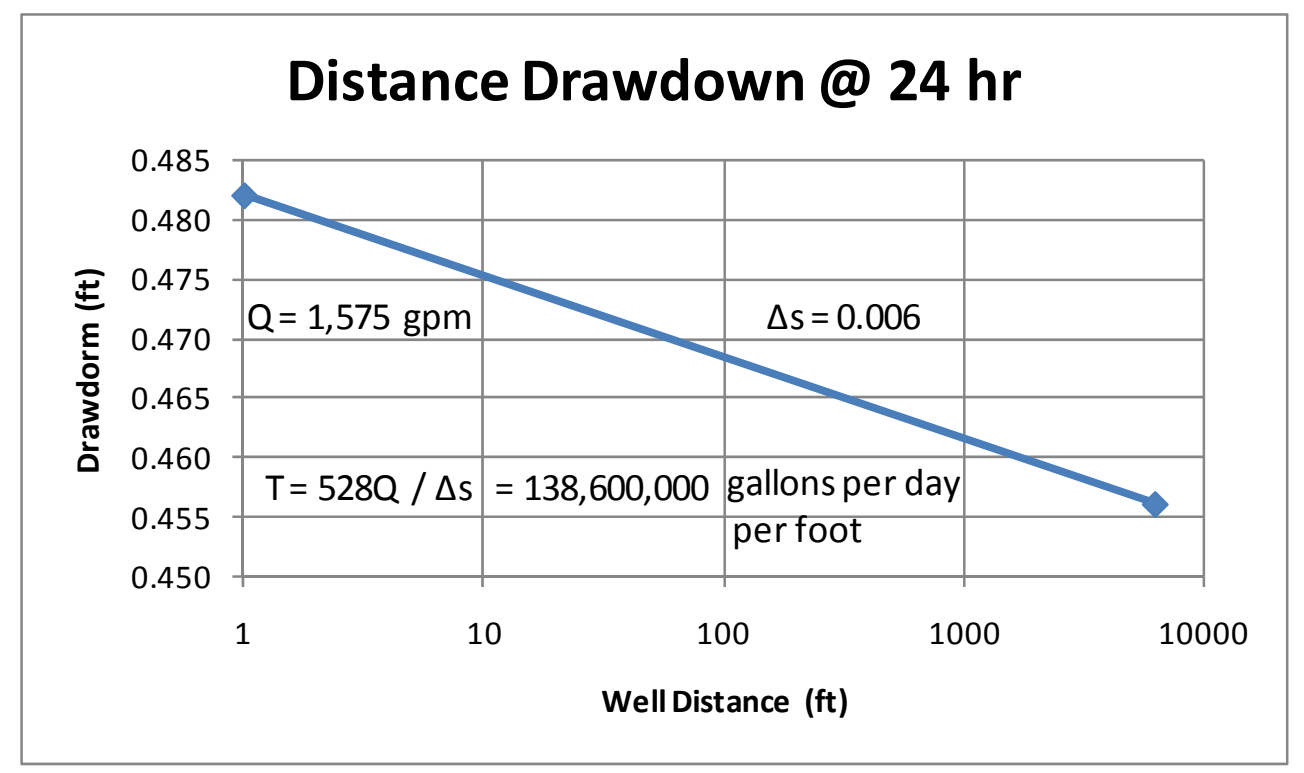

Figure 16. Calculation of transmissivity using the distance drawdown method.

From this calculation a transmissivity of $138,600,000$ gallons per day per foot is determined. Hydraulic conductivity is equal to the transmissivity divided by the aquifer thickness. In this case the aquifer thickness is equal to the mining height, for this analysis 6 feet will be used. This results in a hydraulic conductivity of 23,100,000 gallons per day per square foot or $2.31^{*} 10^{7}$.

Hydraulic conductivity, in natural aquifers, has a very wide range of values from $10^{6}$ to $10^{-4}$ gallons per day per square foot. In comparison, the Pitts \#3 mine at $2.31^{*} 10^{7}$ is highly conductive and can easily serve as a conduit for the transfer of mine water.

Water that is stored in mine voids can be used during periods of low recharge to augment the diminished flows that occur at that time. In order to evaluate this storage the discharge at JB-1 was shut off and the water level was allowed to rise for a period of 9 days between August 20 and August 29, 2007. The average discharge for the 24 hour period before shut-in was $465.6 \mathrm{gpm}$. The average discharge on September 17, after the system had returned to normal following the test was $431.0 \mathrm{gpm}$. These two flows were used to estimate the mine flow for each 15 minute period during the test using the formula:

$$
Q=-3.845 t+465.6
$$


Where $Q$ is the mine discharge in gallons per minute, and $t$ is the time in days after August 20, 2007. Applying this formula a total of 5,816,660 gallons was stored in the mine. During the same time period the elevation of water in the mine was monitored at the Pitts \#3 monitoring well. The water level in this well rose from elevation 1001.46 feet to 1002.84 feet resulting in a rise of 1.38 feet. Based on these data Pitts \#3 has a reservoir capacity of $4.21 * 10^{6}$ gallons per foot of drawdown. Low flows at JB-1 have been observed around $400 \mathrm{gpm}$. During such a dry weather period this mine could be pumped at $1,000 \mathrm{gpm}$ for 4.88 days and only reduce the water level by 1 foot. Ten feet of drawdown would yield almost 49 days of pumping at 1,000 gpm. Mine water used in this way can be recharged during wet weather conditions allowing the process to be repeated. The amount of water available from mine storage is unique to each mine and will vary with flooded area, coal extraction ratio, and the amount of surface subsidence.

\subsubsection{Montour \#1}

The Montour \#1 mine was a very large operation most of which lies outside of the five mile radius from the proposed power plant. This mine discharges into Miller Run a tributary of Chartiers Creek, some 8.25 miles from the Beech Hollow site near the town of Gladden, PA.

Evaluation of the mine maps indicated that one section of the mine, east of the Primrose mine, should be flooded. Even though a significant portion of this part of the mine lies outside the five mile limit, pumping water from this section of the mine, within the five mile limit, could expand the recharge area available to the power plant without increasing the amount of pipeline required to deliver the water to Beech Hollow.

A monitoring well was drilled into the Montour \#1 mine in the vicinity of Southview, Pa. The mine was found to be flooded up to elevation 1011. This elevation was used to plot the extent of flooding on the mine map. Based on this elevation it is evident that this mine pool does not discharge directly to the surface but overflows to another mine pool further to the east. A pressure transducer was installed in this well and the data are presented in Figure 18. This hydrograph shows a seasonal fluctuation of about 1.5 feet with the high water level occurring in May - June and the low water level in November January. There is an unexpected variation in head on a daily basis. This fluctuation can be on the order of 0.5 feet. The source of this fluctuation is the release of gas into the well bore. The gas originates in the mine and may be methane although it was not tested. This release causes bubbling in the well thus affecting the water level reading. The presence of the gas also caused difficulty with manual water level measurement.

The mine water in Montour \#1 was a constant $53.27 \mathrm{~F}^{\circ}$. 


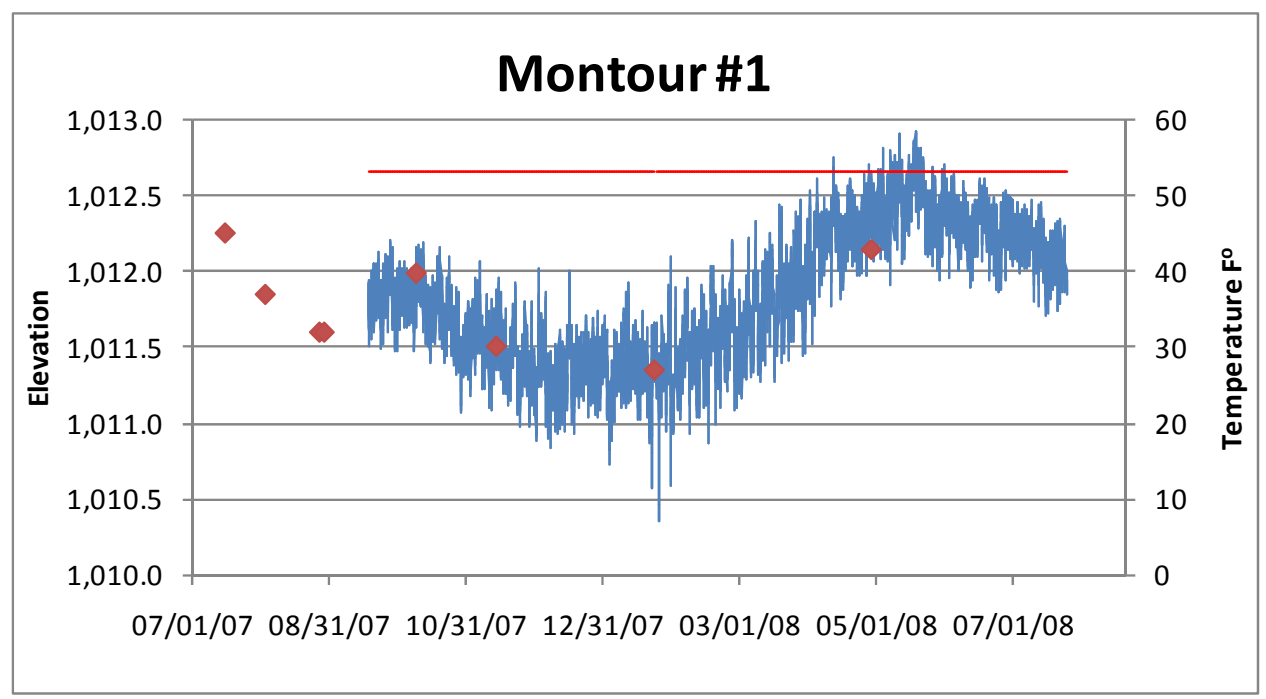

Figure 17. Montour \#1 Hydrograph.

\subsection{GIS Mapping}

Maps of underground mines were collected and assembled into a ArcMap file under a previous project. While these maps covered much of the area, the prior projects focused on below drainage mines and did not include all of the above drainage underground mines. In some cases, the mining that had been previously mapped was at a large scale some of which was prepared during the great depression.

Mine maps were obtained from several map repositories in the area. They include: the Hillman library, Pittsburgh, PA; the Pennsylvania Bureau of Deep Mine Safety, Uniontown, PA; and the Pennsylvania Department of Environmental Protection, McMurray, PA (currently California, PA).

Some of the maps were available in electronic format, and some existed either as paper prints or, mylar or linen tracings. In one case the only high quality mapping existed as a hard back. A hard back is a cloth backed paper roll five feet in width and over ten feet in length. Where hard copies existed they were scanned and converted into electronic files. These file were then georeferenced in ArcMap using points that existed on both the mine map and the USGS topographic quadrangle maps. Occasionally, a physical feature could be indentified on the mine map and on the ground but not on the USGS mapping. In these cases a hand held GPS receiver was used to obtain coordinates that could then be used in the Georeferencing process. Some of the maps were at a scale of 100 feet to the inch which required a number of maps to provide coverage of a single 
mine. These maps were fitted together to form a mosaic. Since georeferenceable features are not vary abundant it was necessary to mosaic the map and then georeferenced the mosaic. In all over 60 mine maps were obtained.

Once the map was georeferenced the outline of the mine was digitized to create a shape file in Arc Map. These mine outline shape files are presented in Figure 3 above. The elevation of water in the mine was either measured as is the case with the Montour \#1 well and the Pitts \#3 well or it was assumed based on the elevation of the mine discharge. These elevations were compared to the structure contour map. Mine areas below the discharge elevation were mapped as flooded (blue) and mine areas above the discharge elevation are shown in gray.

From these maps total mine area and flooded mine area was calculated. Table 3 contains the results of these calculations. Some individual mines or portions of mines flow to a single discharge and constitute a hydrologic unit. In other cases multiple mines flow to a single discharge which creates a more complex hydrologic unit. Table 3 shows this grouping by hydrologic unit.

Table 3. Approximate area of flooding of mines in vicinity of Beech Hollow

\begin{tabular}{|c|c|c|c|}
\hline \multirow{2}{*}{ Hydrologic Unit } & Mine Name & $\begin{array}{c}\text { Mine Area } \\
\text { Ac. }\end{array}$ & $\begin{array}{c}\text { Area Within Unit } \\
\text { Ac. }\end{array}$ \\
\hline \multirow{4}{*}{ JB-1 } & Pitts \#2 & 1253.1 & 1253.1 \\
\cline { 2 - 4 } & Pitts \#3 & 492.1 & 492.1 \\
\cline { 2 - 4 } & Varner & 1031.2 & 1031.2 \\
\cline { 2 - 4 } & Armide & 406.6 & 304.1 \\
\cline { 2 - 4 } & Montour \#9 & 674.8 & 674.8 \\
\cline { 2 - 4 } & TOTAL JB-1 & $\mathbf{3 8 5 7 . 8}$ & $\mathbf{3 7 5 5 . 3}$ \\
\hline Armide West & Armide & 406.6 & 102.5 \\
\hline Bulger & Bulger & 1109.7 & 1109.7 \\
\hline \multirow{2}{*}{ Primrose } & Primrose & 886.9 & 886.9 \\
\cline { 2 - 4 } & Island Creek & 199.3 & 199.3 \\
\cline { 2 - 4 } & TOTAL Primrose & $\mathbf{1 0 8 6 . 2}$ & $\mathbf{1 0 8 6 . 2}$ \\
\hline Montour \#1 & Montour \#1 & 8165.1 & 2085.0 \\
\hline \multirow{2}{*}{ McDonald } & Clinton Block & 7374.0 & 1678 est. \\
\hline
\end{tabular}




\subsection{Select Mine Water Source}

Of all of the mine discharges identified within five miles of the proposed Beech Hollow facility no single discharge has sufficient flow to meet the summer needs of the power plant. As a result, mine water utilization will depend on the collection of multiple mine water sources. Because the goal of this study is to maximize economical mine water use a combination of multiple mine discharges were considered.

Several factors were considered in selecting the mine water sources to be used in this analysis. These include: the amount of water available; the ability to move the water while maintaining the cool water temperature; the availability of water during the summer months when a cool water source is most beneficial; and the amount of pipeline required.

The amount of water available from mine sources in the area is shown in Table 4.

Table 4. Available mine water in vicinity of Beech Hollow

\begin{tabular}{|c|c|}
\hline $\begin{array}{c}\text { Hydrologic } \\
\text { Unit }\end{array}$ & $\begin{array}{l}\text { Average } \\
\text { Discharge } \\
\text { gpm }\end{array}$ \\
\hline Armide West & 30 est. \\
\hline Bulger & 293 est. \\
\hline Hopper & 0 to 1400 \\
\hline JB-1 & 941 \\
\hline Montour \#1 & 545 est. \\
\hline McDonald & 496 \\
\hline North Branch & 30 \\
\hline Primrose & 210 \\
\hline $\begin{array}{c}\text { Seabright } \\
\text { Road }\end{array}$ & 122 \\
\hline $\begin{array}{c}\text { Erie, } \\
\text { Langloth, } \\
\text { Frances } \\
\text { Total }\end{array}$ & 500 est. \\
\hline
\end{tabular}

Estimated mine recharge rates are based on the average recharge rate observed at the JB-1 discharge of 5.1 inches per year. 


\subsection{Design Collection, Piping, and Treatment}

JB-1 is the largest single source within the study. If this source is to be utilized then a water transfer system must be designed that will convey the water to the power plant using the least amount of pipe and at the same time collecting other mine water sources where possible. The JB-1 discharge is 4.45 miles straight line distance from the propose Beech Hollow facility. Pipeline installation frequently follows road right-of-ways in order to obtain the property easements that are needed for this type of construction. Following a road right-of-way will add length to the pipeline and may increase both the static and dynamic head that must be overcome to convey the water to the power plant. If there are additional mine water sources near the right-of-way they can be added to the water collection network. However if the water sources are widely distributed then multiple pipelines may be needed potentially adding to the system cost.

Two methods of mine water transfer are in use within the Appalachian region for consolidating sources for central treatment. These are pipeline and in mine injection and withdrawal. Mining companies have used the injection and withdrawal technique since the mid 1970's when the clean water act required water treatment. In West Virginia several Pittsburgh seam mines with numerous discharge points were able to transfer the water to the mined out Sewickley seam and then withdraw it at a centralized treatment facility. A similar approach is possible here.

The mine water discharge rates were compared with the mine geometry to generate a water transfer plan that would maximize the amount of water available, maximize the amount of water that is available during hot weather, minimize the pipeline length, and minimize the overland pumping lift. In this conceptual layout, water from the McDonald site is transferred in a dedicated overland pipe to the power plant treatment facility. In our evaluation, the benefit of conveying the McDonald mine water to the treatment plant was offset by the long pipeline required for this purpose, 25,230 feet. Figure 19 is a map of the conceptual water transfer system. 


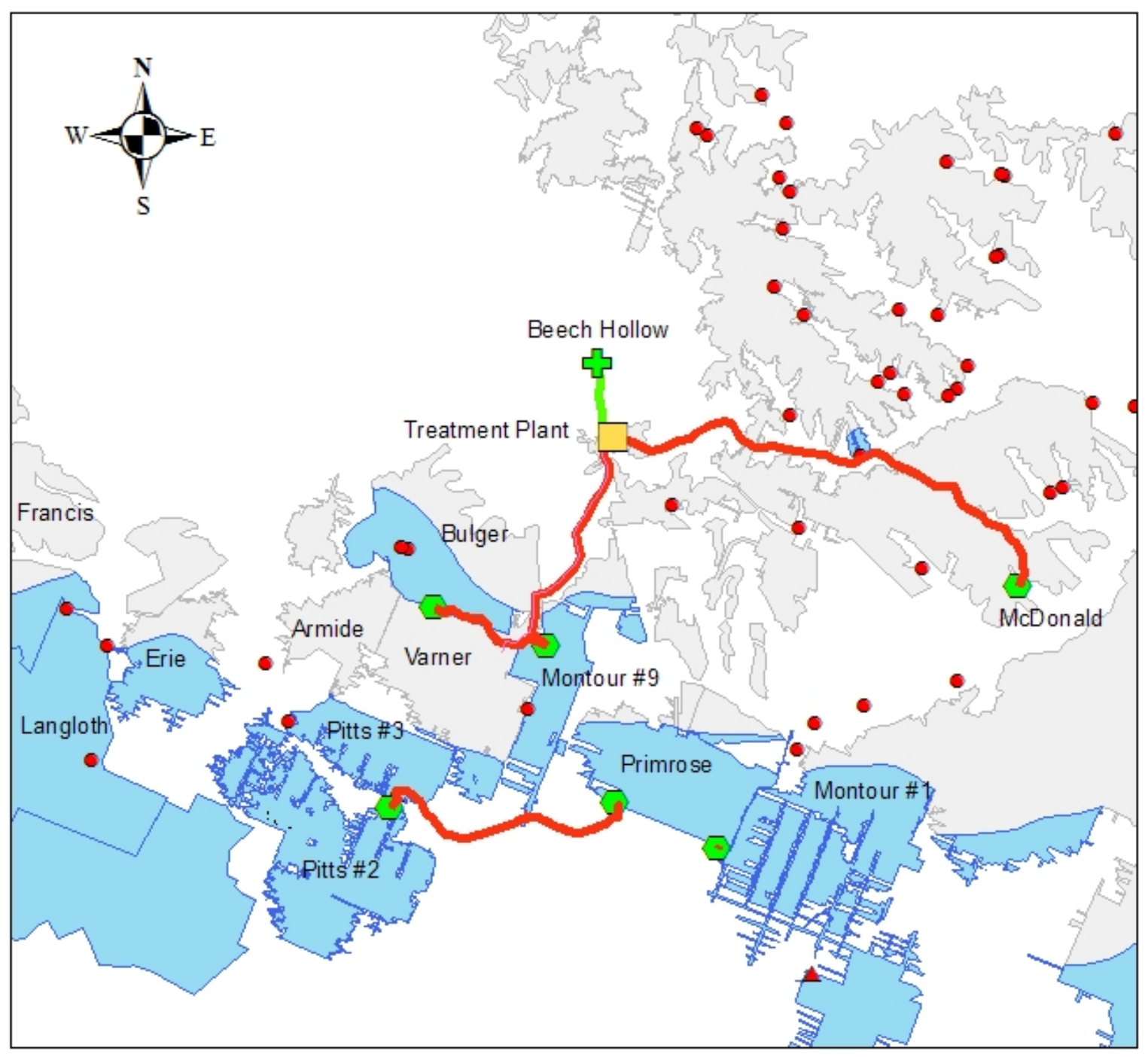

Figure 18. Conceptual water handling system for the Beech Hollow Facility.

The water handling system design uses mine to mine water transfer to gather the water from five different source locations and combine them into one flow. This significantly reduces the amount of overland pipe that would be needed to take each of these flows individually to the water treatment plant. Table 5 contains the recommended pump capacity and the length of the pipeline required for each segment of the water transfer. 
Table 5. Recommended pump capacity and pipeline length

\begin{tabular}{|l|l|c|c|}
\hline \multicolumn{1}{|c|}{ From } & \multicolumn{1}{|c|}{ To } & $\begin{array}{c}\text { Pump Capacity } \\
\text { (gal) }\end{array}$ & $\begin{array}{c}\text { Length } \\
(\mathrm{ft})\end{array}$ \\
\hline Pitts \#2 & Montour \#9 & 1,000 & 8,934 \\
\hline Montour \#1 & Primrose & 600 & 151 \\
\hline Primrose & Montour \#9 & 800 & 5,823 \\
\hline Bulger & Montour \#9 & 300 & 6,552 \\
\hline Montour \#9 & Treatment Plant & 2,300 & 12,460 \\
\hline Treatment Plant & Power Plant & 2,200 & 3,825 \\
\hline
\end{tabular}

Water from the JB-1 hydrologic unit is pumped to the Southern end of Montour \#9 where it is injected. Water from Montour \#1 is pumped over the barrier pillar and injected into the Primrose mine, hence the short pipeline length. This combined flow is then pumped out of Primrose and is also injected into Montour \#9 mine at its southern end. The Montour \#9 mine is aligned in a Northeasterly direction which is in the direction of the Beech Hollow facility. Water is then pumped from Montour \#9 and combined with the flow from the Bulger mine. This combined flow is transferred by overland pipe to a water treatment facility.

In laying out this pumping-pipeline system a number of factors were considered. The mine pumps are specified as deepwell turbine pumps. These pumps have the motor on the surface and a line shaft that travels inside the discharge pipe to the pump at the bottom of the hole. This type of pump is the industry standard for mine water. The pumping holes are located to maximize underground water storage and to provide a minimum of 20 feet submergence at the pump intake to prevent vortexing. In addition, the holes are located to minimize vertical lift, to take advantage of existing roads for pipeline right-of-way, and to intersect potential transmissive entries in the source mine.

Injection points were selected to minimize vertical lift and to intersect the underground mine workings where mine haulage entries could handle the flow underground. The ability of the mine to handle this flow was tested and confirmed in Pitts \#3 but it has not been tested in Montour \#9 or Primrose.

Water from Erie, Langloth, Francis (ELF) and Armide (west) have not been included in this concept but they could potentially be injected into Pitts \#3 at the JB-1 discharge point adding more than $500 \mathrm{gpm}$ to the total mine water available. A proposal has been made to transfer the ELF water to Raccoon Creek because the current discharges are contaminating Burgetts Fork and there are not any feasible locations for a treatment facility. A report evaluating the potential of moving the ELF water to the Raccoon creek valley downstream of JB-1 is in preparation. Pump testing of the Erie and Langloth 
mines has indicated that they are highly transmissive and are capable of transferring the water should the system be built; the connection to Francis is less certain.

Mine water in storage can be used to provide flow to the power plant during periods of low recharge such as in summer and fall. The five mine pools that are proposed in this study were evaluated to estimate the amount of water that might be available for this purpose. The area of flooded mine pool 20 feet above the pump set point was determined using the GIS mapping. This area was multiplied by the mining height of 5.9 feet to determine the maximum volume of the flooded area. This value was then multiplied by an extraction ratio of 0.5 representing 50 percent mining of the resource. A further reduction of $10 \%$ was taken to account for subsidence. The resulting volume was converted into gallons and is reported in Table 8 . This is expressed in the following formula where $Q_{s}$ is the quantity of water in storage; $A_{20}$ is the area of flooded mine greater than 20 feet above the set point of the pump intake; $E_{r}$ is the extraction ratio; $h_{m}$ is the mining height; and $S_{r}$ is the percent of the mine void lost to subsidence.

$Q_{s}=A_{20}{ }^{*} E_{r}{ }^{*} h_{m}{ }^{*}\left(1-S_{r}\right)$

The total volume in storage of $1,071,294,484$ gallons is equal to 372 days of operation at 2,000 gallons per minute assuming no recharge. In place storage such as this is essential in demonstrating the reliability of the mine water source when potentially large investments are made in this technology. 
Table 6. Available Mine water storage

\begin{tabular}{|c|c|c|c|c|}
\hline Pump & $\begin{array}{c}\text { Pum } \\
\text { p Set } \\
\text { Point } \\
\mathrm{ft} \mathrm{msl}\end{array}$ & $\begin{array}{c}\text { Static } \\
\text { Water } \\
\text { Elevatio } \\
\mathrm{n}\end{array}$ & $\begin{array}{c}\text { Max } \\
\text { Potential } \\
\text { Drawdow } \\
\mathrm{n}\end{array}$ & $\begin{array}{c}\text { Water in } \\
\text { Storage } \\
\text { Available to } \\
\text { Pump gal }\end{array}$ \\
\hline Pitts \#2 & 1,060 & 1100 & 20 & $\begin{array}{c}278,763,87 \\
4\end{array}$ \\
\hline $\begin{array}{c}\text { Montour } \\
\# 1\end{array}$ & 940 & 1,010 & 50 & $\begin{array}{c}430,698,19 \\
6\end{array}$ \\
\hline $\begin{array}{c}\text { Primros } \\
\mathrm{e}\end{array}$ & 980 & 1,040 & 40 & $\begin{array}{c}361,832,41 \\
4\end{array}$ \\
\hline Bulger & 1,080 & 1,100 & 0 & 0 \\
\hline $\begin{array}{c}\text { Montour } \\
\# 9\end{array}$ & 1,080 & 1,100 & 0 & 0 \\
\hline TOTAL & & & & $1,071,294,484$ \\
\hline
\end{tabular}




\subsection{Projecting Mine Water Availability from Underground Mines}

The future utilization of water from closed underground mines is dependent on the reliable projection of water availability from these mines. Water infiltration to individual underground mines is not only dependant on mine area, overburden thickness and geology, but also on variations in the annual precipitation. For a mine water supply to be useful for power plant cooling, or any other industrial purpose, the amount of water available from the mine must be sufficient in dry as well as wet years. The methodology presented here estimates mine discharge based on mine discharge records and statistical precipitation data.

Infiltration to underground coal mines is not uniform throughout the year. During the growing season plants take up water through their roots and transpire it into the atmosphere. Temperatures are higher so water is more readily evaporated. In addition, a portion of the rainfall is intercepted by the plants and is later evaporated without ever reaching the ground. As a result, there is very little deep infiltration during the growing season. At the end of the growing season the soil typically has very little moisture. Before deep infiltration can occur this soil must be resaturated. Unfortunately, in the Pennsylvania / West Virginia area late fall and early winter are typically low precipitation months therefore the advent of recharge is delayed until enough rain has fallen to fully resaturate the soil.

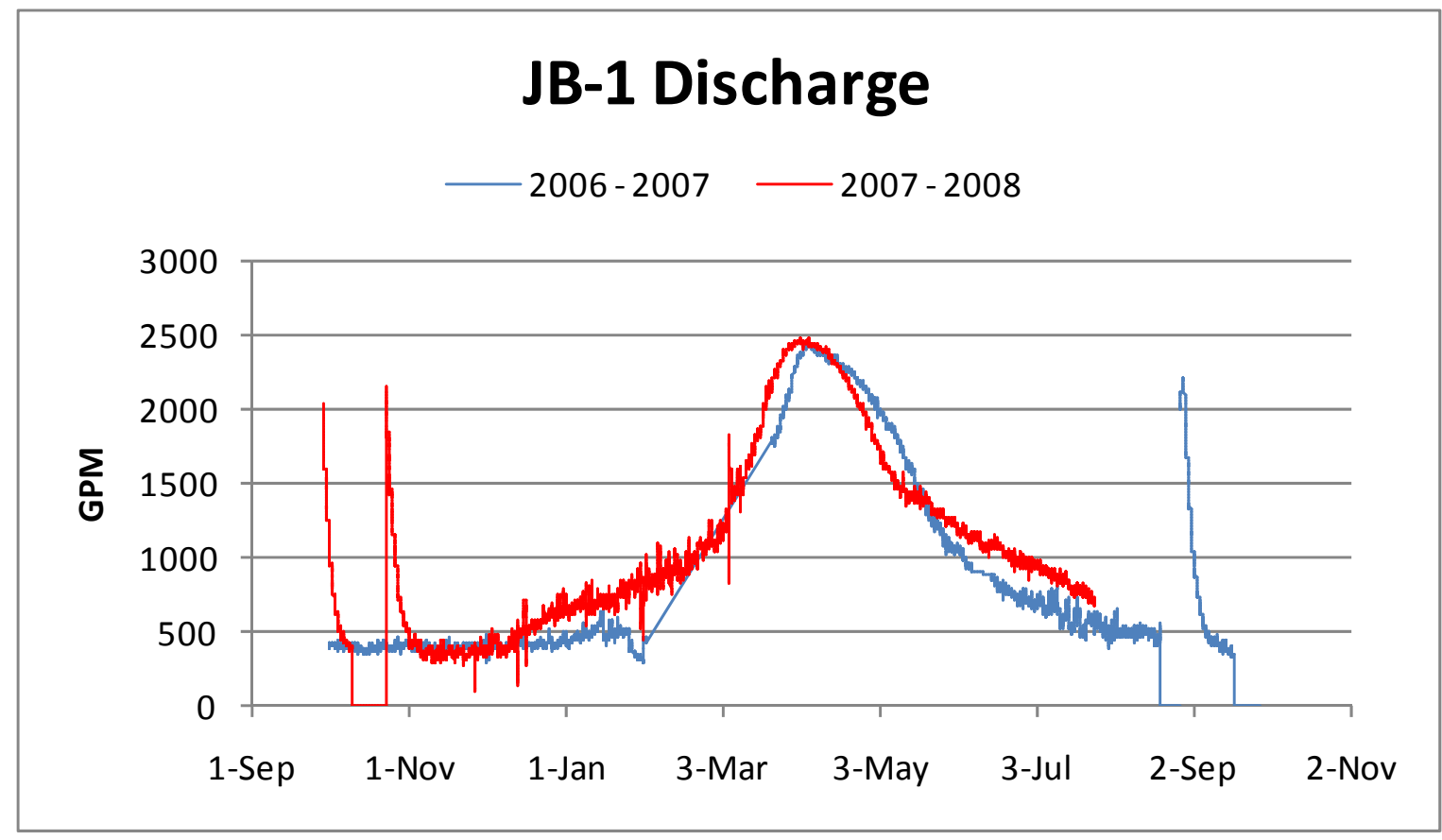

Figure 19. Two year hydrograph of the JB-1 discharge 
Figure 19 represents a hydrograph of the JB-1 discharge in northern Washington County, Pennsylvania. Mine discharge was initially measured using an $\mathrm{H}$-flume and pressure transducer, but after construction of a passive system in April 2007 the flow was based on a pressure transducer and a rating curve. Note the similarity between the two years. The three spikes in flow, one in late 2006-2007 and two in early 2007-2008 were induced by shutting off the discharge for a period of time causing the water to build up in the mine. In the absence of this testing the mine discharge would have been at base flow conditions. In the period February to April 2007 no flow data were collected due to the construction of a passive system at the site.

It is clear from the hydrographs that there is little to no summer recharge resulting from summer precipitation. If evapotranspiration limits recharge, then the end of evapotranspiration should mark the point in time when effective recharge is possible. Data from the "Soil Survey of Washington and Greene Counties Pennsylvania" show that a freeze of $28^{\circ} \mathrm{F}$ occurs on or before October 1 every five out of ten years. For this analysis October 1 has been chosen to represent the beginning of negligible evapotranspiration and hence the beginning of the recharge period. The time between the beginning of the recharge period and the arrival of recharge in the mine represents the amount of water needed to resaturate the soil. Travel time is believed to be negligible because the initial evidence of recharge would be due to the high conductivity flow paths. In the 2007-2008 water year the increase in flow began on December 1 , 2007. Rainfall records from the Greater Pittsburgh International Airport show that 6.68 inches of precipitation were received between October 1 and December 1 . This represents the amount of rainfall needed for resaturation. It is believed that an equivalent amount of water will eventually be lost once evapotranspiration resumes in the spring.

Groundwater recharge estimates generated by the US Geological Survey for Raccoon Creek, PA indicate that recharge reaches its maximum in March and is essentially over by the end of May, Table 9. Combining the October 1 date and the May 31 date there are eight months in which recharge to the mine is possible. The total amount of rainfall received between October 1 and May 31 minus the 6.68 inches needed to resaturate the soil represents the maximum amount of water potentially available for recharge. 
Table 7. Groundwater recharge estimates

Percent of Mean Annual Recharge - Raccoon Creek

\begin{tabular}{|c|c|c|c|c|c|c|}
\hline Month & January & February & March & April & May & June \\
\hline Percent & 11.3 & 16.5 & 20.8 & 12.5 & 10.7 & 3.3 \\
\hline Month & July & August & September & October & November & December \\
\hline Percent & 2.5 & 2.1 & 1.7 & 3.0 & 5.8 & 9.6 \\
\hline
\end{tabular}

Using the hydrograph data it is possible to calculate the total volume of water emanating from a mine in the course of a year. This represents the total recharge for that mine plus or minus any water diversions within the mine. If the total annual mine discharge is divided by the total precipitation available for recharge then percentage of precipitation that becomes mine recharge can be determined. In the case of the JB-1 discharge that value is 27 percent.

Combining these terms leads to a mine recharge model for the JB-1 discharge in the following form:

Recharge $_{\text {inches }}=(\Sigma$ Precipitation $($ October - May $)-6.68$ inches $) * 0.27$

Because this equation is based on precipitation, it is possible to use monthly rainfall probabilities generated by NOAA to determine the amount of mine water available in average years, and years with a one in ten recurrence interval.

While this equation is specific to the JB-1 discharge, the form of the equation can be applied at other locations where detailed mine discharge data are available and where the mine area can be reliably identified. The data requirements include one year of accurate daily flow and precipitation data. The length of the recharge season can be adapted to local conditions and the amount of water needed to resaturate the soil can be identified based on the hydrograph response.

This recharge formula was applied to the mines in this study in order to determine the expected average annual water discharge under mean, $10^{\text {th }}$ percentile and $90^{\text {th }}$ percentile rainfall conditions. Data published by the National Oceanic and Atmospheric Administration (NOAA) on the "Monthly Precipitation Probabilities and Quintiles 1971 2000", NOAA 2002, were used to supply rainfall data for use in the calculation. Table 8 contains the result of this calculation. 
Even though a separate formula should be developed for each of these mines the JB-1 formula is able to supply data that approximates the observed data. The observed JB-1 flow is augmented by barrier pillar leakage from Montour \#9. Hence JB-1 is higher than projected and Montour \#9 is lower than projected. Data from primrose indicate that a lower infiltration percentage of 0.24 may be more appropriate than the 0.27 calculated at JB-1.

Table 8. Mine recharge rates

\begin{tabular}{|l|c|c|c|c|c|}
\hline \multirow{2}{*}{ Mine } & Acreage & Observed & Mean & $10^{\text {th }}$ & $90^{\text {th }}$ \\
& & gpm & Flow & Percentile & Percentile \\
& & & gpm & gpm & gpm \\
\hline JB-1 & 3,060 & 941.3 & 707.2 & 534.4 & 901.4 \\
\hline Primrose & 887 & 210 & 251.0 & 118.7 & 319.9 \\
\hline Montour \#9 & 675 & 111.4 & 155.9 & 117.8 & 198.8 \\
\hline McDonald & 1678 est. & 495.7 & 498.5 & 380.6 & 640.8 \\
\hline Montour \#1 & 2,085 & N/A & 481.9 & 364.2 & 614.3 \\
\hline Bulger & 1,009 & N/A & 256.5 & 193.8 & 326.9 \\
\hline Total & 9,394 & 1,758 & 2,351 & 1,710 & 3,002 \\
\hline
\end{tabular}

\subsection{Pipe selection}

Many types of pipe are available for overland piping. These include steel, fiberglass, polyvinylchloride (PVC), and High density polyethylene (HDPE). In order to limit the variables that must be considered in the computer design aid this selection was limited to HDPE. HDPE is widely used in the AMD industry. It is non reactive in mine drainage, it is very smooth which reduces friction loss over great distance, it is not brittle, and it is easy to install. HDPE comes in a variety of pressure ratings. For the purpose of the design aid DR 11.0 was specified. This is the minimum wall thickness that will resist collapse under negative pressure. DR 11.0 is rated at 160 psi this is equal to a head of 370 feet which should be sufficient in most circumstances.

The total cost of an overland piping system includes both the capital cost of installation as well as the ongoing cost of operation. As pipeline diameter increases so does capital cost, but at the same time a larger pipe diameter will lower operational costs. Consequently, a balance must be made between these two competing factors. The computer design aid calculates the capital and operational costs for several pipe diameters utilizing net present value to aid in the selection of pipe size. 


\subsection{Treatment Plant Design}

Whenever mine waters are mixed it is likely that they will be of different water chemistries. For example the JB-1 discharge has very little alkalinity $(9 \mathrm{mg} / \mathrm{l})$ but an acidity of $305 \mathrm{mg} / \mathrm{l}$. In contrast the Hopper discharge has no acidity and an alkalinity of $376 \mathrm{mg} / \mathrm{l}$. These diverse waters will be blended in situ with a resulting water quality that is different from the source waters. The computer design aid blends these waters at a basic level to determine the amount of treatment required. However, this is not a substitute for more detailed geochemical modeling.

For the purpose of the computer design aid it is assumed that all mine water will have to undergo treatment before it can be used by the power plant. The standard treatment is hydrated lime based but a number of options have been included so that the user can evaluate these options and their effect on the water quality and the cost of treatment.

Standard treatment consists of a hydrated lime storage tank feeding lime into raw mine water. This mixture is aerated to introduce oxygen which converts ferrous to ferric iron. The feeding of the hydrated lime is controlled by the $\mathrm{pH}$ of the treated water typically 8 to 9 standard units. The aerated water flows to a clarifier or a pond where the precipitates are allowed to settle. Although clarifiers are more costly they provide an automatic means of sludge disposal through the under flow. This is an operational advantage because pond cleaning is avoided. An additional advantage of clarifiers is that there is very little temperature rise through the treatment process. In contrast treatment in ponds can significantly increase the water temperature by the time the treatment process is completed.

A number of equations were developed to estimate the size and cost of various components within the treatment process. These equations are based upon data from equipment manufactures or from cost and sizing information from a high density sludge plant that was built by a mining company to treat water pumped from its closed mining operation. These equations are listed in this report in the computer design aid section below. A description of the purpose of the various equations is provided in this section.

\subsubsection{Pre-aeration}

A pre-aeration step is included as an option in the treatment plant design aid. Mine waters, particularly from flooded Pittsburgh seam mines frequently contain dissolved carbon dioxide. This $\mathrm{CO}_{2}$ adds to the water acidity in the form of carbonic acid. Aeration of the raw mine water prior to alkaline addition will release this $\mathrm{CO}_{2}$ and it can significantly reduce the amount of alkalinity required to achieve neutralization, hence 
reducing the cost of operation and the amount of excess calcium in the treated water. Note that this $\mathrm{CO}_{2}$ release is $\mathrm{CO}_{2}$ neutral because $\mathrm{CO}_{2}$ would be released from the process of converting calcite into hydrated lime which is needed to neutralize the carbonic acid. The aeration process requires a tank and a mechanical aerator. Low speed aeration is typically the most efficient method of aeration and it is the basis of the cost and oxygen transfer rates that are used in the design aid. The size of the preaeration tank is calculated based on the horsepower need to raise the DO of the raw water from 0 to $12 \mathrm{mg} / \mathrm{l}$. Low speed aerators can deliver 3.5 pounds of oxygen per horsepower hour to oxygen deficient water. This delivery rate is assumed to be 70 percent effective given that the oxygen delivery rate will diminish as the $\mathrm{O}_{2}$ level rise.

The volume calculated by this method is in cubic feet. For cost estimation purposes the pre-aeration tank is assumed to be constructed of cast in place reinforced concrete 15 feet in depth with 3 feet of freeboard. The width and length are varied to accommodate the necessary volume. From this, the volume of concrete is calculated and multiplied by a user defined estimating factor, the default value is $\$ 550.00$ per cubic yard. This default value includes concrete, reinforcement and labor. Lower cost options that are potentially available include steel construction and pond construction, although ponds are not favored due to water temperature considerations.

Utilizing data from equipment suppliers' an equation was developed to estimate aerator cost. Figure 21 shows the derivation of this formula. The equipment cost generated by this equation is in 2009 dollars and is for low speed aeration.

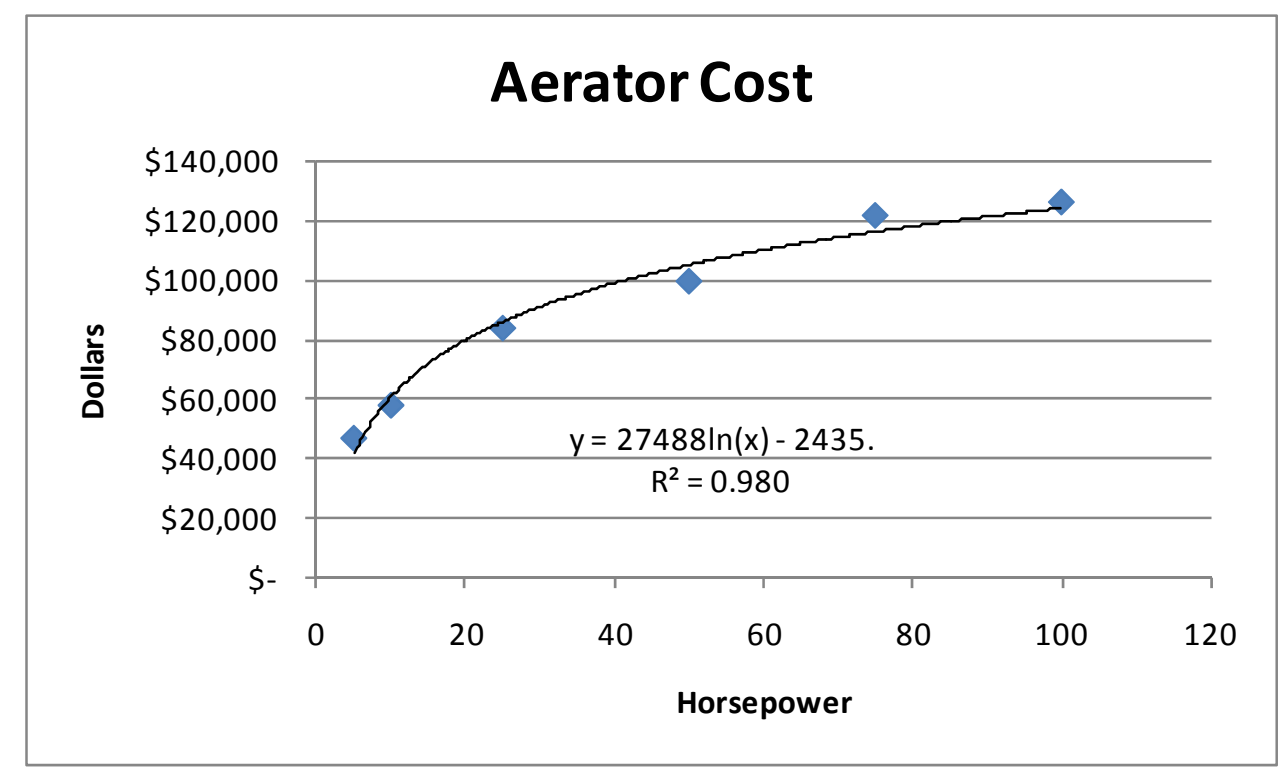

Figure 20. Cost of Low Speed aeration 
Additional costs that are considered include a 5 percent design factor to cover contingencies, and a 40 percent erection factor to cover the cost of aerator installation.

\subsubsection{Standard hydrated lime treatment}

The components of a standard treatment plant include: a lime silo with a "live bottom" to keep the hydrated lime from bridging in the tank; a variable speed lime feeder; a mixer / aerator to keep the lime suspended until it can fully dissolve while aerating the water to oxidize the ferrous iron; and a clarifier to separate the sludge from the treated mine water. The computer design aid calculates the size, based on design flow, of these components and then calculates their cost.

The design aid assumes that AMD treatment for power plant consumption will be both high volume and moderate to good quality raw water. As such, a single lime silo is included. This pricing includes: the silo, a live bottom, a lime feeder, dust controls, $\mathrm{pH}$ controls, a mix tank and a mixer. Cost data for this equipment is derived from the cost of similar equipment purchased by a coal operator for their AMD treatment plant.

The aerator is sized based on the design flow of the treatment plant and the maximum iron content of the raw mine water. For the purpose of the design aid, all iron is assumed to be in the ferrous from. If a mine water is being evaluated that does not contain any ferrous iron or is comprised of a mixture of ferrous and ferric iron then only the maximum ferrous iron should be input into the program. The aerator pricing graph Figure 20 is used as the basis for the pricing of this component. Because the water being aerated is already at saturation with respect to oxygen an efficiency factor of 50 percent is applied to the aerator oxygen delivery rating of 3.5 pounds per hour.

Clarifier sizing is based on the maximum flow rate of the mine water and is not dependant on sludge volume. For AMD treatment plants a surface area of two square feet must be provided for each gallon per minute of flow. Using the maximum flow rate for the system, the clarifier size can be determined and the concrete volumes can be calculated. The clarifier cost factor is used to compute the cost of the clarifier's mechanical equipment. The value of $\$ 2,240$ per foot of clarifier diameter was derived from the cost of a 130 foot diameter thickener built by a coal mine operator for AMD treatment. The cost of components such as clarified water pumps, control room, polymer systems, and sludge pumps are considered constants that are not influenced by the flow through the plant or the water chemistry. The cost basis for these components is taken from the same AMD plant construction used previously. 
Sludge disposal is assumed to be via injection into an abandoned mine. The selection of the injection site should be as close as possible to the plant to minimize cost, and it should be into a portion of the mine that will not create a situation where the treatment plant sludge is recirculated to the mine dewatering pumps. Sufficient mine void must be available for sludge storage. The computer based design aid assumes that this storage is available and that this method of sludge disposal will be used. The design aid will calculate the sludge flow rate based on the treatment plant rated capacity and the raw water iron content. High levels of aluminum in the raw water or gypsum formation in the treatment process will cause the sludge flow rate to be under reported. HDPE pipe is used for the sludge disposal piping. The diameter of this pipe is a function of the sludge disposal flow rate, but in no case is the pipe diameter to be less than six inches. Once the diameter and length of the sludge pipe are determined the design aid will determine the total dynamic head and from that it will calculate the sludge pump horsepower.

\subsubsection{Lime - Soda Ash Softening (option)}

Mine waters frequently contain elevated levels of calcium and magnesium. This hardness can cause deposits to form in cooling towers reducing their efficiency and potentially leading to major cooling tower maintenance. Lime soda ash softening is one method for reducing hardness by precipitation. In the process, the $\mathrm{pH}$ of the water is elevated until calcium and magnesium precipitate as calcium or magnesium carbonate. Because hydrated lime is already used for $\mathrm{pH}$ adjustment in the water treatment process the addition of soda ash to the process will not add greatly to the capital cost of the system. It is expected that the same clarifier could serve in either design. The computer based design aid provides for a calculation of the capital cost of the addition of a soda ash system. The cost basis for the soda ash equipment uses the same cost factors as the hydrated lime equipment.

\subsubsection{High Density Sludge (option)}

Sludge from a standard treatment system frequently contains less than 2 percent solids. Because of the high water to solids ratio a large amount of treated water is used for sludge disposal. This reduces the amount of water available to the power plant from the water treatment process. The high density sludge process increases the solids content of the sludge to frequently greater than 10 percent thus reducing the impact on the treated water flow rate.

The high density sludge process modifies the standard AMD plant design by taking a portion of the clarifier underflow (sludge) and pumping it to a conditioning tank. Instead

of adding the hydrated lime to the raw mine water, the lime is added to the sludge and 
allowed to react with it. The conditioned sludge is then added to the mine water where precipitation occurs on the existing sludge thereby increasing its density. Increased density leads to faster settling and increased solids concentration in the underflow.

Adding the high density sludge option requires the addition of sludge recirculation pumps and a conditioning tank. The size of the tank is based on residence time. The default value for the design aid is 20 minutes.

\subsubsection{Peroxide oxidation (option)}

Hydrogen Peroxide can be used instead of aeration for ferrous oxidation in some situations. In many cases oxidation via aeration is the most cost effective option. However, the rate of ferrous iron oxidation via aeration is $\mathrm{pH}$ dependant. As the $\mathrm{pH}$ increases the time required for the reaction to come to completion is reduced. To deal with this the standard AMD plant raises the $\mathrm{pH}$ to 8.5 to $9.5 \mathrm{su}$. During the aeration step the oxidation of ferrous iron releases acidity which brings the $\mathrm{pH}$ back down to within the discharge limits. This is a time proven approach to iron oxidation.

However, if the water is to be used for power plant cooling the use of hydrogen peroxide may be advantageous for the following reasons:

- The use of hydrated lime increases the calcium content of the water which is detrimental to cooling tower operation.

- During the summer months blowing hot air into the mine water can raise the temperature of the water slightly.

- The time required for oxidation via aeration means that large aeration tanks are needed which add capital cost.

- Aerator capital and maintenance costs are eliminated.

These advantages of hydrogen peroxide come at the price of a higher reagent cost.

The hydrogen peroxide reaction with ferrous iron is very rapid causing a drop in the $\mathrm{pH}$ as the ferrous iron is oxidized. If the mine water is net alkaline then the reaction can proceed without the addition of an alkaline agent. If this is possible then the capital cost of the hydrated lime feed system can also be eliminated.

The use of hydrogen peroxide does not affect dissolved carbon dioxide in the mine water. The carbon dioxide can be removed prior to peroxide addition or after peroxide addition. Where the treated water will be used in a cooling tower, the cooling tower would drive the exsolution of the $\mathrm{CO}_{2}$ raising the $\mathrm{pH}$ of the water at that time. 
The design aid calculates the amount of peroxide required, calculates the cost of a tank based on a 10 minute retention time, calculates a tank and storage building for the peroxide, and calculates the cost of a peroxide mixer. Under the right design conditions it may be possible to eliminate the mix tank and the mixer.

The use of peroxide instead of aeration is a site specific decision and bench testing is highly recommended if the cost and conditions of peroxide use seem justified.

\subsection{Results-Computer Based Design Aid}

\subsection{Sources of Data}

The most important data for the use of the design aid is the discharge flow rate and water chemistry of the mine sources. Without this information, the design aid cannot be used. For mine water sources that have not been sampled by the user, water chemistry and discharge flow rate data may be available from the mine regulatory agencies in the state where the discharges are located.

\subsection{Module 1 General}

The purpose of the general module is to allow the user to input basic information about the power plant site and the contact information for the owner and operator of the power plant. The requested information about the power plant site is as follows:

- Name

- Mailing Address

- City

- State

- Zip Code

- Point of Contact (POC)

The requested information about the power plant site's POC is as follows:

- Office Telephone Number

- Home Telephone Number

- Cell Phone Number

- E-mail Address

The requested information about the power plant owner is as follows: 
- Name

- Mailing Address

- City

- State

- Zip Code

- Office Telephone Number

- Home Telephone Number

- Cell Phone Number

- E-mail Address

This information is requested to make the preparation of a formal design document easier for the user. The design aid can be used without this information.

\subsection{Module 2 Water Source}

The purpose of the water source module is to allow the user to specify the discharge flow rate and water chemistry data for each of the mine water sources that will be employed. This module creates a worksheet in the mine water source spreadsheet for each of the mine water sources employed.

It is important that the user specifies a unique name for each of the mine water sources because the name of the worksheet created consists of the string "S-" followed by the name of the mine water source. The minimum data required to operate this module consists of:

- Mine Water Source Name

- Name and Path of the Water Quality Data File

- Name and Path of the Discharge Flow Rate Data File

If the Water Quality Data File does not exist, then the following data must be entered directly in the appropriate textboxes on the Control worksheet:

- Water Temperature, ${ }^{\circ} \mathrm{F}$

- $\mathrm{pH}$

- Dissolved oxygen, $\mathrm{mg} / \mathrm{L}$

- Specific Conductivity, $\mu$ mhos

- Field Alkalinity, mg/L $\mathrm{CaCO}_{3}$

- Mg Concentration, $\mathrm{mg} / \mathrm{L}$

- Ca Concentration, mg/L 
- Fe Concentration, $\mathrm{mg} / \mathrm{L}$

- Al Concentration, $\mathrm{mg} / \mathrm{L}$

- Mn Concentration, $\mathrm{mg} / \mathrm{L}$

- $\mathrm{SO}_{4}$ Concentration, $\mathrm{mg} / \mathrm{L}$

- TDS Concentration, $\mathrm{mg} / \mathrm{L}$

- Si Concentration, $\mathrm{mg} / \mathrm{L}$

- Na Concentration, $\mathrm{mg} / \mathrm{L}$

- $\mathrm{Cl}$ Concentration, $\mathrm{mg} / \mathrm{L}$

If the Discharge Flow Rate Data File does not exist, then the design discharge flow rate in gpm for the mine water source must be entered directly on the Control worksheet. In addition to copying the water chemistry and discharge flow rate data to the output worksheet, this module calculates the maximum Langelier Saturation Index (LSI) and the Gypsum Solubility Index (GSI).

The LSI is much less than zero, when there is no potential for calcium carbonate scaling in pipes and tanks; much greater than zero, when there is a strong potential for calcium carbonate scaling; and approximately equal to zero, when there is a borderline potential for calcium carbonate scaling. The LSI is calculated using the following formulas:

$$
\begin{aligned}
& \mathrm{LSI}=\mathrm{pH}-9.3-a-b+c+d \\
& a=0.1 \log _{10}(\mathrm{TDS})-0.1 \\
& b=-13.12 \log _{10}(\mathrm{~T})+34.55 \\
& c=\log _{10}\left(2.4972 C_{\mathrm{Ca}}\right)-0.4 \\
& d=\log _{10}(\text { Alk })
\end{aligned}
$$

Where:

$\mathrm{pH}=\quad$ Negative logarithm of the proton activity.

TDS $=$ Total Dissolved Solids concentration, mg/L.

$\mathrm{T}=$ Water temperature, ${ }^{\circ} \mathrm{C}$.

$C_{C a}=$ Calcium concentration, $\mathrm{mg} / \mathrm{L}$. 
Alk $=$ Total alkalinity, $\mathrm{mg} / \mathrm{L} \mathrm{CaCO}_{3}$ equivalents.

The GSI is much less than one, when gypsum, calcium sulfate, is under saturated; equal to one, when gypsum is saturated; and much greater than one, when gypsum is supersaturated. The GSI is calculated using the following formula:

$\mathrm{GSI}=\frac{\left[\mathrm{Ca}^{+}\right]\left[\mathrm{SO}_{4}^{+}\right]}{K_{s p}}$

Where:

$\left[\mathrm{Ca}^{+}\right]=$Molar concentration of calcium, moles/L.

$\left[\mathrm{SO}_{4}^{+}\right]=\quad$ Molar concentration of sulfate, moles/L.

$\mathrm{K}_{\mathrm{sp}}=\quad$ Solubility product of gypsum, $\mathrm{moles}^{2} / \mathrm{L}^{2}$.

\subsection{Module 5 Supply Pipeline}

The supply pipeline module is that part of the design aid that prepares the preliminary design of the pipelines that will transport the mine water from the mine water sources to the treatment plant. Like the mine water source module, all of the input data for this module is entered by the user on the Control worksheet. As this module runs, it creates an output worksheet that has the string "P-" followed by the unique name of the pipeline. To use this design aid, the following input parameters must be entered in the textboxes on the Control worksheet.

- Name and Path of the Mine Water Source Spreadsheet

- Pipeline Name

- Pipeline Starting Location

- Pipeline Ending Location

- Mine Water Source Elevation, feet.

- Mine Water Destination Elevation, feet

- Maximum Elevation of the Pipeline, feet

- Length of the Pipeline, feet

- Pump Elevation, feet

- Mine Elevation, feet

- Number of Mine Water Sources (>0 and <11) 
- Name of each Mine Water Source

- Design Discharge Flow Rate for each Mine Water Source, gpm

- Number of Pumps

The module's default values for some of the design parameters are listed in Table 1.

The first step of the module is the calculation of the maximum LSI and GSI using the formulas discussed above for the mine water source module. The next step is the determination of the type of pump to use. If the pump elevation is more than 20 feet higher than the minimum water elevation in the system, then a vertical turbine pump is employed, otherwise a horizontal centrifugal pump is used. After the pump type is selected, the module then performs the calculations for the first specified pipeline diameter. The pipeline diameters employed by the design module are listed in Table 2. 
Table 9. Supply pipeline design parameters with default values.

\begin{tabular}{|l|r|c|}
\hline \multicolumn{1}{|c|}{ Design Parameter } & Default & Symbol \\
\hline Number of pumps & 2 & $n$ \\
\hline Should pumps be used for downward flow? & No & $\mathrm{N} / \mathrm{A}$ \\
\hline Hazen-Williams C for the pipeline & 150 & $C_{H W}$ \\
\hline Pipeline Installation Cost, \$/ft & 150.00 & $C_{I}$ \\
\hline Pipeline Right-of-Way Cost, \$/ft & 4.00 & $C_{R}$ \\
\hline Ambient Ground Temperature, ${ }^{\circ} \mathrm{F}$ & 54.0 & $T_{A}$ \\
\hline Mine Water Temperature, ${ }^{\circ} \mathrm{F}$ & 54.0 & $T_{M}$ \\
\hline Pipe Insulation Thickness, inches & 0.0 & $t_{1}$ \\
\hline Pipe In. Thermal Cond., BTU-in-hr-1 -ft $^{-2}{ }^{\circ}{ }^{-1}{ }^{-1}$ & 3.5 & $K_{2}$ \\
\hline Maximum Allowable Friction Slope, $\mathrm{ft}_{\mathrm{ft}}$ & 0.02 & $S_{M A X}$ \\
\hline Pump Efficiency & $78 \%$ & $e_{P}$ \\
\hline Motor Efficiency & $95 \%$ & $e_{M}$ \\
\hline Electrical Cost, \$/kW-hr & $5 \%$ & $C_{E}$ \\
\hline Maintenance Cost Factor, 1/yr & $5 \%$ & $C_{F}$ \\
\hline Annual Discount Rate, $1 / \mathrm{yr}$ & $6 \%$ & $d$ \\
\hline Pipeline Longevity, years & 20.0 & $I$ \\
\hline Maximum Drawdown, feet & 10.0 & $D_{M A X}$ \\
\hline Pump Capital Cost Estimation Factor, \$/HP & $1,200$. & $P_{C E}$ \\
\hline Pump Drawdown Factor, \$/ft & 100.00 & $P_{D}$ \\
\hline Un-wetted Column Pipe Factor, \$/ft & 50.00 & $U$ \\
\hline Borehole Factor, \$/ft & 50.00 & $B$ \\
\hline Sump Retention Time, minutes & 40.0 & $T_{S}$ \\
\hline Sump Pump Estimation Factor, \$/HP & 120.00 & $P_{S}$ \\
\hline Sump Factor, \$/gallon & 10.00 & $P_{F}$ \\
\hline
\end{tabular}

Because the goal of this step is to calculate the minimum pipeline diameter that satisfies the maximum allowable friction slope, the Table 2 is scanned from top to bottom. For a given record number, the nominal diameter and inside diameter are taken from the table. The design discharge flow rate in gpm, $Q$, Hazen-Williams $C, C_{H W}$, and inside diameter in inches, $D$, are then used to calculate the friction slope, $S$.

$$
S=10.44\left(\frac{Q}{C_{H W}}\right)^{1.85} D^{-4.865}
$$


The friction slope, $S$, and pipeline length in feet, $L$, are then used to calculate the dynamic head in feet, $H_{D}$.

$$
H_{D}=S L
$$

Table 10. Pipeline diameters employed by the Supply Pipeline Design Module

\begin{tabular}{|r|c|c|c|c|}
\hline Record & $\begin{array}{c}\text { Nominal Diameter, } \\
\text { in }\end{array}$ & Inside Diameter, in & $\begin{array}{c}\text { Wall Thickness, } \\
\text { inches }\end{array}$ & $\begin{array}{c}\text { Unit Cost, } \\
\$ / \mathrm{ft}\end{array}$ \\
\hline 1 & 4 & 3.633 & 0.409 & 3.842 \\
\hline 2 & 5 & 4.490 & 0.506 & 5.889 \\
\hline 3 & 6 & 5.349 & 0.602 & 8.338 \\
\hline 4 & 8 & 6.963 & 0.784 & 14.126 \\
\hline 5 & 10 & 8.679 & 0.977 & 21.961 \\
\hline 6 & 12 & 10.293 & 1.159 & 30.886 \\
\hline 7 & 14 & 11.301 & 1.273 & 37.245 \\
\hline 8 & 16 & 12.915 & 1.455 & 48.653 \\
\hline 9 & 18 & 14.532 & 1.636 & 61.555 \\
\hline 10 & 20 & 16.146 & 1.818 & 76.000 \\
\hline 11 & 22 & 17.760 & 2.000 & 91.972 \\
\hline 12 & 24 & 19.374 & 2.182 & 109.453 \\
\hline 13 & 26 & 20.988 & 2.364 & 128.461 \\
\hline 14 & 28 & 22.605 & 2.545 & 148.946 \\
\hline 15 & 30 & 24.219 & 2.727 & 170.991 \\
\hline 16 & 32 & 25.833 & 2.909 & 194.563 \\
\hline 17 & 34 & 27.447 & 3.091 & 219.661 \\
\hline 18 & 36 & 29.061 & 3.273 & 246.286 \\
\hline
\end{tabular}

If the mine water destination elevation is greater than the mine water source elevation, then the static head, $H_{S}$, is calculated by subtracting the mine water source elevation from the maximum pipeline elevation, otherwise the static head is calculated by taking the maximum of $-30 \mathrm{ft}$ and the source elevation subtracted from the destination elevation. The static head and the dynamic head are then used to calculate the total dynamic head in feet, $H_{T}$.

$$
H_{T}=H_{S}+H_{D}
$$

If the total dynamic head is greater than zero or the module was instructed to use pumps where gravity flow would work, then the number of pumps is set equal to the 
specified number, otherwise the number of pumps is equal to zero. Then the aforementioned table is used with the length of the pipeline to calculate the cost of the pipeline, $C_{\text {PIPE. }}$. The length of the pipeline is then used to calculate the installation cost, $C_{l}$, and the right-of-way cost, $C_{R}$, by multiplying it by the appropriate input parameters.

The wall thickness from the table, $t_{2}$, is then used with the thickness of the pipe insulation, $t_{1}$, the thermal conductivity of the pipe, $K_{1}$, and the thermal conductivity of the pipe insulation, $K_{2}$, to calculate the effective thermal conductivity, $K$.

$$
K=\frac{t_{1}+t_{2}}{\frac{t_{1}}{K_{1}}+\frac{t_{2}}{K_{2}}}
$$

The effective thermal conductivity is then used with the mine and ambient temperatures in ${ }^{\circ} \mathrm{F}, T_{M}$ and $T_{A}$, respectively, in the following formulas to calculate the temperature of the pipe, $T_{P}$.

$$
\begin{aligned}
& T_{1}=\frac{\pi D K}{t_{1}+t_{2}} \\
& T_{2}=T_{1} T_{A}+\frac{0.1390281398 Q S}{780} \\
& T_{P}=\frac{T_{2}-\left(T_{2}-T_{1} T_{M}\right) \exp \left(-T_{1} L\right)}{T_{1}}
\end{aligned}
$$

If pumps are to be employed, then the following formulas are used to calculate the power of the pumps in HP, $P$, and the operation cost of the pumps in $\$ / y e a r, C_{O}$, from the efficiency of the motor, $e_{M}$, the efficiency of the pump, $e_{P}$, and the cost of the electricity in $\$$ per kW-hr, $C_{E}$.

$$
\begin{aligned}
& P=\max \left[\frac{H_{T} Q}{3960 e_{M} e_{P}}, 1\right] \\
& C_{O}=C_{E} P 6535
\end{aligned}
$$

If vertical turbine pumps are employed, then the following formulas are used to calculate the capital cost of the pumps in $\$, C_{C}$, the capital cost of the borehole in $\$, C_{B}$, and the 
maintenance cost of the pumps in $\$$ per year, $C_{M}$, using the pump capital cost estimation factor in $\$ / \mathrm{HP}, P_{C E}$, the pump drawdown factor, $P_{D}$, the un-wetted column pipe factor in $\$ / \mathrm{ft}, U$, the maximum pipeline elevation in feet, $E_{M A X}$, the pump elevation in feet, $E_{P}$, the borehole factor in $\$ / \mathrm{ft}, B$, the maintenance cost factor, $C_{F}$, and the number of pumps, $n$.

$$
\begin{aligned}
& C_{C}=n\left[P_{C E} P+P_{D}\left(D_{M A X}+20\right)+U\left(E_{P}-E_{M A X}\right)\right] \\
& C_{B}=n B\left(E_{P}-E_{M A X}\right) \\
& C_{M}=C_{F}\left(C_{C}+C_{B}\right)
\end{aligned}
$$

If horizontal centrifugal pumps are employed, then the following formulas are used to calculate the cost of the pumps in $\$, C_{C}$, the capital cost of the borehole in $\$, C_{B}$, and the maintenance cost of the pumps in $\$$ per year, $C_{M}$, using the sump retention time in minutes, $T_{S}$, the sump pump estimation factor, $P_{S}$, and the sump factor, $P_{F}$.

$$
\begin{aligned}
& C_{C}=n\left[T_{S} Q P_{F}+P_{S} P\right] \\
& C_{B}=0 \\
& C_{M}=C_{F}\left(C_{C}+C_{B}\right)
\end{aligned}
$$

The capital cost of the pipeline in $\$, C$, is calculated by summing all of the aforementioned costs.

$$
C=C_{P I P E}+C_{I}+C_{R}+C_{C}+C_{B}
$$

The O\&M cost of the pipeline in $\$$ per year, $O$, is calculated by summing the operational cost and the maintenance cost.

$$
C=C_{O}+C_{M}
$$

The present O\&M cost in $\$, C_{O M}$, is calculated with the discount formula using the O\&M cost, the discount rate, $d$, and the estimated longevity of the pipeline, $I$.

$$
C_{\text {OM }}=O\left[1-\frac{1}{d(1+d)^{l}}\right]
$$


The total evaluation cost in $\$, C_{T}$, is calculated by summing the capital cost with the present O\&M cost.

$C_{T}=C+C_{O M}$

If the friction slope is less than the maximum allowable friction slope, then the program loop that moves downward through the table is exited. If this is the first record in the table, then this nominal diameter is the first choice of nominal diameter for the pipeline and the next two records are the second and third choices of the nominal diameter.

If this is the last record in the table, then this nominal diameter is the first choice of nominal diameter for the pipeline and the previous two records are the second and third choices of nominal diameter. Otherwise, this is the first choice for the nominal diameter, the previous record (one nominal diameter smaller) is the second choice, and the next record (one nominal diameter larger) is the third choice.

The formulas for calculating the cost of the pipeline are followed again to calculate the pipeline cost for the second and third choices of nominal pipeline diameter. The total evaluation cost is then used by the summary design module to select which pipeline diameter is recommended.

After the module has executed, the output worksheet contains a copy of the input data along with three pipe diameters that satisfy the demands of the design parameters. The output design parameters written for each proposed pipeline nominal diameter are as follows:

- Pipeline Nominal Diameter

- Friction Slope

- Static Pump Head

- Dynamic Pump Head

- Total Dynamic Pump Head

- Number of Pumps

- Pump Power

- Pump Cost

- Borehole Cost

- Electricity Cost

- Maintenance Cost

- Pipeline Cost

- Pipeline Installation Cost 
- Pipeline Right-Of-Way Cost

- Pipeline Water Exit Temperature

- Capital Cost

- O\&M Cost

- Present Value of O\&M Cost

- Total Evaluation Cost (Capital Cost + Present Value of O\&M Cost)

\subsection{Module 4 Water Treatment}

The water treatment module is that part of the design aid that prepares the preliminary design of the treatment plant that will take the mine water supplied by the pipelines and treat it for acidity and total dissolved solids so that it may be used by the cooling tower. Unlike the previous design aid modules, the design input parameters for this module are on eight worksheets in the spreadsheets. The design input parameters to be entered on the Control Worksheet are as follows:

Table 11. Design Parameters for the Water Treatment Module on the Control Worksheet.

\begin{tabular}{|l|c|}
\hline \multicolumn{1}{|c|}{ Design Parameter } & Symbol \\
\hline Name and Path of the Mine Water Source Spreadsheet & \\
\hline Prefix for the Output Worksheets created by this module & $N_{W}$ \\
\hline Number of Mine Water Sources ( $>0$ and <11) & \\
\hline Name of each Mine Water Source & \\
\hline Whether or not Pre-Aeration will be used & \\
\hline Whether or not Soda Ash Softening will be used & $P_{H L}$ \\
\hline Should Peroxide Aeration of Mechanical Aeration be used & $P_{S A}$ \\
\hline Hydrated Lime Purity & $C_{S S}$ \\
\hline Soda Ash Purity & $E_{H L}$ \\
\hline Sludge Solids Content & $C_{S L U D G E}$ \\
\hline pH Endpoint for Hydrated Lime & $C_{\text {LAND }}$ \\
\hline Sludge Pipeline Capital Cost, \$ & \\
\hline Total Treatment Plant Land Cost, \$ &
\end{tabular}




\subsubsection{Treatment Plant Simulation}

The first step in the treatment plant simulation portion of the treatment plant design module is the determination of the starting and stopping time for the simulation. The starting time is the latest date that is no later than the starting time of the mine water source hydrographs, and the stopping time is the earliest date that is no earlier than the stopping time of the mine water source hydrographs. The simulation proceeds with a one day time step.

The simulation loop starts by scanning the discharge flow rate and water quality hydrograph arrays for each mine water source to calculate the discharge flow rate and water quality of the treatment plant inflow for the current simulation time. The total acidity of the inflow in $\mathrm{mg} / \mathrm{L} \mathrm{CaCO} 3$ equivalents, Acd, is calculated with the $\mathrm{pH}$, the aluminum concentration in $\mathrm{mg} / \mathrm{L}, C_{\mathrm{Al}}$, the iron concentration in $\mathrm{mg} / \mathrm{L}, C_{\mathrm{Fe}}$, and the manganese concentration in $\mathrm{mg} / \mathrm{L}, C_{M n}$, using the following equation.

$$
\operatorname{Acd}=50.04\left[\frac{3 C_{A l}}{26.982}+\frac{2 C_{F e}}{55.847}+\frac{2 C_{M n}}{54.938}+10^{3-\mathrm{pH}}\right]
$$

After the current water quality of the treatment plant inflow is calculated, the maximum inflow iron concentration is stored for the design calculations.

The next step is to calculate the current LSI and GSI of the treatment plant inflow using equations (1) through (6). Hydrated lime and oxygen are then added to the treatment plant inflow; the lime dosage in Ibs/MG, $D_{H L}$, is calculated by summing the metal acidity, the magnesium equivalent concentration, and the difference between the current proton acidity and the proton acidity at the hydrated lime treatment $\mathrm{pH}$ endpoint.

$$
D_{H L}=309.17\left[\frac{3 C_{A l}}{26.982}+\frac{2 C_{F e}}{55.847}+\frac{2 C_{M n}}{54.938}+\frac{2 C_{M g}}{24.305}+10^{3-\mathrm{pH}}-10^{3-E_{H L}}\right]
$$

Then the mass of sludge created at this stage is calculated and saved, the $\mathrm{pH}$ set to the hydrated lime $\mathrm{pH}$ endpoint, and the aluminum, iron, and manganese concentrations are zeroed, and the total acidity recalculated. The mass of the sludge per liter of inflow, $S_{H L}$, is calculated using the following equation.

$$
S_{H L}=\frac{101.961 C_{\mathrm{Al}}}{26.982}+\frac{105.959 C_{\mathrm{Fe}}}{55.847}+\frac{86.936 C_{\mathrm{Mn}}}{54.938}
$$


The concentration of gypsum in the sludge, $C_{G}$, is calculated by first calculating the GSI with equation (6). If the GSI is less than or equal to one, then the gypsum concentration in the sludge is zero, otherwise the following quadratic equation must be solved.

$$
\begin{aligned}
& x^{2}+B x+C=0 \\
& B=-\frac{C_{C a}}{40080}-\frac{C_{S O 4}}{96056} \\
& C=\frac{C_{C a} C_{S O 4}}{3849924480} \\
& C_{G}=\min \left(x_{1}, x_{2}\right)
\end{aligned}
$$

If soda is to be used for water softening, the next step in the simulation is to add soda ash to the inflow. First the following equation is used to calculate the total hardness in $\mathrm{mg} / \mathrm{L} \mathrm{CaCO}_{3}$ equivalents, $H_{T}$.

$$
H_{T}=50.04\left[\frac{2 C_{M g}}{24.304}+\frac{2 C_{C a}}{40.08}\right]
$$

If the total hardness is less than or equal to $80 \mathrm{mg} / \mathrm{L} \mathrm{CaCO}{ }_{3}$ equivalents, then the soda ash dosage is zero, otherwise the following equations are used to calculate the soda ash dosage. The following formula is then used to calculate the non-carbonate hardness in $\mathrm{mg} / \mathrm{L} \mathrm{CaCO}_{3}$ equivalents, $\mathrm{H}_{\mathrm{NC}}$, using the total alkalinity of the treatment plant inflow in $\mathrm{mg} / \mathrm{L} \mathrm{CaCO}_{3}$ equivalents, Alk.

$$
H_{N C}=H_{T}-50.04 \min \left(\frac{H_{T}}{50.04}, \frac{2 D_{H L} P_{H L}}{74.094(8.3454)}+\frac{\text { Alk }}{50.04}\right)
$$

And the soda ash dosage in $\mathrm{Ibs} / \mathrm{MG}, D_{S A}$, is calculated from the non-carbonate hardness.

$D_{S A}=\frac{105.988(8.3454) P_{S A} H_{N C}}{50.04(2)}$

The amount of sludge created by the addition of soda as in $\mathrm{mg} / \mathrm{L}, \mathrm{S}_{S A}$, is calculated by solving the following quadratic equations. 


$$
\begin{aligned}
& x^{2}+B x+C=0 \\
& B=-\frac{C_{C a}}{40.08}-\left[\mathrm{CO}_{3}^{-2}\right] \\
& C=\frac{C_{C a}}{40.08}\left[\mathrm{CO}_{3}^{-2}\right]-10^{6} K_{S P} a_{C a} \\
& {\left[\mathrm{CO}_{3}^{-2}\right]=\left[\mathrm{HCO}_{3}^{-1}\right] 10^{\mathrm{pH}-10.33}} \\
& {\left[\mathrm{HCO}_{3}^{-1}\right]=\frac{2 D_{H L} P_{H L}}{74.094(8.3454)}+\frac{\mathrm{Alk}}{50.04}} \\
& \log _{10} K_{S P}=-171.9065-0.077993 T+\frac{2839.319}{T}+71.595 \log _{10} T \\
& \mathrm{x}_{\mathrm{SA}}=\max \left(0, \min \left(x_{1}, x_{2}, \frac{C_{C a}}{40.08}-\frac{40}{100.08}\right)\right) \\
& y^{2}+D y+E=0 \\
& D=-\frac{C_{M g}}{24.305}-\left[\mathrm{OH}^{-1}\right] \\
& C=\frac{C_{M g}}{24.305}\left[\mathrm{OH}^{-1}\right]-10^{6} K_{P S} a_{M g} \\
& \log _{10} K_{P S}=-11.2518 \\
& \mathrm{y}_{\mathrm{SA}}=\max \left(0, \min \left(y_{1}, y_{2}, \frac{C_{\mathrm{Mg}}}{24.305}-\frac{40}{100.08}\right)\right) \\
& \mathrm{S}_{\mathrm{SA}}=\mathrm{x}_{\mathrm{SA}}+\mathrm{y}_{\mathrm{SA}}
\end{aligned}
$$

If there is any gypsum in the sludge, the next step is to trigger the high density sludge flag. Then the total acidity is calculated for the water after hydraulic lime treatment and after soda ash treatment using equation (26). Then the total dissolved solids 
concentration (in $\mathrm{mg} / \mathrm{L}$ ) is calculated from the post-treatment constituent concentrations, and the LSI of the treated water is calculated using equations (1) through (5).

The sludge variables that were calculated in $\mathrm{mg} / \mathrm{L}$ are then converted to $\mathrm{lbs} / \mathrm{day}$, and the calculated output parameters are written to the simulation output worksheet. At the end of the treatment simulation loop, the maximum lime and soda ash dosage rates are tabulated, the mean and maximum sludge generation rates are tabulated, mean discharge outflow rate and water quality are calculated and stored, and the simulation time is updated.

\subsubsection{Design Calculations}

On the Pre-Aeration worksheet, the following design input parameters may be entered. Default values for these design input parameters can be specified by either checking a checkmark on this worksheet or on the Control worksheet.

Table 12. Water Treatment Module Pre-Aeration Design Parameters

\begin{tabular}{|c|c|c|c|c|}
\hline Design Parameter & Default & Symbol & Min. & Max. \\
\hline DO Target, $\mathrm{mg} / \mathrm{L}$ & 12.0 & $O_{P A}$ & 8.0 & 13.0 \\
\hline Low Speed Aeration, Ibs/hr & 3.5 & $A_{P A}$ & 3.0 & 4.0 \\
\hline Aerator Efficiency & $70 \%$ & $e_{P A}$ & $60 \%$ & $80 \%$ \\
\hline Tank Volume Factor $\# 1, \mathrm{ft}^{3} / \mathrm{HP}$ & $1,133.0$ & $V_{P A 1}$ & $1,100.0$ & $1,200.0$ \\
\hline Tank Volume Factor \#2, $\mathrm{ft}^{3}$ & $2,812.0$ & $V_{P A 2}$ & $2,800.0$ & $2,900.0$ \\
\hline Tank Height, $\mathrm{ft}$ & 15.0 & $H_{P A}$ & 10.0 & 20.0 \\
\hline Tank Freeboard, ft & 3.0 & $F_{P A}$ & 3.0 & \\
\hline Tank Concrete Thickness, in & 12.0 & $T_{P A}$ & 12.0 & \\
\hline Concrete Unit Cost, $\$ / \mathrm{yd}^{3}$ & 550.00 & $U_{C P A}$ & 500.00 & 600.00 \\
\hline Pre-Aerator Cost Factor $\# 1, \$$ & $27,488.00$ & $F_{P A 1}$ & 27,000 & 28,000 . \\
\hline Pre-Aerator Cost Factor $\# 2, \$$ & $2,435.00$ & $F_{P A 2}$ & 2,400 . & 2,500 . \\
\hline Pre-Aerator Cost Factor \#3 & $50 \%$ & $F_{P A 3}$ & $40 \%$ & $60 \%$ \\
\hline Pre-Aerator Design Factor & $5 \%$ & $F_{P A D}$ & $4 \%$ & $6 \%$ \\
\hline Pre-Aerator Erection Factor & $40 \%$ & $F_{P A E}$ & $30 \%$ & $50 \%$ \\
\hline
\end{tabular}

If pre-aeration is selected, then the following formulas are employed to perform the preliminary design and calculations and estimate the capital cost. The maximum required oxygen in Ibs/hr, $O_{\text {MAX }}$, that will need to be added to the treatment inflow using the maximum treatment mine water inflow rate in gpm, $Q_{M A X}$, and the target dissolved oxygen concentration in $\mathrm{mg} / \mathrm{L}, O_{P A}$. 
$O_{\text {MAX }}=\frac{3.785(60) Q_{M A X} O_{P A}}{453600}$

The required power of the motor for the pre-aerator in HP, $P_{P R E}$, is calculated with the aerator efficiency, $e_{P A}$, the maximum required oxygen in $\mathrm{lbs} / \mathrm{hr}, O_{M A X}$, and the low speed aeration rate in $\mathrm{lbs} / \mathrm{hr}, A_{P A}$ using the following formula.

$P_{P R E}=\frac{O_{M A X}}{A_{P A} e_{P A}}$

The volume of the pre-aeration tank in $\mathrm{ft}^{3}, V_{P R E}$, is calculated with the following formula and the power of the pre-aerator motor, $P_{P R E}$, and the tank volume factors, $V_{P A 1}$ and $V_{P A 2}$, respectively.

$V_{P R E}=V_{P A 1} P_{P R E}+V_{P A 2}$

The volume of concrete needed for the pre-aeration tank in $\mathrm{yd}^{3}, V_{C P R E}$, is calculated with the following equations.

$d_{1}=\sqrt{\frac{V_{P R E}}{H_{P A}}}$

$d_{2}=\frac{2 d_{1}\left(H_{P A}+F_{P A}\right) T_{P A}}{12}$

$d_{3}=2\left(d_{1}+\frac{2 T_{P A}}{12}\right)\left(H_{P A}+F_{P A}\right) \frac{T_{P A}}{12}$

$d_{4}=\frac{T_{P A}}{12}\left(d_{1}+\frac{T_{P A}}{12}\right)^{2}$

$V_{\text {CPRE }}=\frac{d_{2}+d_{3}+d_{4}}{27}$

This volume is then used to calculate the cost of the concrete pre-aeration tank in $\$$, $C_{C P A}$.

$C_{C P A}=V_{C P R E} U_{C P A}$ 
The following empirical formula is then used to calculate the cost of the pre-aerator in $\$$, $C_{P A}$, from the pre-aerator motor horsepower, $P_{P R E}$.

$C_{P A}=\left(F_{P A 1} \ln \left(P_{P R E}\right)-F_{P A 2}\right)\left(1+F_{P A 3}\right)$

Finally, the capital cost of the pre-aeration system in $\$, C_{T P A}$, is calculated with the following formulas.

$$
\begin{aligned}
& C_{S P A}=C_{C P A}+C_{P A} \\
& C_{D P A}=F_{P A D} C_{S P A} \\
& C_{E P A}=F_{P A E} C_{S P A} \\
& C_{T P A}=C_{S P A}+C_{D P A}+C_{E P A}
\end{aligned}
$$

On the Mech-Aeration worksheet, the following design input parameters may be

\begin{tabular}{|c|c|c|c|c|}
\hline Design Parameter & Default & Symbol & Min. & Max. \\
\hline Aerator Efficiency & $50 \%$ & $e_{M A}$ & $40 \%$ & $60 \%$ \\
\hline Low Speed Aeration Rate, Ibs/hr & 3.5 & $A_{M A}$ & 3.0 & 4.0 \\
\hline Tank Factor \#1, $\mathrm{ft}^{3} / \mathrm{HP}$ & $1,133.0$ & $V_{M A 1}$ & 1,100 & 1,200 . \\
\hline Tank Factor \#2, $\mathrm{ft}^{3}$ & $2,812.0$ & $V_{M A 2}$ & 2,800 & 2,900 . \\
\hline Tank Height, ft & 15.0 & $H_{M A}$ & 10.0 & 20.0 \\
\hline Tank Freeboard, ft & 3.0 & $F_{M A}$ & 2.0 & 4.0 \\
\hline Tank Thickness, in & 18.0 & $T_{M A}$ & 12.0 & 24.0 \\
\hline Tank Concrete Unit Cost, $\$ / y d^{3}$ & 550.00 & $U_{C M A}$ & 500.00 & 600.00 \\
\hline Aerator Factor \#1, \$ & $27,488.0$ & $F_{M A 1}$ & 27,000 & 28,000 . \\
\hline Aerator Factor \#2, \$ & $2,435.0$ & $F_{M A 2}$ & 2,400 & 2,500 . \\
\hline Excavation Unit Cost, $\$ / y^{3}{ }^{3}$ & 3.00 & $U_{E R M A}$ & 2.00 & 4.00 \\
\hline Mechanical Erection Factor & $40 \%$ & $F_{M A E}$ & $30 \%$ & $50 \%$ \\
\hline Mechanical Design Factor & $5 \%$ & $F_{M A D}$ & $4 \%$ & $6 \%$ \\
\hline
\end{tabular}
entered. Default values for these design input parameters can be specified by either checking a checkmark on this worksheet or on the Control worksheet.

Table 13. Water Treatment Module Mech-Aeration Design Parameters.

If the mechanical aeration is selected, then the following formulas are used to calculate the capital cost of the mechanical aeration equipment. The required oxygen that needs 
to be added to the treatment plant inflow in $\mathrm{lbs} / \mathrm{hr}, O_{M O R}$, is calculated from the maximum inflow rate in $\mathrm{gpm}, Q_{\operatorname{MAX}}$, and the maximum iron concentration in $\mathrm{mg} / \mathrm{L}$, $C_{\text {MAXFe. }}$

$O_{\text {MOR }}=\frac{0.25(3.785)(60) Q_{\text {MAX }} C_{\text {MAXFe }}}{453600}$

The required power for the mechanical aerator pump motor in horsepower, $P_{M A}$, is calculated by the following formula.

$P_{M A}=\frac{O_{M O R}}{e_{M A} A_{M A}}$

This formula is then used to calculate the mechanical aeration tank volume, $V_{M A}$, using the following empirical formula.

$V_{M A}=P_{M A} V_{M A 1}+V_{M A 2}$

And this volume is used to calculate the residence time in minutes of the mechanical aeration tank, $R_{M A}$.

$R_{M A}=\frac{7.4805 V_{M A}}{Q_{M A X}}$

The volume of the mechanical aeration tank, $V_{M A}$, is then used with the following formulas to calculate the width of the mechanical aeration tank, $W_{M A}$, and the volume of concrete needed to construct the mechanical aeration tank in $\mathrm{yd}^{3}, V_{C M A}$.

$$
\begin{aligned}
& W_{M A}=\sqrt{\frac{V_{M A}}{H_{M A}}} \\
& d_{1}=\left(H_{M A}+F_{M A}\right)\left(W_{M A}+\frac{T_{M A}}{12}\right) \\
& d_{2}=W_{M A}+\frac{2 T_{M A}}{12}
\end{aligned}
$$


$V_{C M A}=\frac{4 d_{1}+d_{2}^{2}}{27}$

This formula is then used to calculate the cost of the concrete in the mechanical aeration tank, $C_{C M A}$.

$C_{C M A}=V_{C M A} U_{\text {CMA }}$

The capital cost of the mechanical aerator, $C_{M A}$, is calculated with the following empirical formula.

$C_{M A}=F_{M A 1} \ln \left(P_{M A}\right)+F_{M A 2}$

The cost and volume of the excavation required for the mechanical aerator, $C_{E M A}$ and $V_{E M A}$, respectively, is then calculated with the following equations.

$V_{E M A}=\frac{H_{M A}\left(W_{M A}+8\right)^{2}}{27}$

$C_{E M A}=V_{E M A} U_{E M A}$

The capital cost of the mechanical aeration system in $\$, C_{T M A}$, is calculated with the following formulas.

$$
\begin{aligned}
& C_{S M A}=C_{C M A}+C_{M A}+C_{E M A} \\
& C_{D M A}=C_{S M A} U_{D M A} \\
& C_{E R M A}=C_{S M A} U_{E R M A} \\
& C_{T M A}=C_{S M A}+C_{D M A}+C_{E R M A}
\end{aligned}
$$

On the Lime-Plant worksheet, the following design input parameters may be entered. Default values for these design input parameters can be specified by either checking a checkmark on this worksheet or on the Control worksheet. 
Table 14. Water Treatment Module Lime-Plant Design Parameters.

\begin{tabular}{|l|r|r|r|r|}
\hline \multicolumn{1}{|c|}{ Design Parameter } & \multicolumn{1}{c|}{ Default } & \multicolumn{1}{c|}{ Symbol } & \multicolumn{1}{c|}{ Min. } & \multicolumn{1}{c|}{ Max. } \\
\hline Clarifier overflow rate, gpm/ft ${ }^{2}$ & 0.5 & $O_{L C}$ & 0.1 & 1.0 \\
\hline Clarifier cost factor, \$/ft & $2,240.00$ & $C_{C F}$ & $2,200$. & $2,300$. \\
\hline Clarifier concrete thickness, in & 12.0 & $T_{C F}$ & 12. & 24. \\
\hline Clarifier height, ft & 15.0 & $H_{C}$ & 10. & 20. \\
\hline Clarifier freeboard, ft & 3.0 & $F_{C}$ & 2. & 4. \\
\hline Clarifier concrete factor & $5 \%$ & $F_{C F}$ & $3 \%$ & $7 \%$ \\
\hline Concrete unit cost, \$/yd & 550.00 & $U_{C C}$ & 500. & 600. \\
\hline Excavation unit cost, \$/yd ${ }^{3}$ & 3.00 & $U_{E C}$ & 2.00 & 4.00 \\
\hline Lime silo cost, \$ & $19,900.00$ & $C_{L S}$ & $18,000$. & $21,000$. \\
\hline Lime live bottom cost, \$ & $6,650.00$ & $C_{L B}$ & $6,000$. & $7,000$. \\
\hline Lime feeder cost, \$ & $7,550.00$ & $C_{F}$ & $7,000$. & $8,000$. \\
\hline Lime dust control cost, \$ & $4,200.00$ & $C_{D C}$ & $4,000$. & $5,000$. \\
\hline Lime pH control cost, \$ & $1,650.00$ & $C_{P C}$ & $1,500$. & $1,800$. \\
\hline Lime mix tank cost, \$ & $5,000.00$ & $C_{L M T}$ & $4,000$. & $6,000$. \\
\hline Lime mixer cost, \$ & $3,000.00$ & $C_{L M}$ & $2,000$. & $4,000$. \\
\hline Clarified water pumps cost, \$ & $3,000.00$ & $C_{C W P}$ & $2,000$. & $4,000$. \\
\hline Control room cost, \$ & $60,000.00$ & $C_{C R}$ & $50,000$. & $70,000$. \\
\hline Polymer system cost, \$ & $30,000.00$ & $C_{P S}$ & $20,000$. & $40,000$. \\
\hline Sludge disposal pipe length, ft & $5,000.00$ & $L_{S D P}$ & $4,000$. & $6,000$. \\
\hline $\begin{array}{l}\text { Sludge disposal system static head, } \\
\text { ft }\end{array}$ & 200.0 & $H_{S D S H}$ & 100.0 & 500.0 \\
\hline 6-in sludge pipe cost, \$/ft & 100.00 & $C_{S 6}$ & 80.00 & 130.00 \\
\hline 8-in sludge pipe cost, \$/ft & 110.00 & $C_{S B}$ & 80.00 & 130.00 \\
\hline Sludge pump cost, \$ & $10,000.00$ & $C_{S P}$ & $8,000$. & $12,000$. \\
\hline Sludge injection overburden, ft & 300.0 & $H_{S I O}$ & 200.0 & 400.0 \\
\hline Sludge well construction depth, ft & 25.0 & $H_{S W C}$ & 10.0 & 50.0 \\
\hline Sludge injection well cost rate, \$/ft ${ }^{2}$ & 2.00 & $F_{I W C R}$ & 1.00 & 3.00 \\
\hline Sludge miscellaneous steel cost & $15 \%$ & $F_{M S C}$ & $10 \%$ & $20 \%$ \\
factor & & & & \\
\hline Lime plant erection factor & $40 \%$ & $F_{L P E}$ & $30 \%$ & $50 \%$ \\
\hline Lime plant design factor & $5 \%$ & $F_{L P D}$ & $4 \%$ & $6 \%$ \\
\hline
\end{tabular}

The capital cost of the lime plant system is calculated with the following equations. The diameter of the clarifier in $\mathrm{ft}, D_{C}$, and the cost of the clarifier in $\$, C_{C}$, are calculated from the maximum treatment plant inflow rate in gpm, $Q_{M A X}$, and the clarifier overflow rate in $\mathrm{gpm} / \mathrm{ft}^{2}, O_{L C}$, using the following equation. 


$$
\begin{aligned}
& D_{C}=2 \sqrt{\frac{Q_{M A X}}{\pi O_{L C}}} \\
& C_{C}=D_{C} C_{C F}
\end{aligned}
$$

The cost of the concrete in the clarifier in $\$, C_{C C}$, is calculated from the geometric design input parameters with the following equations.

$$
\begin{aligned}
& d_{1}=\pi D_{C}\left(H_{C}+F_{C}\right) \frac{T_{C F}}{12(27)} \\
& d_{2}=\frac{\pi}{27}\left(\frac{D_{C}}{2}+\frac{T_{C F}}{12}\right)^{2} \frac{T_{C F}}{12} \\
& V_{C C}=\left(d_{1}+d_{2}\right)\left(1+F_{C F}\right) \\
& C_{C C}=V_{C C} U_{C C}
\end{aligned}
$$

The cost of the excavation for the clarifier in $\$, C_{E C}$, is calculated with the following equations.

$$
\begin{aligned}
& V_{E C}=\frac{\pi}{27}\left(\frac{D_{C}}{2}+\frac{T_{C F}}{12}+8\right)^{2}\left(H_{C}+\frac{T_{C F}}{12}\right) \\
& C_{E C}=V_{E C} U_{E C}
\end{aligned}
$$

The cost of the lime plant in $\$, C_{L P}$, is calculated with the following equation.

$$
C_{L P}=C_{L S}+C_{L B}+C_{F}+C_{D C}+C_{P C}+C_{L M T}+C_{L M}
$$

The sludge volumetric flow rate in gpm, $Q_{s}$, is calculated from the maximum treatment plant inflow rate, $Q_{M A X}$, and the maximum inflow iron concentration, $C_{\text {MAXFe, }}$ using the following equation.

$$
Q_{S}=\max \left(\frac{3(3.785) Q_{\text {MAX }} C_{\text {MAXFe }}}{454(20)(8.54)}, 100\right)
$$


If the sludge volumetric flow rate, $Q_{S}$, is greater than $300 \mathrm{gpm}$, then the following formulas are used to calculate the parameter $d_{2}$, the sludge pipe cost, $C_{S P L}$, and the sludge pipe nominal diameter in inches, $D_{S}$.

$$
D_{S}=6
$$

$C_{S P L}=L_{S D P} C_{S 6}$

$d_{2}=5.349^{4.8655}$

If the sludge volumetric flow rate, $Q_{S}$, is less than or equal to $300 \mathrm{gpm}$, then the following formulas are used to calculate the parameter $d_{2}$, the sludge pipe cost, $C_{S P}$, and the sludge pipe nominal diameter in inches, $D_{s}$.

$$
\begin{aligned}
& D_{S}=6 \\
& C_{S P L}=L_{S D P} C_{S 6} \\
& d_{2}=7.5^{4.8655}
\end{aligned}
$$

And the following formulas are used to calculate the sludge disposal pipe total dynamic head in feet, $H_{S T D H}$, using the variable, $d_{2}$.

$$
\begin{aligned}
& d_{1}=0.002083 L_{S D P}\left(\frac{Q_{S} 100}{140}\right)^{1.85} \\
& H_{S T D H}+H_{S D S H}+\frac{d_{1}}{d_{2}}
\end{aligned}
$$

This formula is then used to calculate the power of the sludge disposal pump in HP, $P_{S D P}$, using an estimated pump and motor efficiency of $75 \%$.

$$
P_{S D P}=\frac{H_{S T D H} Q_{S}}{3960(0.75)}
$$

These calculated parameters are then used with the following formulas to calculate the total cost of the lime treatment system in $\$, C_{T L C}$. 


$$
\begin{aligned}
& C_{S I W}=F_{I W C R} H_{S I O} H_{S W C} \\
& C_{S}=C_{S P}+C_{S P L}+C_{S I W} \\
& C_{M S C}=F_{M S C}\left(C_{C}+C_{C C}+C_{E C}\right) \\
& C_{L S T}=C_{C}+C_{C C}+C_{E C}+C_{L P}+C_{C W P}+C_{C R}+C_{P S}+C_{S}+C_{M S C} \\
& C_{L P E}=C_{L S T} F_{L P E} \\
& C_{L P D}=C_{L S T} F_{L P D} \\
& C_{T L C}=C_{L S T}+C_{L P E}+C_{L P D}
\end{aligned}
$$

On the Soda-Ash worksheet, the following design input parameters may be entered. Default values for these design input parameters can be specified by either checking a checkmark on this worksheet or on the Control worksheet.

Table 15. Water Treatment Module Soda-Ash Design Parameters.

\begin{tabular}{|l|r|r|r|r|}
\hline \multicolumn{1}{|c|}{ Design Parameter } & Default Value & Symbol & \multicolumn{1}{c|}{ Min. } & \multicolumn{1}{c|}{ Max. } \\
\hline Soda silo cost, \$ & $19,900.00$ & $C_{S S}$ & $19,000$. & $20,000$. \\
\hline Soda live bottom cost, \$ & $6,650.00$ & $C_{S L B}$ & $6,000$. & $7,000$. \\
\hline Soda lime feeder cost, \$ & $7,550.00$ & $C_{S L F}$ & $7,000$. & $8,000$. \\
\hline Soda dust collector cost, \$ & $4,200.00$ & $C_{S D C}$ & $4,000$. & $5,000$. \\
\hline Soda pH control cost, \$ & $1,650.00$ & $C_{S P C}$ & $1,000$. & $2,000$. \\
\hline Soda mix tank cost, \$ & $5,000.00$ & $C_{S M T}$ & $4,000$. & $6,000$. \\
\hline Soda mixer cost, \$ & $3,000.00$ & $C_{S M}$ & $2,000$. & $4,000$. \\
\hline Soda ash erection factor & $40 \%$ & $F_{S E}$ & $30 \%$ & $50 \%$ \\
\hline Soda ash design factor & $5 \%$ & $F_{S D}$ & $4 \%$ & $6 \%$ \\
\hline
\end{tabular}

If soda ash is being used for water softening, then the following formulas are used to calculate the cost of the soda ash treatment system in $\$, C_{S T}$.

$$
\begin{aligned}
& C_{S S T}=C_{S S}+C_{S L B}+C_{S L F}+C_{S D C}+C_{S P C}+C_{S M T}+C_{S M} \\
& C_{S E}=C_{S S T} F_{S E}
\end{aligned}
$$




$$
C_{S D}=C_{S S T} F_{S D}
$$

$$
C_{S T}=C_{S S T}+C_{S E}+C_{S D}
$$

On the High-Density-Sludge worksheet, the following design input parameters may be entered. Default values for these design input parameters can be specified by either checking a checkmark on this worksheet or on the Control worksheet.

Table 16. Water Treatment Module High-Density-Sludge Design Parameters.

\begin{tabular}{|l|r|c|r|r|}
\hline \multicolumn{1}{|c|}{ Design Parameter } & \multicolumn{1}{c|}{ Default } & Symbol & \multicolumn{1}{c|}{ Min. } & \multicolumn{1}{c|}{ Max. } \\
\hline Conditioning tank recirculation flow ratio & 30 & $R_{C T R F}$ & 20 & 40 \\
\hline Conditioning tank residence time, min & 20.0 & $T_{C T R}$ & 10.0 & 30.0 \\
\hline Conditioning tank freeboard, ft & 2.0 & $F_{C T}$ & 1.0 & 3.0 \\
\hline Conditioning tank depth, ft & 5.0 & $D_{C T}$ & 4.0 & 6.0 \\
\hline Conditioning tank thickness, in & 18.0 & $T_{C T}$ & 12.0 & 24.0 \\
\hline Concrete unit cost, \$/yd & 350.00 & $U_{C C}$ & 500.00 & 600.00 \\
\hline $\begin{array}{l}\text { Recirculation system total dynamic head, } \\
\text { ft }\end{array}$ & 25.0 & $H_{R S T D}$ & 20.0 & 30.0 \\
\hline Number of recirculation pumps & & & & \\
\hline Recirculation pipe length, ft & 2 & $N_{R P}$ & 2 & 3 \\
\hline Recirculation pipe unit cost, \$/ft & 20.00 & $L_{R P C}$ & 300.0 & 400.0 \\
\hline Recirculation pump unit cost, \$/pump & $5,000.00$ & $U_{R P C}$ & 10.00 & 30.00 \\
\hline Recirculation control cost, \$ & $15,000.00$ & $C_{R P}$ & $4,000$. & $6,000$. \\
\hline High density sludge erection factor & $40 \%$ & $F_{H D S E}$ & $30 \%$ & $50 \%$ \\
\hline High density sludge design factor & $5 \%$ & $F_{H D S D}$ & $4 \%$ & $6 \%$ \\
\hline
\end{tabular}

If a high density sludge system is needed, then the following formulas are used to perform the basic design calculations for and calculate the cost of the high density sludge system. The conditioning tank recirculation flow rate in gpm, $Q_{C T R}$, is calculated from the maximum treatment plant inflow in gpm, $Q_{M A X}$, and the conditioning tank recirculation flow ratio, $R_{C T R F}$.

$$
Q_{C T R}=\frac{Q_{M A X}}{R_{C T R F}}
$$

The conditioning tank recirculation flow rate in gpm, $Q_{C T R}$, is used with the conditioning tank residence time in minutes, $T_{C T R}$, to calculate the volume of the conditioning tank in $\mathrm{ft}^{3}, V_{\text {HCT }}$. 
$V_{\text {HCT }}=\frac{Q_{C T R} T_{C T R}}{7.4805}$

This volume is used with the input design parameters to calculate the volume of concrete for the conditioning tank in $\mathrm{yd}^{3}, V_{C C T}$, with the following equations.

$$
\begin{aligned}
& S_{H C T}=\sqrt{\frac{V_{H C T}}{D_{C T}}} \\
& d_{1}=4\left(D_{C T}+F_{C T}\right)\left(S_{H C T}+\frac{T_{C T}}{12}\right) \\
& d_{2}=S_{H C T}+\frac{2 T_{C T}}{12} \\
& V_{C C T}=\frac{d_{1}+d_{2}^{2}}{27}
\end{aligned}
$$

The high density sludge tank cost in $\$, C_{H D S T}$, and mixer cost in $\$, C_{H D S M}$, are calculated from the cost of the lime mix tank cost in $\$, C_{L M T}$, and the lime mixer cost in $\$, C_{L M}$.

$$
\begin{aligned}
& C_{H D S T}=V_{C C T} U_{C C}-C_{L M T} \\
& C_{H D S M}=5,000-C_{L M}
\end{aligned}
$$

The power of the recirculation pumps in HP, $P_{R P}$, is calculated from the recirculation total dynamic head in feet, $H_{R S T D}$, and the recirculation flow rate in $\mathrm{gpm}, Q_{C T R}$, with an assumed motor and pump efficiency of $70 \%$.

$$
P_{R P}=\frac{H_{R S T D} Q_{C T R}}{3960(0.7)}
$$

The total cost of the high density sludge system in $\$, C_{H D S}$, is calculated by the following equations.

$$
\begin{aligned}
& C_{R P I C}=U_{R P C} N_{R P} L_{R P C} \\
& C_{R P C}=C_{R P} N_{R P}
\end{aligned}
$$




$$
\begin{aligned}
& C_{S H D S}=C_{H D S T}+C_{H D S M}+C_{R P I C}+C_{R P C}+C_{R C} \\
& C_{E H D S}=C_{S H D S} F_{H D S E} \\
& C_{D H D S}=C_{S H D S} F_{H D S D} \\
& C_{H D S}=C_{S H D S}+C_{E H D S}+C_{D H D S}
\end{aligned}
$$

On the Peroxide worksheet, the following design input parameters may be entered.

\begin{tabular}{|c|c|c|c|c|}
\hline Design Parameter & Default Value & Symbol & Min. & Max. \\
\hline Peroxide dosing rate & 0.35 & $R_{P D}$ & 0.3 & 0.4 \\
\hline Peroxide delivery schedule, days & 7.0 & $S_{P D}$ & 2 & 15 \\
\hline Tank design factor & 1.13 & $F_{P T D}$ & 1.00 & 2.00 \\
\hline Building unit cost, $\$ / \mathrm{ft}^{2}$ & 50.00 & $U_{P A B}$ & 40.00 & 60.00 \\
\hline Tank detention time, min & 10.0 & $T_{P T D}$ & 5.0 & 15.0 \\
\hline Tank height, ft & 8.0 & $H_{P T}$ & 6.0 & 10.0 \\
\hline Tank freeboard, ft & 3.0 & $F_{P T}$ & 2.0 & 4.0 \\
\hline Tank thickness, in & 12.0 & $T_{P T}$ & 12.0 & 24.0 \\
\hline Concrete unit cost, $\$ / \mathrm{yd}^{3}$ & 550.00 & $U_{P A C}$ & 500.00 & 600.00 \\
\hline Peroxide mixer factor $\# 1, \$ / \mathrm{ft}^{3}$ & -0.00000644 & $F_{P M F 1}$ & -0.000007 & -0.000006 \\
\hline Peroxide mixer factor $\# 2, \$ / \mathrm{ft}^{3}$ & 1.486 & $F_{P M F 2}$ & 1.400 & 1.500 \\
\hline Peroxide mixer factor $\# 3, \$ / \mathrm{ft}^{3}$ & $40,301.00$ & $F_{P M F 3}$ & 40,000 . & 41,000 . \\
\hline Excavation unit cost, $\$ / \mathrm{yd}^{3}$ & 3.00 & $U_{P A E}$ & 2.00 & 4.00 \\
\hline Peroxide aeration erection factor & $40 \%$ & $F_{P A E}$ & $30 \%$ & $50 \%$ \\
\hline Peroxide aeration design factor & $5 \%$ & $F_{P A D}$ & $3 \%$ & $5 \%$ \\
\hline
\end{tabular}
Default values for these design input parameters can be specified by either checking a checkmark on this worksheet or on the Control worksheet.

Table 17. Water Treatment Module Peroxide Design Parameters.

If peroxide treatment will be used for aeration, then the basic design of and the calculation of the cost of the peroxide treatment system is performed by the following formulas. The required oxygen that needs to be added to the treatment plant inflow in $\mathrm{lbs} / \mathrm{hr}, O_{M O R}$, is calculated from the maximum inflow rate in $\mathrm{gpm}, Q_{M A X}$, and the maximum iron concentration in $\mathrm{mg} / \mathrm{L}, C_{\text {MAXFe }}$.

$$
O_{M O R}=\frac{0.25(3.785)(60) Q_{\text {MAX }} C_{\text {MAXFe }}}{453600}
$$


The required peroxide rate in $\mathrm{lbs} / \mathrm{hr}, R_{\mathrm{H} 2 \mathrm{O} 2}$, is calculated from the required oxygen that needs to be added in $\mathrm{lbs} / \mathrm{hr}, O_{M O R}$, and the peroxide dosing rate, $R_{P D}$.

$$
R_{H 2 O 2}=\frac{O_{M O R}}{2 R_{P D}}
$$

The peroxide delivery amount in $\mathrm{Ibs}, D_{\mathrm{H} 2 \mathrm{O} 2}$, is calculated from the required peroxide rate in $\mathrm{lbs} / \mathrm{hr}, R_{\mathrm{H} 2 \mathrm{O} 2}$, and the peroxide delivery schedule, $S_{P D}$.

$$
D_{H 2 O 2}=24 R_{H 2 O 2} S_{P D}
$$

This mass is then used to calculate the volume of the peroxide storage tank in gallons, $V_{\mathrm{H} 2 \mathrm{O} 2 \text {. }}$

$$
V_{H 2 O 2}=\frac{1.1 D_{H 2 O 2}}{8.54}
$$

This volume is then used to calculate the area of the peroxide storage building in $\mathrm{ft}^{2}$, $A_{P A B}$.

$$
A_{P A B}=\frac{4 V_{H 2 O 2}}{7.4805(6) \pi}
$$

This area is then used to calculate the cost of the peroxide storage building in $\$, C_{P A B}$.

$$
C_{P A B}=A_{P A B} U_{P A B}
$$

The volume of the tank where the peroxide is mixed with the inflow in $\mathrm{ft}^{3}, V_{P T D}$, is calculated from the maximum treatment plant inflow in $\mathrm{gpm}, Q_{M A X}$, and the peroxide mixing tank detention time in minutes, $T_{P T D}$.

$$
V_{P T D}=\frac{Q_{M A X} T_{P T D}}{7.4805}
$$

This volume is then been used to calculate the width of the peroxide mixing tank in $\mathrm{ft}$, $S_{P T D}$.

$$
S_{P T D}=\sqrt{\frac{V_{P T D}}{H_{P T}}}
$$


And the volume of concrete in the peroxide mixing tank in $\mathrm{yd}^{3}, V_{C P T}$, is calculated using the following formulas.

$$
\begin{aligned}
& d_{1}=H_{P T}+F_{P T}+\frac{T_{P T}}{12} \\
& d_{2}=S_{P T D}+\frac{2 T_{P T}}{12} \\
& V_{C P T}=\frac{T_{P T}}{12(27)}\left(4 d_{1}+d_{2}^{2}\right)
\end{aligned}
$$

This volume is then used to calculate the cost of the concrete in the peroxide mixing tank in $\$, C_{C P T}$.

$$
C_{C P T}=V_{C P T} U_{P A C}
$$

This volume is also used in the following empirical formula to calculate the cost of the peroxide mixer in $\$, C_{P M}$.

$$
C_{P M}=F_{P M F 1} V_{C P T}^{2}+F_{P M F 2} V_{C P T}+F_{P M F 3}
$$

The width of the peroxide mixing tank in feet, $S_{P T D}$, is then used to calculate the cost of the required excavation for the peroxide mixing tank in $\$, C_{E P T}$.

$$
\begin{aligned}
& V_{E P T}=\frac{H_{P T}\left(S_{P T}+8\right)^{2}}{27} \\
& C_{E P T}=V_{E P T} U_{P A E}
\end{aligned}
$$

Using these calculated parameters, the cost of the peroxide aeration treatment system in $\$, C_{P A}$, is calculated.

$$
\begin{aligned}
& C_{S P A}=C_{P A B}+C_{C P T}+C_{P M}+C_{E P T} \\
& C_{E P A}=C_{S P A} F_{P A E} \\
& C_{D P A}=C_{S P A} F_{P A D}
\end{aligned}
$$


$C_{P A}=C_{S P A}+C_{E P A}+C_{D P A}$

The following equation is used to calculate the total capital cost of the treatment system in $\$, C$. If pre-aeration is not used in this treatment plant, then the cost of the treatment plant pre-aeration system in $\$, C_{T P A}$, is zero. If mechanical aeration is used, then the cost of the peroxide aeration system in $\$, C_{P A}$, is zero. If peroxide aeration is used, then the cost of the mechanical aeration system in $\$, C_{T M A}$, is zero. If soda ash is not used for water softening, then the cost of the soda ash treatment system in $\$, C_{S T}$, is zero. If a high density sludge system is not needed, then the cost of the high density sludge system in $\$, C_{H D S}$, is zero. The cost of the land for the treatment plant in $\$, C_{\text {LAND }}$, and the cost of the sludge pipeline in $\$, C_{\text {SLUDGE }}$, are specified as input parameters for the treatment plant module of the design aid.

$C=C_{T P A}+C_{P A}+C_{T M A}+C_{T L C}+C_{S T}+C_{H D S}+C_{L A N D}+C_{S L U D G E}$

On the Annual-Cost worksheet, the following design input parameters may be entered. Default values for these design input parameters can be specified by either checking a checkmark on this worksheet or on the Control worksheet. 
Table 18. Water Treatment Module Annual-Cost Design Parameters.

\begin{tabular}{|l|r|r|r|r|}
\hline \multicolumn{1}{|c|}{ Design Parameter } & Default Value & \multicolumn{1}{c|}{ Symbol } & \multicolumn{1}{c|}{ Min. } & Max. \\
\hline Length of work week, hrs/week & 40.0 & $W$ & 0 & \\
\hline Hourly labor rate, \$/hr & 25.00 & $H$ & 0 & \\
\hline Vacation weeks per year, weeks/yr & 3.0 & $V$ & 0 & \\
\hline Benefit rate & $70 \%$ & $B$ & 0 & \\
\hline Electricity unit cost, \$/kW-hr & 0.05 & $U_{E}$ & 0.01 & 0.1 \\
\hline Sludge pipeline repair rate, $1 / \mathrm{yr}$ & $1 \%$ & $R_{S P R}$ & $0.1 \%$ & $10 \%$ \\
\hline Vertical turbine repair rate, $1 / \mathrm{yr}$ & $1 \%$ & $R_{V T R}$ & $0.1 \%$ & $10 \%$ \\
\hline High aerator repair rate, $1 / \mathrm{yr}$ & $5 \%$ & $R_{\text {HARR }}$ & $1 \%$ & $10 \%$ \\
\hline Low aerator repair rate, $1 / \mathrm{yr}$ & $1 \%$ & $R_{\text {LARR }}$ & $0.1 \%$ & $10 \%$ \\
\hline Clarifier repair rate, $1 / \mathrm{yr}$ & $1 \%$ & $R_{C R R}$ & $0.1 \%$ & $10 \%$ \\
\hline Appraisal rate & $1 \%$ & $R_{A}$ & $0.1 \%$ & $10 \%$ \\
\hline Millage & 150 & $M$ & 100 & 200 \\
\hline Insurance rate & $0.7 \%$ & $R_{I}$ & $0.1 \%$ & $10 \%$ \\
\hline Repayment period, years & 30 & $N_{R P}$ & 10 & 50 \\
\hline Annual interest rate, $1 / \mathrm{yr}$ & $6 \%$ & $I$ & $1 \%$ & $10 \%$ \\
\hline
\end{tabular}

The annual costs associated with the operation of the treatment plant in $\$ / \mathrm{yr}, A$, are calculated using the following equations. The first step is to calculate the labor cost in $\$ / y r, A_{L}$, the benefits cost in $\$ / y r, A_{B}$, and the electricity cost in $\$ / y r, A_{E}$.

$$
\begin{aligned}
& A_{L}=W H(52+V) \\
& A_{B}=A_{L} B \\
& P=P_{P R E}+P_{M A}+P_{S D P}+P_{R P} \\
& A_{E}=0.746(24)(365.25) P U_{E}
\end{aligned}
$$

The annual repair cost for the sludge pipeline in $\$ / y r, A_{S P R}$, the annual repair cost for the vertical turbine pumps in $\$ / \mathrm{yr}, A_{V T R}$, and the annual repair cost for the clarifier in $\$ / \mathrm{yr}$, $A_{C}$, are calculated using the following equations.

$$
\begin{aligned}
& A_{S P R}=C_{S L U D G E} R_{S P R} \\
& A_{V T R}=C_{M} R_{V T R}
\end{aligned}
$$




$$
A_{C}=C_{C} R_{C R R}
$$

If either the LSI or the GSI is greater than one, then the following equation is used to calculate the annual repair cost of the mechanical aerators in $\$ / y r, A_{M A}$, if mechanical aeration is used.

$$
A_{M A}=C_{M A} R_{H A R R}
$$

If both the LSI or the GSI are less than one, then the following equation is used to calculate the annual repair cost of the mechanical aerators in $\$ / y r, A_{M A}$, if mechanical aeration is used.

$$
A_{M A}=C_{M A} R_{L A R R}
$$

The taxes for the treatment plant in $\$ / y r, A_{T A X}$, and the insurance for the treatment plant in $\$ / y r, A_{l}$, are calculated with the following formulas.

$$
\begin{aligned}
& A_{T A X}=\frac{C R_{A} M}{10} \\
& A_{I}=\left(C-C_{L A N D}-C_{S L U D G E}\right) R_{I}
\end{aligned}
$$

The debt service cost in $\$ / \mathrm{yr}, A_{D}$, is calculated with the following standard formula.

$$
A_{D}=C \frac{I(1+I)^{N_{R P}}}{(1+I)^{N_{R P}}-1}
$$

And the total annual cost in $\$ / y r, A$, is calculated with the following formula.

$$
A=A_{L}+A_{B}+A_{E}+A_{S R P}+A_{V T R}+A_{M A}+A_{C}+A_{T A X}+A_{I}+A_{D}
$$

The output for this module primarily consists of three worksheets that are created in the spreadsheet: Summary, Simulation, and Design. If the user has specified a prefix for these worksheets, then the names of the worksheets are: Prefix Summary, Prefix Simulation, and Prefix Design. If no prefix is specified, then the worksheet names are: Summary, Simulation, and Design. 


\subsubsection{Summary Output Worksheet}

The Summary output worksheets contains a table with the mean flow rate and mean water quality constituent concentrations for: each of the specified sources, the inflow as a whole, the outflow after acid neutralization but before water softening, and the outflow after water softening. The mean flow rate and water quality after water softening is calculated by the module regardless of the value of water softening checkbox on the Control worksheet. This feature was included to give the planner an idea of the material and sludge disposal needs with and without water softening.

The second section of the Summary worksheet contains the mean sludge production rate from acid neutralization alone in terms of pounds per day, tons per day, and gallons per minute; the mean gypsum content in the sludge after acid neutralization; the mean lime dosage rate for acid neutralization in pounds per million gallons and tons per day; and the mean soda ash dosage rate for acid neutralization in pounds per million gallons and tons per day.

The third section of the Summary worksheet contains the mean sludge production rate from water softening alone in terms of pounds per day, tons per day, and gallons per minute; the mean gypsum content in the sludge after water softening; the mean lime dosage rate for water softening in pounds per million gallons and tons per day; and the mean soda ash dosage rate for water softening in pounds per million gallons and tons per day.

The fourth section of the Summary worksheet contains the specified value for the sludge solids content and the $\mathrm{pH}$ endpoint for the hydrated lime treatment. The fifth and final section of the Summary worksheet contains the maximum calculated Langelier Saturation Index (LSI) and the maximum Gypsum Saturation Index (GSI) for both the raw water entering the treatment plant and the treated water leaving the treatment plant. The GSI is calculated by multiplying the calcium activity by the sulfate activity and dividing by the solubility product for gypsum. When the LSI is much less than zero, there is no potential for $\mathrm{CaCO}_{3}$ precipitation and scaling. When the $\mathrm{LSI}$ is much greater than zero, $\mathrm{CaCO}_{3}$ can precipitate and cause scaling. When the $\mathrm{LSI}$ is approximately equal to zero, there is a borderline potential for $\mathrm{CaCO}_{3}$ precipitation and scaling.

\subsubsection{Simulation Output Worksheet}

The Simulation output worksheet consist of a table that shows the inflow rate, inflow temperature, inflow water quality, outflow temperature, outflow water quality, sludge production rate in pounds per day, sludge production rate in gallons per minute, sludge 
gypsum mass content, lime dosage rate in pounds per million gallons, and soda ash dosage in pounds per million gallons.

The inflow water quality constitutes include: $\mathrm{pH}$, magnesium, calcium, iron, aluminum, manganese, sulfate, total dissolved solids, silicate, sodium, chloride, calculated acidity, and lab alkalinity. The outflow water quality constitutes include: $\mathrm{pH}$, magnesium, calcium, iron, aluminum, manganese, sulfate, total dissolved solids, silicate, sodium, chloride, and calculated acidity. The acidity and alkalinity parameters have the units of milligrams per liter of $\mathrm{CaCO}_{3}$ equivalents. With the exception of $\mathrm{pH}$, the units for all of the other parameters are milligrams per liter.

\subsubsection{Design Output Worksheet}

The Design output worksheet contains a table of the mine water source name, maximum inflow rate in gallons per minute, average inflow rate in gallons per minute, maximum metal acidity in milligrams per liter of $\mathrm{CaCO}_{3}$ equivalents, and maximum total acidity in milligrams per liter of $\mathrm{CaCO}_{3}$ equivalents for each of the mine water sources contributing flow to the treatment plant.

The second section of the Design output worksheet contains the maximum metal and total acidity from all sources, the maximum and average inflow rate from all sources, the maximum hydrated lime and soda ash dosage, and the purity of the hydrated lime and soda ash. The soda ash parameters are included in this section regardless of the value of the water softening checkbox on the Control worksheet in order to allow the user to judge material needs if water softening is to be employed.

The third section of the Design output worksheet contains the maximum and average sludge generation rates for the lime neutralization process only, the maximum and average sludge generation rates for both the lime neutralization process and water softening process, the sludge solids content, and the $\mathrm{pH}$ endpoint for the lime neutralization process. The water softening parameters are included in this section regardless of the value of the water softening checkbox on the Control worksheet in order to allow the user to judge material needs if water softening is to be employed.

The fourth section of the Design output worksheet contains the input and output parameters for the pre-aeration cost calculations (if the pre-aeration checkbox on the Control checkbox was selected). The pre-aeration output parameters include:

- Required oxygen, Ibs/hr

- Pump power, HP 
- Tank volume, $\mathrm{ft}^{3}$

- Concrete volume, $\mathrm{yd}^{3}$

- Tank cost, \$

- Aerator cost, \$

- Subtotal cost, \$

- Design cost, $\$$

- Erection cost, \$

- Total cost, \$

The fifth section of the Design output worksheet contains the lime plant input and output parameters. The output parameters include:

- Clarifier area, $\mathrm{ft}^{2}$

- Clarifier diameter, ft

- Clarifier cost, \$

- Concrete volume, $\mathrm{yd}^{3}$

- Excavation volume, $\mathrm{yd}^{3}$

- Lime plant cost, \$

- Sludge volume flow rate, gpm

- Sludge pipe diameter, in

- Sludge pipe cost, \$

- Sludge disposal total dynamic head, $\mathrm{ft}$

- Sludge pump power, HP

- Sludge injection well cost, \$

- Sludge cost, \$

- Sludge miscellaneous steel cost, \$

- Lime plant subtotal cost, \$

- Lime plant erection cost, \$

- Lime plant design cost, \$

- Lime plant total cost, \$

The sixth section of the Design output worksheet contains the soda ash input and output parameters, (if the water softening checkbox on the Control worksheet was checked). The output parameters include:

- Soda ash subtotal cost, \$

- Soda ash design cost, \$

- Soda ash erection cost, \$ 
- Soda ash total cost, \$

The seventh section of the Design output worksheet contains the high density sludge input and output parameters, if the module determined that this step was needed due to the presence of gypsum in the sludge. The output parameters include:

- Conditioning tank recirculation flow, gpm

- Conditioning tank volume, $\mathrm{ft}^{3}$

- Conditioning tank side, $\mathrm{ft}$

- Conditioning tank concrete volume, $\mathrm{yd}^{3}$

- Conditioning tank cost, \$

- Conditioning tank mixer cost, \$

- Recirculation pump power, HP

- Recirculation pipe cost, \$

- Recirculation pump cost, \$

- High density sludge subtotal cost, $\$$

- High density sludge erection cost, \$

- High density sludge total cost, $\$$

The eighth section of the Design output worksheet contains the peroxide aeration input and output parameters (if the peroxide aeration checkbox on the Control worksheet was checked). The output parameters include:

- Required peroxide dosage rate, $\mathrm{lbs} / \mathrm{hr}$

- Peroxide mass per delivery, lbs

- Storage tank volume, gal

- Storage building area, $\mathrm{ft}^{2}$

- Storage building cost, $\$$

- Tank volume, $\mathrm{ft}^{3}$

- Tank width, $\mathrm{ft}$

- Tank concrete volume, $\mathrm{yd}^{3}$

- Tank concrete cost, \$

- Mixer cost, \$

- Excavation volume, $\mathrm{yd}^{3}$

- Excavation cost, $\$$

- Peroxide subtotal cost, $\$$

- Peroxide erection cost, $\$$

- Peroxide design cost, \$ 
- Peroxide total cost, \$

The ninth section of the Design output worksheet contains the mechanical aeration input and output parameters (if the mechanical aeration checkbox on the Control worksheet was checked). The output parameters include:

- Oxygen required, lbs/hr

- Power required, HP

- Tank volume, $\mathrm{ft}^{3}$

- Tank residence time, min

- Tank width, $\mathrm{ft}$

- Concrete volume, $\mathrm{yd}^{3}$

- Tank cost, \$

- Aerator cost, \$

- Excavation volume, $\mathrm{yd}^{3}$

- Excavation cost, $\$$

- Mechanical aeration subtotal cost, $\$$

- Mechanical aeration design cost, \$

- Mechanical aeration erection cost, \$

- Mechanical aeration total cost, $\$$

The tenth section of the Design output worksheet contains the results of the capital cost calculations. The output parameters for the capital cost calculations are:

- Pre-aeration total cost, $\$$

- Lime neutralization total cost, \$

- Soda ash softening total cost, \$

- High density sludge total cost, \$

- Peroxide or Mechanical aeration total cost, $\$$

- Treatment plant capital cost, \$

- Raw water pipeline capital cost, $\$$

- Clean water pipeline capital cost, \$

- Sludge pipeline capital cost, \$

- Land capital cost, \$

- Total capital cost, \$ 
The eleventh section of the Design output worksheet contains the input and output parameters for the annual cost calculations. The output parameters for the annual cost calculations are:

- Labor cost, $\$ / y r$

- Benefits cost, $\$ / y r$

- Electricity cost, $\$ / y r$

- Raw water pipeline repair cost, $\$ / y r$

- Clean water pipeline repair cost, $\$ / y r$

- Sludge pipeline repair cost, $\$ / y r$

- Vertical turbine pump repair cost, $\$ / y r$

- Aerator repair cost, $\$ / y r$

- Clarifier repair cost, $\$ / y r$

- Taxes per year, $\$ / y r$

- Insurance per year, $\$ / y r$

- Debt service on capital cost, $\$ / y r$

- Total annual cost, $\$ / y r$

\subsection{Module 5 Thermal Efficiency}

\subsubsection{Design Module Input Data}

The purpose of the thermal efficiency module of the design aid is to determine both the cost and the savings associated with the use of mine water to provide make up water for the power plant's cooling tower. Input data for this module are specified by the user on four worksheets: Control, EP-COAL, TGPC-CTPC, and Municipal-Water.

On the Control worksheet, the user specifies dew point data, power level parameters, electricity value parameters, the cooling tower discharge temperature ${ }^{\circ} \mathrm{F}$, the treatment plant effluent water quality file, the treatment plant effluent discharge flow rate data file, and the number of cooling tower cycles. The dew point data is specified either by selecting a National Weather Service station that the program will use stored average dew point data or manually entering in mean dew point data for each of the twelve months in a year.

The power level parameters consist of the nominal power for the generating station and the name of the output worksheet. The VBA program employs a default nominal power level of $511 \mathrm{MW}$. The electricity value parameters consist of three parameters: the value of the electricity to the utility in $\$ / \mathrm{kW}-\mathrm{hr}$, the estimated longevity of the power plant 
in years, and the annual interest rate. In order to allow the user to compare the results of the calculation against a known standard, the checkbox allows the user to specify test values for these parameters.

The cooling tower discharge temperature will be a function of the operating policy of the power plant and should be approximately $80^{\circ} \mathrm{F}$. The treatment plant effluent water quality file and treatment plant effluent discharge flow rate data file are specified on the Control worksheet in textboxes.

The easiest way to specify the treatment plant effluent water quality file (treatment plant effluent discharge flow rate data file) is to click the button entitled "Treatment Plant Effluent Water Quality File:" ("Treatment Plant Effluent Discharge Flow Rate File:") and opening the treatment plant effluent water quality file (treatment plant effluent discharge flow rate data file) that was created by the simulation part of the Treatment Plant design module. The number of cooling tower cycles is specified in the textbox that is just below the treatment plant effluent water quality file textbox. If no cooling tower cycles are specified, then the program assumes that five cooling tower cycles are specified.

The exhaust pressure parameters are specified on the EP-COAL worksheet. These parameters consist of the relative percent increase in heat rate for various exhaust pressures between 0.5 and 5.0 in of $\mathrm{Hg}$. In order to allow the user to compare calculations against a standard, a checkbox on this worksheet allows the user to use test values for the relative increase in heat rate for various exhaust pressure levels.

The design input parameters from the coal assay are also specified on the EP-COAL worksheet. These design input parameters include the following items. The user has the option of specifying that test values of these parameters be used in the module.

- Dry Heating Value, BTU/lb

- Dry Carbon Content

- Dry Sulfur Content

- Dry Mercury Content

- Dry Nitrogen Content

The TGPC-CTPC worksheet contains the Turbine Generator Power Curve and Cooling Tower Performance Curve parameter groups. The Turbine Generator Power Curve parameters consists of specified values for the power loss in $\mathrm{kW}$ for various water temperatures between $61^{\circ} \mathrm{F}$ and $86{ }^{\circ} \mathrm{F}$. In order to allow the user to compare the calculations against a standard, there is a Turbine Generator Power Curve checkbox on 
this worksheet that allows the user to use test values for the power loss parameters with various water temperatures.

The Cooling Tower Performance Curve is defined by two parameters on the TGPCCTPC worksheet: the cold water temperature that corresponds to a wet bulb temperature of $20^{\circ} \mathrm{F}$ and the cold water temperature that corresponds to a wet bulb temperature of $80^{\circ} \mathrm{F}$. In order to allow the user to compare the calculations against a standard, there is a Cooling Tower Performance Curve checkbox on this worksheet that allows the user to use test values for these two parameters.

\subsubsection{Design Module Calculations}

The first step in the thermal efficiency design module is the calculation of the annual gain in power that results from the use of cold water in kW-hr, $E_{\text {GAIN. Th }}$ This accomplished by looping through the months of the year and calculating the power gain for each month from the month's mean dew point temperature in ${ }^{\circ} \mathrm{F}, T_{D E W i}$, the slope of the cooling tower performance curve, $m_{C T}$, the intercept of the cooling tower performance curve in ${ }^{\circ} \mathrm{F}, b_{C T}$, the turbine generator power curve function, $f$, and the number of days in each month, $D_{i}$, using the following equations.

$$
\begin{aligned}
& T_{C W}=T_{D E W i} m_{C T}+b_{C T} \\
& P_{\text {GAINi }}=f\left(T_{C W}\right) \\
& E_{\text {GAIN }}=24 \sum_{i=1}^{12}\left(D_{i} P_{\text {GAINi }}\right)
\end{aligned}
$$

The following equations are used to calculate the capital gain in $\$, C_{\text {GAIN }}$, and the annual gain, $A_{\text {GAIN }}$, due to the use of cold water using the value of electricity in $\$ / \mathrm{kW}-\mathrm{hr}, E_{\text {VALUE, }}$ the longevity of the power plant, $N_{P P}$, and the annual interest rate, $I$.

$$
\begin{aligned}
& C_{\text {GAIN }}=E_{\text {VALUE }} E_{\text {GAIN }} \\
& A_{\text {GAIN }}=C_{\text {GAIN }} \frac{1-(1+I)^{-N_{P P}}}{I}
\end{aligned}
$$

The reduction in the consumption of coal in tons/yr, $R_{C}$, and release of $\mathrm{CO}_{2}, \mathrm{SO}_{\mathrm{x}}$, and $\mathrm{NO}_{\mathrm{x}}$ into the environment, $R_{\mathrm{CO} 2}$ in tons/yr, $R_{\mathrm{SO}}$ in tons/yr, $R_{\mathrm{NO}}$ in Ibs/yr, respectively, are calculated from the heating value of the coal in BTU/lb, $H_{V A L U E}$, the carbon content 
of the coal in $\mathrm{g}-\mathrm{C} / \mathrm{g}$-coal, $C_{C}$, the sulfur content of the coal in g-S/g-coal, $C_{S}$, the mercury content of the coal in $\mathrm{g}-\mathrm{Hg} / \mathrm{g}$-coal, $C_{\mathrm{Hg}}$, the nitrogen content of the coal in $\mathrm{g}-\mathrm{N} / \mathrm{g}-\mathrm{coal}$, $C_{N}$, and the thermodynamic efficiency of the power plant, $e_{T}$.

$$
\begin{aligned}
& R_{C}=\frac{3412.14 E_{\text {GAIN }}}{2000 H_{\text {VALUE }} e_{T}} \\
& R_{C O 2}=3.6642 R_{C} C_{C} \\
& R_{S O X}=2.0478 R_{C} C_{S} \\
& R_{N O X}=3.2841 R_{C} C_{N O X} \\
& R_{H g}=2000 R_{C} C_{H g}
\end{aligned}
$$

The following equations are then used to calculate the amount of blowdown water required for power plant heat rejection in gpm, $Q_{B D}$, from the thermodynamic efficiency of the power plant, $e_{T}$, the temperature range in ${ }^{\circ} \mathrm{F}, T_{R}$, the number of cycles, $N_{C}$, and the power plant nominal power in MW, $P_{N}$.

$$
\begin{aligned}
& H_{R}=56869.0272 P_{N} \frac{1-e_{T}}{e_{T}} \\
& Q=\frac{7.4805 H_{R}}{62.4 T_{R}} \\
& Q_{E}=0.0008 Q T_{R} \\
& Q_{D}=0.0002 Q \\
& Q_{B D}=\frac{Q_{E}-Q_{D}\left(N_{C}-1\right)}{N_{C}}
\end{aligned}
$$

The fraction of the blowdown water that must come from an alternative source, $F_{A L T}$, is calculated from the mean treated mine water discharge flow rate in $\mathrm{gpm}, Q_{M T}$, and the blowdown water required in gpm, $Q_{B D}$. 


$$
F_{A L T}=\max \left(1-\frac{Q_{M T}}{Q_{B D}}, 0\right)
$$

This fraction is then used with the price of the alternative source water in $\$$ per 1,000 gallons, $C_{A L T}$, to calculate the annual cost of the water from the alternative source in $\$ / y r, A_{A L T}$.

$$
A_{A L T}=\frac{365.25(24)(60) F_{A L T} Q_{B D} C_{A L T}}{1000}
$$

The thermal efficiency design module then opens the mine water treatment plant effluent water quality data file and loops through the records. After mixing the treated mine water with water from the alternative source, the module calculates the total acidity of the combined water using equation (26) and the alkalinity of the treated water in $\mathrm{mg} / \mathrm{L}$ $\mathrm{CaCO} 3$ equivalents, Alk, using the partial pressure of $\mathrm{CO}_{2}$ in the atmosphere, $\mathrm{P}_{\mathrm{CO} 2}$, Henry's Law constant for $\mathrm{CO}_{2}, \mathrm{~K}_{\mathrm{H}}$, the dissolution constant for water, $K_{W}$, and the $\mathrm{CO}_{2}$ dissolution constants, $\mathrm{K}_{1}$ and $\mathrm{K}_{2}$, with the following equations.

$$
C_{\mathrm{CO} 2}=\frac{P_{\mathrm{CO} 2}}{K_{H}}
$$

$\left[\mathrm{HCO}_{3}^{-1}\right]=C_{\mathrm{CO} 2} K_{1} 10^{\mathrm{pH}}$

$\left[\mathrm{CO}_{3}^{-2}\right]=\left[\mathrm{HCO}_{3}^{-1}\right] K_{2} 10^{\mathrm{pH}}$

$$
\mathrm{Alk}=2\left[\mathrm{CO}_{3}^{-2}\right]+\left[\mathrm{HCO}_{3}^{-1}\right]+K_{W} 10^{\mathrm{pH}}-10^{-\mathrm{pH}}
$$

With the alkalinity of the treated water calculated, the design module then calculates the LSI of the water leaving the treatment plant and leaving the cooling tower using equations (1) through (5). The GSI of the water leaving the treatment plant and leaving the cooling tower are calculated using equation (6).

The maximum LSI and GSI values for the water entering and leaving the cooling tower are tabulated and written, with the rest of the output data, to the output worksheet when the treatment plant effluent water quality file loop is completed. 


\subsubsection{Output Worksheet}

The output worksheet has the following design output parameters: the potential energy gain due to the use of cold mine water in kW-hrs for each month and the entire year, the value of the annual potential energy gain, the capitalized potential energy gain, and the maximum LSI and GSI values for the water entering and leaving the cooling tower for various concentration cycles. Bar charts of the maximum LSI and GSI values for the water leaving the cooling tower for various concentration cycles are also created in this worksheet.

Because the alkalinity of the treatment plant effluent was not calculated by the treatment plant module, code was inserted in this module to estimate the alkalinity of the treatment plant effluent from the $\mathrm{pH}$ and the partial pressure of carbon dioxide in the atmosphere so that the LSI calculations could be performed accurately. This section of code was based upon the relations between $\mathrm{pH}$; the carbon dioxide content of the atmosphere; the equilibrium relationships between dissolved carbon dioxide, carbonic acid, bicarbonate ion, and carbonate ion; and the definition of alkalinity.

Code was also added to translate the annual potential energy gain from using cold water into annual reductions in the amount of coal burned and in the amount of $\mathrm{SO}_{\mathrm{x}}$, $\mathrm{CO}_{2}, \mathrm{Hg}$, and uncontrolled $\mathrm{NO}_{x}$ released to the environment.

\subsection{Module 6 Report Generator}

For the sake of simplicity, all of the aforementioned modules have been written into individual Microsoft Excel spreadsheets. The results of each module are summarized by a design summary module. The input data for this module is located on the worksheet Control. The input parameters on this worksheet are: output worksheet name, site information spreadsheet, mine water source spreadsheet name, supply pipeline spreadsheet name, treatment plant spreadsheet name, water cooling spreadsheet name, and the annual interest rate.

The names of the spreadsheets can be specified by clicking the button on the immediate left of the appropriate textboxes. The default value for the annual interest rate can be specified with a checkbox below the annual interest rate textbox. The main body of the VBA program is executed by clicking the button entitled "Mine Water System Design Summary Report" on the Control worksheet.

The output worksheet contains a summary of the output from all of the aforementioned design modules and a cost summary section. The cost summary section lists all of the 
capital and O\&M costs calculated by the other modules and the annual potential energy value due to the use of constant cold water. These costs, the annual potential energy value due to the use of constant cold water, and the specified annual interest rate are used to calculate the net present value of the project. If the net present value of the project is positive, then the internal rate of return and the capital recovery period in years are also calculated. The following parameters are listed in the cost summary section of the output worksheet:

- System Longevity, years

- Pipeline System Capital Cost, \$

- Pipeline System O\&M Cost, $\$ / y r$

- Treatment System Capital Cost, \$

- Treatment System O\&M Cost, $\$ / y r$

- Total Capital Cost, \$

- Total O\&M Cost, $\$ / y r$

- Annual Potential Energy Worth, $\$ / y r$

- Annual Cost of Municipal Water, $\$ / y r$

- Net Present Value, \$

- Interest Rate for NPV, 1/yr

- Internal Rate of Return, $1 / y r$

- Capital Recovery Period, years

The users manual for the computer-based design aid for assessing the use of mine water for thermoelectric generation can be found in the following Appendix A.

\subsection{Benefits of Using Mine Water for Beech Hollow}

The use of constant cool makeup water to a power plant has numerous advantages. The principle advantage is that the power plant is able to generate more electricity without increasing its burn rate or derating the unit during hot humid summer days. This also has a number of secondary advantages including reduced coal consumption resulting in reduced emissions of $\mathrm{CO} 2$, SOX, NOx, and mercury. Appendix C contains a detailed discussion of the thermal and emission reduction benefits resulting from using constant temperature mine water.

\subsection{Cost of Using Mine Water for Beech Hollow}


Table 19. Computer design aid example inputs

\begin{tabular}{|c|c|c|c|c|c|c|c|c|c|}
\hline From & To & $\begin{array}{c}\text { Pump } \\
\text { Capacit } \\
\text { y } \\
(\mathrm{gpm})\end{array}$ & $\begin{array}{c}\text { Length } \\
\text { (ft) }\end{array}$ & $\begin{array}{c}\text { Surface } \\
\text { Elevation }\end{array}$ & $\begin{array}{c}\text { Coal } \\
\text { Elevation }\end{array}$ & $\begin{array}{c}\text { Water } \\
\text { Elevation }\end{array}$ & $\begin{array}{c}\text { Max } \\
\text { Elevation }\end{array}$ & $\begin{array}{c}\text { Destination } \\
\text { Elevation }\end{array}$ & $\begin{array}{c}\text { Water } \\
\text { Quality }\end{array}$ \\
\hline Pitts \#2 & $\begin{array}{c}\text { Montour } \\
\# 9\end{array}$ & 8,934 & 1060 & 960 & 1000 & 1100 & 1100 & JB-1 \\
\hline Montour \#1 & Primrose & 600 & 151 & 1280 & 940 & 1010 & 1280 & 1280 & Primrose \\
\hline Primrose & $\begin{array}{c}\text { Montour } \\
\# 9\end{array}$ & 800 & 5,823 & 1130 & 980 & 1040 & 1100 & 1130 & Primrose \\
\hline Bulger & $\begin{array}{c}\text { Transfer } \\
\text { Sump }\end{array}$ & 300 & 6,552 & 1230 & 1080 & 1100 & 1200 & 1270 & JB-1 \\
\hline Montour \#9 & $\begin{array}{c}\text { Transfer } \\
\text { sump }\end{array}$ & 2,000 & 100 & 1200 & 1080 & 1100 & 1200 & 1200 & $\begin{array}{c}\text { Montour } \\
\# 9\end{array}$ \\
\hline $\begin{array}{c}\text { Transfer } \\
\text { Sump }\end{array}$ & $\begin{array}{c}\text { Treatment } \\
\text { Plant }\end{array}$ & 2,300 & 12,460 & 1200 & N/A & 1200 & 1240 & 1240 & $\begin{array}{c}\text { Blend } \\
\text { water }\end{array}$ \\
\hline $\begin{array}{c}\text { Treatment } \\
\text { Plant }\end{array}$ & $\begin{array}{c}\text { Power } \\
\text { Plant }\end{array}$ & 2250 & 3,825 & 1240 & N/A & 1240 & 1180 & 1240 & $\begin{array}{c}\text { treated } \\
\text { water }\end{array}$ \\
\hline
\end{tabular}

The mine water handling plan described above is used as an example problem. The McDonald discharge was excluded due to the length of pipe involved. The data contained in Table 11 was used as input to the model. The mines that are used as source water are: Bulger, Montour \#1, Montour \#9, Pitt\#2, and Primrose. Combined these mines are expected to produce $2,300 \mathrm{gpm}$ to the water treatment plant on a continuous basis. The input water temperature in the mine is $54 \mathrm{~F}^{\circ}$ based on field observations.

Using these input data the computer based design aid generated the results contained in Table 12. This analysis evaluates both standard water treatment and standard water treatment with softening. Mechanical aeration is used throughout, high density sludge is not used. 
Table 20. Example Results

\begin{tabular}{|c|c|c|c|}
\hline & No Softening & Softening & \\
\hline Treatment System Capital Cost $=$ & $\$ 1,933,704.13$ & $\$ 2,022,879.13$ & \\
\hline Treatment System O\&M Cost $=$ & $\$ 407,899.87$ & $\$ 422,604.29$ & $1 / \mathrm{yr}$ \\
\hline $\begin{array}{c}\text { Treatment System Annualized Cost } \\
=\end{array}$ & $\$ 548,381.37$ & $\$ 569,564.26$ & $1 / \mathrm{yr}$ \\
\hline Mean Discharge Flow Rate $=$ & $2,250.0$ & $2,086.8$ & $\mathrm{gpm}$ \\
\hline Water Treatment Cost $=$ & $\$ 463.39$ & $\$ 518.93$ & $1 / \mathrm{MG}$ \\
\hline Cooling Tower Information & & & \\
\hline Nominal Power $=$ & 511 & 511 & $\mathrm{MW}$ \\
\hline Weather Station $=$ & Pittsburgh, PA & Pittsburgh, PA & \\
\hline Annual Potential Energy Gain $=$ & $10,003,508.48$ & $10,003,508.48$ & $\mathrm{~kW}-\mathrm{hrs} / \mathrm{yr}$ \\
\hline Annual Potential Energy Worth $=$ & $\$ 630,221.03$ & $\$ 630,221.03$ & $1 / \mathrm{yr}$ \\
\hline Capitalized Potential Energy Worth & $\$ 9,137,099.81$ & $\$ 9,137,099.81$ & \\
\hline$=$ & & & \\
\hline Cost Summary & & & \\
\hline System Longevity $=$ & 35.00 & 35.00 & $\mathrm{years}$ \\
\hline Pipeline System Capital Cost $=$ & $\$ 9,087,310.38$ & $\$ 9,087,310.38$ & \\
\hline Pipeline System O\&M Cost $=$ & $\$ 196,225.03$ & $\$ 196,225.03$ & $1 / \mathrm{yr}$ \\
\hline Treatment System Capital Cost $=$ & $\$ 1,933,704.13$ & $\$ 2,022,879.13$ & \\
\hline Treatment System O\&M Cost $=$ & $\$ 407,899.87$ & $\$ 422,604.29$ & $1 / \mathrm{yr}$ \\
\hline Total Capital Cost $=$ & $\$ 11,021,014.51$ & $\$ 11,110,189.51$ & \\
\hline Total O\&M Cost $=$ & $\$ 604,124.90$ & $\$ 618,829.32$ & $1 / \mathrm{yr}$ \\
\hline & $\$ 630,221.03$ & $\$ 630,221.03$ & \\
\hline
\end{tabular}

The combined capital cost of the standard system, rounding to the nearest $\$ 1,000$, is $\$ 11,021,000$ representing $\$ 9,087,000$ for the water collection system and $\$ 1,934,000$ for the water treatment plant. Annual operating costs are estimated to be $\$ 604,000$. The cost benefit of having cool mine water is calculated to be $\$ 630,000 / y r$ which completely offsets the operational cost of the water collection and treatment system.

The Beech Hollow power plant is not located near a surface water source where makeup water can be obtained. Consequently they have proposed using public water to supply their makeup water requirements. At this time the cost of this water is $\$ 3.00$ per 1000 gallons from the utility company. Ignoring the benefit of the cooler mine water on the operation of the power plant, the cost of mine water collection and treatment is $\$ 504.38$ per million gallons compared to $\$ 3,000.00$ per million gallons for municipal water. 
Mine water typically contains a higher total dissolved solids load than a surface water source, with elevated levels of calcium and sulfate. This TDS load will affect the suitability of the water for use in a cooling tower application. Consequently, acquisition cost alone is insufficient to fully evaluate the suitability of mine water for power plant cooling. To address this issue the computer based design aid provides a graphic presentation of the effect of increasing cycles of concentration on the Langelier Saturation Index (LSI). Figure 22 shows the output of the LSI calculation for treated but unsoftened mine water. The negative value for LSI indicates that this water is not likely to deposit calcium carbonate.

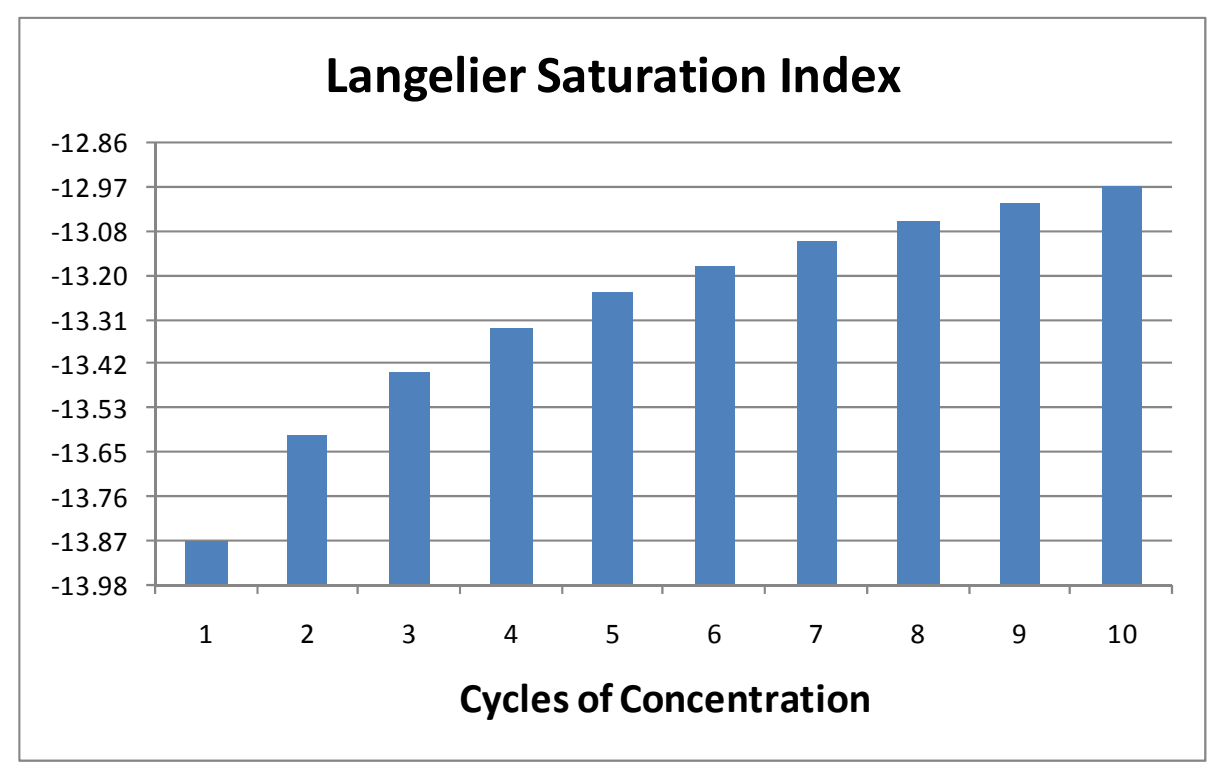

Figure 21. LSI of example treated mine water without softening

Gypsum precipitation is also an issue with mine water. The addition of calcium based alkalinity can drive the water toward gypsum precipitation. The computer based design aid calculates the solubility of gypsum over ten cycles of concentration. Figure 23 is a plot of these data from the example problem. For GSI values less than 1, gypsum is under saturated and for values greater than 1, gypsum precipitation can be expected. Based on these calculations, gypsum precipitation can be expected after two cycles of concentration. This calculation does not include the effect of any chemical program to inhibit precipitation. 


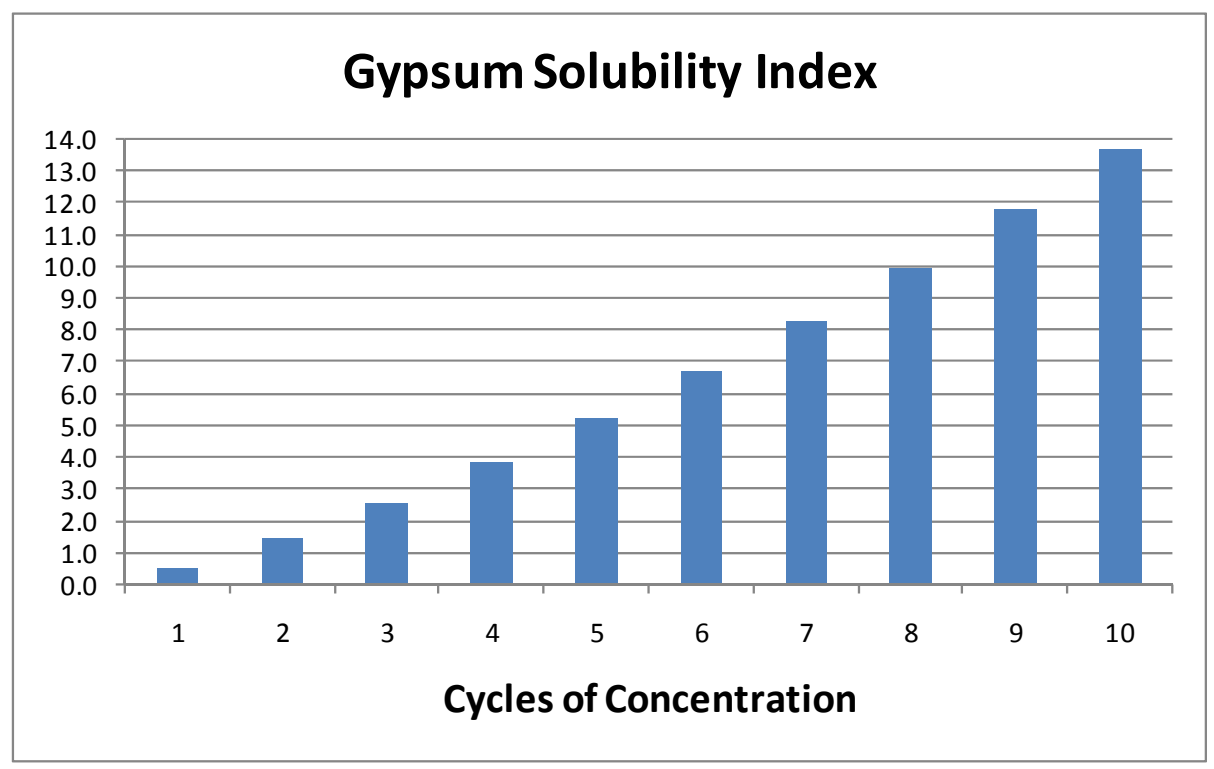

Figure 22. GSI of example treated mine water without softening

Plant design, particularly makeup water volume, for the Beech Hollow facility calls for 10 cycles of concentration. Clearly this water does not meet that criteria utilizing standard water treatment. The computer based design aid includes a number of options for improving water quality. For net alkaline waters, the addition of hydrogen peroxide without the addition of hydrated lime can precipitate the iron without increasing the calcium in the mine water. A second option is to utilize lime - soda ash softening.

The equipment needed for lime - soda ash softening is very similar to the equipment needed for standard mine drainage treatment. All that is needed is the addition of soda ash storage and feeding equipment, and the increase in sludge volume will require a larger underflow pump from the clarifier. The example problem has been run utilizing lime - soda ash softening.

The cost of the water collection system remains unchanged at $\$ 9,087,000$, while the cost of the treatment plant increase to $\$ 2,023,000$, an increase of $\$ 89,000$. The cost of operation with the lime - soda ash softening system increases to $\$ 619,000$ per year an increase of $\$ 15,000$ per year. The cost of treated water increases to $\$ 519$ per million gallons treated an increase of $\$ 56$. This cost of softened mine water is still very favorable compared to the cost of municipal water at $\$ 3,000$ per million gallons. Because of the increase in sludge to be disposed from the softening process there is a corresponding increase in the amount of water required for this disposal. This reduces the amount of treated water available from the treatment plant by 173 gallons per minute. 
The computer based design aid calculated the LSI and the GSI for the softened water. These data are presented in Figures 24 and 25. Water softening has improved both the LSI and the GSI. In particular, LSI is less negative, and gypsum remains under saturated even after ten cycles of concentration. If field testing of this calculation confirms the result then additional cycles of concentration could be considered.

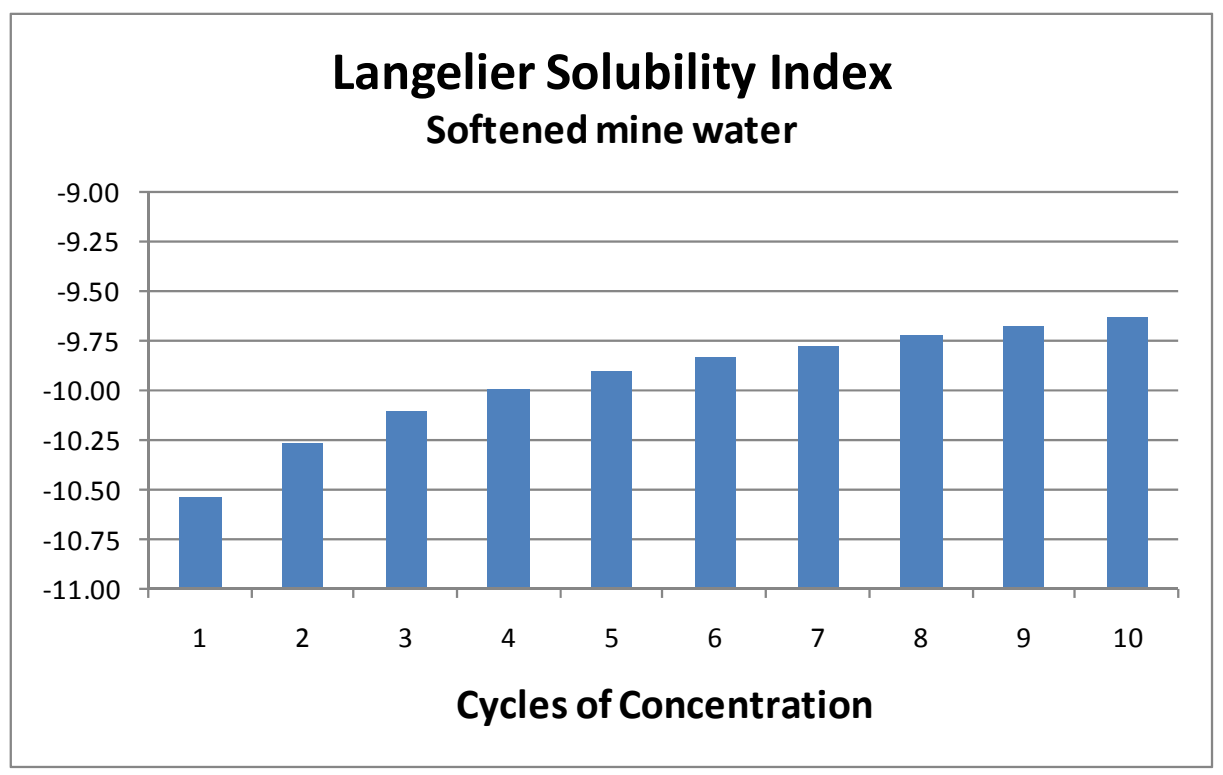

Figure 23. LSI of example treated mine water with softening 


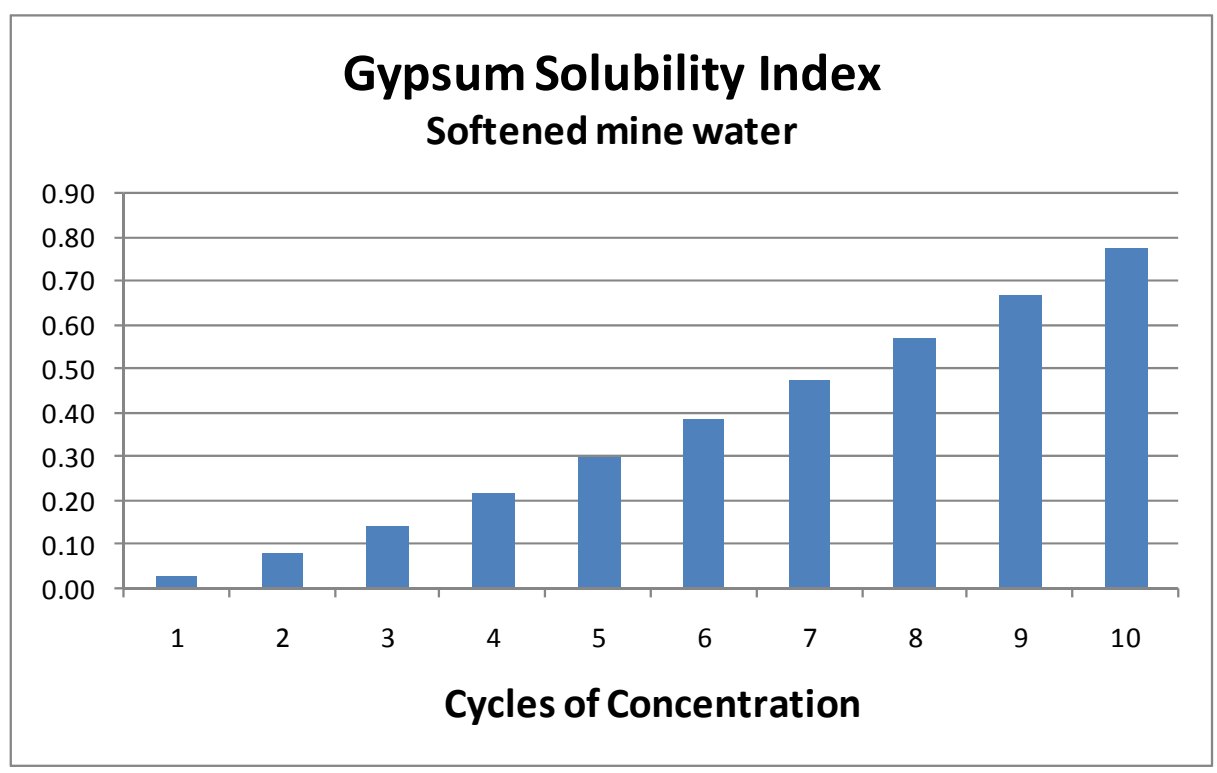

Figure 24. GSI of example treated mine water with softening 


\subsection{Emission Benefits of Using Mine Water}

The use of cool makeup water improves the efficiency of the power plant and as a result reduces the plant emissions. Appendix $C$ contains a discussion of these savings and $a$ description of how they are calculated. These calculations have been included in the computer based design aid.

Utilizing the mine water system designed for the Beech Hollow plant in this report, the emissions reductions resulting from the use of the mine water at the power plant were calculated. These results are contained in Table 21.

Table 21. Emission Reduction Benefits

\begin{tabular}{|l|c|}
\hline Component & Reduction \\
\hline Coal & $8,707 \mathrm{t} / \mathrm{yr}$ \\
\hline Carbon Dioxide & $10,210 \mathrm{t} / \mathrm{yr}$ \\
\hline SOx & $357 \mathrm{t} / \mathrm{yr}$ \\
\hline Mercury & 3.48 \\
& $\mathrm{lb} / \mathrm{yr}$ \\
\hline NOx & $143 \mathrm{t} / \mathrm{yr}$ \\
\hline
\end{tabular}

These results indicate that the environmental benefit of using constant temperature mine water extends well beyond the improvement of stream quality resulting from the treatment and utilization of that water.

\subsection{Conclusion}

Mine water is available from underground mines in the vicinity of the proposed Beech Hollow power plant. The amount of water economically available is dependent on the number of discharges that are captured, the size of those discharges, and the amount and cost of the collection and transmission system, and the water quality. For purposes of the example problem the five largest and spatially compact discharges were selected yielding an aggregate flow of 2,300 gpm. An additional 1,000+ gpm are available from large sources if the collection system is extended to the east and west.

Based on the field data a method for estimating the amount of water available from mines utilizing precipitation records was developed. This methodology will allow estimation of mine water flow during dry years as well as wet years thus reducing the uncertainty that is the natural consequence of utilizing a new water source. 
Water pumping, transmission and treatment were based on mining industry standards utilizing vertical turbine pumps, HDPE piping, and standard hydrated lime treatment. A clarifier is used to minimize temperature rise in the treatment process and to facilitate sludge disposal. Additional options in the computer based design aid include high density sludge, hydrogen peroxide oxidation, lime soda ash softening, and thermal insulation on the buried pipeline.

Cost data from equipment suppliers were used in conjunction with cost data from a recently built hydrated lime water treatment plant to create estimation equations for the various components of a mine water collection and treatment system. These equations were built into a computer based design aid that will allow an engineer, who may be unfamiliar with mine drainage pumping, transmission and treatment to estimate the cost and benefit of using mine water for makeup water in a coal fired power plant. In addition, the computer based design aid calculates the thermal benefit of cool makeup water in the power plant operation. This benefit is expressed in the value of electric power that can be generated without increasing the heat rate and the emissions that are avoided by not increasing the heat rate.

Using mine water from the five mines in the example problem the amount of additional generation is calculated to be $10,003,508.48 \mathrm{Kwh} / \mathrm{yr}$ which is equal to $\$ 630,221.03$ based on an electricity rate of $\$ 0.063 / \mathrm{kwh}$. The avoided emissions from this site are $10,210 \mathrm{t} / \mathrm{yr}$ of carbon dioxide, $357 \mathrm{t} / \mathrm{yr}$ of sulfur dioxide, $143 \mathrm{t} / \mathrm{yr}$ of NOx and $3.48 \mathrm{lb} / \mathrm{yr}$ of mercury. The cost of building the water collection and treatment system is $\$ 11,110,189.51$ with an estimate cost of operation of $\$ 618,829.32$. This translates into a water acquisition cost of $\$ 518.93$ /million gallons compared to a cost of $\$ 3,000.00$ per million gallons from the municipal water supply. 


\section{Appendix A. User Manual}

\section{Using Microsoft Excel Spreadsheets with Macros}

In Microsoft Office 2007, Excel spreadsheets normally have the .xlsx suffix. Microsoft Excel spreadsheets with Visual Basic for Applications macros have the .xlsm suffix. Before opening a spreadsheet with a macro, the user needs to change the security settings in Excel so that the program provides notification when content is blocked and that all macros are blocked with notification. One could operate the design aid with Excel allowing the execution of all macros without any notification, but this setting can be dangerous when opening Excel spreadsheets downloaded from the Internet. The parameters in the Trust Center portion of the Excel Options to be specified are shown below in Figures 1 and 2.

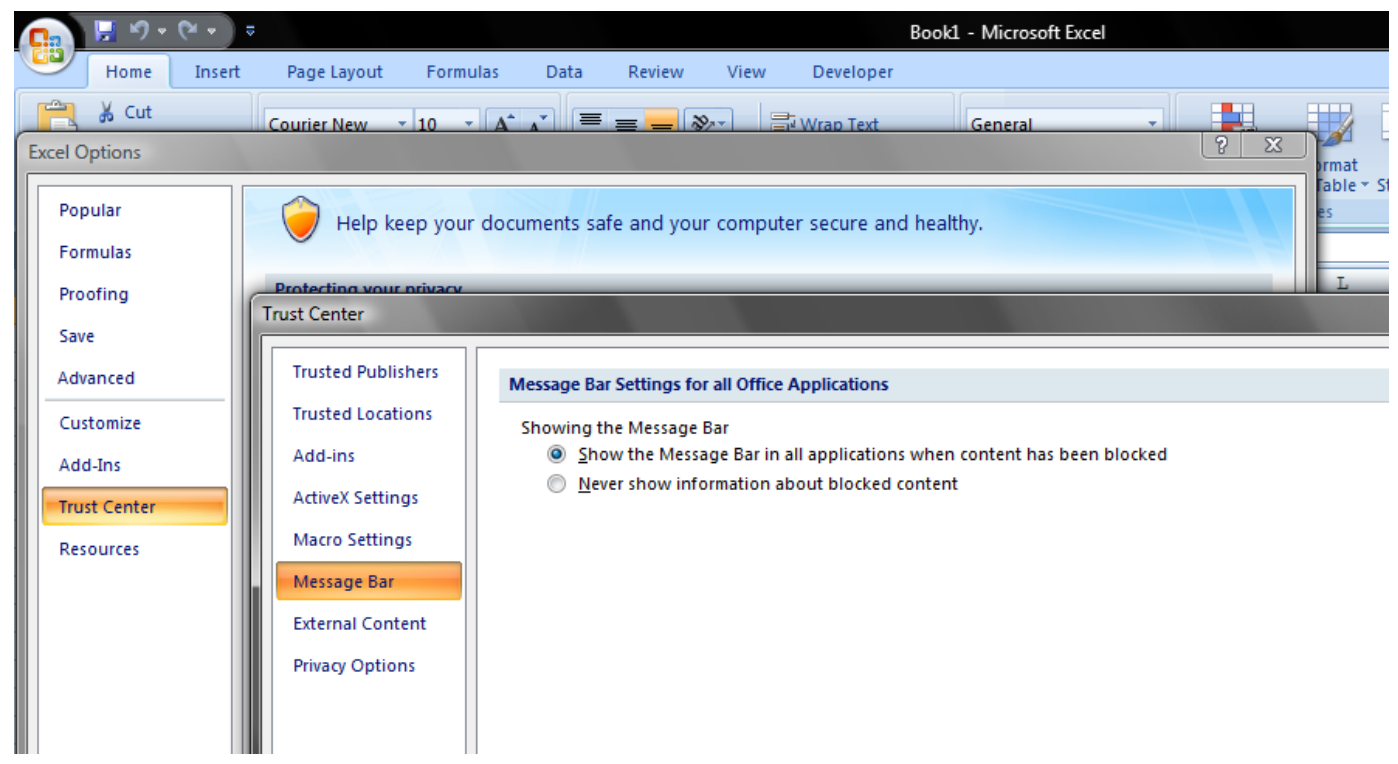

Figure 1. Required message bar setting to allow execution of macros. 


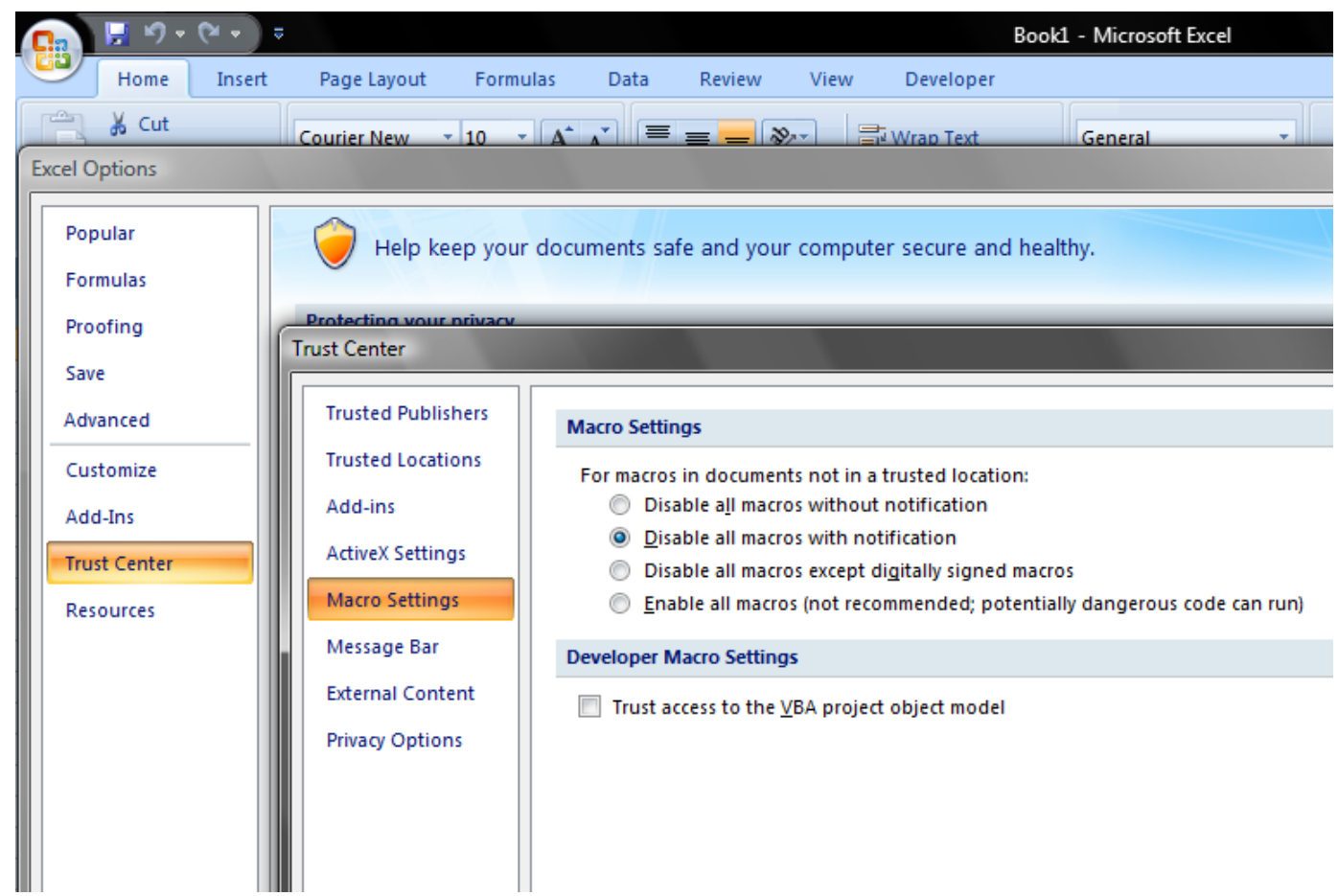

Figure 2. Required macro setting.

When opening an Excel spreadsheet with a macro, one should see a Security Warning that says, "Some active content has been disabled". Before attempting to execute the macro, one needs to click the "Options..." button on the right side of the Security Warning and activate the macros.

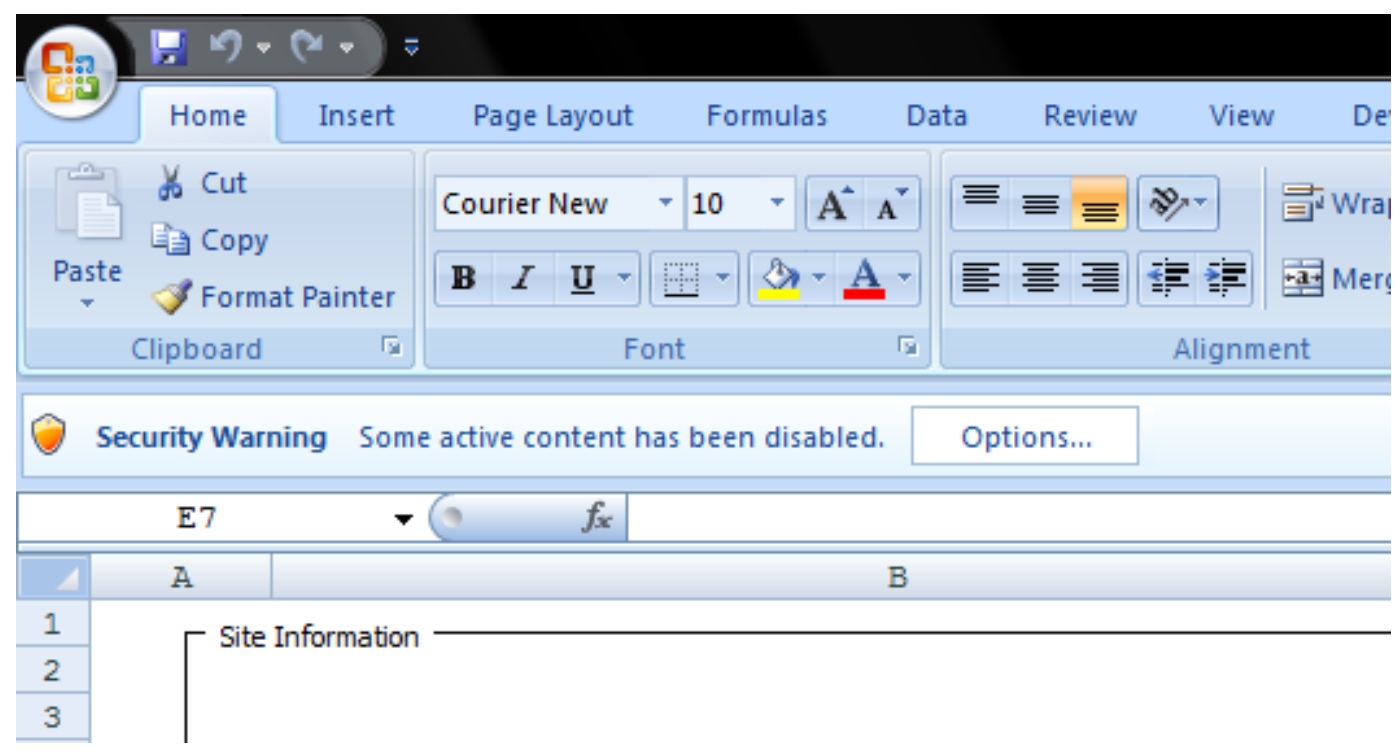


Figure 3. Activating macros in an Excel spreadsheet.

\section{Module 1: General Information}

General site information is supplied to the design aid by using the general information module, site.xlsm. Figure 4 shows the information that is required to operate this module. Because the site information will be different for each application, this module does not allow the user to use any default or test values for these input parameters. The values for the input parameters are specified by typing the data in the light violet boxes that correspond to the input parameters labeled in black. The module is executed by clicking the light blue box with the caption "Site Information". As shown in Figure 4, these boxes are on the Control worksheet. After the module has finished executing, an output worksheet in the spreadsheet entitled "Site Information" is created that contains the general site information parameters. If the module is executed when there is already a worksheet entitled "Site Information", then the old worksheet is deleted and the new information is placed in a new worksheet entitled "Site Information". If a worksheet is deleted during the operation of this module, the user will be asked to OK the deletion of the worksheet. Canceling the deletion of the worksheet will cause the overwriting of the data in the old worksheet and the creation of an empty blank worksheet.

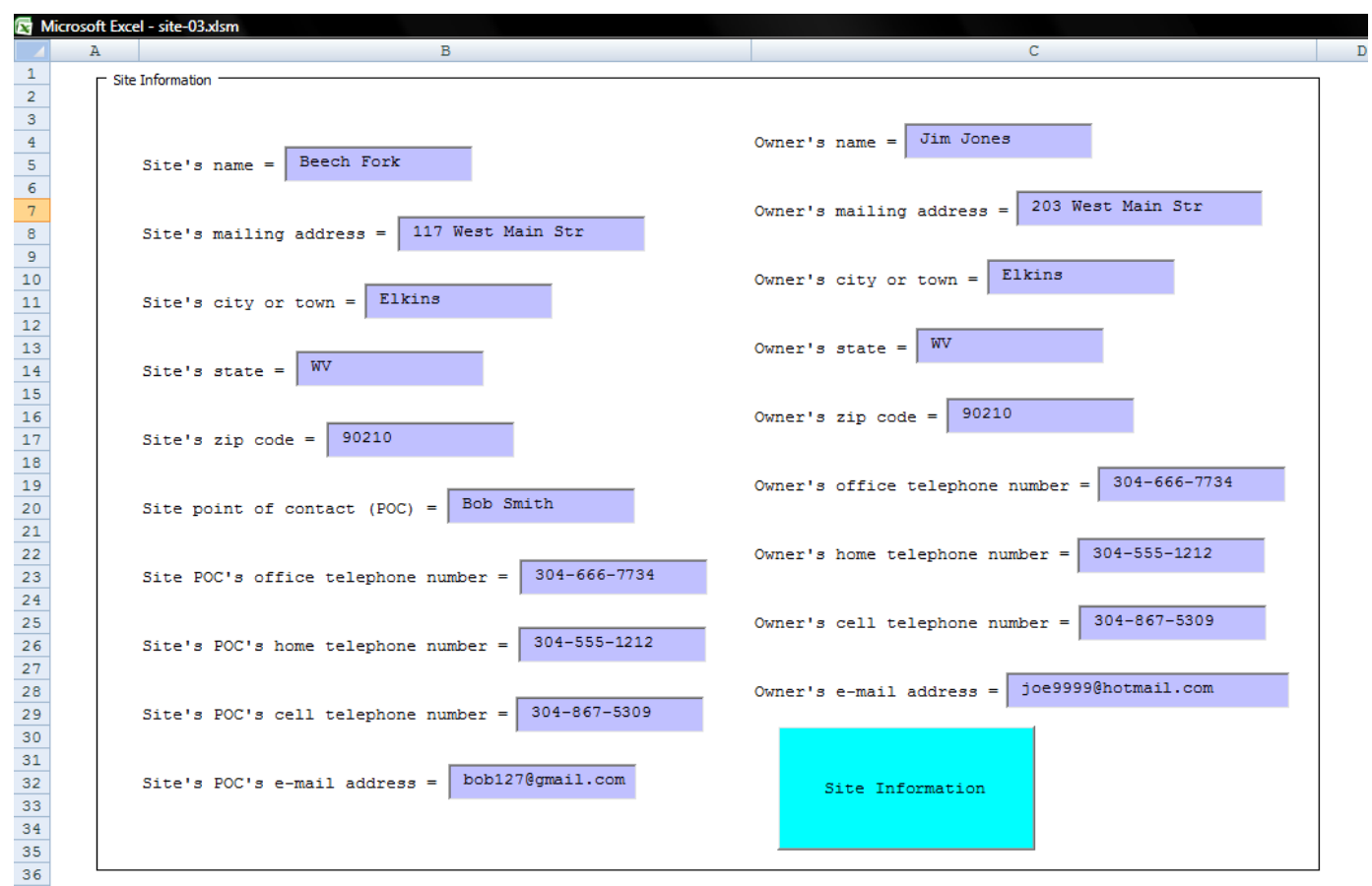


Figure 4. General Information Module Input Parameters.

\section{Module 2: Water Source}

The input parameters for the water source module of the design aid, source.xlsm, are shown in Figure 5. The first step in using this design module is to specify the name of the mine water source in the violet box labeled "Mine Water Source Name" on the Control worksheet. During the execution of this module, a new worksheet will be created with the title "S-" and the name of the mine water source. If a module is employed to specify the discharge flow rate and water quality of a source named "George", the output worksheet created by the module will be named "S-George". If the module is executed when there is already a worksheet with the same name as the new output worksheet, then the old worksheet is deleted and the new information is placed in a new worksheet entitled "Site Information". If a worksheet is deleted during the operation of this module, the user will be asked to OK the deletion of the worksheet. Canceling the deletion of the worksheet will cause the overwriting of the data in the old worksheet and the creation of an empty blank worksheet.

If a file containing the discharge flow rate data for the mine water source exists, then the checkbox entitled "Flow file exists" needs to be checked and the user will be asked to give the name of the flow file during the operation of the module using a Microsoft Windows open file procedure. If a flow file does not exist for this mine water source, then the checkbox should not be checked and the design discharge flow rate specified in the violet box labeled "Design Discharge Flowrate (gpm)". The flow file is a commadelimited file with the format given in Table 1. 


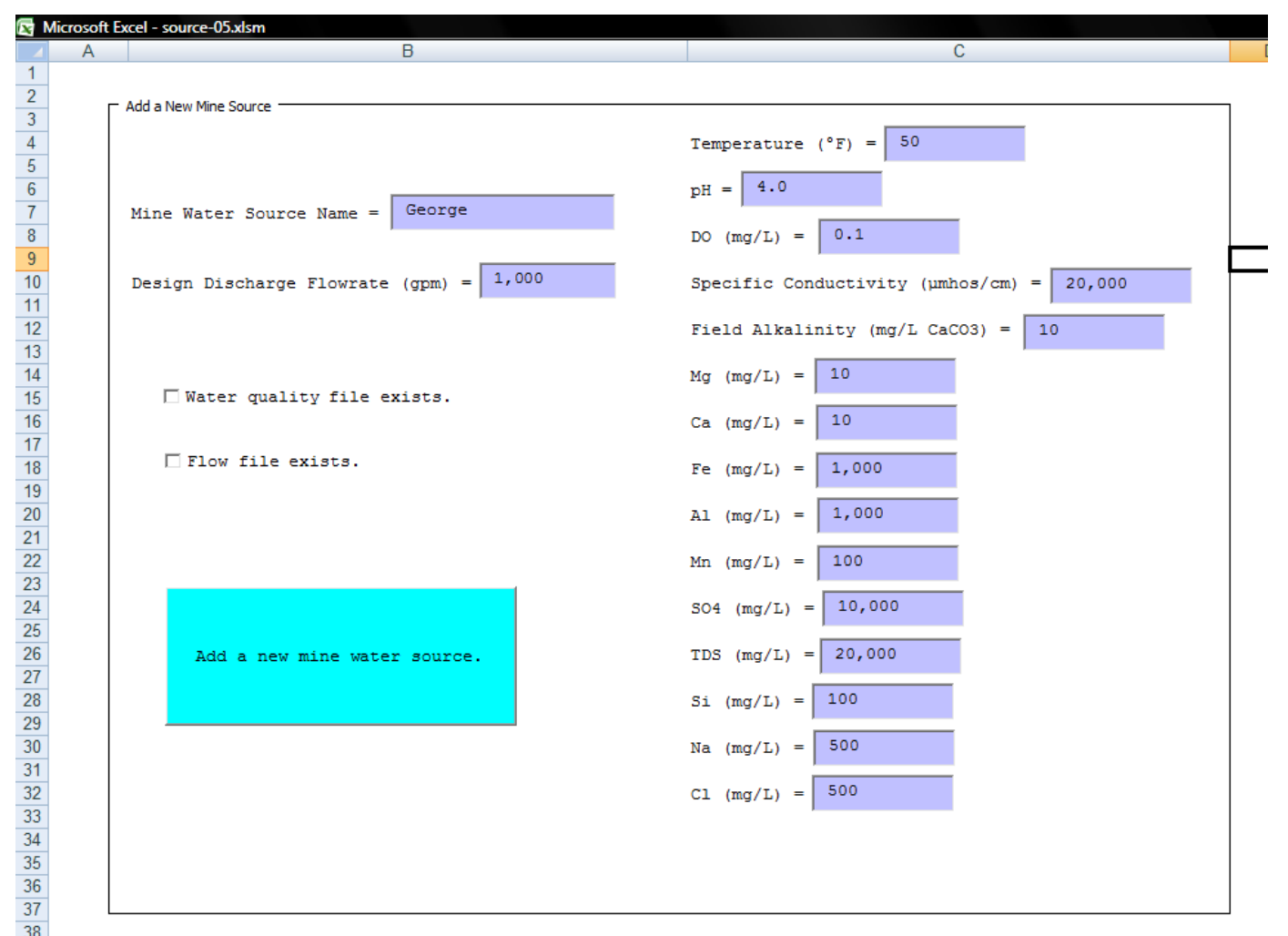

Figure 5. Water Source Module Input Parameters.

Table 1. Format of the mine water source flow file.

\begin{tabular}{|l|c|l|l|}
\hline \multicolumn{1}{|c|}{ Record } & \multicolumn{1}{|c|}{ Field } & \multicolumn{1}{c|}{ Description } & \multicolumn{1}{c|}{ Format } \\
\hline 1 & Ignored by the module. & MM/DD/YYYY HH:MM \\
\hline $2,3, \ldots, \mathrm{n}$ & 1 & Time & General \\
\cline { 2 - 4 } & 2 & Discharge Flow Rate in gpm & \multicolumn{2}{|c|}{} \\
\hline
\end{tabular}

If a water quality file for this mine water source exists, then the checkbox "Water quality file exists" must be checked and the module will ask for the name of the water quality file during the execution of the module. The format of this comma-delimited water quality file is given in Table 2. If a water quality file for this mine water source does not exist, then the water quality file checkbox should not be checked and the water quality parameters entered in the other violet boxes on the Control worksheet. If the water quality file does not exist, then the water quality parameters that must be entered include: temperature in ${ }^{\circ} \mathrm{F}, \mathrm{pH}$, dissolved oxygen concentration in $\mathrm{mg} / \mathrm{L}$, specific conductivity in $\mu \mathrm{mhos} / \mathrm{cm}$, field alkalinity in $\mathrm{mg} / \mathrm{L} \mathrm{CaCO} 3$ equivalents, magnesium concentration in $\mathrm{mg} / \mathrm{L}$, calcium concentration in $\mathrm{mg} / \mathrm{L}$, iron concentration in $\mathrm{mg} / \mathrm{L}$, 
aluminum concentration in $\mathrm{mg} / \mathrm{L}$, manganese concentration in $\mathrm{mg} / \mathrm{L}$, sulfate concentration in $\mathrm{mg} / \mathrm{L}$, total dissolved solids in $\mathrm{mg} / \mathrm{L}$, silicate concentration in $\mathrm{mg} / \mathrm{L}$, sodium concentration in $\mathrm{mg} / \mathrm{L}$, and chloride concentration in $\mathrm{mg} / \mathrm{L}$.

Table 2. Format of the mine water quality file.

\begin{tabular}{|c|c|c|c|}
\hline Record & Field & Description & Format \\
\hline 1 & \multicolumn{3}{|c|}{ Ignored by the module. } \\
\hline \multirow{20}{*}{$\begin{array}{l}2,3, \ldots, \\
n\end{array}$} & 1 & Station & Quoted String \\
\hline & 2 & Time & $\begin{array}{l}\text { MM/DD/YYYY } \\
\mathrm{HH}: M M\end{array}$ \\
\hline & 3 & Temperature in ${ }^{\circ} \mathrm{F}$ & \multirow{18}{*}{$\begin{array}{l}\text { General Numeric } \\
\text { Format }\end{array}$} \\
\hline & 4 & Field $\mathrm{pH}$ & \\
\hline & 5 & $\mathrm{DO}$ in $\mathrm{mg} / \mathrm{L}$ & \\
\hline & 6 & Conductivity in $\mu \mathrm{mhos} / \mathrm{cm}$ & \\
\hline & 7 & $\begin{array}{l}\text { Field alkalinity in } \mathrm{mg} / \mathrm{L} \mathrm{CaCO}_{3} \\
\text { equiv. }\end{array}$ & \\
\hline & 8 & Lab pH & \\
\hline & 9 & $\begin{array}{l}\text { Total acidity in } \mathrm{mg} / \mathrm{L} \mathrm{CaCO}_{3} \\
\text { equiv. }\end{array}$ & \\
\hline & 10 & $\begin{array}{l}\text { Lab alkalinity in } \mathrm{mg} / \mathrm{L} \mathrm{CaCO}_{3} \\
\text { equiv. }\end{array}$ & \\
\hline & 11 & Magnesium in $\mathrm{mg} / \mathrm{L}$ & \\
\hline & 12 & Calcium in $\mathrm{mg} / \mathrm{L}$ & \\
\hline & 13 & Iron in $\mathrm{mg} / \mathrm{L}$ & \\
\hline & 14 & Aluminum in $\mathrm{mg} / \mathrm{L}$ & \\
\hline & 15 & Manganese in $\mathrm{mg} / \mathrm{L}$ & \\
\hline & 16 & Sulfate in $\mathrm{mg} / \mathrm{L}$ & \\
\hline & 17 & Total Dissolved Solids in $\mathrm{mg} / \mathrm{L}$ & \\
\hline & 18 & Silicate in $\mathrm{mg} / \mathrm{L}$ & \\
\hline & 19 & Sodium in $\mathrm{mg} / \mathrm{L}$ & \\
\hline & 20 & Chloride in $\mathrm{mg} / \mathrm{L}$ & \\
\hline
\end{tabular}

\section{Module 3: Supply Pipeline}

Like the previous modules, the design input parameters for the Supply Pipeline module of the Design Aid, supply-pipeline.xlsm, are entered on the Control worksheet. The first part of this worksheet is shown in Figure 6, and the second part is shown in Figure 7. The first parameter to be specified is the path and file name of the mine water source 
module spreadsheet, source.xlsm. This file can either be specified by typing the complete path and file name in the long violet box at the top of the Control worksheet, or one can click the light blue box entitled, "Mine Water Source Spreadsheet". Clicking this box activates a Microsoft Windows procedure that allows the user to interactively select the proper file.

After specifying the mine water source spreadsheet, the user must specify the name of the pipeline in the violet box underneath the light blue "Mine Water Source Spreadsheet" box. During the execution of the module, a new output worksheet will be created with the name "P-" and the name of the pipeline. If a pipeline with the name "Main" is designed with this module, the output worksheet will be named "P-Main". If the module is executed when there is already a worksheet with the same name as the new output worksheet, then the old worksheet is deleted and the new information is placed in a new worksheet entitled "Site Information". If a worksheet is deleted during the operation of this module, the user will be asked to OK the deletion of the worksheet. Canceling the deletion of the worksheet will cause the overwriting of the data in the old worksheet and the creation of an empty blank worksheet.

The next parameters to be entered in the violet boxes on the left side of the Control worksheet are: name of the pipeline starting location, name of the pipeline ending location, source elevation in $\mathrm{ft}$, destination elevation in $\mathrm{ft}$, pipeline maximum elevation in $\mathrm{ft}$, length of the pipeline in $\mathrm{ft}$, elevation of the pump in $\mathrm{ft}$, elevation of the mine in $\mathrm{ft}$, number of mine water sources that contribute water that will flow through this pipeline (no more than 10 mine water sources per pipeline), name of each contributing mine water source, and discharge flow rate from each contributing mine water source in gpm.

The rest of the input parameters have default values that can be specified by clicking the "Use Default Values for these Parameters" checkbox that is at the top of the column on the right side and directly underneath the long violet box for the path and file name of the mine water source spreadsheet. If the user does not want to use the default values for any of these remaining parameters, then uncheck the checkbox and modify the remaining appropriate violet boxes. 


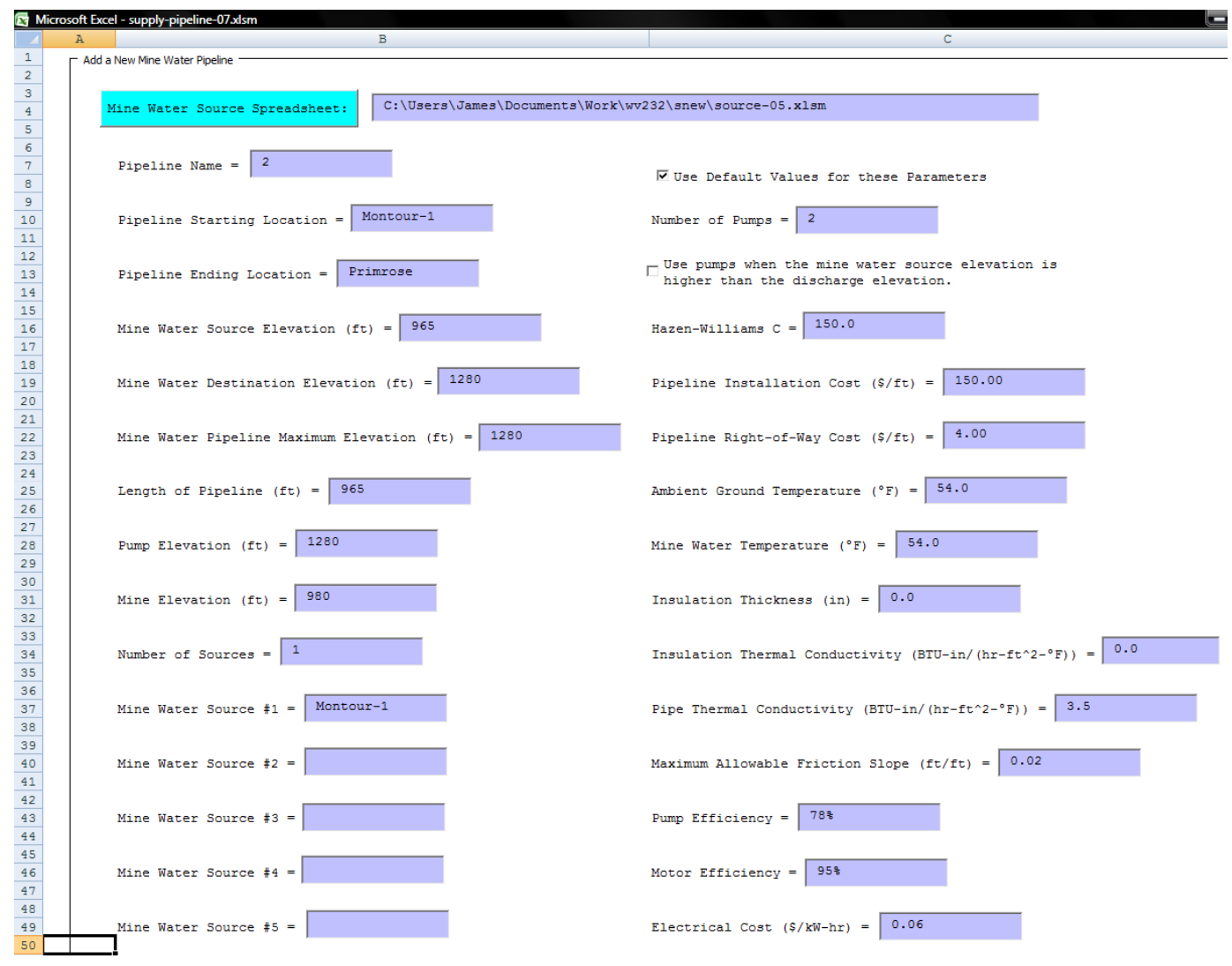

Figure 6. Supply Pipeline Module Input Parameters, Part 1.

The remaining input parameters with default values include: number of pumps, should pumps be designed when the mine water source is higher than the discharge elevation, Hazen-Williams $C$ of the pipeline, pipeline installation cost in $\$ / f t$, pipeline right-of-way cost in $\$ / \mathrm{ft}$, ambient ground temperature in ${ }^{\circ} \mathrm{F}$, mine water temperature in ${ }^{\circ} \mathrm{F}$, pipeline insulation thickness in inches, thermal conductivity of the pipeline insulation in BTUin $/ \mathrm{hr}-\mathrm{ft}^{2}-{ }^{\circ} \mathrm{F}$, thermal conductivity of the pipe itself, in $\mathrm{BTU}-\mathrm{in} / \mathrm{hr}-\mathrm{ft}^{2}-{ }^{\circ} \mathrm{F}$, maximum allowable friction slope in $\mathrm{ft} / \mathrm{ft}$, pump efficiency, motor efficiency, cost of electricity in $\$ / \mathrm{kW}$-hr, maintenance cost factor in $\$ / \mathrm{yr}$, annual discount rate in $1 / \mathrm{yr}$, expected pipeline longevity in yrs, maximum drawdown in $\mathrm{ft}$, pump capital cost estimation factor, $\$ / \mathrm{HP}$, pump drawdown factor in $\$ / \mathrm{ft}$, un-wetted column pipe factor in $\$ / \mathrm{ft}$, borehole factor in $\$ / \mathrm{ft}$, sump retention time in minutes, sump pump cost estimation factor, $\$ / \mathrm{HP}$, and sump factor, \$/gallon.

The module is executed by clicking the light blue box at the bottom of the right column with the title "Add a new mine water pipeline". 


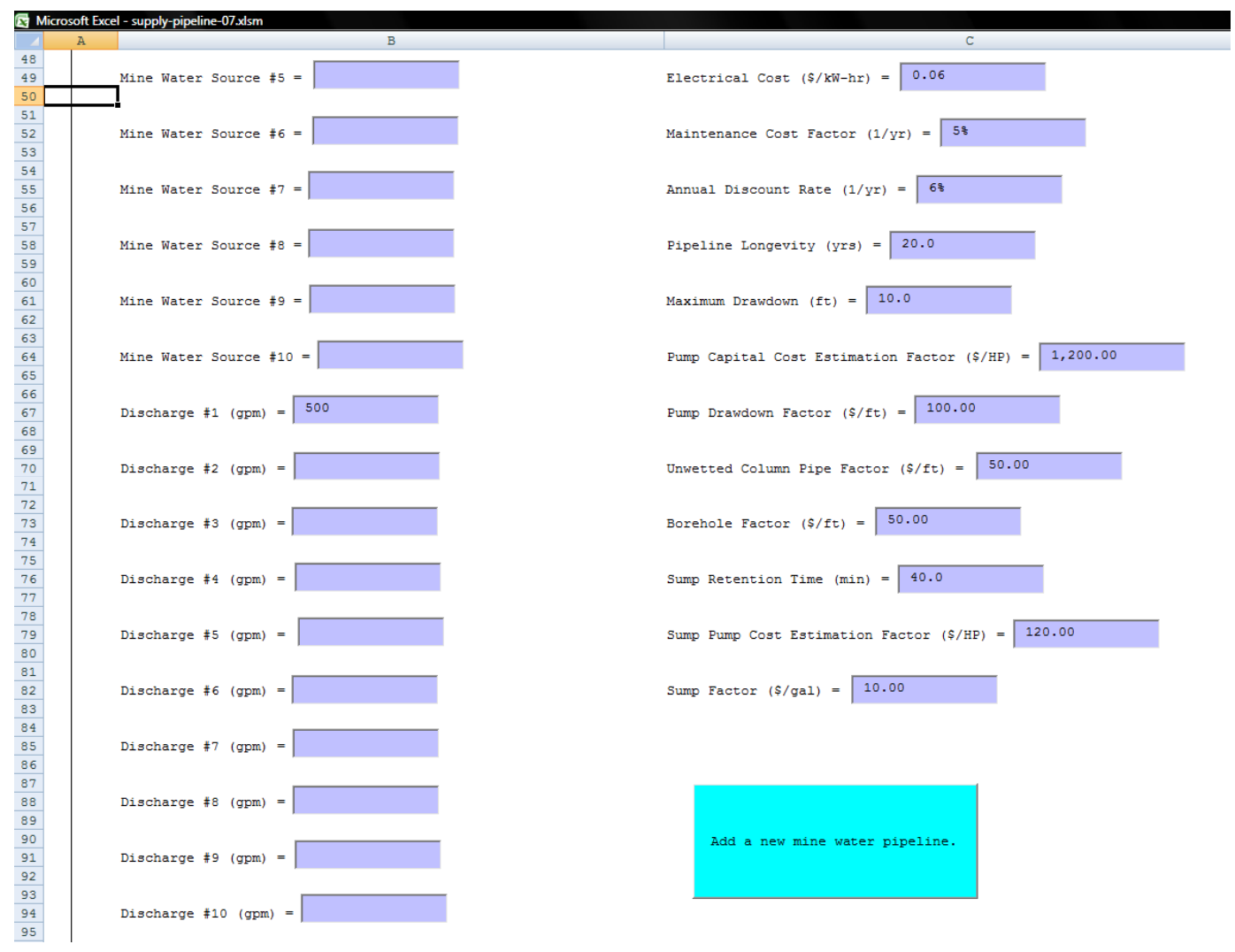

Figure 7. Supply Pipeline Module Input Parameters, Part 2.

\section{Module 4: Water Treatment}

Unlike the previous modules, the design input parameters for the Water Treatment module of the Design Aid, treatment-plant.xlsm, are entered on several worksheets. The input worksheets include: Control, Pre-Aeration, Mech-Aeration, Lime-Plant, SodaAsh, High-Density-Sludge, Peroxide, and Annual-Cost. These worksheets are shown in Figures 8 through 15. 


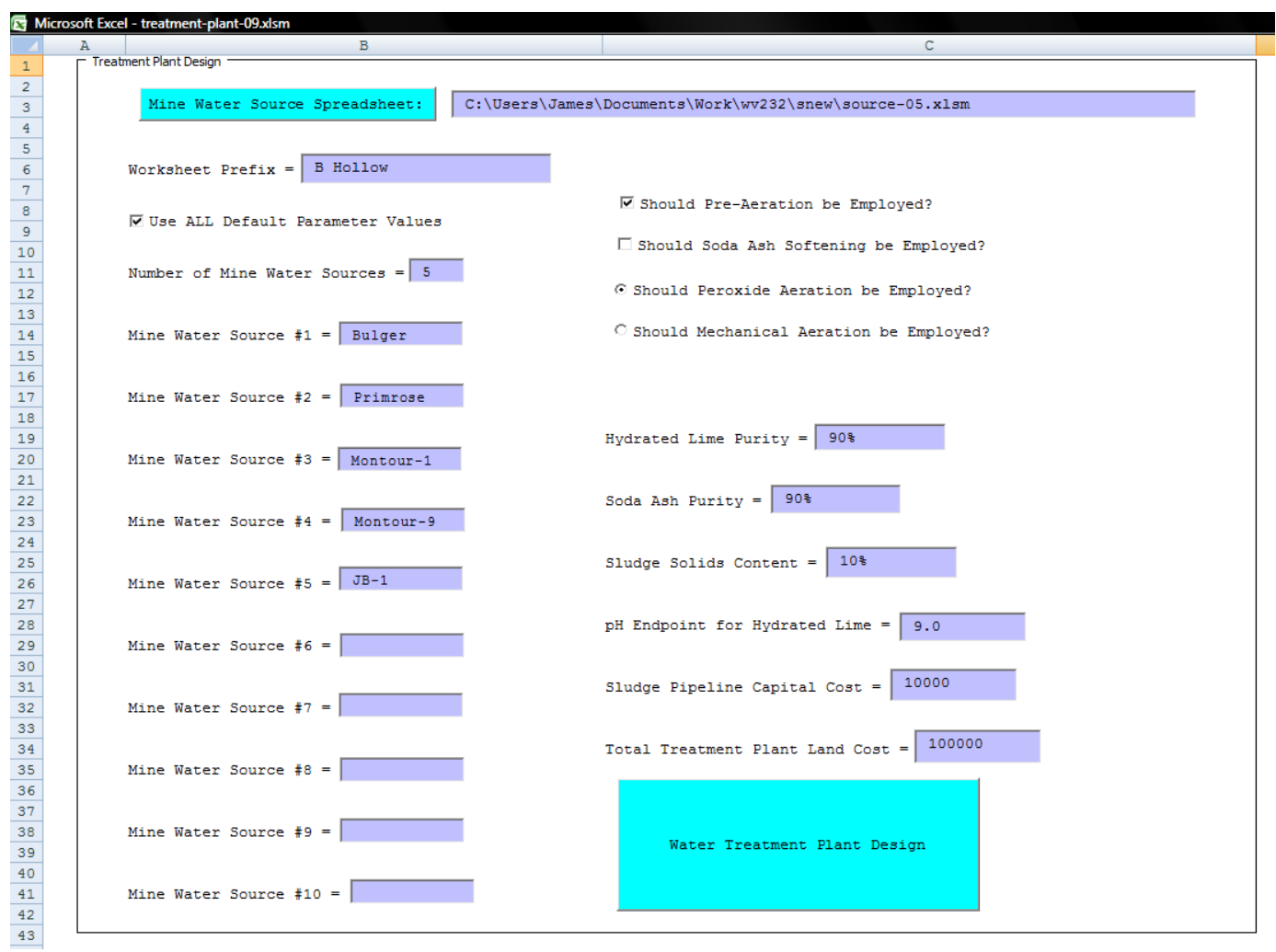

Figure 8. Control worksheet in the Water Treatment module of the design aid.

The first parameter to be specified is the path and file name of the mine water source module spreadsheet, source.xlsm. This file can either be specified by typing the complete path and file name in the long violet box at the top of the Control worksheet, or one can click the light blue box entitled, "Mine Water Source Spreadsheet". Clicking this box activates a Microsoft Windows procedure that allows the user to interactively select the proper file.

The second parameter is the worksheet prefix for the main output worksheet. When a worksheet prefix is not given, the main output worksheets will have the names Summary, Simulation, and Design. When the worksheet prefix is given, the names of the main output worksheets are the prefix plus a space plus Summary, Simulation, and Design.

The second input parameter on the left column of the Control worksheet consists of a checkbox that allows the user to use all of the default parameters on the Pre-Aeration, Mech-Aeration, Lime-Plant, Soda-Ash, High-Density-Sludge, Peroxide, and AnnualCost input worksheets. The next group of input parameters is the number of mine water sources contributing inflow to the treatment plant (no more than 10 mine water sources 
per treatment plant) and the name of each mine water source contributing inflow to the treatment plant.

On the right column of the Control worksheet, there are two checkboxes that allow the user to specify if pre-aeration will be employed at the treatment plant and if soda ash water softening will be used at the treatment plant. Following the two checkboxes, there are a pair of option boxes that allow the user to indicate if peroxide aeration or mechanical aeration will be employed. Because peroxide aeration and mechanical aeration are mutually exclusive, checking one option box un-checks the other box.

The next three input parameters, on the right column of the Control worksheet, are violet boxes for the hydrated lime purity, the soda ash purity, and the sludge solids content. These parameters may either be expressed as a percentage with the percent sign or as a fraction without the percent sign.

The final three parameters are: the $\mathrm{pH}$ endpoint for hydrated lime treatment, the capital cost of the sludge pipeline in $\$$, and the total capital cost of the land for the treatment plant in $\$$. The capital costs can be entered with commas to break up the thousands. The module is executed by clicking the light blue box at the bottom of the right column with the title "Water Treatment Plant Design".

The pre-aeration input design parameters are on the Pre-Aeration worksheet (Figure 9) and include: dissolved oxygen target in $\mathrm{mg} / \mathrm{L}$, low speed aeration rate in $\mathrm{lbs} / \mathrm{hr}$, first tank volume factor in $\mathrm{ft}^{3} / \mathrm{HP}$, second tank volume factor in $\mathrm{ft}^{3}$, tank height in $\mathrm{ft}$, tank freeboard in $\mathrm{ft}$, tank thickness in inches, concrete unit cost in $\$ / \mathrm{yd}^{3}$, first pre-aerator cost factor in $\$$, second pre-aerator cost factor in $\$$, third pre-aerator cost factor, pre-aerator design factor, and peroxide erection factor. 


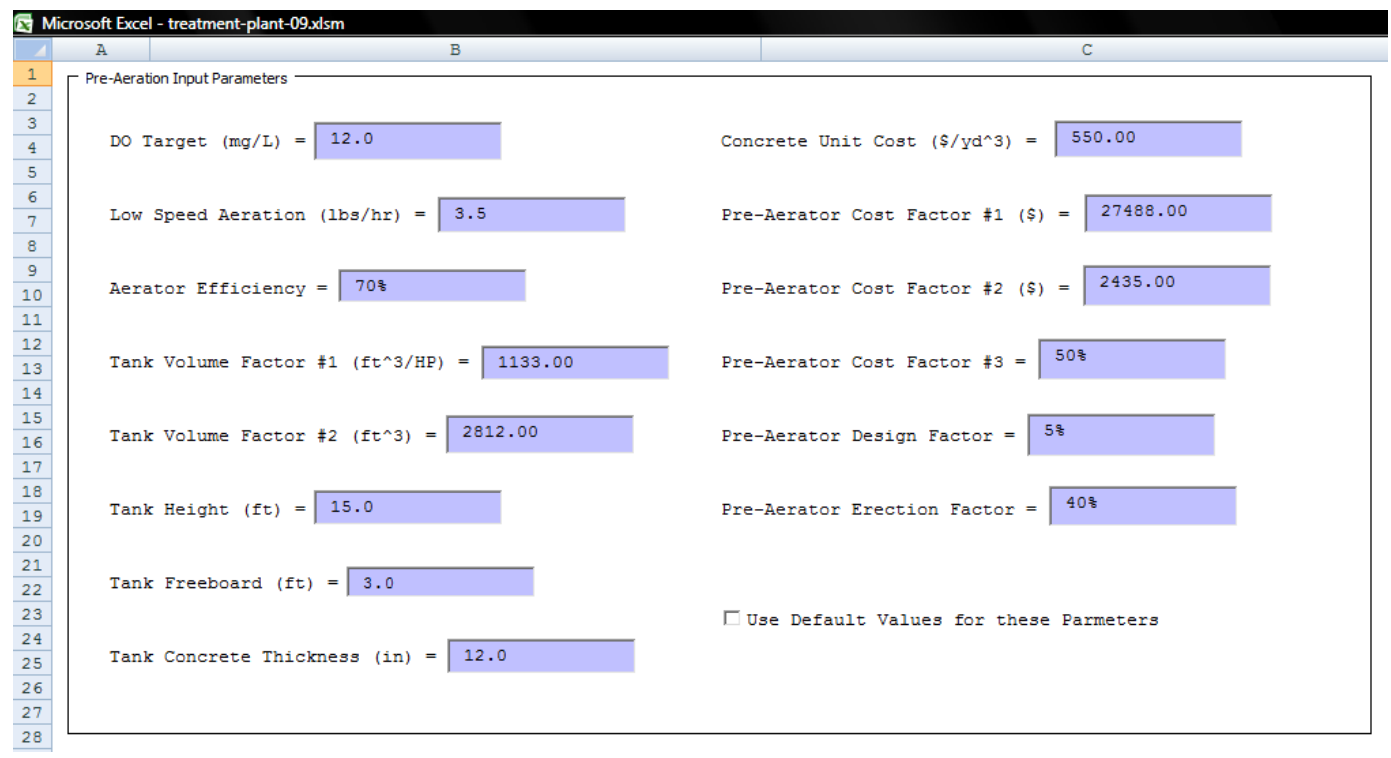

Figure 9. Pre-Aeration worksheet in the Water Treatment module of the design aid.

The default values for the pre-aeration design parameters can be used by checking the checkbox on the bottom of the Pre-Aeration worksheet entitled "Use Default Values for these Parameters". If the default values for any of these parameters are not to be used, then this checkbox needs to be unchecked, and the values in the appropriate textboxes modified.

The mechanical aeration input design parameters are on the Mech-Aeration worksheet (Figure 10) and include: aerator efficiency, low speed aeration rate in $\mathrm{lbs} / \mathrm{hr}$, first tank volume factor in $\mathrm{ft}^{3} / \mathrm{HP}$, second tank volume factor in $\mathrm{ft}^{3}$, tank height in $\mathrm{ft}$, tank freeboard in $\mathrm{ft}$, tank thickness in inches, concrete unit cost in $\$ / \mathrm{yd}^{3}$, first aerator factor in $\$$, second aerator cost factor in $\$$, excavation unit cost in $\$ / y d^{3}$, mechanical aeration erection factor, and mechanical aeration design factor.

The default values for the mechanical aeration design parameters can be used by checking the checkbox on the bottom of the Mech-Aeration worksheet entitled "Use Default Values for these Parameters". If the default values for any of these parameters are not to be used, then this checkbox needs to be unchecked, and the values in the appropriate textboxes modified. 


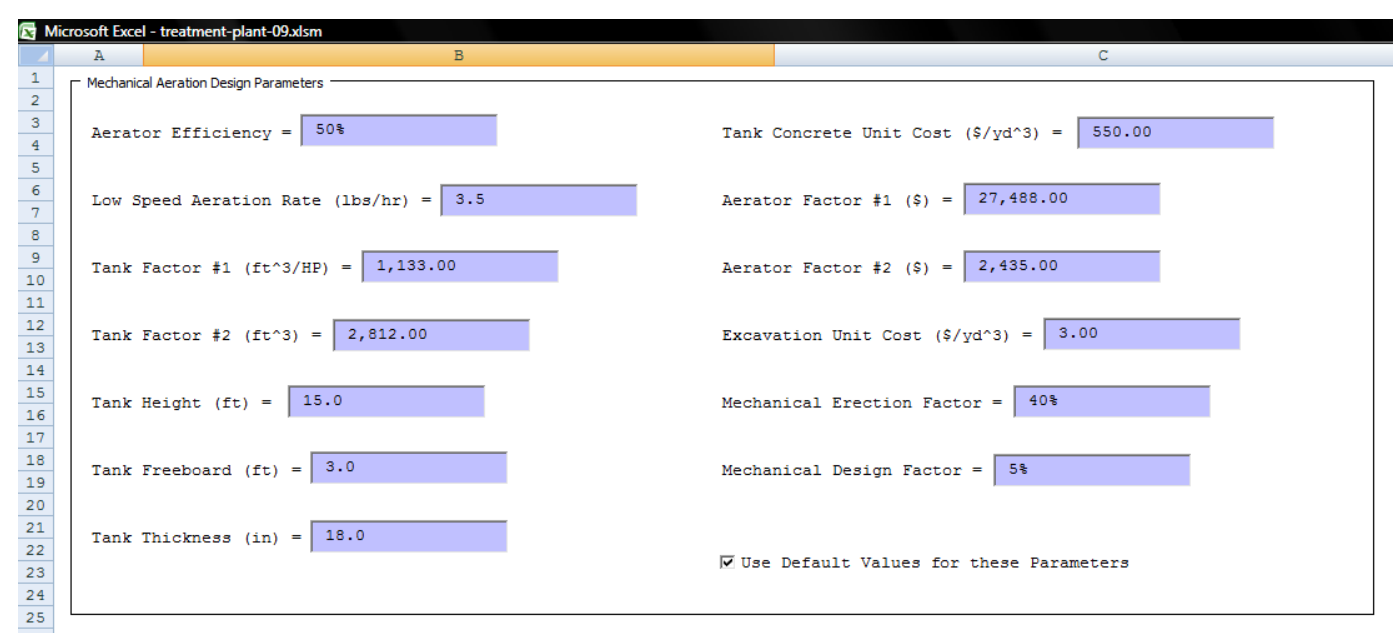

Figure 10. Mech-Aeration worksheet in the Water Treatment module of the design aid.

The lime plant input design parameters are on the Lime-Plant worksheet (Figure 11) and include: clarifier overflow rate in $\mathrm{gpm} / \mathrm{ft}^{2}$, clarifier cost factor in $\$ / \mathrm{ft}$, clarifier concrete thickness in inches, clarifier height in $\mathrm{ft}$, clarifier freeboard in $\mathrm{ft}$, clarifier concrete factor, concrete unit cost in $\$ / y d^{3}$, clarifier excavation unit cost in $\$ / y d^{3}$, lime silo cost in $\$$, lime live bottom cost in $\$$, lime feeder cost in $\$$, lime dust control system cost in $\$$, lime pH control cost in $\$$, lime mix tank cost in $\$$, lime mixer cost in $\$$, clarifier water pump cost in $\$$, control room cost in $\$$, polymer system cost in $\$$, sludge disposal pipe length in $\mathrm{ft}$, sludge disposal static head in ft, 6" sludge pipe unit cost in $\$ / \mathrm{ft}, 8$ " sludge pipe unit cost in $\$ / \mathrm{ft}$, sludge pump cost in $\$$, sludge injection overburden in $\mathrm{ft}$, sludge well construction depth in $\mathrm{ft}$, sludge injection well cost rate in $\$ / \mathrm{ft}^{2}$, sludge miscellaneous steel cost factor, lime plant erection factor, and lime plant design factor.

The default values for the lime plant design parameters can be used by checking the checkbox on the bottom of the Lime-Plant worksheet entitled "Use Default Values for these Parameters". If the default values for any of these parameters are not to be used, then this checkbox needs to be unchecked, and the values in the appropriate textboxes modified. 


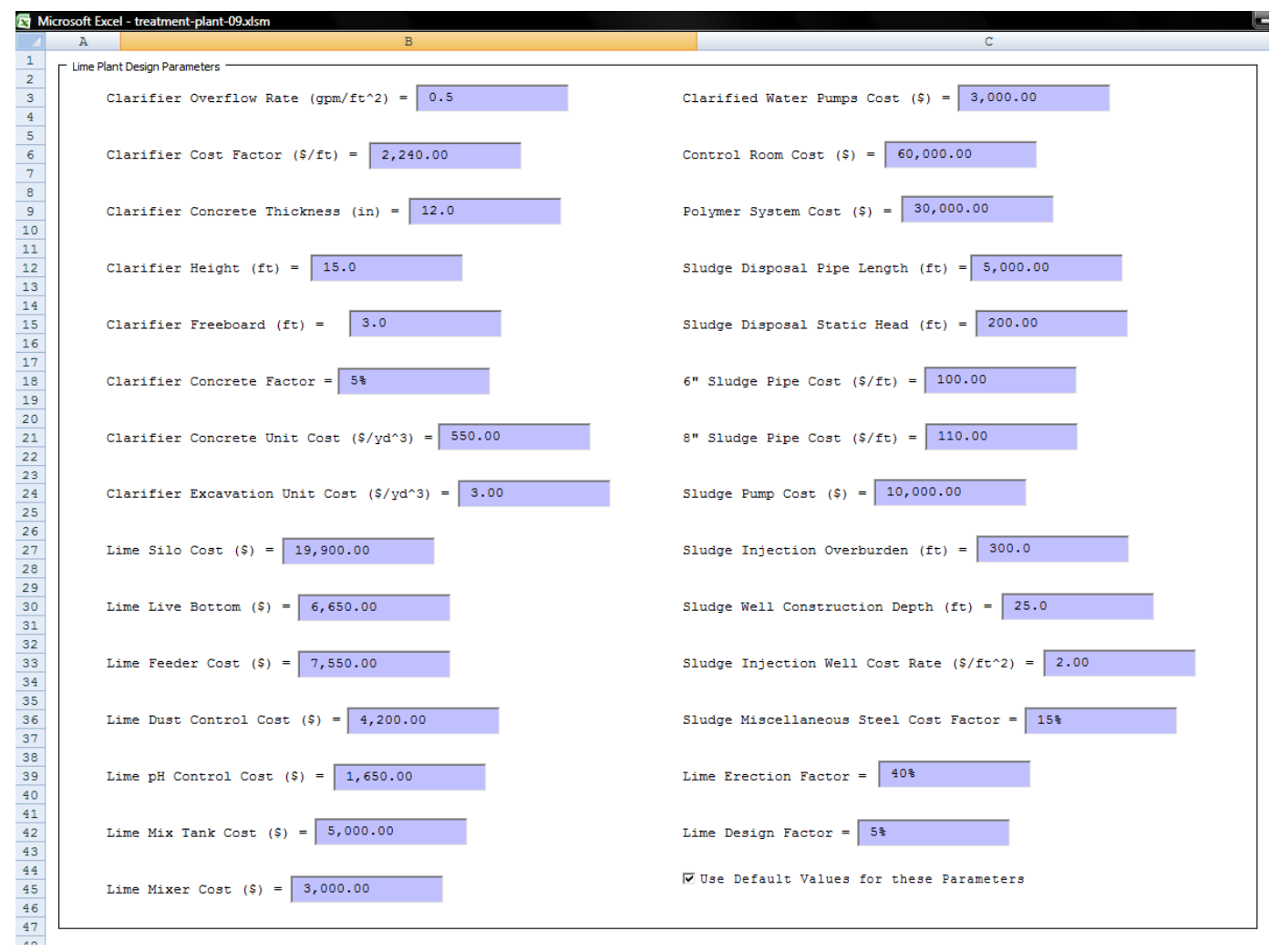

Figure 11. Lime-Plant worksheet in the Water Treatment module of the design aid.

The soda ash input design parameters are on the Soda-Ash worksheet (Figure 12) and include: soda silo cost in $\$$, soda live bottom cost in $\$$, soda lime feeder cost in $\$$, soda dust collector cost in $\$$, soda $\mathrm{pH}$ control cost in $\$$, soda mix tank cost in $\$$, soda mixer cost in $\$$, soda erection factor, and soda design factor.

The default values for the soda ash design parameters can be used by checking the checkbox on the bottom of the Soda-Ash worksheet entitled "Use Default Values for these Parameters". If the default values for any of these parameters are not to be used, then this checkbox needs to be unchecked, and the values in the appropriate textboxes modified. 


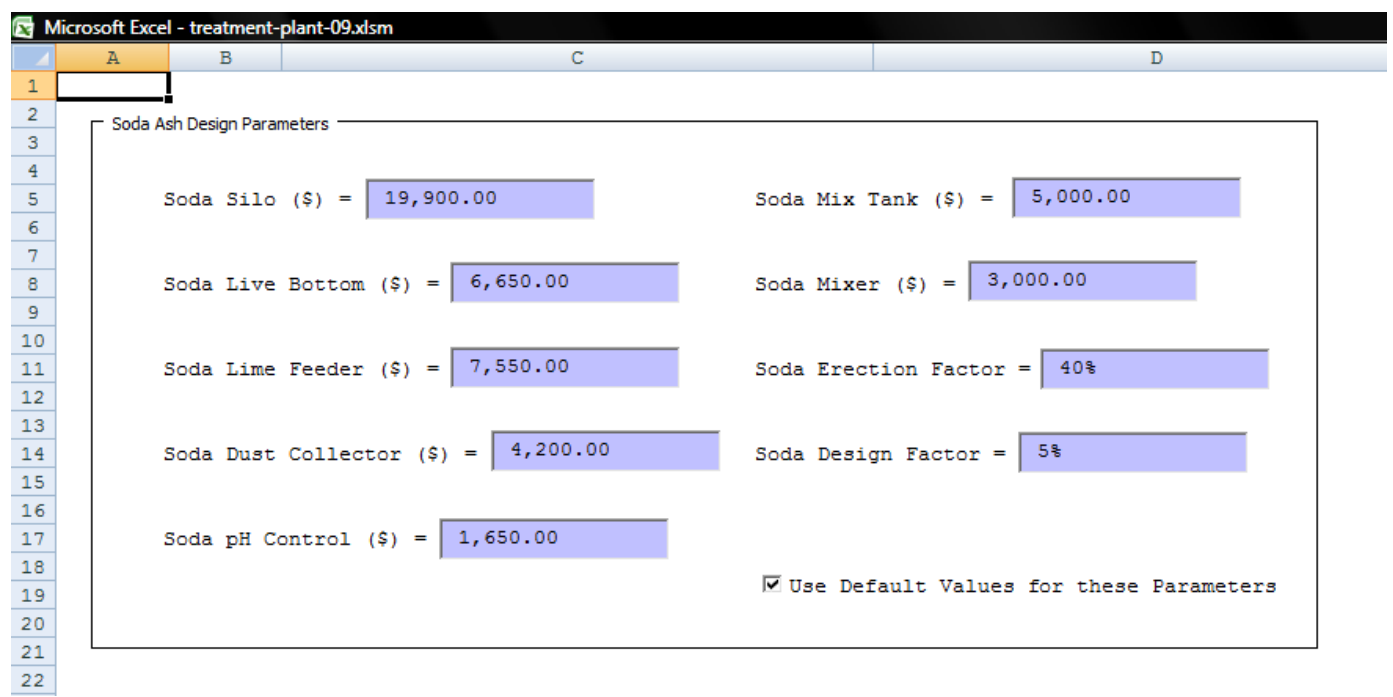

Figure 12. Soda-Ash worksheet in the Water Treatment module of the design aid.

The high density sludge input design parameters are on the High-Density-Sludge worksheet (Figure 13) and include: conditioning tank recirculation flow ratio, conditioning tank residence time in minutes, conditioning tank freeboard in $\mathrm{ft}$, conditioning tank depth in $\mathrm{ft}$, conditioning tank thickness in inches, concrete unit cost in $\$ / \mathrm{yd}^{3}$, recirculation total dynamic head in $\mathrm{ft}$, number of recirculation pumps, recirculation pipe length in $\mathrm{ft}$, recirculation pipe unit cost in $\$ / \mathrm{ft}$, recirculation pump unit cost in $\$ /$ pump, cost of recirculation controls in $\$$, high density sludge erection factor, and high density sludge design factor.

The default values for the high density sludge design parameters can be used by checking the checkbox on the bottom of the High-Density-Sludge worksheet entitled "Use Default Values for these Parameters". If the default values for any of these parameters are not to be used, then this checkbox needs to be unchecked, and the values in the appropriate textboxes modified. 


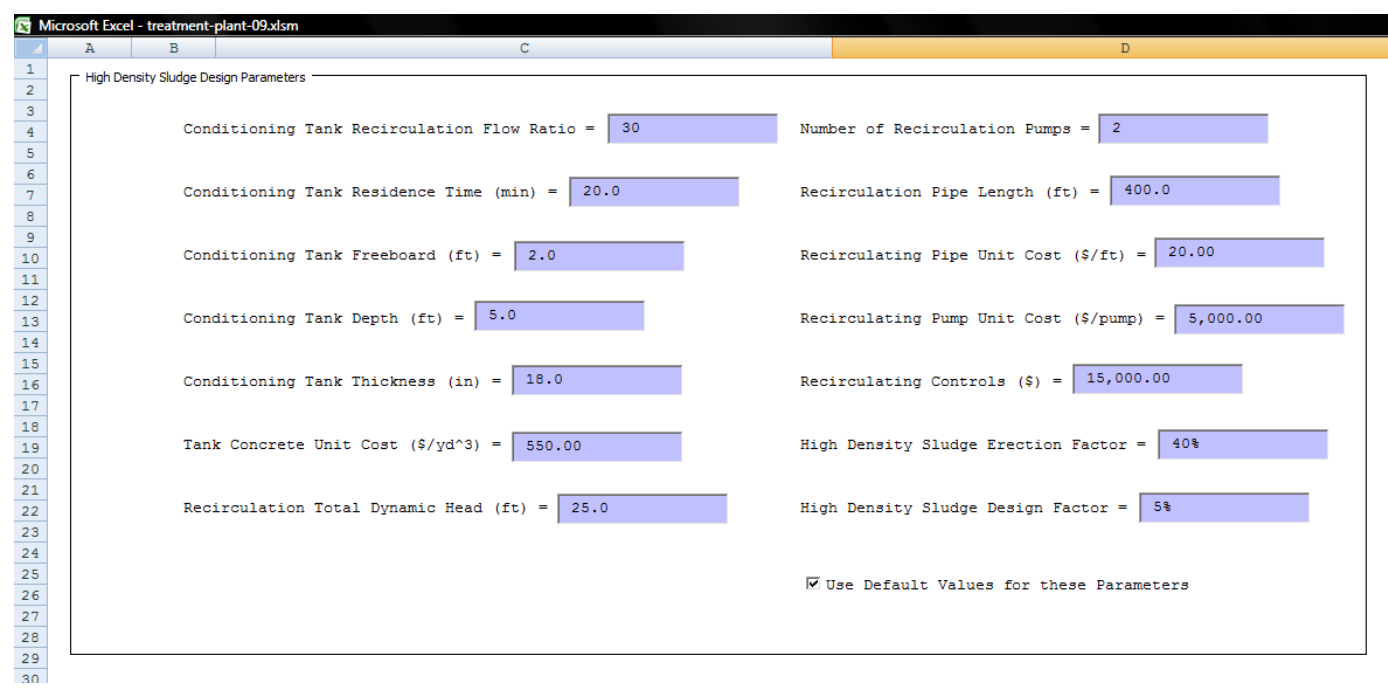

Figure 13. High-Density-Sludge worksheet in the Water Treatment module of the design aid.

The peroxide aeration input design parameters are on the Peroxide worksheet (Figure 14) and include: peroxide dosing rate, peroxide delivery schedule in days, peroxide tank design factor, peroxide building unit cost in $\$ / \mathrm{ft}^{2}$, peroxide tank detention time in minutes, peroxide tank height in $\mathrm{ft}$, peroxide tank freeboard in $\mathrm{ft}$, peroxide tank thickness in inches, concrete unit cost in $\$ / \mathrm{yd}^{3}$, first peroxide mixer factor in $\$ / \mathrm{ft}^{6}$, second peroxide mixer factor in $\$ / \mathrm{ft}^{3}$, third peroxide mixer factor in $\$$, excavation unit cost in $\$ / \mathrm{yd}^{3}$, peroxide erection factor, and peroxide design factor.

The default values for the peroxide aeration design parameters can be used by checking the checkbox on the bottom of the Peroxide worksheet entitled "Use Default Values for these Parameters". If the default values for any of these parameters are not to be used, then this checkbox needs to be unchecked, and the values in the appropriate textboxes modified. 


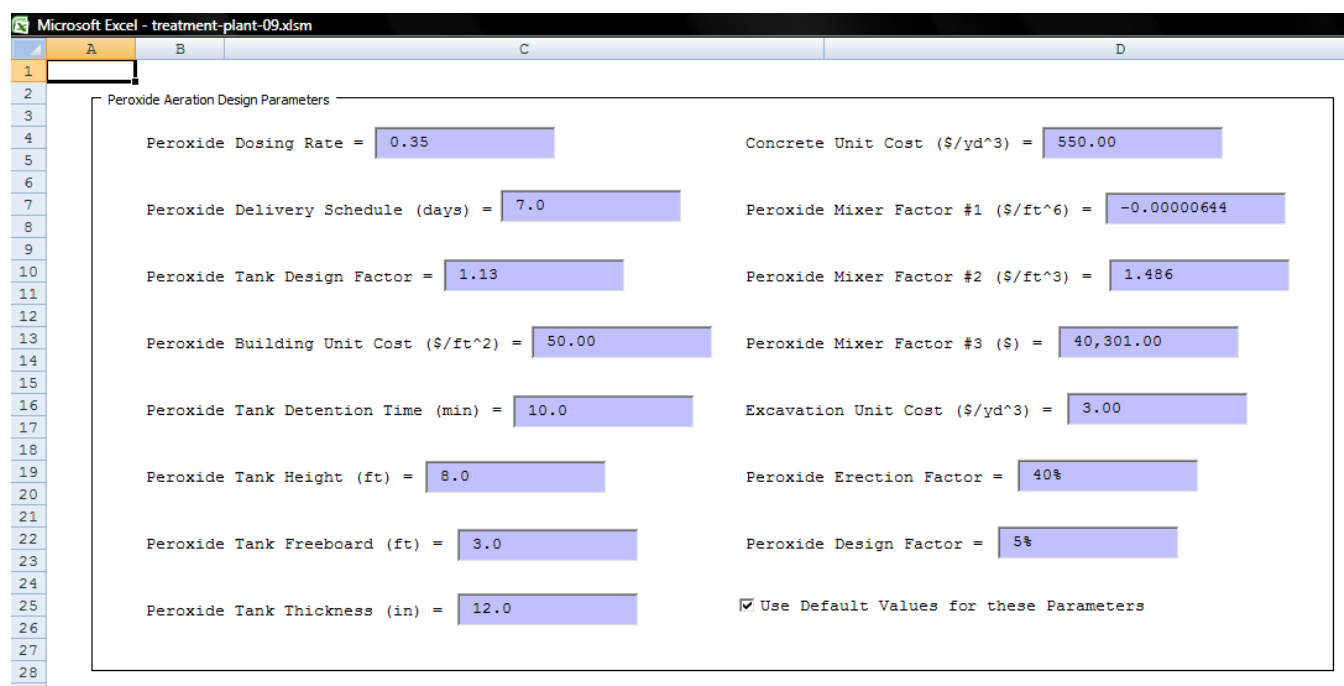

Figure 14. Peroxide worksheet in the Water Treatment module of the design aid.

The annual cost input design parameters are on the Annual-Cost worksheet (Figure 15) and include: work week in hrs/week, hourly rate in $\$ / \mathrm{hr}$, vacation time in weeks/yr, benefit rate, electricity unit cost in $\$ / \mathrm{kW}-\mathrm{hr}$, sludge pipeline repair rate in $1 / \mathrm{yr}$, vertical turbine repair rate in $1 / \mathrm{yr}$, high aerator repair rate in $1 / \mathrm{yr}$, low aerator repair rate in $1 / \mathrm{yr}$, clarifier repair rate in 1/yr, appraisal rate, millage, insurance rate, repayment period, yrs, and annual interest rate in $1 / y r$.

The default values for the annual cost design parameters can be used by checking the checkbox on the bottom of the Annual-Cost worksheet entitled "Use Default Values for these Parameters". If the default values for any of these parameters are not to be used, then this checkbox needs to be unchecked, and the values in the appropriate textboxes modified. 


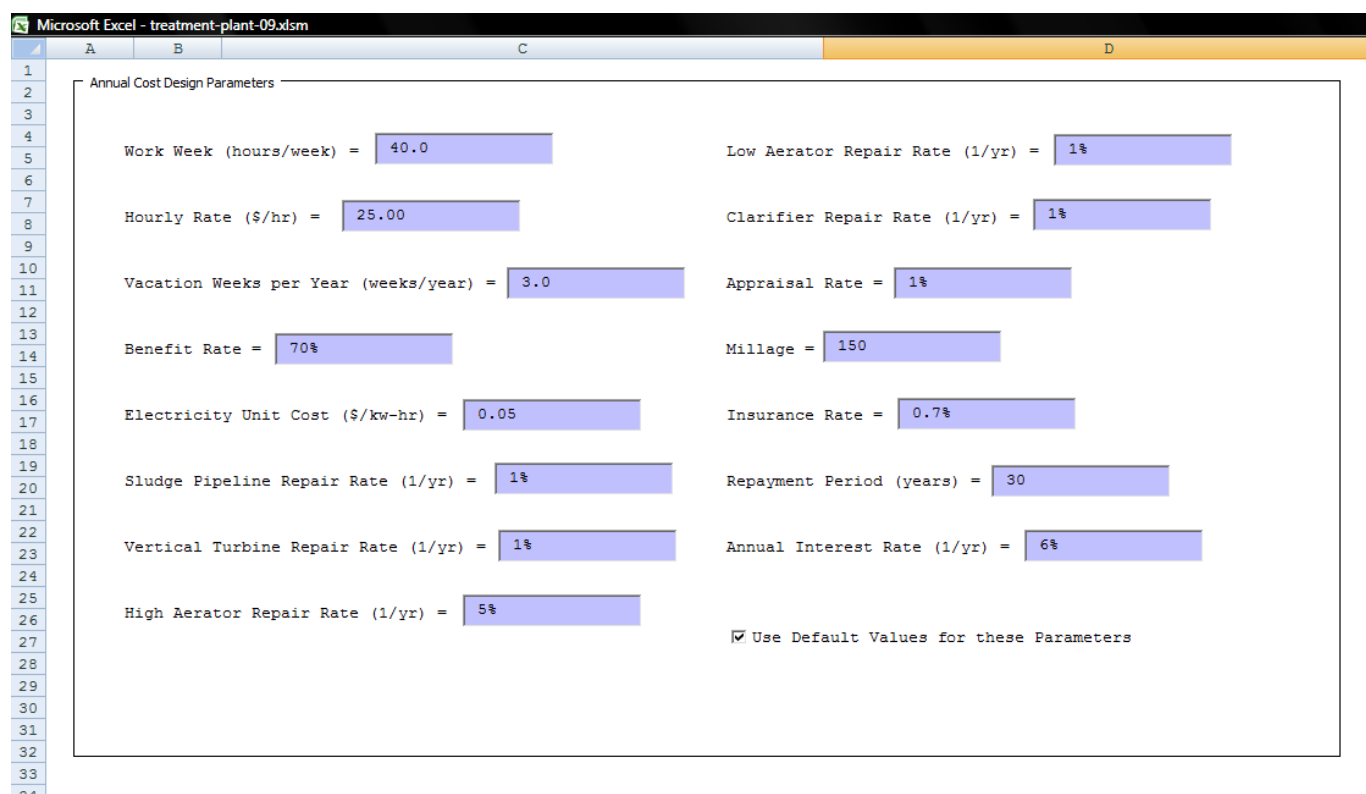

Figure 15. Annual-Cost worksheet in the Water Treatment module of the design aid.

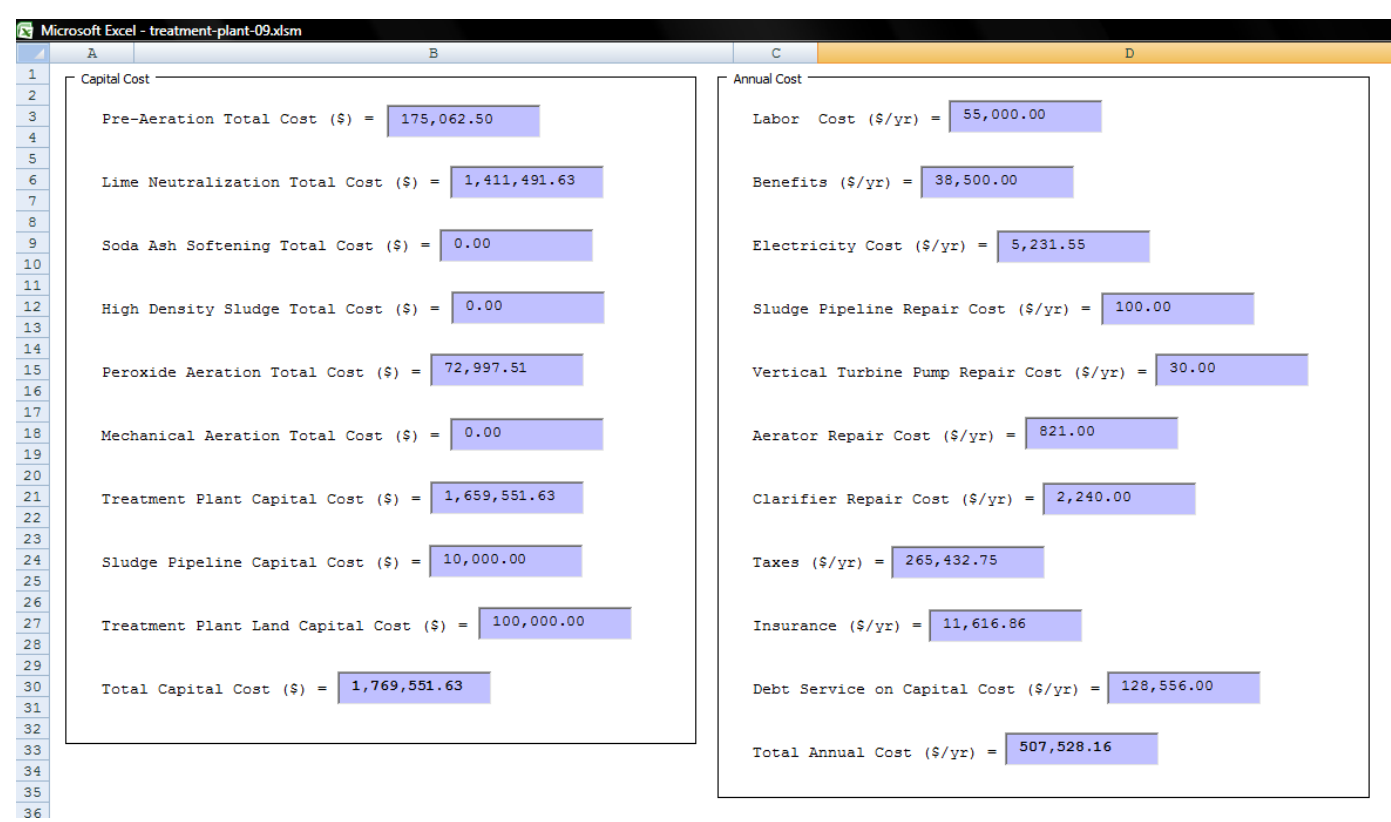

Figure 16. Cost output worksheet in the Water Treatment module of the design aid.

After the execution of the treatment plant design aid, the basic capital and annual costs are summarized on the Cost worksheet. A copy of the Cost worksheet created by an execution of the design module is shown in Figure 16. 


\section{Module 5: Thermal Efficiency}

The design input parameters for the Thermal Efficiency module of the Design Aid, water-cooling.xlsm, are entered on four worksheets: Control, EP-COAL, TGPC-CTPC, and Alternative-Water. These worksheets are shown in Figures 17 through 20.

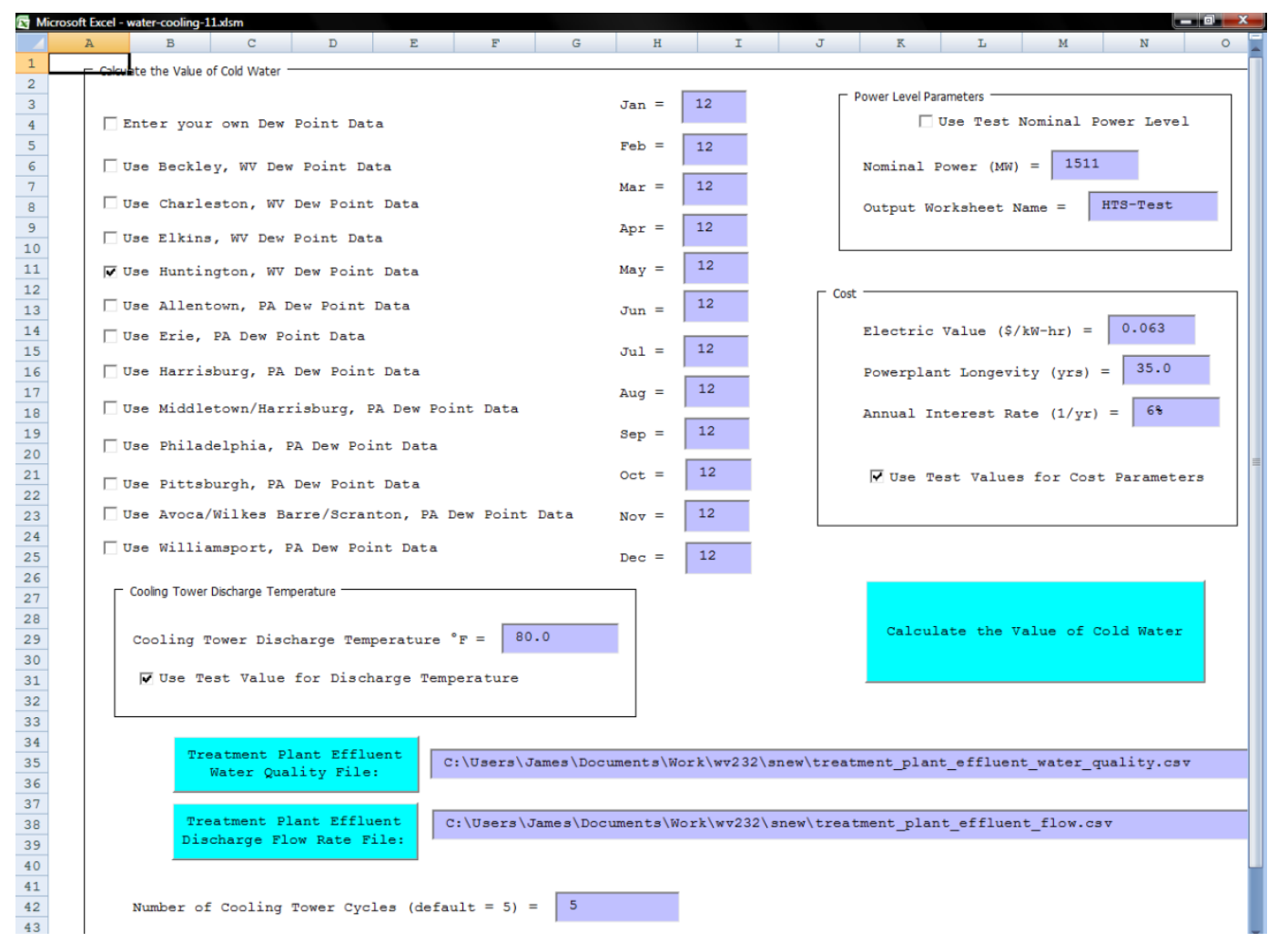

Figure 17. Control worksheet of the Thermal Efficiency Module.

The first parameters to be entered are the path and file names of the treatment plant effluent and discharge flow rate files. These files were created during the operation of the treatment plant module of the design aid and the file and path names were assigned by the user while the module was running. The path and file names are specified by the user for this module by clicking on the two light blue boxes entitled "Treatment Plant Effluent Water Quality File" and "Treatment Plant Effluent Discharge Flow Rate File". The second parameter to be entered on this worksheet is the number of cooling tower cycles. The violet textbox for this parameter is located beneath the textboxes for the path and file names for the aforementioned input data files.

The next set of parameters to be entered on the Control worksheet is the dew point data. If the power plant site is near one of the specified NWS stations, check the 
appropriate checkbox for that weather station. The specified weather stations are: Beckley, Charleston, Elkins, Huntington, Allentown, Erie, Harrisburg, Middletown, Philadelphia, Pittsburgh, Wilkes-Barre, and Williamsport. If the power plant is not near one of these stations, then the user can specify the mean dew point temperature at the site for each of the twelve months in a year.

The cooling tower discharge temperature in ${ }^{\circ} \mathrm{F}$ is specified in a textbox beneath the dew point data boxes. While this parameter will be different for different cooling tower designs, the user is allowed to specify that a test value for this parameter be used so as to check the module's results against the results of test calculations that were performed during the testing process.

The nominal power output from the power plant in MW is specified in a textbox on the upper right side of the worksheet. While this parameter will be different for different power plant designs, the user is allowed to specify that a test value for this parameter be used so as to check the module's results against the results of test calculations that were performed during the testing process. The name of the output worksheet to be created by the module is specified in a textbox that is directly underneath the nominal power textbox. If a worksheet with the specified name already exists when the module is executed, the user will be asked to OK the deletion of the old worksheet. If the user does not OK the deletion of the old worksheet, then the new data is written on the old worksheet, and a blank worksheet is added to the spreadsheet.

The cost parameters are specified in textboxes that are beneath the nominal power and output worksheet name textboxes. The cost parameters for the thermal efficiency design module are electric value in $\$ / \mathrm{kW}$-hr, power plant longevity in years, and annual interest rate in $1 / y r$. While these parameters will be different for different sites, the user is allowed to specify that test values for these parameters be used so as to check the module's results against the results of test calculations that were performed during the testing process.

The module is executed by clicking the light blue box entitled "Calculate the Value of Cold Water", which is located underneath the textboxes of the cost parameters and across from the textbox for the cooling tower discharge temperature. 


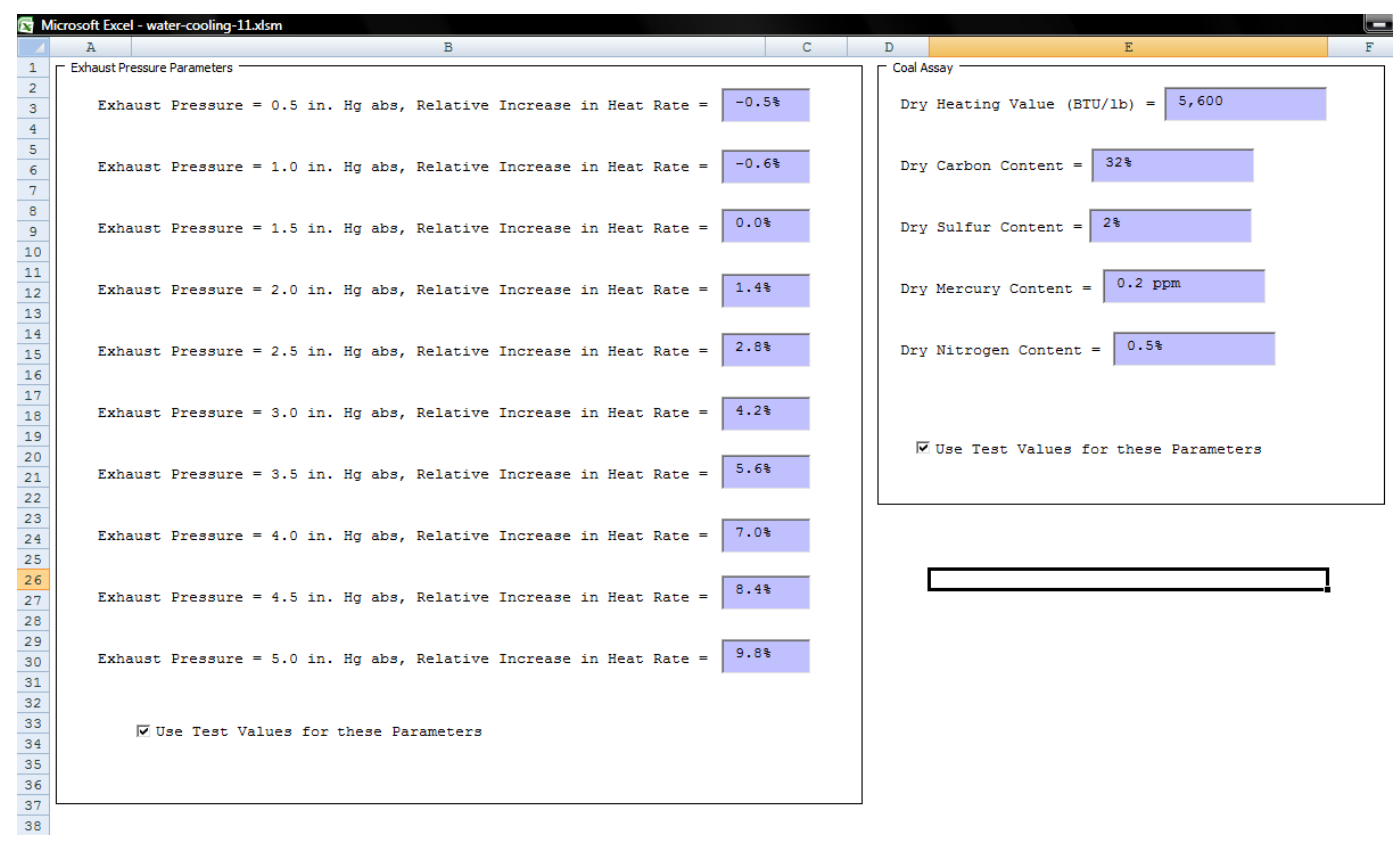

Figure 18. EP-COAL worksheet of the Thermal Efficiency Module.

The relative increases in heat rate for various levels of exhaust pressure are specified in a group of textboxes on the left side of the EP-COAL worksheet. While these parameters will be different for different steam turbine designs, the user is allowed to specify that test values for these parameters be used so as to check the module's results against the results of test calculations that were performed during the testing process.

The coal assay parameters are specified in a group of textboxes that are on the right side of the EP-COAL worksheet. The coal assay parameters are: dry heating value in BTU/lb, dry carbon mass content, dry sulfur mass content, dry mercury mass content, and dry nitrogen mass content. The mass contents can be expressed as either a fraction with neither a percent sign nor the suffix ppm, a percentage with a percent sign, or a parts per million using the suffix ppm. While these parameters will be different for different coals, the user is allowed to specify that test values for these parameters be used so as to check the module's results against the results of test calculations that were performed during the testing process. 


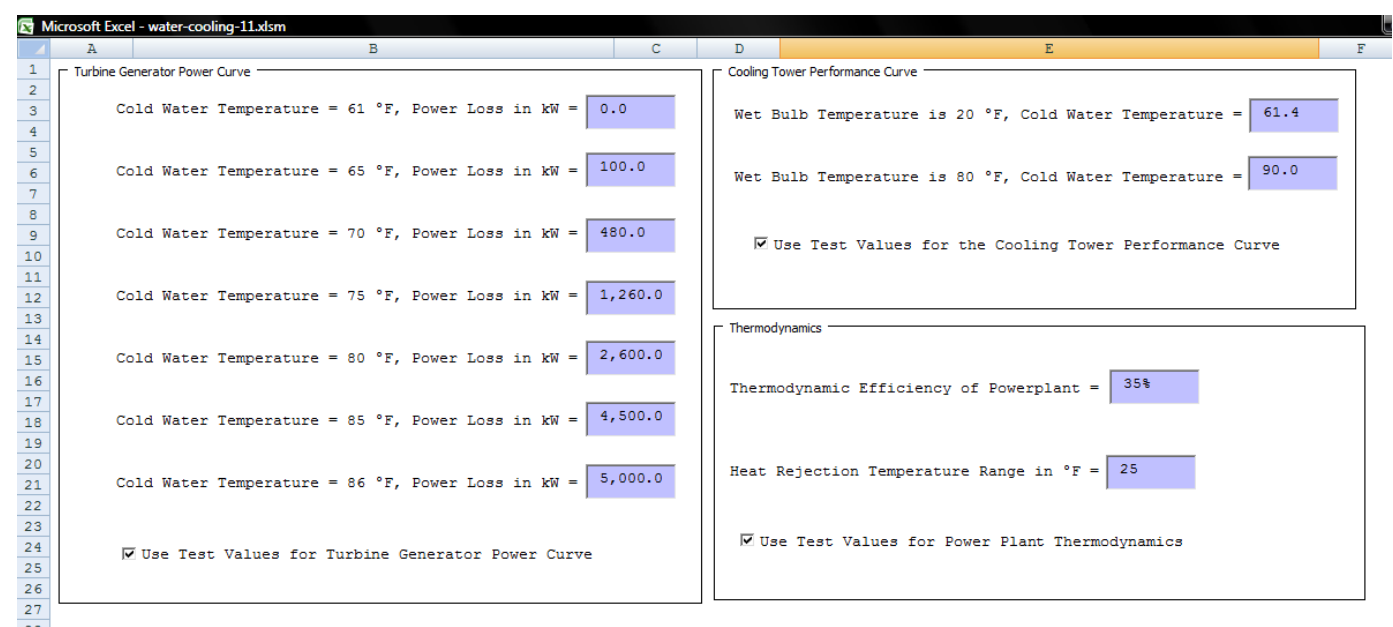

Figure 19. TGPC-CTPC worksheet of the Thermal Efficiency Module.

The turbine generator power curve parameters are specified in a group of textboxes that are on the left side of the TGPC-CTPC worksheet. These parameters consist of the power loss in $\mathrm{kW}$ at various cold water temperatures. While this curve will be different for different turbine designs, the user is allowed to specify that test values for these parameters be used so as to check the module's results against the results of test calculations that were performed during the testing process.

The cooling tower performance curve parameters are specified in a group of textboxes that are on the upper right side of the TGPC-CTPC worksheet. These parameters consist of the cold water temperature in ${ }^{\circ} \mathrm{F}$ for the wet bulb temperature at $20{ }^{\circ} \mathrm{F}$ and 80 ${ }^{\circ} \mathrm{F}$. While this curve will be different for different cooling tower designs, the user is allowed to specify that test values for these parameters be used so as to check the module's results against the results of test calculations that were performed during the testing process.

The thermodynamic parameters are specified in a pair of textboxes that are on the lower right side of the TGPC-CTPC worksheet (Figure 19). These parameters consist of the thermodynamic efficiency of the power plant and the heat rejection temperature range in ${ }^{\circ} \mathrm{F}$. While these parameters will be different for different power plant designs, the user is allowed to specify that test values for these parameters be used so as to check the module's results against the results of test calculations that were performed during the testing process. 


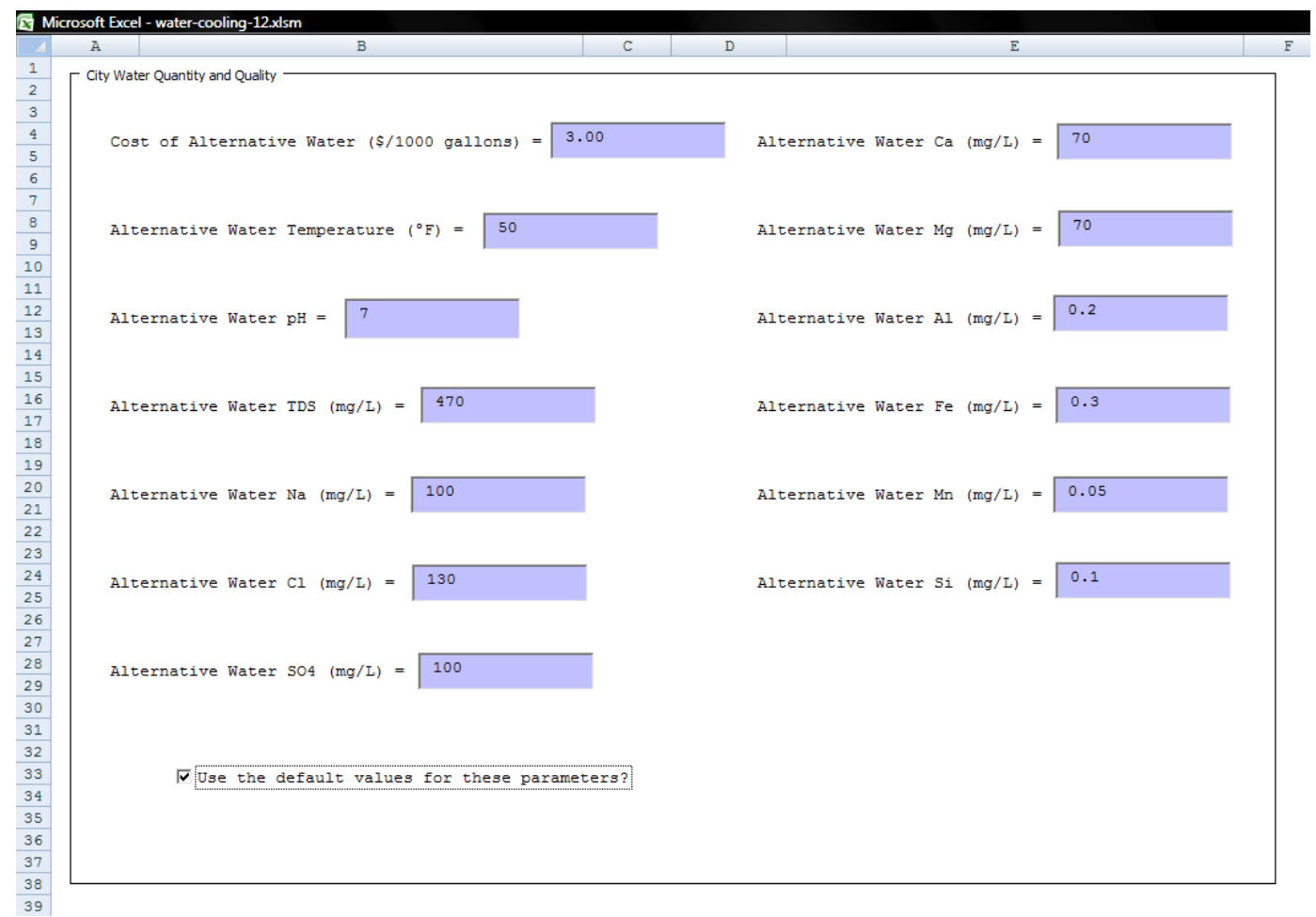

Figure 20. Alternative-Water worksheet of the Thermal Efficiency Module.

The alternative water source parameters are specified on the Alternative-Water worksheet. These parameters consist of: price of alternative water in \$/thousand gallons, alternative water temperature in ${ }^{\circ} \mathrm{F}$, alternative water $\mathrm{pH}$, alternative water TDS in $\mathrm{mg} / \mathrm{L}$, alternative water sodium concentration in $\mathrm{mg} / \mathrm{L}$, alternative water chloride concentration in $\mathrm{mg} / \mathrm{L}$, alternative water sulfate concentration in $\mathrm{mg} / \mathrm{L}$, alternative water calcium concentration in $\mathrm{mg} / \mathrm{L}$, alternative magnesium concentration in $\mathrm{mg} / \mathrm{L}$, alternative aluminum concentration in $\mathrm{mg} / \mathrm{L}$, alternative iron concentration in $\mathrm{mg} / \mathrm{L}$, alternative manganese concentration in $\mathrm{mg} / \mathrm{L}$, and alternative silicate concentration in $\mathrm{mg} / \mathrm{L}$. While these parameters will be different for each alternative water source, the user is allowed to specify that default values for these parameters be used so as to check the module's results against the results of test calculations that were performed during the testing process.

\section{Module 6: Integration}

The design input parameters for the Integration module of the Design Aid, summary.xlsm, are entered on the Control worksheet. This worksheet is shown in Figure 21. 


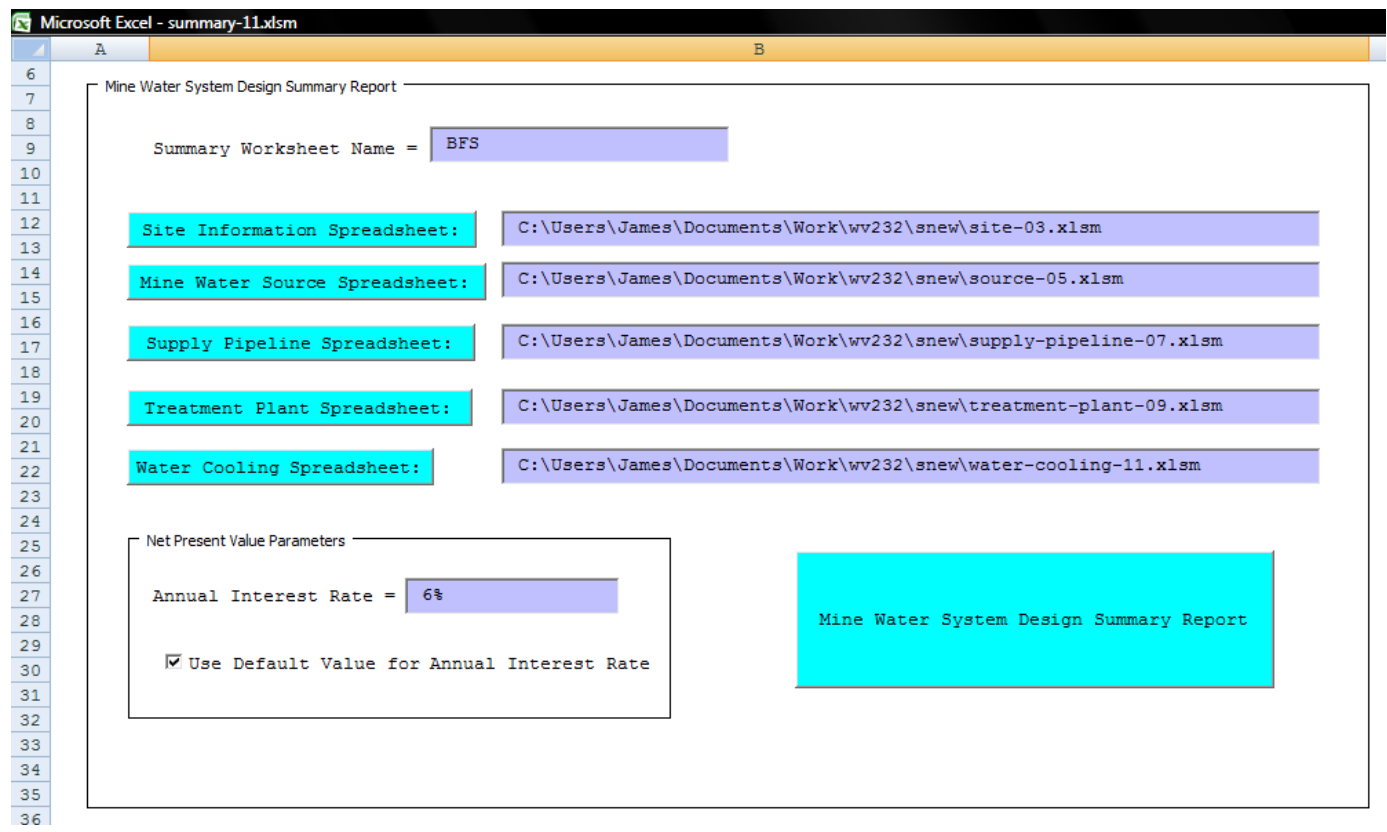

Figure 21. Control worksheet of the Integration Module.

The first parameter to be entered is the name of the output worksheet. This name is entered in the violet textbox at the top of the Control worksheet. If another worksheet with the same name is present in the spreadsheet, then the user will be prompted to OK the deletion of the old worksheet. If the user does not OK the deletion of the old worksheet, then the new information is written in the old worksheet and a blank worksheet is added to the integration module spreadsheet.

The second set of parameters to be entered on the Control worksheet are the full path and file names of the spreadsheets for the other design modules. The full path and file names of these spreadsheets are added by clicking the light blue boxes entitled: "Site Information Spreadsheet:", "Mine Water Source Spreadsheet:", "Supply Pipeline Spreadsheet:", "Treatment Plant Spreadsheet:", and "Water Cooling Spreadsheet:".

The final parameter to be entered on the Control worksheet is the annual interest rate. While this parameter will be different for different power plants, the user is allowed to specify that the default value for this parameter be used so as to check the module's results against the results of test calculations that were performed during the testing process.

The module is executed by clicking the light blue box entitled "Mine Water System Design Summary Report", which is located on the lower right side of the Control worksheet. 


\title{
Appendix B
}

\section{Mine Water Quality Data}

\author{
Depth DO Sp. Lab
}

Sample Site Date (in.) Temp (mglL) Cond Field pH Field Alk Lab pH acidity Cond alkalinity SO4 TDS Total Mg Total Ca Total Fe Total Al

\begin{tabular}{|c|c|c|c|c|c|c|c|c|c|c|c|c|c|c|c|c|}
\hline Hopper & 2.40 & 14.4 & 2.66 & 2081 & 6.00 & 370 & 5.68 & 0 & & 347.13 & 306.19 & 12426 & 73.48 & 215.16 & 30.01 & $<0.1$ \\
\hline $7 / 25107$ & 0.00 & & & & & & & & & & & & & & & \\
\hline Hopper & 0.00 & & & & & & & & & & & & & & & \\
\hline Hopper & 0.00 & & & & & & & & & & & & & & & \\
\hline 1/23308 & 4.56 & & 2.98 & & 6.59 & 382 & 5.93 & 0.00 & & 330.40 & 859 & 1724.0 & 83.97 & 254.80 & 39.36 & $<0.1$ \\
\hline 71101006 & 10.80 & 12.3 & 0.22 & 1526 & 4.61 & & 3.53 & 322.61 & & 0.00 & 866 & 1438 & 48.74 & 146.85 & 33.31 & 9.15 \\
\hline 8114106 & & 12.6 & 0.92 & 1150 & 4.54 & 0 & 3.44 & 244.81 & & 0.00 & 832 & 1164 & 47.00 & 152.71 & 77.97 & 9.26 \\
\hline 9/13100 & 9.00 & 12.3 & 0.33 & 1563 & 4.46 & 0 & 3.11 & 290.22 & & 0.00 & 824 & 1438 & 41.91 & 135.73 & 11.15 & 7.82 \\
\hline 10/16/106 & & 12.3 & 0.38 & 1554 & 5.05 & & 3.43 & 294.00 & & 0.00 & 838 & 1254 & 50.58 & 153.37 & 92.42 & 8.75 \\
\hline 11/141/06 & 8.25 & 12.2 & 1.08 & 1556 & 5.53 & 22 & 4.53 & 380.23 & & 0.00 & 1048 & 1144 & 41.73 & 128.96 & 75.08 & 6.31 \\
\hline 12/1400 & 8.88 & 12.3 & 0.76 & 1580 & 4.80 & 27 & 4.54 & 349.44 & & 0.00 & 702 & 1158 & 51.12 & 147.20 & 85.76 & 7.21 \\
\hline 1/1/8107 & 10.75 & 12.1 & 0.38 & 1572 & 4.83 & 17 & 3.27 & 241.08 & & 8.35 & 744 & 1372 & 53.67 & 157.39 & 88.49 & 8.35 \\
\hline 3212107 & 12.10 & 12.1 & 0.35 & 1391 & 5.25 & 20 & 4.49 & 203.95 & & 0.00 & & 1088 & 42.47 & 120.22 & 67.10 & 5.65 \\
\hline 18107 & & 12.1 & 0.47 & 1625 & 4.61 & 10 & 2.8 & 360.38 & 2070 & 0 & 864 & 1632 & 44.83 & 109.74 & 75.36 & 13.89 \\
\hline 22107 & & 13.5 & 0.66 & 1611 & 4.11 & 0 & 3.51 & 314.07 & & 0.00 & 866.0 & 1.3 & 43.10 & 107.17 & 92.55 & 18.50 \\
\hline 507 & & 12.7 & 1.13 & 1654 & 4.03 & 0 & 3.38 & 331.56 & & 0 & 322.81 & 1408 & 43.77 & 129.13 & 92.94 & 16.34 \\
\hline 5.107 & & 12.5 & 0.16 & 1614 & 4.36 & 0 & 4.62 & 400.96 & & 0.00 & 692.0 & 1434.0 & 53.99 & 158.35 & 99.76 & 16.58 \\
\hline 407 & & 12.3 & 0.75 & 1592 & 4.66 & 5 & 4.51 & 333.76 & 1643 & 0 & 894 & 1360 & 43.39 & 127.04 & 92.38 & 11.83 \\
\hline 101250707 & & 12.2 & 0.83 & 1685 & 4.66 & & 3.03 & 200.00 & & 0.00 & 835 & 602.0 & 47.69 & 140.51 & 92.16 & 7.96 \\
\hline 9/13106 & & 13.9 & 2.80 & 1229 & 4.34 & $v$ & 3.85 & 190.29 & & 0.00 & 634 & 1020 & 51.09 & 105.86 & 2.53 & 3.43 \\
\hline 10/16/106 & & 12.9 & 0.43 & 1228 & 4.86 & 12 & 3.77 & 207.56 & & 0.00 & 648 & 1062 & 61.29 & 124.86 & 45.39 & 5.28 \\
\hline 11/141/06 & 8.00 & 12.2 & 1.27 & 1194 & 5.23 & 18 & 3.95 & 215.48 & & 0.00 & 790 & 802 & 43.93 & 91.69 & 28.00 & 2.55 \\
\hline 12/141/06 & & 12.3 & 0.95 & 1192 & 4.57 & 0 & 4.30 & 203.83 & & 0.00 & 520 & 358 & 53.12 & 103.85 & 32.16 & 2.37 \\
\hline 1/18:07 & & 11.2 & 1.10 & 959 & 5.48 & 47 & 3.37 & 76.03 & & 0.00 & 407 & 786 & 43.21 & 91.99 & 22.33 & 1.21 \\
\hline 321107 & & 11.7 & 0.31 & 1004 & 5.36 & 19 & 4.89 & 0.00 & & 18.20 & & 776 & 41.28 & 84.15 & 19.30 & 2.44 \\
\hline 4/1/8107 & & 12.0 & 0.55 & 1094 & 4.93 & 14 & 3.41 & 122.84 & 1199 & 0 & 485 & 1002 & 37.44 & 69.43 & 14.8 & 3.47 \\
\hline McDonald & & 12.4 & 0.7 & 1269 & 4.57 & 11 & 3.94 & 129.84 & & 0.00 & 676.0 & 946.0 & 50.05 & 87.01 & 22.12 & 5.37 \\
\hline McDonald & & 12.5 & 0.65 & 1338 & 4.20 & 0 & 4.88 & 177.38 & & 0 & 241.44 & 43986 & 52.6 & 109.87 & 25.45 & 4.94 \\
\hline 7125107 & & 12.4 & 0.45 & 1400 & 4.10 & 0 & 5.73 & 588.28 & & 0.00 & 718.0 & 1382.0 & 71.76 & 141.22 & 38.78 & 6.44 \\
\hline 8141407 & & 12.3 & 1.1 & 1390 & 4.50 & 6 & 4.54 & 206.92 & 1419 & 0 & 770 & 1224 & 58.77 & 116.46 & 30.02 & 4.73 \\
\hline 2 & & 12.2 & 1.12 & 1274 & 4.08 & & 3.33 & 131.81 & & 0.00 & 732 & 831.0 & 61.52 & 125.67 & 30.75 & 51 \\
\hline
\end{tabular}




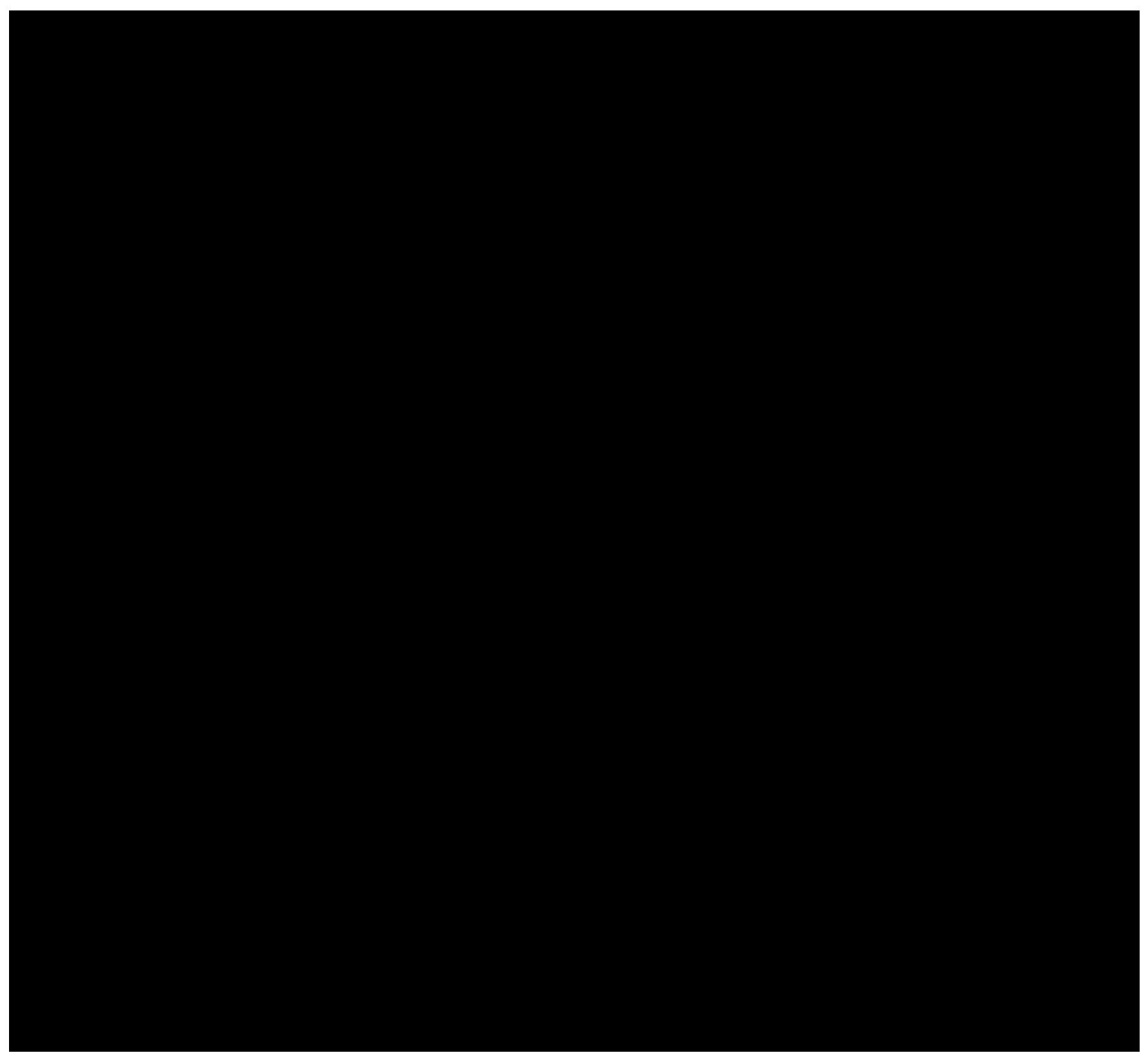




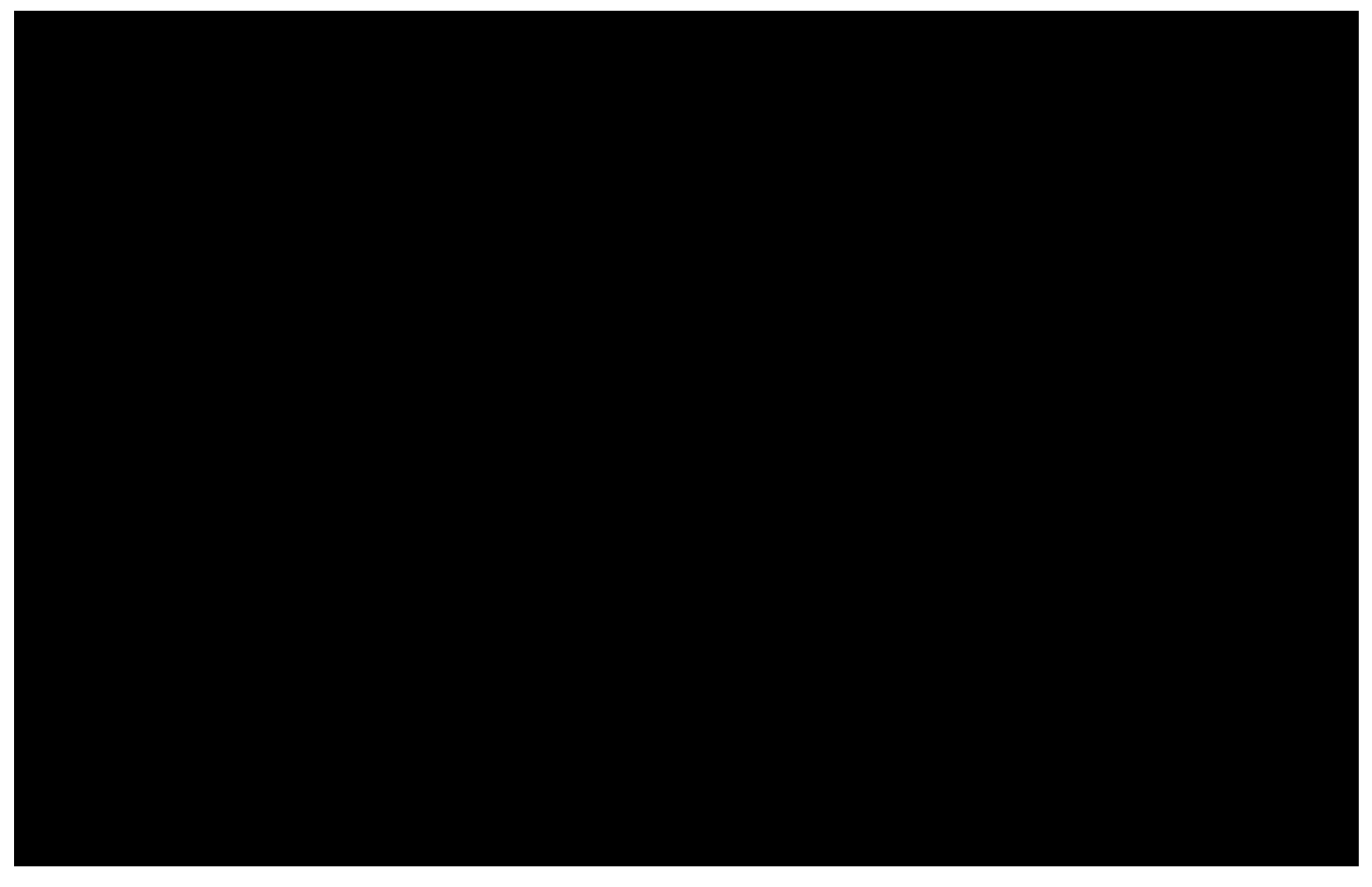




\section{Appendix C. Benefits of Using Constant Temperature Mine Water}

\section{Introduction}

This design aid considers the value of the effect of using constant, lower temperature mine water on the thermal cycle and changes in net heat rate and the change in fuel consumed. A decrease in the net plant heat rate, measured in British thermal units per net kilowatts hours, decreases the fuel rate and results in a net decrease in the stack emission rate. This decrease in fuel use not only reduces the operational cost of fuel but also the cost of pollutant mitigation such as scrubbing, credits, and additives.

The greatest cost savings resulting from using mine water $\left(55^{\circ} \mathrm{F}\right) \mathrm{v} / \mathrm{s}$ higher temperature surface or municipal water will be realized in the summer months when higher ambient water temperatures are in the upper $80^{\circ} \mathrm{F}$ to $90^{\circ} \mathrm{F}$ range. The cooler mine water will reduce the circulating water temperature when injected in the circulating inlet to the condenser. The air relative humidity is considered in the program and will affect the cooling tower performance. The higher the relative humidity in the air, the lower the cooling tower performance, thereby reduces thermal efficiency.

The greater the mine water usage as a proportion to the total water used, the greater the savings in the fuel consumed. If the turbine output is limited in production from high backpressure in the condenser, an increase in generation can be achieved from a lower circulating temperature in the condensing process. This concept is discussed below with a reduction in fuel and emission rates resulting from the reduction of the fuel usage in the process. 


\section{Thermal Efficiency Benefit of Using Mine Water}

The plant energy cycles in use today are responsible for the conversion of energy and are based on what is commonly referred to as the Rankine cycle. This cycle is based on transferring energy from a high temperature heat source (boiler) through a prime mover (turbine) to a low temperature heat sink (condenser) and then returning the low enthalpy energy back to the heat source (boiler). The figure below shows the very basic equipment arrangement for a steam power plant (Rankine

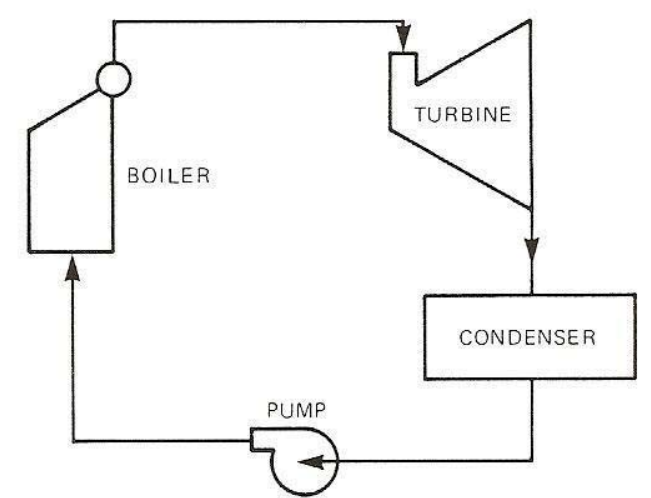

Diagram of Basic Power Plant (Rankine Cycle)

cycle).

As the boiler converts the fuel or chemicals from chemical energy to thermal energy by increasing the pressure and temperature of the water to a saturated steam, the steam is injected into a turbine converting the thermal energy to mechanical energy by turning the turbine. The exhausted steam is condensed in the condenser to be pumped to the boiler for recycling of the remaining heat.

The thermal energy produced can be measured and quantified as a unit of measure called enthalpy (Btu/\#). The total change in enthalpy is the amount of work produced. The highest enthalpy entering the turbine minus the lowest enthalpy leaving the condenser is the total worked produced.

The most accurate and widely used term for describing the performance of a power plant is HEAT RATE. Heat rate is defined as the amount of fuel, in Btu, needed to produce one kilowatt-hour of electricity. The unit of measure for heat rate is Btu/kw-hr. There are three types of heat rate; turbine heat rate, gross heat rate, and net heat rate. 
We use the net heat rate term when referring heat rate in the remainder of this section (Btu/nkw-hr).

Net heat rate is the ratio of the fuel input to the electrical output delivered to the transmission line leaving the plant and thereby reflects the performance of the entire plant. Whereas, gross heat rate is the performance of the fuel input to the generator compared to the electrical output not accounting for the electrical energy consumed in the plant to operate plant equipment. Heat rates are also calculated for a given period of time so that any changes in plant performance can be recognized and corrected.

Heat Rate $=$ Energy in/Energy out

$=$ Btu/nkw-hr

The problem with using the energy in/energy out method is that fuel measurement and analysis is often not sufficiently accurate to provide the necessary data to calculate the exact heat rate. The method general used is the flow input and output method.

Heat Rate $=$ Boiler duty/ (Boiler efficiency $\times$ Generator output)

The boiler duty is a term used to identify the amount of energy converted and delivered by the boiler. This is determined by measuring the flow and enthalpy of the steam and water into and out of the boiler. The difference is the energy produced by the boiler. Boiler efficiency can be measured and then calculated and the generator output minus the aux load can be measured very accurately.

To determine the economic importance of heat rate is to determine the cost associated with one Btu/nkw-hr reduction in heat rate. Accurate heat rate is important because a small decrease in heat rate can result in a large operational cost savings.

The factor that has the most negative impact on the performance of the turbine is the heat lost in the condenser. The major portion of this loss is the latent heat given off when the exhaust steam condenses. We can determine the approximate heat given up to the circulating water in the following calculation:

Circulating water heat absorbed=Turbine exhaust enthalpy- hotwell enthalpy

This large heat loss is the prime reason the turbine cycle efficiency is around $40 \%$ in super critical units. 
The table below illustrates the effect of inlet steam pressure, turbine cycle efficiency, and vacuum on turbine efficiency as described above.

Effect of Pressure, Temperature, and Vacuum on Rankine Cycle Efficiencies

\begin{tabular}{|lccc|}
\hline Initial Conditions & $\begin{array}{c}\text { Condenser Pressure, } \\
\text { Abs. }\end{array}$ & $\begin{array}{c}\text { Efficiency } \\
(\%)\end{array}$ & $\begin{array}{c}\text { Ratio of Efficiencies } \\
\text { Based on First Case }\end{array}$ \\
\hline 100 psia, saturated & $14.7 \mathrm{psi}$ & 13.92 & 1.00 \\
200 psia, saturated & $14.7 \mathrm{psi}$ & 18.68 & 1.342 \\
$400 \mathrm{psia}$, saturated & $14.7 \mathrm{psi}$ & 22.9 & 1.645 \\
100 psia, $650^{\circ} \mathrm{F}$ & $14.7 \mathrm{psi}$ & 15.88 & 1.141 \\
$100 \mathrm{psia}$, saturated & $1 \mathrm{in} . \mathrm{Hg}$ & 28.6 & 2.055 \\
\hline
\end{tabular}

Courtesy: John Wiley \& Sons

Source: Power Plant Theory and Design, Table 11-1.

The effect on the heat rate and turbine exhaust pressure in the following "exhaust pressure correction factors" curve below is typical for most modern fossil fuel power plants. 
EXHAUST PRESSURE CORRECTION FACTORS

$408278 \mathrm{KW} 2.5$ IN HG. RBS. 4.2 PCT MU

FOR BOILER BLOWDOWN AND SOOT BLOWING

TC2F-33.5 IN LSB 3600 RPM

2400 PSIG $1000 / 1000 \mathrm{~F}$

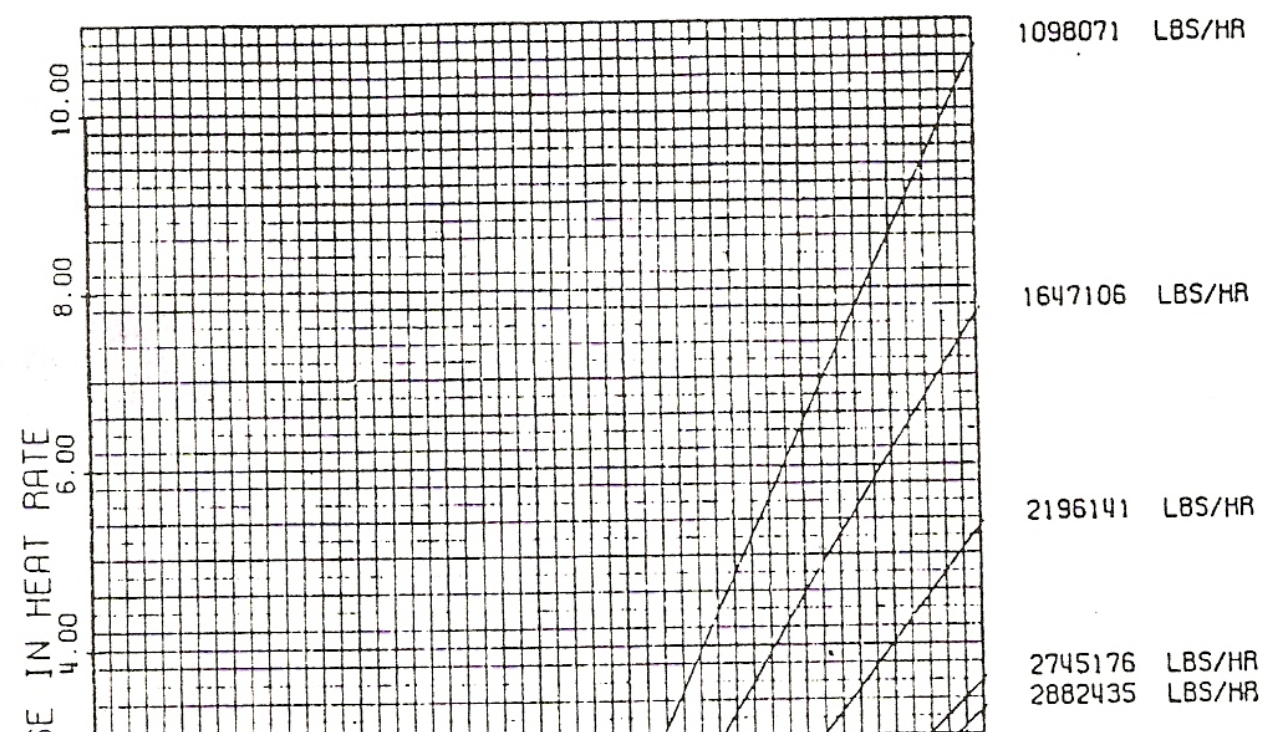

2882435 LBS/HB

FLOWS NEAR CURVES ARE THROTTLE FLOWS AT 2400 PSIG $1000 \mathrm{~F}$

THESE CORRECTION FACTORS ASSUME CONSTANT CONTROL VALVE OPENING APPLY CORRECTIONS TO HEAT RATES AND KW LOADS

AT 2.5 IN HG. ABS 4.2 PCT MU 
The above curve of exhaust pressure verse heat rate shows that a small change in exhaust pressure results in a significant change in heat rate.

Using constantly lower temperature mine water will reduce the cooling tower temperature and thereby, reduce the condensate temperature from the condenser hotwell. This will result in an increase in plant efficiency, lower heat rate, and lower fuel consumption at constant load. The lower circulating water temperature will result in the most fuel savings and therefore lower emissions. This design aid has various temperature profiles to determine the reduction in plant net heat rate and thereby lower fuel flow and lower pollution output.

By using the design aid one can assume a $55^{\circ} \mathrm{f}$ (default) mine water temperature at a $10 \%$ flow rate compared to the total flow of the circulating water flow to the condenser. For example, by assuming the circulating water temperature is $75{ }^{\circ} \mathrm{F}$ before the addition of the mine water, the mixed temperature of the circulating water will be $73^{\circ} \mathrm{f}$., This lower circulating water temperature will reduce the turbine back pressure as found in the turbine back pressure curves. At this reduced temperature there would be a $0.3 \%$ reduction in the plant net heat rate. This heat rate reduction (Btu/nkw-hr) can now be applied to the total energy produced by the plant and will be variable with seasonal conditions.

Assuming constant condition at a 500 Megawatt plant operating at $95 \%$ capacity factor, the total electrical net energy produced would be $4,161,000,000 \mathrm{Kw}$-hr at a typical heat rate of 10,000 Btu/nkw-hr (total energy consumed would be 41,610,000,000,000 Btu). In the same plant configuration, If the fuel used is assumed to be $5,600 \mathrm{Btu} / \#$ (typical waste coal) a total of $7,430,357,143 \mathrm{lbs}$ or $3,715,179$ tons of fuel would be used. Therefore, with a $0.3 \%$ reduction in heat rate on the average of the entire year of operation the fuel savings in the plant using waste coal would be 11,145 tons.

\section{Emission Reduction Benefits of Using Mine Water}

As discussed above, the use of lower temperature mine water reduces the circulating temperature resulting in reduced fuel consumption in the chemical process or combustion of the fuel and therefore a reduction in emissions. The resulting emission reductions can be calculated based on the chemical content of the fuel.

Chemical reactions during full combustion are exact procedures according to the law of combining weights which states that all substances combine in accordance with simple definite weight relationships. This is illustrated by the reaction of carbon and oxygen that forms carbon dioxide. This relation can be shown as follows: 


$$
\mathrm{C}+\mathrm{O}_{2} \rightarrow \mathrm{CO}_{2}
$$

Mole wt $12+$ mole wt. $32=$ mole wt. 44

This reaction shows that for any given amount of carbon there is an exact amount of oxygen needed to produce carbon dioxide. In this example, 12 pounds of carbon react with 32 pounds of oxygen to produce 44 pounds of carbon dioxide.

Combustion air requirements are part of the chemical process of the fuel or in this case coal. Perfect combustion is a release of all energy in the fuel mixture using the theoretical quantity of oxygen and time. Ambient air contains $76.8 \%$ nitrogen and $20.9 \%$ oxygen with the remainder inert gases.

Since air is only $20.9 \%$ oxygen it is necessary to have 4.78 pounds of air for one pound of oxygen. In order to determine the theoretical amount of air needed for combustion of a pound of fuel, one must simply total the air needed for the combustion of each element. Therefore, one pound of carbon requires 2.67 pounds of oxygen to form 3.67 pounds of $\mathrm{CO} 2$.

The same approach described above is used to resolve the reactions of all the elements in the fuel.

$$
2 \mathrm{H}_{2}+\mathrm{O}_{2}->2 \mathrm{H}_{2} \mathrm{O} \text { and has a mole weight of } 36
$$

Therefore, $8 \mathrm{lbs}$ of oxygen is required for the combustion of $1 \mathrm{lb}$ of $\mathrm{H}_{2}$, so if there is $1.48 \%$ of $\mathrm{H}_{2}$ in the fuel. The oxygen required is $.0148 \times 8=0.118 \mathrm{lb}$ of oxygen.

The oxygen requirement for the combustion of sulfur is the same relation as above.

$$
\mathrm{S}+\mathrm{O}_{2} \rightarrow \mathrm{SO}_{2}
$$

The mole relationship for combustion of sulfur is $32+32=64$

Therefore, combustion of one $\mathrm{lb}$ of sulfur in the fuel requires $1 \mathrm{lb}$ of oxygen in the reaction to form $2 \mathrm{lbs}$ of $\mathrm{SO}_{2}$. So, assuming a $2 \%$ sulfur content in the fuel, the oxygen required would be $0.02 \times 1$ or $0.02 \mathrm{lbs}$ of oxygen.

The combustion on Nitrogen in the fuel is the same as the other elements.

$$
\mathrm{N}+\mathrm{O}_{2}->\mathrm{NO}_{2}
$$


The mole relationship for combustion of nitrogen in the fuel is $14+32=46$

Thus the combustion of one $\mathrm{lb}$ of nitrogen in the fuel requires $2.28 \mathrm{lb}$ of oxygen in the reaction to form $3.28 \mathrm{lbs}$ of $\mathrm{NO}_{2}$.

In the example above the reduction in fuel use resulting from a lower circulating water temperature was expected to be 11,145 tons. Therefore, the commensurate reduction in $\mathrm{CO}_{2}$ is calculated based on the ultimate analysis of Carbon in the fuel $(32 \%)$. So, the reduction in the carbon dioxide emission would be a product of 11,145 tons of fuel $X$ the $32 \%$ carbon $\times 3.67$ for a total reduction of 13,089 tons of $\mathrm{CO} 2$ for the production year.

Sulfur dioxide emission reduction is calculated in the same manner for the reduction of the 11,145 tons of fuel. The fuel from the ultimate analysis had a sulfur content of $2 \%$. The reduction of SO2 would be a product of 11,145 tons of fuel $X 2 \%$ sulfur $X 2.0$ for a total reduction in SO2 emissions of 446 tons per year.

Expected nitrogen dioxide emission reduction is calculated as follows: If the fuel contains $0.5 \%$ nitrogen the reduction of the $\mathrm{NO}_{2}$ would be a product of 11,145 tons of fuel $X 0.5 \%$ nitrogen $X 3.28$ for an expected annual total $\mathrm{NO}_{2}$ emission reduction of 183 tons.

The expected mercury emission reduction is calculated as follows: If the fuel analysis contains $0.2 \mathrm{ppm} \mathrm{Hg}$ the reduction of the $\mathrm{Hg}$ would be the product of 11,145 tons $\mathrm{X}$ $2000 \mathrm{lb} /$ ton $X 0.2 \mathrm{ppm} / 1,000,000$ resulting in a total reduction of $4.46 \mathrm{lbs}$ of $\mathrm{Hg}$ emissions per year.

With the increased scrutiny and regulation of emissions from the combustion of coal or coal waste fuel, the potential for using mine water for thermoelectric production can provide significant environmental benefits. Moreover, as emission controls become more stringent, water resources become more limited and the thermoelectric generation industry becomes more competitive the use of alternate sources of water such as mine water will likely result in a substantial savings in the operations of coal-fired power plants. 